\title{
Molecular and functional characterization of potential pathogenicity related genes from Verticillium longisporum
}

\author{
Molekulare und funktionelle Charakterisierung von \\ potenziell pathogenitätsrelevanten Genen aus \\ Verticillium longisporum
}

\author{
Dissertation \\ zur Erlangung des Doktorgrades \\ der Fakultät für Agrarwissenschaften \\ der Georg-August-Universität Göttingen
}

vorgelegt von Malte Beinhoff

geboren in Hannover

Göttingen, im Juni 2011 
D 7

1. Referent : Prof. Petr Karlovsky

2. Referent : Prof. Andrea Polle

Tag der mündlichen Prüfung: 21. Juli 2011 


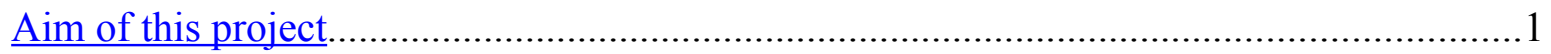

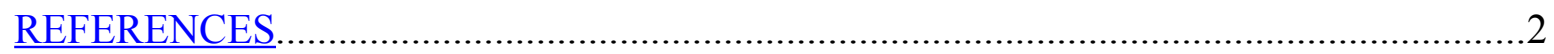

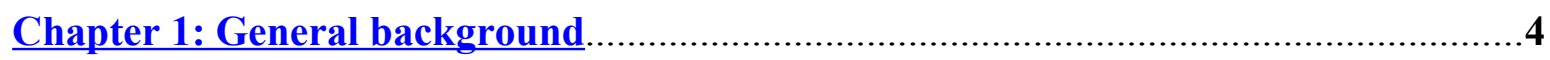

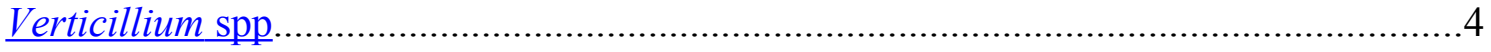

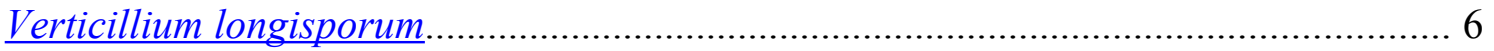

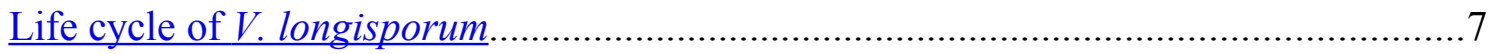

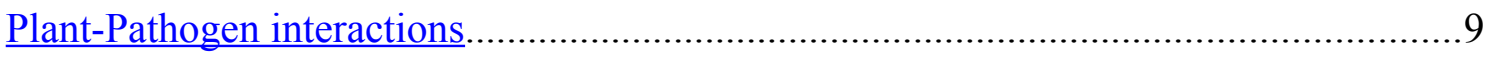

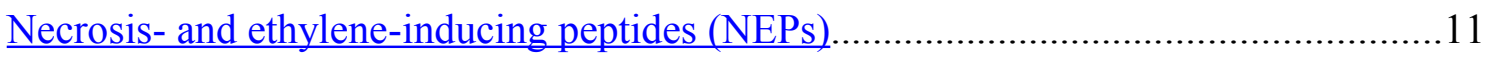

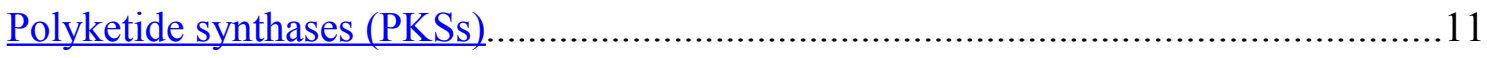

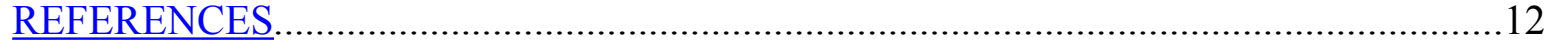

Chapter 2: Gene silencing in Verticillium longisporum: evaluation and establishment of a method for post-transcriptional downregulation of genes ................................23

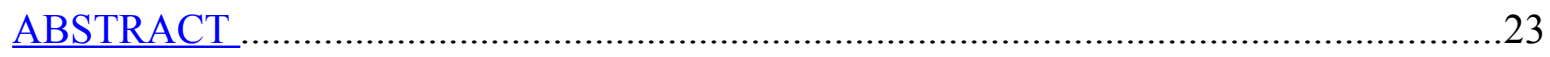

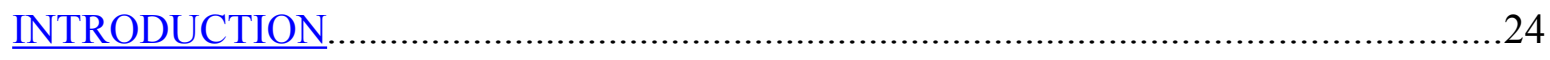

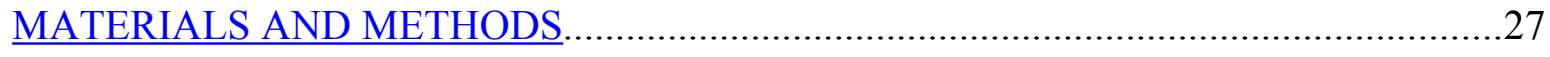

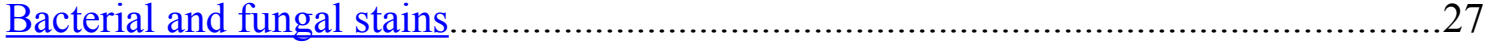

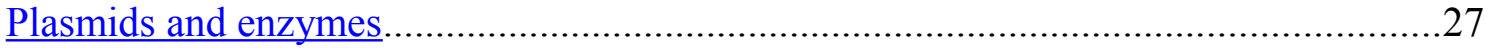

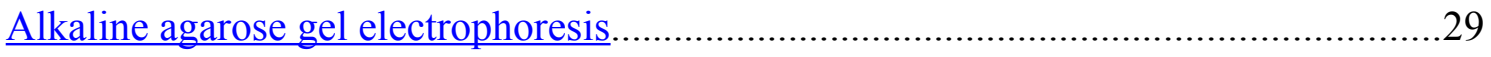

Extraction of genomic DNA (gDNA) and total RNA from fungal mycelium................30

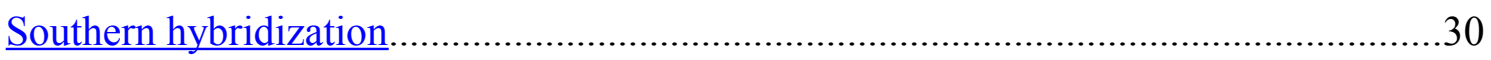

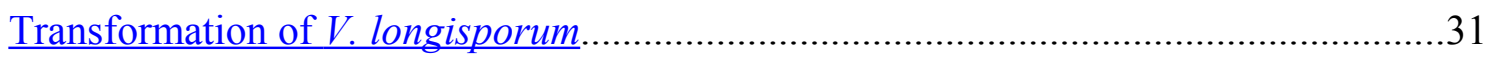

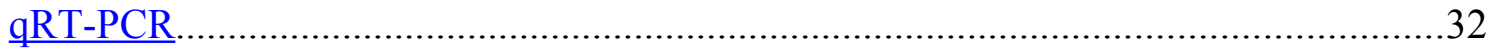

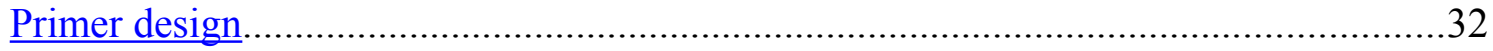

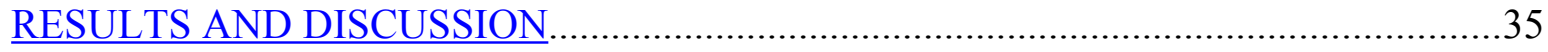

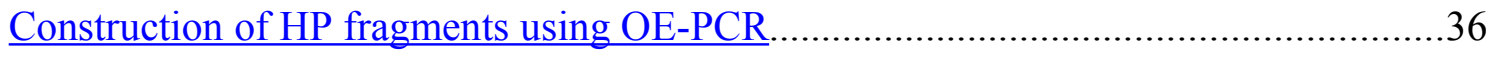

Construction of HP fragments using conventional cloning steps................................48

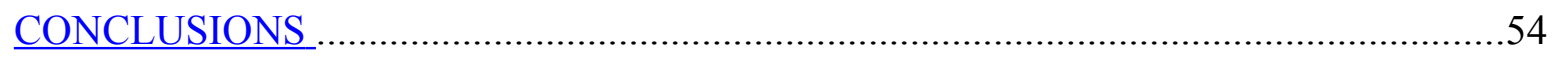

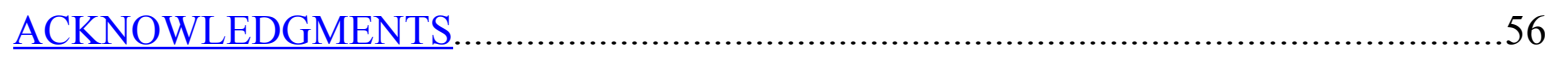

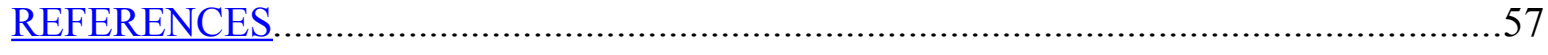

APPENDIX 
Chapter 3: Characterization of NEP-like proteins of Verticillium longisporum according to their relevance for pathogenicity in Brassica napus.............................63

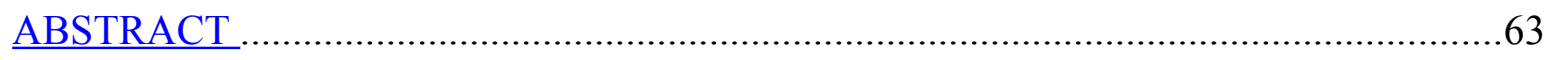

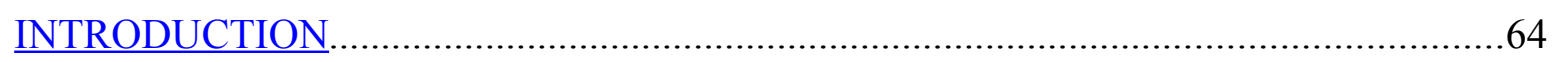

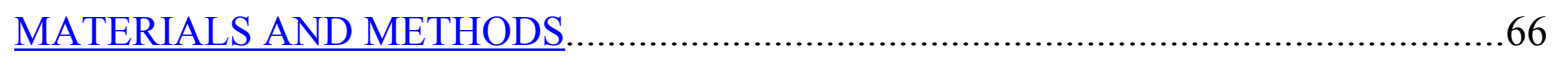

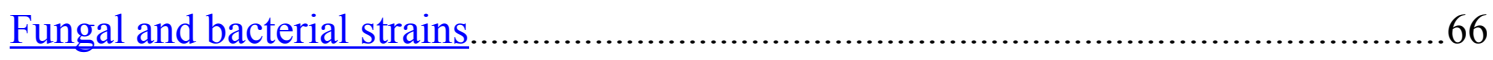

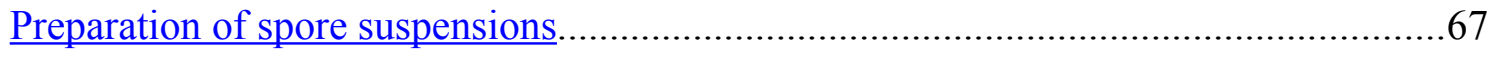

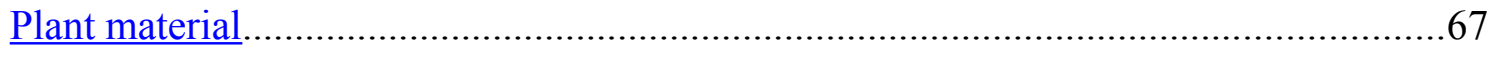

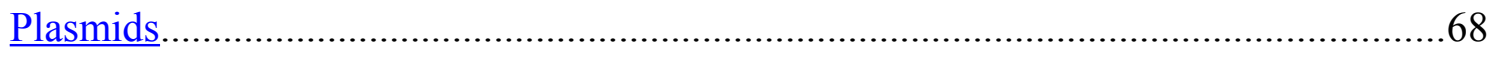

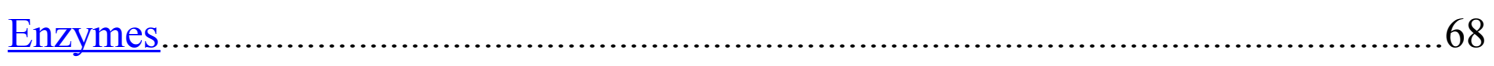

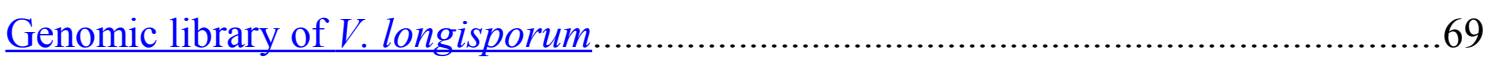

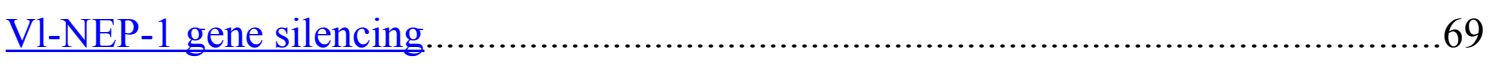

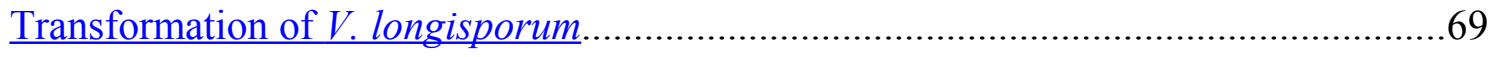

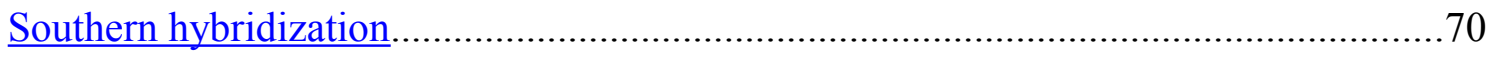

Plant pathogenicity assay using V1-NEP-1 silencing mutants...................................... 70

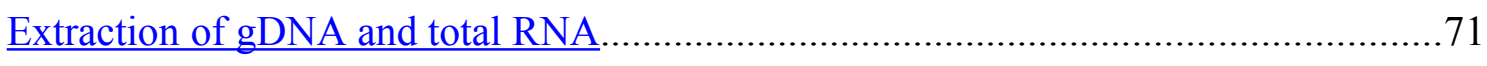

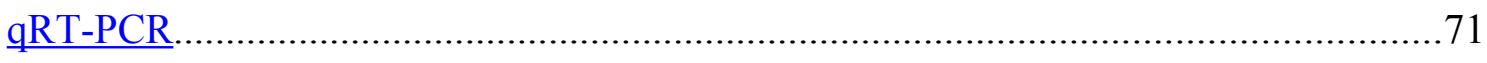

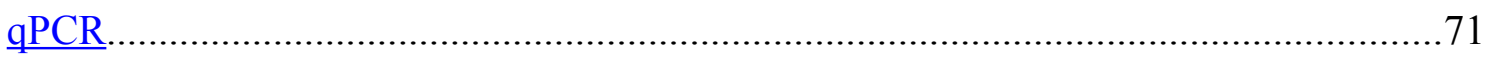

Measurement of ethylene $\left(\mathrm{C}_{2} \underline{\mathrm{H}}_{4}\right)$-production of $V$. longisporum .................................72

High-performance liquid chromatography-mass spectrometry (HPLC-MS) …...........72

Confocal laser scanning microscopy (CLSM) ........................................................... 72

Purification of Vl-NEP-1 protein using pET21 system..............................................73

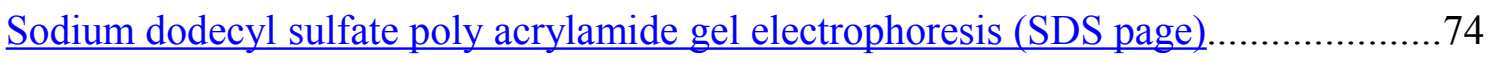

Leaf-infiltration assay with Vl-NEP-1 protein.......................................................... 74

Seedling growth and root development assay........................................................ 74

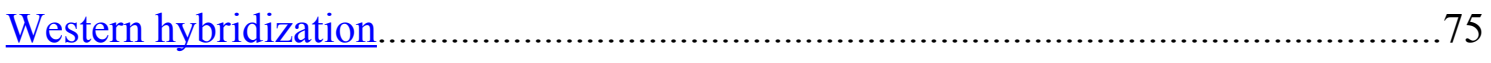

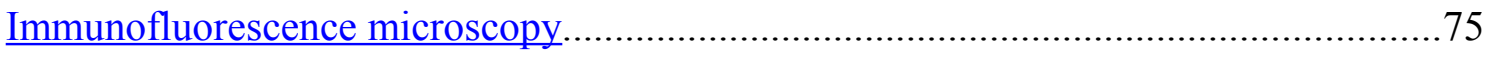

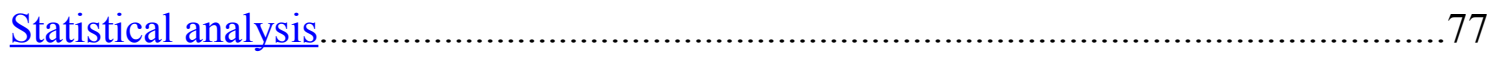

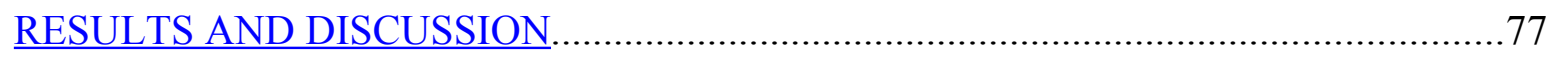

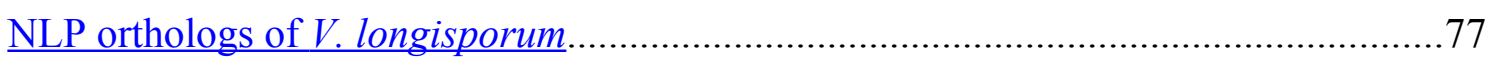

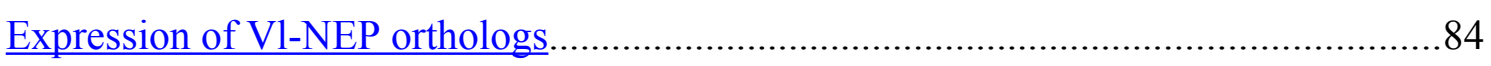




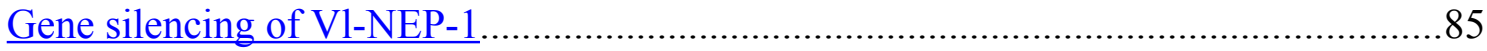

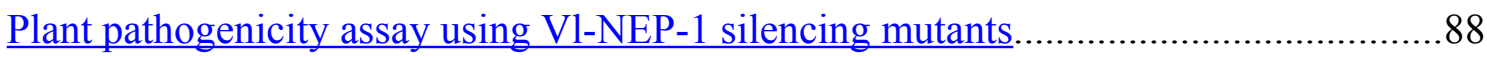

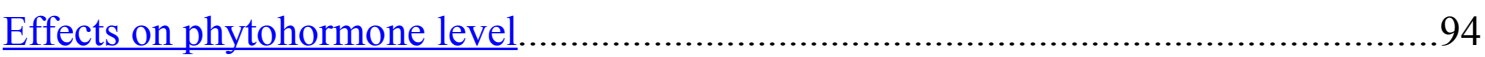

Overexpression and purification of V1-NEP-1 protein and subsequent experiments...102

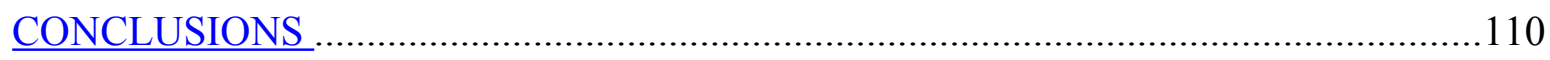

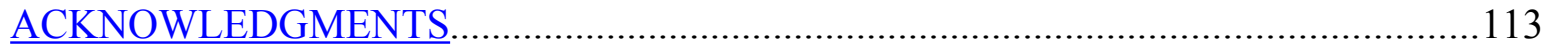

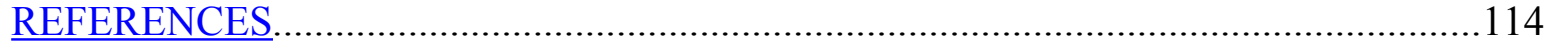

APPENDIX

Chapter 4: Detection and functional analysis of a polyketide synthase gene of

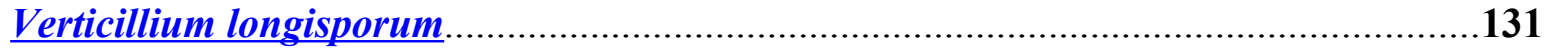

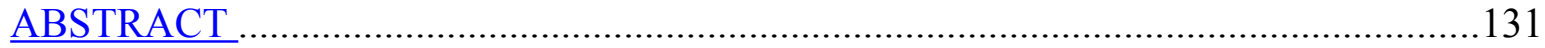

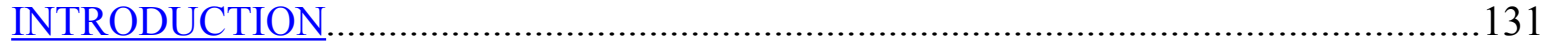

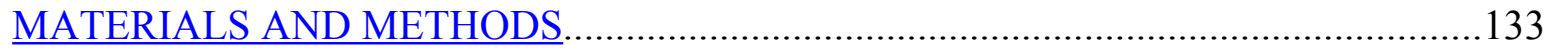

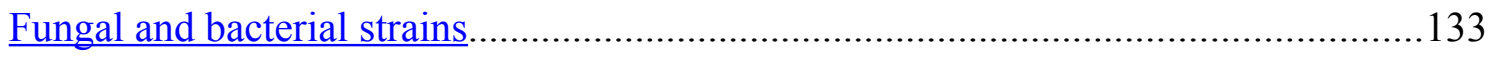

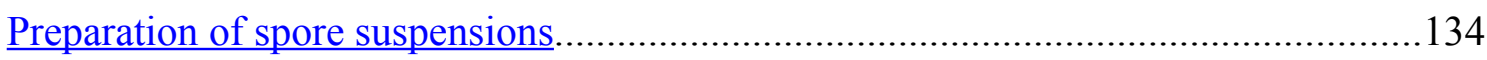

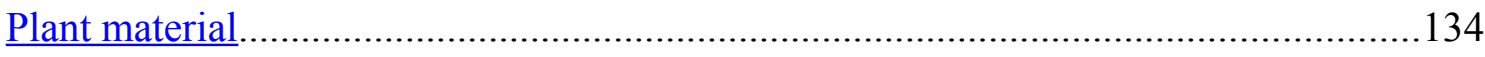

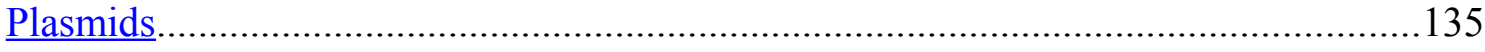

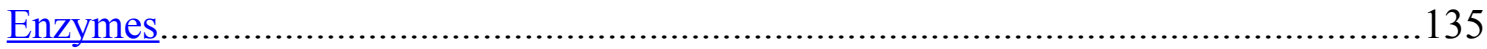

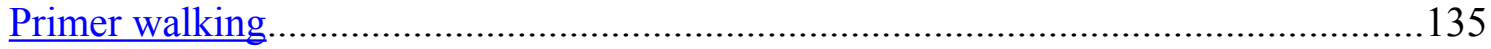

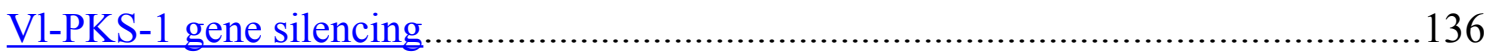

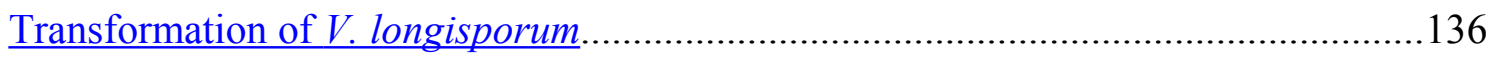

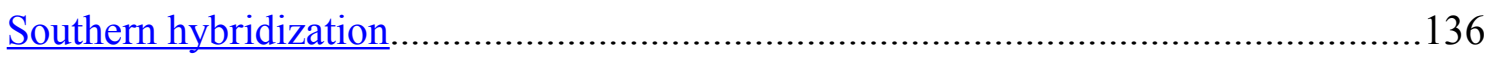

Plant pathogenicity assay using V1-PKS-1 silencing mutants..................................136

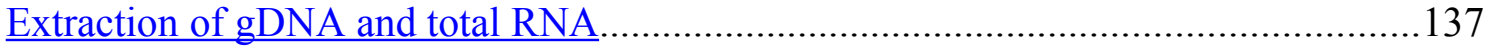

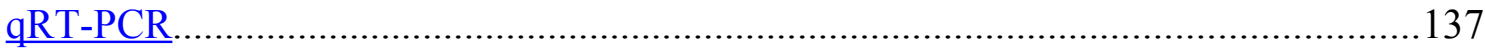

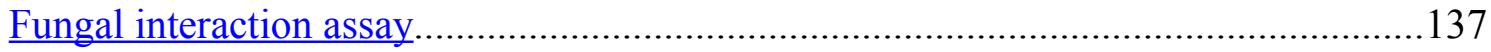

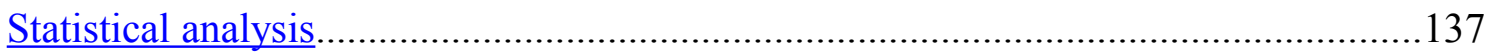

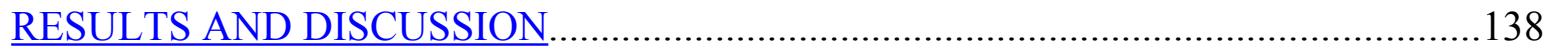

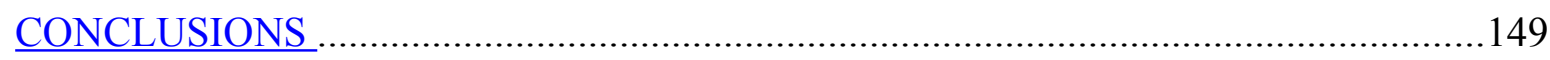

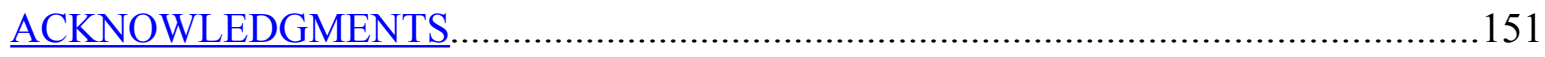

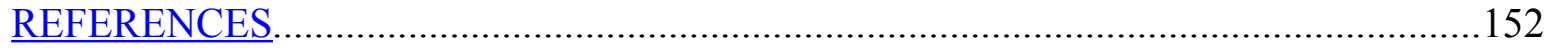


APPENDIX

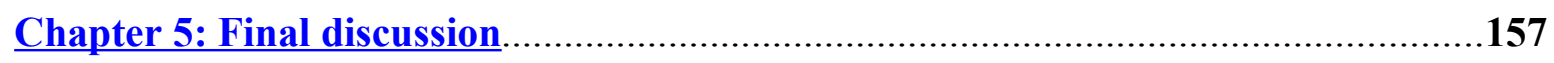

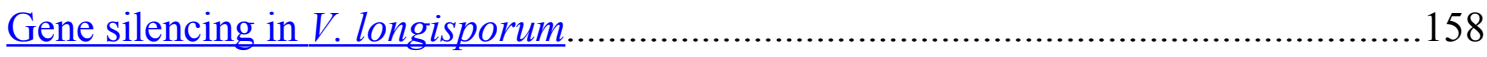

The impact of V1-NEP-1 on the pathogenicity to B. napus........................................159

The role of V1-PKS-1 in the life cycle of $V$. longisporum............................................160

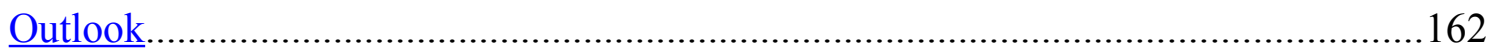

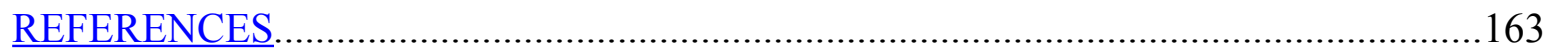

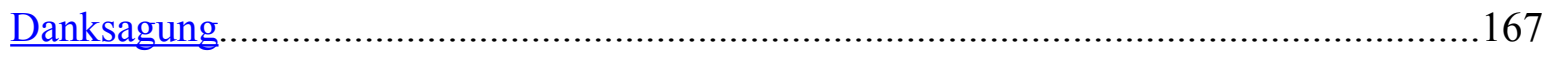

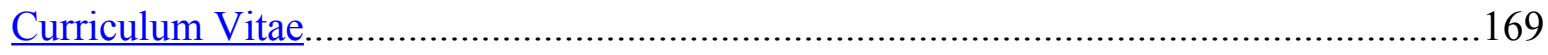

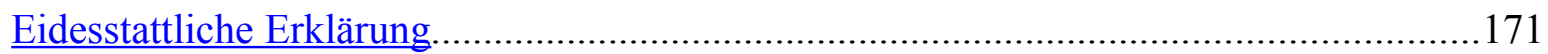




\section{Aim of the project}

This thesis was realized during participation in the research unit FOR 546 ("Signalling between the soil-borne fungus Verticillium longisporum and its host plants") funded by the Deutsche Forschungsgemeinschaft (DFG). The research unit consists of nine different laboratories working in the fields of plant pathology, biochemistry, cell biology, molecular genetics, plant physiology and microbiology, mainly located at the Georg-August University of Göttingen. The major research objectives (1) of this Verticillium unit are:

- The identification of signals of plant and fungal origin that shape the interaction between the pathogen and host plants.

- The elucidation of the response of the plant to the fungus, including signal transduction processes and functional analysis of the elicited responses.

- The elucidation of the response of the fungus to the plant, including signal transduction processes as well as functional analysis of the elicited response for its pathogenicity.

As a member of the "Molecular phytopathology and mycotoxin research" laboratory headed by Prof. Petr Karlovsky we were working on the detection and characterization of fungal genes, putatively involved in the interaction of $V$. longisporum and its host plant Brassica napus. The molecular basis of the adaption of $V$. longisporum on Brassicaceae and the physiological processes in the mycelium during infection are mostly unknown. Therefore, molecular studies on pathogenicity-related genes provides the opportunity for a better understanding of the disease caused by $V$. longisporum and thereby help in finding new strategies for the prevention or the control of infection.

This thesis mainly focuses on the results of analysis of two genes detected in the genome of $V$. longisporum putatively involved in the pathogenic life-cycle of the fungus, and the establishment of a method to trigger post-transcriptional gene silencing in $V$. longisporum. The first gene belongs to a relatively newly described group of proteins, mostly expressed from phytopathogens, called necrosis- and ethylene-inducing peptides (NEP). We detected and sequenced five NEP orthologs in the $V$. longisporum genome, designated as Vl-NEP-1 to -5 , using primers of homologous gene sequences derived from $V$. dahliae published by "The 
Broad Institute Verticillium database" (2). Vl-NEP-1 was chosen for further investigation (see Chapter 3). Vl-NEP-1 is a gene with high homology to other fungal NEP-1 genes, which are known to elicit plant responses and symptom development in different plant systems $(3,4,5)$.

The second gene codes for a polyketide synthase (PKS). This class of enzymes catalyzes the series of small carboxylic acid residues into polyketides (6). Polyketides belong to a large group of secondary metabolites, known to play a role as pathogenicity or virulence factors in phytopathogenic fungi (7). Using degenerate primers for conserved regions of fungal PKS genes, we identified a gene designated as Vl-PKS-1 (8) with high homology to other fungal PKS genes coding for L-ketoacylsynthases that are believed to be involved in the biosynthesis of melanin (9). The role of Vl-PKS-1 for the life cycle of $V$. longisporum should be clarified during this thesis (see Chapter 4).

To check the relevance of these genes for the pathogenic life-cycle of $V$. longisporum and whether they act as virulence or pathogenicity factors we have tried to establish a method for the construction of silencing vectors to trigger post-transcriptional gene silencing of candidate genes in $V$. longisporum (see Chapter 2).

\section{REFERENCES}

1. Research Unit DFG 546 homepage (http://www.ubpb.gwdg.de/ forschergruppe/ index.html).

2. The Broad Institute homepage Verticillium group database (http://www.broad. mit.edu/annotation/genome/verticilliumdahliae/MultiHome.html).

3. Wang J., Cai Y., Gou J., Mao Y., Xu Y., Jiang W., Chen X. (2004). VdNEP, an elicitor from Verticillium dahliae, induces cotton plant wilting. Appl. Environ. Microbiol. 70:4989-4995.

4. Bailey B.A., Apel-Birkhold P.C., Luster D.G. (2002). Expression of NEP1 by Fusarium oxysporum f.sp. erythroxyli after gene replacement and overexpression using polyethylene glycol-mediated transformation. Genet. Resistance 92:833-841. 
5. Qutob D., Kemmerling B., Brunner F., Küfner I., Engelhardt S., Gust A.A., Lacombe Luberacki B., Seitz H.U., Stahl D., Rauhut T., Glawischnig E., Schween G., B., Watanabe N., Lam E., Schlichting R., Scheel D., Nau K., Dodt G., Hubert D., Gijzen M., Nürnberger T. (2002). Phytotoxicity and innate immune responses induced by Nep1-like proteins. Plant Cell 18:3721-3744.

6. Hopwood A. (1997). Genetic Contributions to Understanding Polyketide Synthases.Chem. Rev. 97: 2465-2497.

7. Huang J.-S. (2001). Plant Pathogenesis and Resistance. Dordrecht/Boston/London

8. Hiegl W. (2006). Untersuchung der Biosynthese von Phytohormonen bei Verticillium longisporum. Diplomarbeit, Georg-August Universität Göttingen.

9. Takano Y., Kubo Y., Shimizu K., Mise K., Okuno T., Furusawa I. (1995). Structural analysis of PKS1, a polyketide synthase gene involved in melanin biosynthesis in Colletotrichum lagenarium. Mol. Gen. Genet. 249:162-167. 


\section{Chapter 1: General background}

\section{Verticillium spp.}

Fungi of the genus Verticillium belong to one of the most widespread groups of plant pathogens in the world and are present in both temperate and subtropical regions (1). Verticillium species are soil-borne fungi, and are part of the division ascomycota which comprises the most abundant class of fungal species (45,000 known species, $65 \%$ of all fungal species). Most of the Verticillium species belong to the artificial described class of deuteromycetes (Fungi imperfecti) which is characterized by the lack of any sexual teleomorph (2). Serious economic losses have been recorded caused by the infection of host plants by plant pathogenic Verticillium species (3). The host range of the fungi is considered to be very diverse. Verticillium species has been detected in over 200 plant species (4). At the moment, six plant pathogenic Verticillium species are commonly accepted by plant pathologists (5). The acceptance of a seventh species, named $V$. longisporum (6), which is the subject of this thesis, is a controversial issue that is still under discussion.

\section{Verticillium Nees (1817)}

V. albo-atrum Reinke \& Berthold (1879)

- V. albo-atrum var. caespitosum Wollenweber (1929)

- V. albo-atrum var. caespitosum f. pallens Wollenweber (1929)

- V. albo-atrum var. tuberosum Rudolph (1931)

$>\quad$. dahliae Klebahn (1913)

- V. dahliae var. longisporum Stark (1961)

- V. albo-atrum var. medium Wollenweber (1929)

- V. albo-atrum auct. pro parte

- V. ovatum Berkeley \& Jackson (1926)

$>$ V.nigrescens Pethybridge (1919)

$>$ V. nubilum Pethybridge (1919)

$>$ V. theobromae (Turconi) Mason \& Hughes (1951)

$>$ V.tricorpus Isaac (1953)

$>$ V. longisporum Karapapa \& Stark (1997) 
In contrast to $V$. nigrescens, $V$. nubilum, $V$. theobromae and $V$. tricorpus, which have a relatively small influence on agricultural breeding, $V$. dahliae and $V$. albo-atrum cause high economic yield losses and are therefore the focus of scientific research. Host plants of $V$. dahliae include tomato, pepper, watermelon, mint, muskmelon, lettuce, potato, cotton and strawberry (12). On the other hand $V$. albo-atrum particularly infects alfalfa, hop, tomato and potato (13). Symptoms caused by Verticillium species are very diverse, depending on the host plant (14). The typical symptom of a Verticillium infection is wilting of the host-plant (1). Additionally, stunting of infected plants and also chlorotic and necrotic lesions on leaves may be observed. Inside infected plants, a brown discoloration of the vascular system is shown, which is probably due to an accumulation of phenolic substances (15). Because of the large variety of symptoms caused by Verticillium ssp., clear differentiation of symptoms from those caused by other plant pathogens in the field is very difficult. Only at a late stage of infection and due to the visible formation of microsclerotia in the dying tissues of affected plants, is it possible to differentiate by eye whether symptoms are caused by Verticillium species or other plant pathogenic organisms. Therefore, molecular techniques are often used to make a clear assignment to other plant pathogens in the field (16). Despite the possibility of early detection of Verticillium infection, no fungicides are available which can stop the spread of the fungus in the plant $(17,18,19)$. Because plant pathogenic Verticillium ssp. are soil-borne and the infection of plants is carried out by microsclerotia germination and penetration of the roots, it is difficult to prevent Verticillium infection by the use of common fungicides. The search for resistant varieties of host plants is therefore of great importance. A promising approach is the production of re-synthesized oilseed rapeseed lines $(20,21,22)$. In 2006 , the complete genome of $V$. dahliae was published (23) which allows a more detailed phylogenetic study on the taxonomy of the Verticillium species $(24,25,26,27)$. In 2004, an extensive genome sequencing project for $V$. dahliae and $V$. albo-atrum was founded by the "NSF/USD Microbial Genome Sequencing Program" and the "Broad Institute". As a result of this project, 2600 expressed sequence tags (ESTs) were received from the $V$. dahliae transcriptome. The data was obtained by two independent approaches $(28,29)$ and is available through the NCBI GenBank database. Because of the variety of investigations on the pathosystem Verticillium/host plants, the fungus is on the way to becoming a model system for studying diseases caused by plant pathogenic fungi. 


\section{Verticillium longisporum}

In 1961, Stark described an isolate derived from horseradish with an unusual length of conidia. He named this isolate with elongated conidia as $V$. dahliae var. longisporum (30). In addition to the almost twice as long conidia, $V$. longisporum has an almost twice as large DNA content $(1.78 \mathrm{x})$ compared to $V$. dahliae or $V$. albo-atrum and is described as "neardiploid" $(31,32)$. In addition to this, it was demonstrated that the isolate has even more differences in the molecular characteristics compared to $V$. dahliae and $V$. albo-atrum (e.g. $33,34,35,36,37,38,39,40,41,42)$. Consequently, Karapapa postulated in 1997 that the species $V$. dahliae var. longisporum should be classified as a separate species (6). The taxonomical discussion is still not completed and the classification of $V$. longisporum as a unique species has not been unanimously agreed by plant pathologists.

The first reports about a disease of oilseed rape due to $V$. longisporum infestation occurred 50 years ago in Sweden. Until Verticillium-infected plants were found in the area of the former East Germany (43), symptoms on oilseed rape plants resulting from Verticillium ssp. were considered to represent a problem only in Scandinavian countries (44). The increasing economic importance of rape and the resulting increase in acreage has also been accompanied by a rising occurrence of plant pathogens such as $V$. longisporum (45). In 2006/2007, the rape-growing area was extended to about 6.2 million hectares. Besides wheat and barley, oilseed rape is the crop with the largest agricultural area in Germany at present. Data concerning yield losses caused by Verticillium infection reports losses as about 10- 50\% (46). The host range of $V$. longisporum is limited to the family of Brassicaceae (6). Study of plant/pathogen interaction is impaired by the relatively long life cycle of rape crops used in the field. Consequently, in the 80s, a Brassica species was bred which had a shorter life cycle compared to field crops lasting up to two years (47). This species, referred as "rapid-cycling rape plants", requires 25 days on average to flower and 55 days to reach seed maturity, and has found an application in many research laboratories dealing with diseases of oilseed rape (48). V. longisporum induces stunting, chlorosis and anthocyanin accumulation, affects the flowering time, and triggers early onset of senescence on host plants (49). 

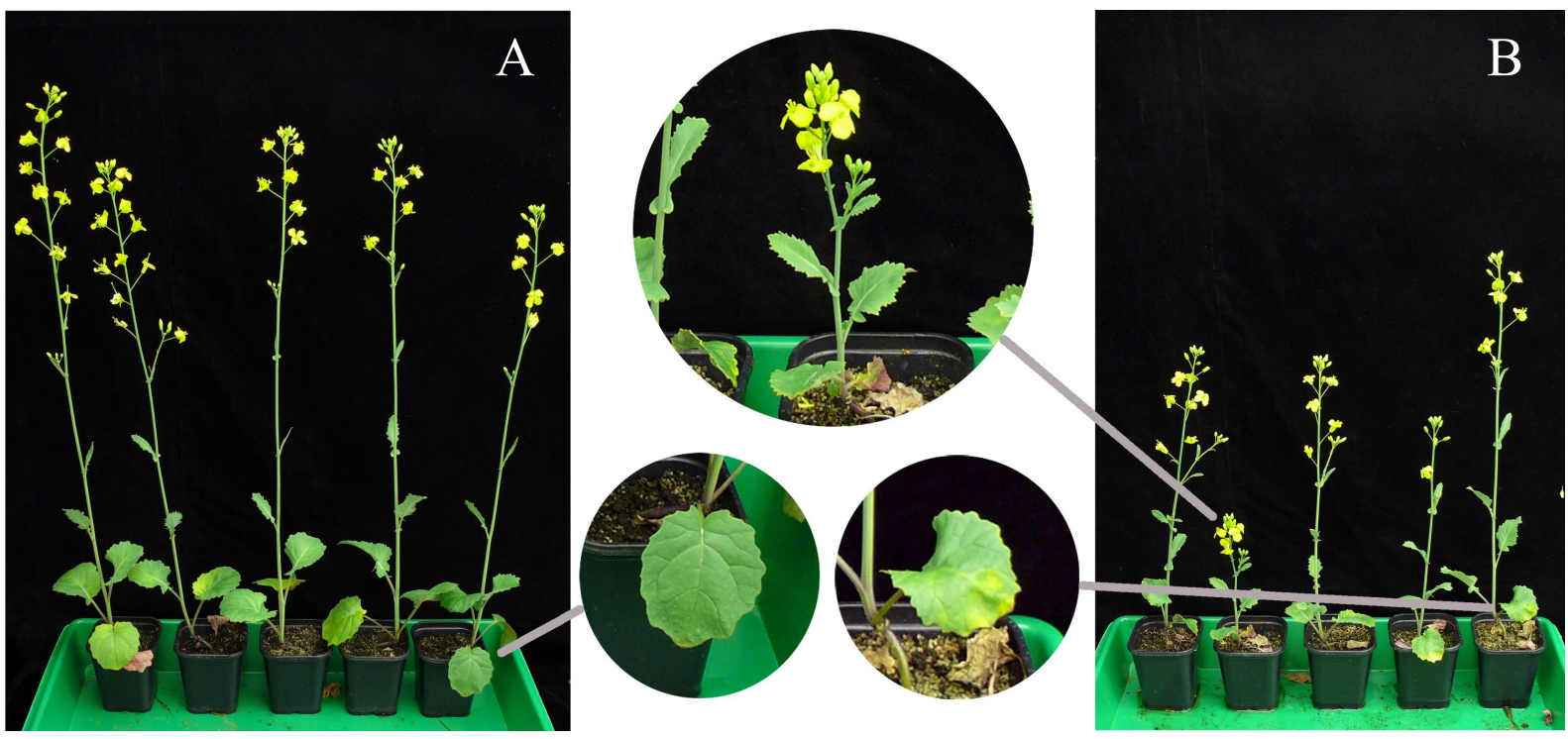

Figure 1: Symptom-development of $V$. longisporum-infected $B$. napus plants under climate chamber conditions (stunting and chlorosis)

A. water inoculated (28 dpi) B. wild type inoculated (28 dpi)

The typical symptom after Verticillium infection is wilting of the host plant (50). In field trials with oilseed rape infected with $V$. longisporum, wilting and also typical stunting effects on plant height $(51,52,53,54)$ could not be observed. Artificially $V$. longisporum inoculated oilseed rape plants show clear stunting of infected plants under greenhouse conditions, but again, no wilting. Compared to other Verticillium species, the control of diseases caused by $V$. longisporum is known to be difficult. The use of chemical fungicides is hampered because of the soil-borne life cycle and the microsclerotia contamination of the soil. The use of any commercially available fungicide shows no effects on crop yield $(55,56)$. Also, biological control with antagonistic microorganisms has not led to any practicable results $(57,58)$. The search for oilseed rape varieties that show resistance to $V$. longisporum infection is therefore in the foreground of current scientific research. Experiments with various rape cultivars show promising differences in the disease severity during infection with $V$. longisporum in the greenhouse $(59,60,61,62,63,64)$ and in the field $(65,66,67)$.

\section{Life cycle of $V$. longisporum}

The life cycle of $V$. longisporum is nearly equal to that of other plant pathogenic Verticillium species and can be divided into three vegetative stages referred to as the dormant, the parasitic, and the saprophytic phases (see Figure 2). 


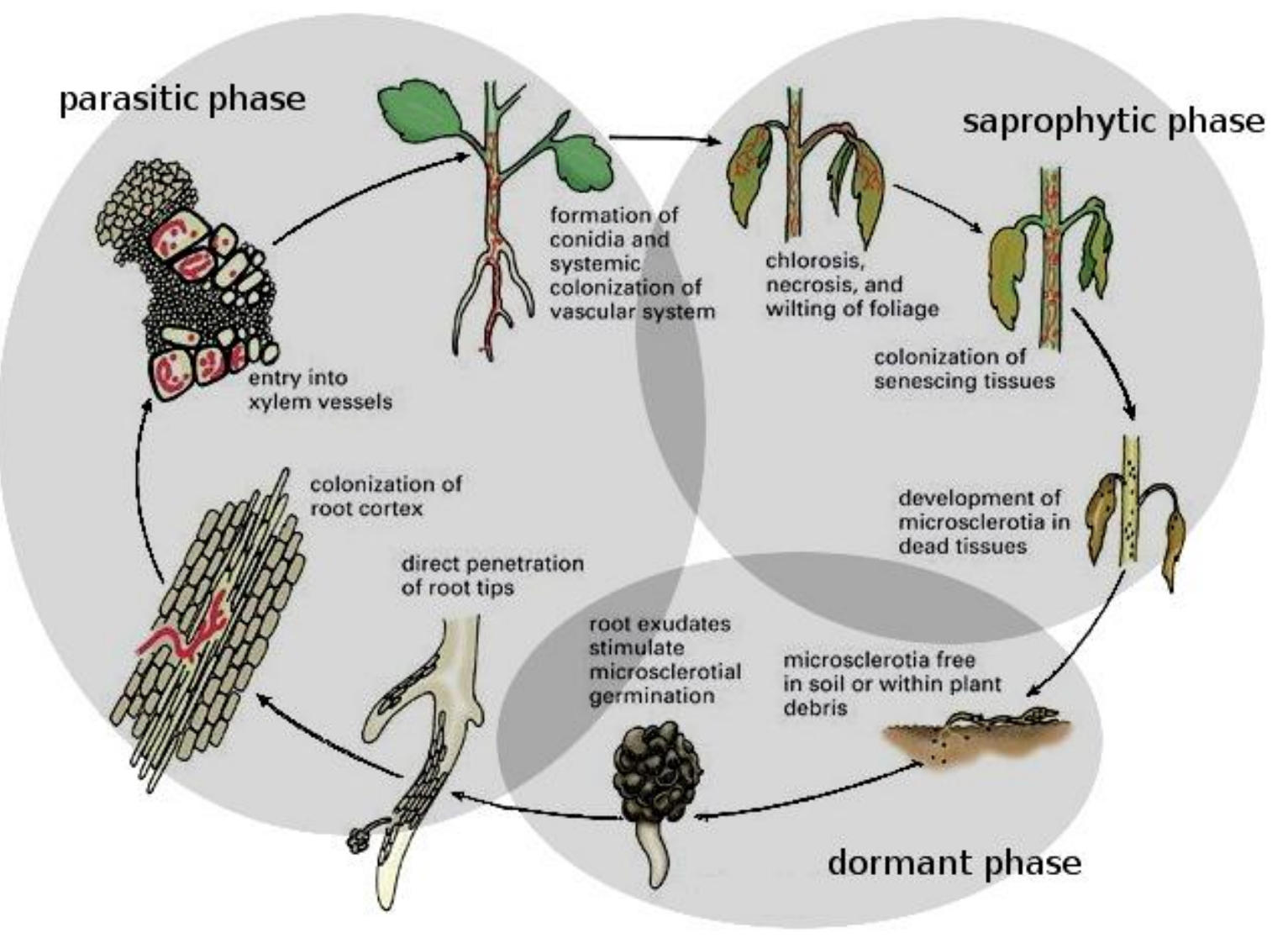

Figure 2: Life cycle of Verticillium spp.

(modified picture, drawn by Vickie Brewster, coloured by Jesse Ewing)

Resting structures of $V$. longisporum are melanized aggregates formed from enlarged hyphal cells which are capable of remaining in the soil for many years $(68,69)$. In contrast to the compact and nodular formed microsclerotia of $V$. dahliae, these so-called microsclerotia are elongated and arranged in irregular fashion in the soil $(6,70)$. In the dormant phase of the $V$. longisporum life cycle, the fungus rests in the soil until the environmental conditions allow it to pass into the next phase. In the following parasitic phase, microsclerotia starts to germinate under the effect of root exudates released from plants into the rhizosphere (71). Grown hyphae are able to travel short distances to reach the host plant and directly penetrate the epidermal cells of the root cortex (72) where they grow in inter and intracellular fashion until they penetrate the vessel system (73). The fungus colonizes the vascular system where it mostly stays during the biotrophic stage of the plant colonization. Spores are transported with the transpiration stream from the root vessels into the shoot to infest the whole plant. It is most likely that the fungus must derive nutrition from the xylem sap to survive and spread in 
the plant but recent reports about xylem sap composition of $B$. napus after $V$. longisporum infection show no limitation of nutrients compared to that of non-infected plants (74) which concludes that $V$. longisporum-induced stunting of oilseed rape is not caused by nutrient limitations. The same study showed that also a putative reduced water supply or a suppression of the photosynthesis is not involved in the symptom development caused by the fungus. It is unknown how the fungus responds to environmental changes to prevent recognition by the plant, thus allowing the biotrophic growth. In later stages of the infection, the fungus enters the saprophytic phase and metabolises nutrients released by dead plant tissue. The life cycle is completed by the formation of microsclerotia that are released to the soil. This change of a biotroph and a necrotrophic stage in the life cycle during plant colonization is characteristic a hemibiotrophic plant pathogen. The molecular processes in $V$. longisporum during infection of the host plant are largely unknown but some virulence factors of Verticillium species are known to set off infection of the plant.

\section{Plant-Pathogen interactions}

Understanding how certain plant pathogens cause disease in one host plant and not in another has long been a concern of modern plant pathologists. Plant-pathogen interaction can be defined as the interplay of plant pathogenic organisms trying to invade the plant, and the recognition by the plant and the attempt to counteract this invasion. Plants have developed various mechanisms to react against an attack of pathogens. One of the most effective defence reactions of plants is the recognition of pathogen-related molecules and the binding of these through receptors which are expressed in response to infection. These receptors are expressed by so-called resistance genes ( $\mathrm{R}$ genes) to bind elicitors such as proteins, polysaccharide or lipids derived from the cell walls of pathogens. If a plant is susceptible to the attack of a pathogen, the interaction is referred to as a 'compatible reaction'. In this case the pathogen is known to be virulent to the plant. If a plant is able to overcome the pathogen infestation the reaction is called 'incompatible' and the pathogen is avirulent. The question of why a pathogen infects a certain plant can probably be answered by the interplay between specific proteins expressed by avirulence genes ( $a v r$ genes) from the pathogen, and the products expressed by the $\mathrm{R}$ genes from the plant. In a compatible reaction, the plant cannot recognize the avr gene product and the pathogen can infect the plant. Conversely, if the plant can recognize the gene product which is expressed by the fungi a diverse pattern of defence genes 
are expressed by the plant to reduce the disease severity (75). As a result of the incompatible reaction, the plant often responds by killing cells at and around the site of infection to generate a physical barrier and to limit the nutrient supply for the pathogen $(76,77)$. This programmed cell death is also termed the 'hypersensitive response' (HR). The HR is accompanied by the induction of several anti-microbial defence molecules such as pathogenesis-related (PR) proteins, glucanases, chitinases and phytoalexins. In addition to local responses, plants can also counteract pathogens through systemic-acquired resistance (SAR), which means that the plant gains the ability to act against pathogens in other areas apart from directly affected plant parts. The SAR is generally evolved within several days after the first infection with the pathogen (78) and is effective against a broad spectrum of pathogens. Many proteins are needed for the SAR, including hydrolytic PR-proteins $(79,80$, 81) and the signal molecule salicylic acid (SA) (82). On the other side, plant pathogenic organisms need the factors of virulence and pathogenicity to overcome the plant defences. Pathogenicity factors are described as compounds which trigger the disease but have no influence on disease severity. Conversely, virulence factors are compounds with an impact on the intensity of the pathogen-propagation. As mentioned previously, the molecular processes of plant-infestation in $V$. longisporum are largely unknown. The biotrophic growth of the fungus inside the plant requires a compatible reaction. In the early stages of the fungal infestation no defence reactions of the plant could be observed. The supply of carbon, which is essential for the fungal growth, is limited by the fact that $V$. longisporum is strictly localized in the xylem vessels of host plants during the biotrophic phase. Therefore, it is most likely that the fungus secretes cell wall-degrading enzymes such as pectin lyases that destabilize the xylem-vessel to release nutrients from the plant tissue $(83,84,85)$. Pectinasedeficient mutants of $V$. longisporum show interfered symptom development in the plant but finally no change in the degree of colonization compared to wild type infected plants. Accordingly, pectinases have been classified as virulence factors and not as pathogenicity factors $(86,87)$. In general, little is known about phytotoxic metabolites of Verticillium spp., but recently a family of small phytotoxic peptides have been described. These so-called necrosis and ethylene-inducing peptides (NEPs) were detected in various organisms, causing wilting and chlorosis in leaves that had been infiltrated by the protein. Several NEPs were tested in different plant systems to discover if any plant responses were triggered. Mostly HRlike symptoms were observed but the mechanisms of initiation remain unclear $(89,90,91)$. 


\section{Necrosis- and ethylene-inducing peptides (NEPs)}

The class of necrosis- and ethylene-inducing peptides (NEPs) belong to a family of relatively small secreted proteins $(24-35 \mathrm{kDa})$ supposed to be involved in plant pathogenic processes. Fifteen years ago, Bailey described a protein from Fusarium oxysporum which triggers cell death in plants (89). This was the first representative of what is currently known in literature as NEP, NIP (necrosis-inducing peptides) or NPP (necrosis-inducing Phytophthora proteins) as designated by different authors $(91,92,93,94)$. Since this time NEPs have been found in many other organisms including bacteria, oomycetes and fungi. Most of the species are known to be plant pathogenic. In fungi and oomycetes, NEPs are dominantly present in species with a hemibiotrophic or a necrotrophic life cycle (94). All NEPs share a highly conserved hepta-peptide motif in the central area of the protein and two to four cystein residues downstream at the $\mathrm{N}$-terminus $(91,95,96)$ which are supposed to be relevant for peptide activity (93). These conserved cysteins are used to classify NEPs into two groups referred to as Group I (proteins including two cysteins) and Group II (proteins including four cysteins) (97). Only dicotyledonous plants are affected by NEP-treatment; all tested monocotyledonous plants are insensitive so far $(96,98,99)$. Sensitive plants respond with different modes of action such as $\mathrm{H}_{2} \mathrm{O}_{2}$ accumulation, production of nitric oxide, release of phytoalexins, expression of PR-genes, and also with the formation of necrotic lesions on affected plant tissue $(93,99,100)$. In 2004, Wang produced the first report on an NEP found in a Verticillium species (88). This protein from $V$. dahliae, designated as VdNEP, triggers the formation of necrotic lesions in cotton and $A$. thaliana after leaf-infiltration with the protein. Less is known about NEPs from $V$. longisporum. For this, we want to detect NEP-like proteins (NLPs) in the fungus to elucidate their putative role in the pathogenic life-cycle.

\section{Polyketide synthases (PKSs)}

Polyketides (PKs) are secondary metabolites from bacteria, plants, animals and fungi, including natural products with manifold biological activities. In pharmacology, PKs are often used to kill or inhibit the growth of bacteria, fungi or animals through their toxic abilities. Polyketide synthases (PKS) catalyze the series of small carboxylic acids into PKs and can be distinguished into two classes according to their functionality. Type I-PKS are modular formed multifunctional enzymes with several domains, forming reduced PKs such as 
erythromycin, which is produced by bacteria of the genus Streptomyces. In contrast, PKS from type II form mostly aromatic PKs such as tetracycline by the use of only a single domain. The biosynthesis of PKs in fungi is derived by large multifunctional type I-PKS, coded by single genes (101). Fungal PKs are scientifically well characterized, and are divided into two functional groups of secondary metabolites. Mould fungi produce a wide range of chemically diverse secreted PKs known as mycotoxins. These include zeralenone, fumonisin and aflatoxin $(102,103,104)$. Mycotoxins have toxic abilities against endothermic animals but their ecological role in fungi is still not clear, for example whether they have an impact, through inhibitory effects, on the competition against other fungal species and microbes (105) or act as virulence factors, through poisonous effects, on plant tissue $(103,106)$. The second group of fungal PKs consist of non-secreted pigments such as melanin which is known to often play a role in plant pathology. A function of melanin in the appressoria-mediated penetration of plant cell walls was first shown in Pyricularia oryzae $(102,107)$. In Colletotrichum lagenarium PKS knock-down mutants change to an albino phenotype with non-melanized appressoria showing a reduced ability to penetrate the cell wall of host-plants (108). Regardless of the absence of appressoria-mediated colonization of plants by $V$. longisporum, we found an upregulated PKS-gene with high homology to the PKS-gene of $C$. lagenarium. This gene is involved in the biosynthesis of 1,8-dihydroxynapthalene (DHN)melanin. The function of this gene will be characterized in this thesis to determine its impact in the life cycle of $V$. longisporum.

\section{REFERENCES}

1. Pegg, G.F., Brady, B.L. (2002). Verticillium Wilts. Wallingford, UK: CAB Publishing.

2. Schwantes, H.O. (1996). Biologie der Pilze. Verlag Eugen Ulmer, Stuttgart. 6.

3. Bhat RG, Subbarao KV (1999). Host range specificity in Verticillium dahliae. Phytopathology 89: 1218-1225.

4. Agrios G.N. (1997). Plant diseases caused by fungi: Verticillium wilts. In Agrios G.N. (ed.): Plant Pathology 346, Academic Press, San Diego. 
5. Barbara, D. J. \& Clewes, E. (2003). Plant pathogenic Verticillium species: how many of them are there? Molecular Plant Pathology 4: 297-305.

6. Karapapa et al. (1997). Advances in Verticillium research and disease management. Tjamos, E.C., Rowe, R.C., Heale, J.B., Fravel, D.R. (eds.), St. Paul, Minnesota, APS Press, 196-203.

7. Reinke, J.; Berthold, G. (1879). Die Zersetzung der Kartoffel durch Pilze, Unters. Bot. Lab. Univ. Göttingen. Heft I. Berlin. 1879.

8. Klebhahn H. (1913). Beiträge zur Kenntnis der Fungi Imperfecti I. Eine Verticillium Krankheit auf Dahliaen. Mycologisches Zentralblatt 3: 49-66.

9. Pethybridge G. H. (1919). Notes on some saprophytic species associated with diseased potato plants and tubers. Transactions of the British Mycological Society 6: 104-120.

10. Mason \& Hughes in Hughes (1951). Studies on microfungi, Mycol. Pap. 45: 27

11. Isaac, I. (1957). Verticillium wilt of Brussels sprout. Annals of Applied Biology 45: 276-283.

12. Gordon, T.R., Kirkpatrick, S.C., Hansen, J., Shaw, D.V. (2006). Response of strawberry genotypes to inoculation with isolates of Verticillium dahliae differing in host origin. Plant Pathology 55: 766-769.

13. Heale, J.B. (2000). Diversification and speciation in Verticillium - An overview. In: Advances in Verticillium research and disease management. Tjamos, E.C., Rowe, R.C., Heale, J.B., Fravel, D.R. (eds.), St. Paul, Minnesota, APS Press, 175-177.

14. Fradin, E.F., Thomma, B.P.H.J. (2006). Physiology and molecular aspects of Verticillium wilt diseases caused by $V$. dahliae and $V$. albo-atrum. Molecular Plant Pathology 7: 71-86.

15. Pegg, G. F. (1976). Response of ethylene-treated tomato plants to infection by Verticillium albo atrum. Physiological Plant Pathology 9: 215-226.

16. Dunker S. (2005). Untersuchungen zur Schadwirkung von Sclerotinia sclerotiorum (Lib. de Bary) und Verticillium longisporum (comb. nov. Karapapa) in Winterraps (Brassica napus). Dissertation, Georg-August Universität Göttingen.

17. Nagtzaam M.P.M., Bollen G.J., Termorshuizen A.J. (1998). Efficacy of Talaromyces flavus alone or in combination with other antagonists in controlling Verticillium dahliae in growth chamber experiments. J. Phytopathol. 146: 165-173. 
18. Tenuta M., Lazarovits G. (2002). Ammonia and nitrous acid from nitrogenous amendments kill the microsclerotia of Verticillium dahliae. Phytopathol. 93: 255-264.

19. Noble R., Coventry E. (2005). Suppression of soil-borne plant diseases with composts: a review. Biocontrol Sci. Techn. 15: 3-20.

20. Happstadius I., Ljunberg A., Kristiansson B., Dixelius C. (2003). Identification of Brassica oleracea germplasm with improved resistance to Verticillium wilts. Plant Breeding 122: 30-34.

21. Rygulla W., Snowdon R.J., Eynck C., Koopmann B., von Tiedemann A., Lühs W., Friedt W. (2007). Broadening the genetic basis of Verticillium longisporum resistance in Brassica napus by interspecific hybridisation. Plant Breeding 126: 596602.

22. Rygulla W., Seyis F., Lühs W., Eynck C., von Tiedemann A., Friedt W., Snowdon R.J. (2007). Combination of resistance to Verticillium longisporum from zero eruic acid Brassica oleracea and oilseed Brassica rapa genotypes in resynthesized rapeseed (Brassica napus) lines. Phytopathology 97: 1391-1396.

23. Pantou M.P., Kouvelis V.N., Typas M.A. (2006). The complete mitochondrial genome of the vascular wilt fungus Verticillium dahliae: a novel gene order for Verticillium and a diagnostic tool for species identification. Curr. Genet. 50:125-136.

24. Zeise K., von Tiedemann A. (2001). Morphological and Physiological Differentiation among Vegetative Compatibility Groups of Verticillium dahliae in Relation to $V$. longisporum. J. Phytopathol. 149: 469-475.

25. Fahleson J., Lagercrantz U., Hu Q., Steventon L.A., Dixelius C. (2003). Estimation of genetic variation among Verticillium isolates using AFLP analysis. Eur. J. Plant Pathol. 109: 361-371.

26. Karapapa V.K. Typas M.A. (2001). Molecular characterization of the host-adapted pathogen Verticillium longisporum on the basis of a group-I intron found in the nuclear SSU-rRNA gene. Curr. Microbiol. 42: 217-224.

27. Kouvelis V.N., Sialakouma A., Typas M.A. (2008). Mitochondrial gene sequences alone or combined with ITS region sequences provide firm molecular criteria for the classification of Lecanillium species. Mycol. Res. 112: 829-844. 
28. Wang J., Cai Y., Gou J., Mao Y., Xu Y., Jiang W., Chen X. (2004). VdNEP, an elicitor from Verticillium dahliae, induces cotton plant wilting. Appl. Environ. Microbiol. 70: 4989-4995.

29. Neumann M.J., Dobinson K.F. (2003). Sequence tag analysis of gene expression during pathogenic growth and microsclerotia development in the vascular wilt pathogen Verticillium dahliae. Fung. Genet. Biol. 38: 54-62.

30. Stark, C. (1961). Das Auftreten der Verticillium-Tracheomykosen in Hamburger Gartenbau-Kulturen. Gartenbauwissenschaft 26: 493-528

31. Typas, M. A., Heale, J. B. (1977). Analysis of ploidy levels in strains of Verticillium using a Coulter counter. Journal of General Microbiology 101: 177-180.

32. Typas, M. A., Heale, J. B. (1980). DNA content of germination spores individual hyphal cells and resting structure cells of Verticillium spp. measured by microdensitometry. Journal of General Microbiology 121: 231-242.

33. Koike, S.T., Subbarao, K.V., Davis, R.M., Gordon, T.R., Hubbard, J.C. (1994). Verticillium wilt of cauliflower in California. Plant Disease 78: 1116-1121.

34. Morton, A., Carder, J. H., Barbara, D. J. (1995). Sequences of the internal transcribed spacers of the ribosomal RNA genes and relationships between isolates of Verticillium alboatrum and V. dahliae. Plant Pathology 44: 183-190.

35. Subbarao, K.V., Chassot, A., Gordon, T.R., Hubbard, J.C., Bonello, P., Mulin, R., Okamoto, D., Davis, R.M., Koike, S.T. (1995). Genetic relationships and cross pathogenicities of Verticillium dahliae isolates from cauliflower and other crops. Phytopathology 85: 1105-1112.

36. Messner, R. Sweigkofler, W., Ibl, M., Berg, G., Prillinger, H. (1996). Molecular characterization of the plant pathogen Verticillium dahliae Kleb. using RAPD-PCR and sequencing of the 18S rRNA-gene. Journal of Phytopathology 144: 347-354

37. Karapapa, V. K., Typas, M. A. (2001). Molecular characterization of the hostadapted pathogen Verticillium longisporum on the basis of a Group-I intron found in the nuclear SSU-rRNA gene. Current Microbiology 42: 217-224.

38. Steventon, L.A., Fahleson, J., Hu, Q., Dixelius, C. (2002). Identification of the causal agent of Verticillium wilt of winter oilseed rape in Sweden, Verticillium longisporum. Mycological Research 106: 570-578. 
39. Zeise K., von Tiedemann A. (2002). Application of RAPD-PCR for Virulence Type Analysis within Verticillium dahliae and Verticillium longisporum. J. Phytopathol. 150: $557-563$.

40. Collins, A., Okoli, A.N., Morton, A., Parry, D., Edwards, S.G., Barbara, D.J. (2003). Isolates of Verticillium dahliae pathogenic to crucifers are of at least three distinct molecular types. Phytopathology 93: 364-376.

41. Fahleson, J., Lagercrantz, U., Hu, Q., Steventon, L. A. \& Dixelius, C. (2003). Estimation of genetic variation among Verticillium isolates using AFLP analysis. European Journal of Plant Pathology 109: 361-371.

42. Collins A., Okoli C.A.N., Morton A., Parry D., Edwards S.G., Barbara D.J. (2003). Isolates of Verticillium dahliae pathogenic to crucifers are of at least three distinct molecular types. Phytopathol. 93: 364-376.

43. Daebeler F, Amelung D, Zeise K. (1988). Verticillium-Welke an WinterrapsAuftreten und Bedeutung. Nachrichtenblatt Pflanzenschutzdienst DDR 42: 71-73.

44. Svensson C., Lerenius C. (1987). An investigation on the effect of Verticillium wilt (Verticillium dahliae Kleb.) on oilseed rape. Bulletin SROP 10: 30-34

45. Krüger, W. (1989)- Untersuchungen zur Verbreitung von Verticillium dahliae Kleb. und anderen Krankheits- und Schaderregern bei Raps in der Bundesrepublik Deutschland. Nachrichtenblatt des Deutschen Pflanzenschutzdienstes 41: 49-56.

46. Dunker S, Keunecke H, Steinbach P, von Tiedemann A. (2008). Impact of Verticillium longisporum on yield and morphology of winter oilseed rape (Brassica napus) in relation to systemic spread in the plant. Journal of Phytopathology, Published Online

47. Williams, P. H. \& Hill, C. B. (1986). Rapid-cycling populations of Brassica. Science 232: $1385-1389$

48. Musgrave, M. E. (2000). Realizing the potential of rapid-cycling Brassica as a model system for use in plant biology research. Journal of Plant Growth Regulation 19: 314325 .

49. Veronese, P., Narasimhan, M. L., Stevenson, R. A., Zhu, J. K., Weller, S. C., Subbarao, K. V. \& D., Davis, R.M., Koike, S.T. (1995). Genetic relationships and cross patho-genicities of Verticillium dahliae isolates from cauliflower and other crops. Phytopathology 85: 1105-1112. 
50. Niederleitner, S., Zinkernagel, V., Bartscherer, H.-C. (1991). Untersuchungen zur Pathogenese von Verticillium dahliae an Impatiens balsamina und Brassica napus. Zeitschrift für Pflanzenkrankheiten und Pflanzenschutz 98: 484-489.

51. Pullman, G. S., De Vay, J. E. (1982). Epidemiology of Verticillium wilt of cotton: A relationship between inoculum density and disease progression. Phytopathology 72: 549-554.

52. Koike M., Fujita M., Nagoa H., Ohshima S. (1996): Random amplified polymorphic DNA analysis of Japanese isolates of Verticillium dahliae and V. albo-atrum. Plant Disease 80: 1224-1227.

53. Xiao C. L., Subbaro K. V. (1998). Relationship between Verticillium dahliae inoculum density and wilt incidence, severity, and growth of cauliflower. Phytopathology 88: 1108-1115.

54. Debode, J., Claeys, D. \& Höfte, M. (2004). Control of Verticillium wilt of cauliflower with crop residues, lignin and microbial antagonists. IOBC WPRS Bull 27: 41-45.

55. Wohlleben, S. (2001). Epidemie- und Schadensdynamik von pilzlichen Krankheitserregern (Leptosphaeria maculans, Sclerotinia sclerotiorum, Verticillium dahliae) an Winterraps (Brassica napus L. var. napus) in Schleswig-Holstein. Dissertation, Christian-Albrechts-Universität Kiel.

56. Keunecke H. (2005). Einfluss von Verticillium longisporum auf die Wurzel- und Sprossentwicklung von Winterraps unter Berücksichtigung von Fungizidapplikationen. Masterarbeit, Georg-August-Universität Göttingen.

57. Berg, G. \& Ballin G. (1994): Bacterial Antagonists to Verticillium dahliae Kleb. J. Phytopathology 141: 99-110.

58. Alström, S. (2000). Root-colonizing fungi from oilseed rape and their inhibition of Verticillium dahliae. J. Phytopathology 148: 417-423.

59. Zeise, K. (1992). Gewächshaustest zur Resistenzprüfung von Winterraps (Brassica napus L. var. oleifera Metzger) gegen den Erreger der Rapswelke Verticillium dahliae Kleb.. Nachrichtenbl. Deutsch. Pflanzenschutzd. 44: 125-128.

60. Zeise, K. \& A. v. Tiedemann (2002). Host specialization among vegetative compatibility groups of Verticillium dahliae in relation to Verticillium longisporum. J. Phytopathology 150: 112-119. 
61. Steventon, L.A., Happstadius, I., Okori, P., Dixelius, C. (2002) Development of a rapid technique for the evaluation of the response of Brassica napus to Verticillium wilt. Plant Disease 86: 854-858.

62. Happstadius I., Ljunberg A., Kristiansson B., Dixelius C. (2003). Identification of Brassica oleracea germplasm with improved resistance to Verticillium wilt. Plant Breeding 122: 30-34.

63. Keunecke, H. (2005). Einfluss von Verticillium longisporum auf die Wurzel- und Sprossentwicklung von Winterraps unter Berücksichtigung von Fungizidapplikationen. Masterarbeit, Georg-August Universität Göttingen.

64. Eynck, C. (2008). Identification of resistance sources and characterisation of resistance factors in Brassica species to Verticillium longisporum. Dissertation, Georg-August Universität Göttingen.

65. Heppner, C. \& Heitefuss R. (1995). Untersuchungen zum Auftreten von Verticillium dahliae Kleb. und anderen pilzlichen Erregern am Erntegut von Winterraps (Brassica napus L. var. oleifera Metzger). Nachrichtenbl. Deutsch. Pflanzenschutzd. 47: 57-61.

66. Zeise K., Steinbach P. (2004). Schwarze Rapswurzeln und der Vormarsch der Verticillium-Rapswelke. Raps 22: 170-174

67. Eynck C. (2007). Identification of resistance sources and characterization of resistance factors in Brassica species to Verticillium longisporum. Dissertation, Georg-August Universität Göttingen.

68. Schnathorst WC. (1981). Life cycle and epidemiology of Verticillium. In: Mace ME, Bell AA, Beckmann CH (eds.) Fungal Wilt Diseases of Plants. Academic Press, New York, 81-111.

69. Heale, J. B. \& V. K. Karapapa, (1999). The Verticillium threat to Canada's major oilseed crop canola. Can. J. Plant. Pathol. 21: 1-7.

70. Zeise, K., von Tiedemann, A. (2001). Morphological and physiological differentiation among vegetative compatibility groups of Verticillium dahliae in relation to $V$. longisporum. Journal of Phytopathology 149: 469-475.

71. Heppner, C., (1995). Nachweis von Verticillium dahliae Kleb. im Boden mit Plattengussfahren und ELISA (enzyme-linked immunosorbent assay) sowie Untersuchungen zur Auswirkung des Inokulums auf den Befall von Winterraps 
(Brassica napus ssp. Oleifera Metzg.). Dissertation, Universität Göttingen, Cuvillier Verlag, Göttingen.

72. Eynck, C., B. Koopmann, G. Grunewaldt-Stoecker, P. Karlovsky \& A. von Tiedemann, (2007). Differential interactions of Verticillium longisporum and Verticillium dahliae with Brassica napus detected with molecular and histological techniques. Eur. J. Plant Pathol. 118: 259-274.

73. Beckmann C.H. (1987). The nature of wilt disease of plants. St.Paul, MN, USA, APS Press.

74. Floerl S, Druebert C, Majcherczyk A, Karlovsky P, Kües U, Polle A. (2008). Defence reactions in the apoplastic proteome of oilseed rape (Brassica napus var. napus) attenuate Verticillium longisporum growth but not disease symptoms. BMC Plant Biol. 8: 129.

75. Feys, B. J. \& Parker, J. E. (2000). Interplay of signaling pathways in plant disease resistance. Trends in Genetics 16: 449-455.

76. Heath, M. C. (1998). Apoptosis, programmed cell death and the hypersensitive response. European Journal of Plant Pathology 104: 117-124.

77. Scheel, D. (1998). Resistance response physiology and signal transduction. Current Opinion in Plant Biology 1: 305-310.

78. Ryals, J. A., Neuenschwander, U. H., Willits, M. G., Molina, A., Steiner, H. Y. \& Hunt, M. D. (1996). Systemic acquired resistance. Plant Cell 8: 1809-1819.

79. Schröder, M., Hahlbrock, K. \& Kombrink, E. (1992). Temporal and spatial patterns of 1,3- $\beta$-glucanase and chitinase induction in potato leaves infected by Phytophthora infestans. Plant Journal 2: 161-172.

80. Hong, J. K., Jung, H. W., Kim, Y. J. \& Hwang, B. K. (2000). Pepper gene encoding a basic class II chitinase is inducible by pathogen and ethephon. Plant Science 159: $39-49$.

81. Jung, H. W. \& Hwang, B. K. (2000). Pepper gene encoding a basic $\beta$-1,3-glucanase is differentially expressed in pepper tissues upon pathogen infection and ethephon or methyl jasmonate treatment. Plant Science 159: 97-106.

82. Ryals, J. A., Neuenschwander, U. H., Willits, M. G., Molina, A., Steiner, H. Y. \& Hunt, M. D. (1996). Systemic acquired resistance. Plant Cell 8: 1809-1819. 
83. Huang L.K., Mahoney R.R. (1999). Purification and characterization of an endopolygalacturonase from Verticillium albo-atrum. J. Appl. Microbiol. 86: 145-156.

84. Mussel H.W., Strause B. (1972). Characterization of two polygalacturonases produced by Verticillium albo-atrum. Can. J. Biochem. 50: 625-632.

85. Wang M.C., Keen N.T. (1970). Purification and characterization of endopolygalacturonase from Verticillium albo-atrum. Arch. Biochem. Biophys. 141: 749-757.

86. Durrands P.K., Cooper R.M. (1988). Selection and characterization of pectinase deficient mutants of the vascular pathogen Verticillium dahliae. Physiol. Mol. Plant Pathol. 32: 343-362.

87. Durrands P.K., Cooper R.M. (1988). The role of pectinases in vascular wilt disease as determined by defined mutants of Verticillium albo-atrum. Physiol. Mol. Plant Pathol. 32: 363-371.

88. Wang J., Cai Y., Gou J., Mao Y., Xu Y., Jiang W., Chen X. (2004). VdNEP, an elicitor from Verticillium dahliae, induces cotton plant wilting. Appl. Environ. Microbiol. 70: 4989-4995.

89. Bailey B.A. (1995). Purification of a protein from cultures filtrates of Fusarium oxysporum that induces ethylene and necrosis in leaves of Erythroxylum coca. Phytopathol. 85: 1250-1255.

90. Bailey, B.A., Jennings, J.C., and Anderson, J.D. (1997). The 24-kDa protein from Fusarium oxysporum f.sp. erythroxyli: occurrence in related fungi and the effect of growth medium on its production. Canadian Journal of Microbiology 43: 45- 55.

91. Pemberton C.L., Salmond G.P.C. (2004). The Nep1-like proteins - a growing family of microbial elicitors of plant necrosis. Mol. Plant Pathol. 5: 353-359.

92. Bailey B.A., Apel-Birkhold P.C., Luster D.G. (2002). Expression of NEP1 by Fusarium oxysporum f.sp. erythroxyli after gene replacement and overexpression using polyethylene glycol-mediated transformation. Genet. Resistance 92: 833-841.

93. Fellbrich G., Romanski A., Varet A., Blume B., Brunner F., Engelhardt S., Felix G., Kemmerling B., Krzymowska M., Nürnberger T. (2002). NPP1, a Phytophthora-associated trigger of plant defense in parsley and Arabidopsis. Plant J. 32: 375-390. 
94. Qutob D., Kemmerling B., Brunner F., Küfner I., Engelhardt S., Gust A.A., Luberacki B., Seitz H.U., Stahl D., Rauhut T., Glawischnig E., Schween G., Lacombe B., Watanabe N., Lam E., Schlichting R., Scheel D., Nau K., Dodt G.,Hubert D., Gijzen M., Nürnberger T. (2002). Phytotoxicity and innate immune responses induced by Nep1-like proteins. Plant Cell 18: 3721-3744.

95. Fradin E.F., Thomma B.P.H.J. (2006). Physiology and molecular aspects of Verticillium wilt diseases caused by $V$. dahliae and $V$. albo-atrum. Mol. Plant Pathol. 7: $71-88$.

96. Staats M., van Baarlem P., Schouten A., van Kan J. A. L., Bakker F. T. (2007). Positive selection in phytotoxic protein-encoding genes of Botrytis species. Fung. Genet. Biol. 44: 52-63.

97. Gijzen, M. and Nürnberger, T. (2006). Nep1-like proteins from plant pathogens: recruitment and diversification of the NPP1 domain across taxa. Phytochemistry 67(16): 1800-1807.

98. Keates S.E., Kostman T.A., Anderson J.D., Bailey B.A. (2003). Altered gene expression in three plant species in response to treatment with Nep1, a fungal protein that causes necrosis. Plant Physiol. 132: 1610-1622.

99. Schouten, A., van Baarlen, P. and van Kan, J. A. L. (2008). Phytotoxic Nep1-like proteins from the necrotrophic fungus Botrytis cinerea associate with membranes and the nucleus of plant cells. New Phytologist 177(2): 493-505.

100. Bae, H., Bowers, J. H., Tooley, P. W. and Bailey, B. A. (2005). NEP1 orthologs encoding necrosis and ethylene inducing proteins exist as a multigene family in Phytophthora megakarya, causal agent of black pod disease on cacao. Mycological Research 109: 1373-1385.

101.Bingle, L.E.H., Simpson, T.J. \& Lazarus, C.M. (1999). Ketosynthase Domain Probes Identify Two Subclasses of Fungal Polyketide Synthase Genes. Fungal Genetics and Biology 26: 209-223.

102. Kim Y.T., Lee Y.R., Jin J., Han K.H., Kim H., Kim J.C., Lee T., Yun S.H., Lee Y.W. (2005). Two different polyketide synthase genes are required for zearalenone in Gibberellazeae. Mol. Microbiol. 58: 1102-1113. 
103. Proctor R.H., Desjardins A.E., Plattner R.D., Hohn T.M. (1999). A polyketide synthase gene required for biosynthesis of fumonisin mycotoxins in Gibberella fujikuroi mating population A. Fung. Genet. Biol. 27: 100-112.

104.Watanabe C.M., Wilson D., Linz J.E., Townsend C.A. (1996). Demonstration of the catalytic roles and evidence for the physical association of type I fatty acid synthases and a polyketide synthase in the biosynthesis of aflatoxin B1. Chem. Biol. 3: 463-469.

105. Greenberg J.T., Yao N. (2004). The role and regulation of programmed cell death in plant-pathogen interactions. Cell. Microbiol. 6: 201-211.

106. Gómez B.L., Nosanchuuk J.D. (2003). Melanin and fungi. Curr. Opin. Infect. Dis. 16: 91-96.

107. Howard R.J., Ferrari M.A., Roach D.H., Money N.P. (1991). Penetration of hard substrates by a fungus employing enormous tugor pressures. PNAS 88: 11281-11284.

108. Takano Y., Kubo Y., Shimizu K., Mise K., Okuno T., Furusawa I. (1995). Structural analysis of PKS1, a polyketide synthase gene involved in melanin biosynthesis in Colletotrichum lagenarium. Mol. Gen. Genet. 249: 162-167. 


\title{
Chapter 2: Gene silencing in Verticillium longisporum: evaluation and establishment of a method for post-transcriptional downregulation of genes
}

\author{
Malte Beinhoff, Arne Weiberg and Petr Karlovsky \\ Molecular Plant Pathology and Mycotoxin Research Unit, Department for Crop Sciences, \\ Georg-August University of Goettingen, Grisebachstrasse 6, 37077 Goettingen, Germany.
}

\begin{abstract}
The detection and characterization of fungal genes putatively involved in the interaction of $V$. longisporum and its host plants provide the opportunity for a better understanding of the disease caused by $V$. longisporum, and thereby help in finding new strategies for the prevention or the control of infection. $V$. longisporum is described to be near-diplod and it is therefore most likely that most of the fungal genes are present in two copies in the genome. Therefore, we employed a technique for downregulation of gene function by a process referred to as RNA-interference (RNAi) for analysing the gene function of putative pathogenicity-related genes. Gene silencing using RNAi was triggered by intracellular expression of hairpin (HP) RNA which was reported to be the most potent inductor for the degradation of cognate mRNA in a sequence-specific manner. For the construction of HP fragments, our main focus was on the establishment of a method that has been published recently relying on a technique referred to as overlap-extension polymerase chain reaction (OE-PCR). Problems encountered during establishment gave new insights into the applicability of OE-PCR for construction of HP fragments. Nevertheless, many candidate genes were efficiently silenced by intracellular expression of HP cassettes during this research, so that we obtained a reliable tool for the characterization of putative pathogenicityrelated candidate genes of $V$. longisporum.
\end{abstract}




\section{INTRODUCTION}

The functional characterization of pathogenicity-related genes is of major interest in plant pathogenic research. One of the first steps in the characterization of up-regulated genes in plant-pathogen interactions is to turn off the gene function in order to get a clue to the role of the gene product in the pathogenic life cycle of plant pathogens. On the basis of knowledge about the central dogma of molecular biology (1), which is defined as the flow of information from gene to protein, three possible attachment sites can be considered to exert an influence on gene expression. Various methods are therefore described in modern research to negatively affect the gene-function of certain gene products by exerting an influence at the level of DNA, at the level of transcribed mRNA, or at the protein level. The inhibition of genefunction at protein level by the use of specific antibodies against the gene product of the candidate gene is known as immunodepletion (2). In contrast, gene targeting by homologous recombination is used as a technique to affect a gene of interest at DNA level. The possibility of knocking out or modifying the gene by insertion of nucleotide-sequences into the open reading frame (ORF) was first described in 1989 (3) and is mostly used in research into haploid organisms.

The plant pathogenic fungus Verticillium longisporum is described as an amphihaploid, interspecific hybrid of parental haploid $V$. dalhiae and $V$. albo-atrum strains $(4,5)$. Therefore, $V$. longisporum often carries more than one copy of a gene and is described as near-diploid (5). Gene knockout of organisms with more than one gene-copy is laborious and requires the presence of more than one available marker for selection. However, single gene knockout is often insufficient to cause a phenotype because in the genome of haploid organisms a gene may have several homologs that have redundant functions. Therefore a novel technique which relies on the regulation of gene expression on the post-transcriptional level is often used to "silence" genes in organisms. Gene silencing triggered by an external influence was first demonstrated in 1998 (6) by injection of double-stranded RNA-molecules (dsRNA) into Caenorhabditis elegans and the causal downregulation of the expression of the corresponding protein by the degradation of the specific mRNA. In research to date, different intracellularyexpressed constructs have been tested showing the ability to trigger post-transcriptional downregulation of target-genes by the expression of sense-, antisense-, or HP- RNAs. 


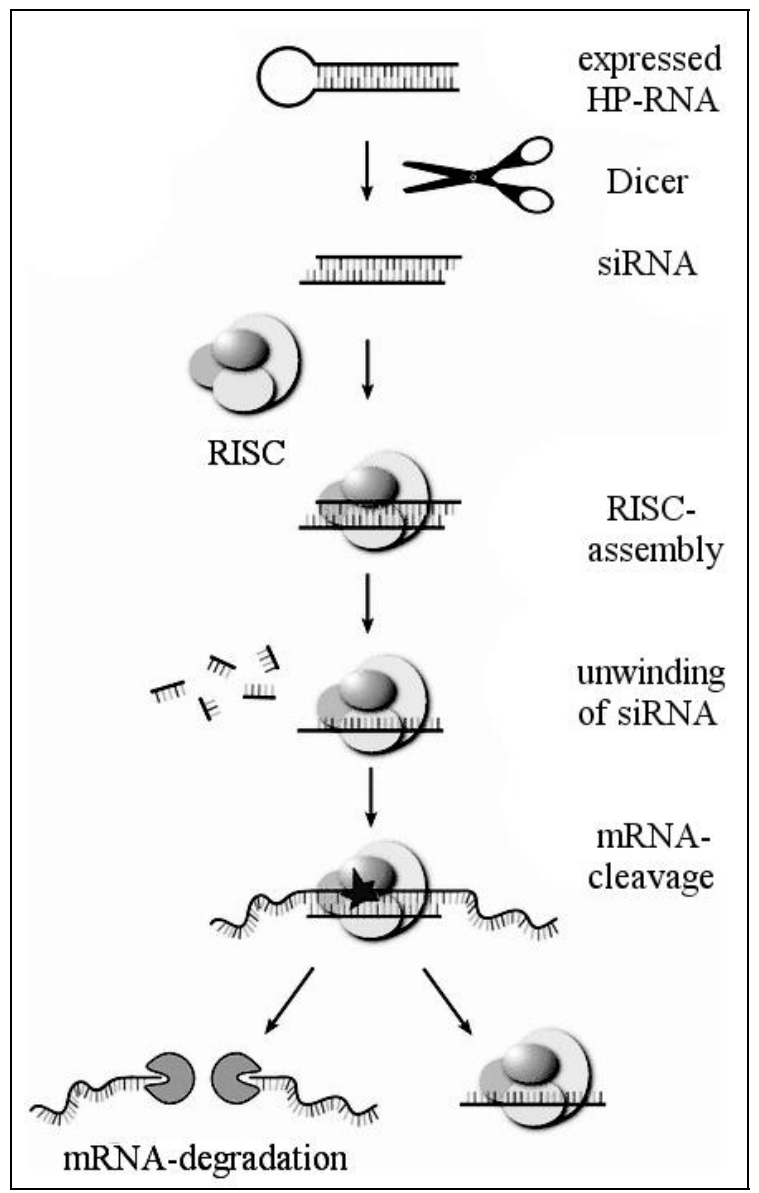

Figure 1: RNAi machinery triggered by intracellulary-expressed HP RNA (modified drawing, according to Cejka et al. 2006 (16))

DsRNA precursors derived from artificially introduced plasmids containing HP construct are cleaved by a dicer to create siRNA; siRNA is incorporated into RISC followed by unwinding of the ds-siRNA molecule by the helicase activity of the RISC; the antisense strand binds to the homologous region of candidate genes' mRNA, which is cleaved by RISC and subsequently degraded by cellular nucleases.

These methods are the basis of a process referred to as RNAi, which is important for the regulation of growth processes or defence against viruses (7) in vivo. Intracellulary-expressed dsRNA structures mostly occur during replication of viral RNA and induce the synthesis of an enzyme called Dicer, which cuts the dsRNA into small interfering RNA (siRNA)-fragments. These fragments provide a two base-pair overhang at the 3 ' end and a phosphate group at the 5' end which is recognized by an RNA-helicase, called Argonaute2, which separates the double strands into single strands (8). This strand is integrated into the RNA-induced silencing complex (RISC)-complex and serves as a recognition sequence for the binding and subsequent cleavage of complementary mRNA molecules by an endonucleolytically active 
component of the RISC enzyme complex (9). Laboratory design of molecules triggering the intracellular expression of dsRNA is often carried out by the transformation of targetorganisms with vectors carrying HP cassettes. HP cassettes consist of a promoter and terminator suitable for the expression of the intervening HP fragment, composed of candidate gene sequences in sense- and antisense-orientation with a spacer sequence forming the eponymous loop in between. In plants, HP RNA constructs with a spliceable intron as a spacer sequence had the highest efficiency, with $80 \%-100 \%$ transformants showing silencing of target genes $(10,11)$. Currently, HP technology has become one of the most powerful tools for gene discovery and gene engineering in plants $(12,13,14,15)$.

Recently it was demonstrated that the mechanism of RNAi induced by the intracellular expression of HP constructs exists in $V$. longisporum (17). V. longisporum silencing-mutants of two isogenes of chorismate synthase Vlaro2 constructed using the pSilent1-system showed a suppressed protein-expression of up to $94 \%$ compared to wild type expression. Here we report our attempts to establish a method that have been published recently dealing with the construction of HP fragments by the use of an overlap-extension polymerase-chain reaction (OE-PCR). OE-PCR was first described in 1988 by Higuchi et al. (18) and was originally used to insert specific mutations in sequences during PCR. To utilize this method for the construction of HP fragments we followed the idea of producing polynucleotides from smaller DNA fragments with homologous sequences that can overlap during the annealing-step of PCR and that can be filled up with desoxyribonucleotide (dNTP) by a DNA polymerase during the elongation-step. The method relies on the ability of DNA polymerases to upfill DNA sequences by polymerization of dNTPs to only the 3 ' end of the newly-formed strand. This results in elongation of the new strand in a 5'-3' direction. Therefore, the ability to upfill overlapped ssDNA during OE-PCR is reduced to $50 \%$ (see Figure 2). 


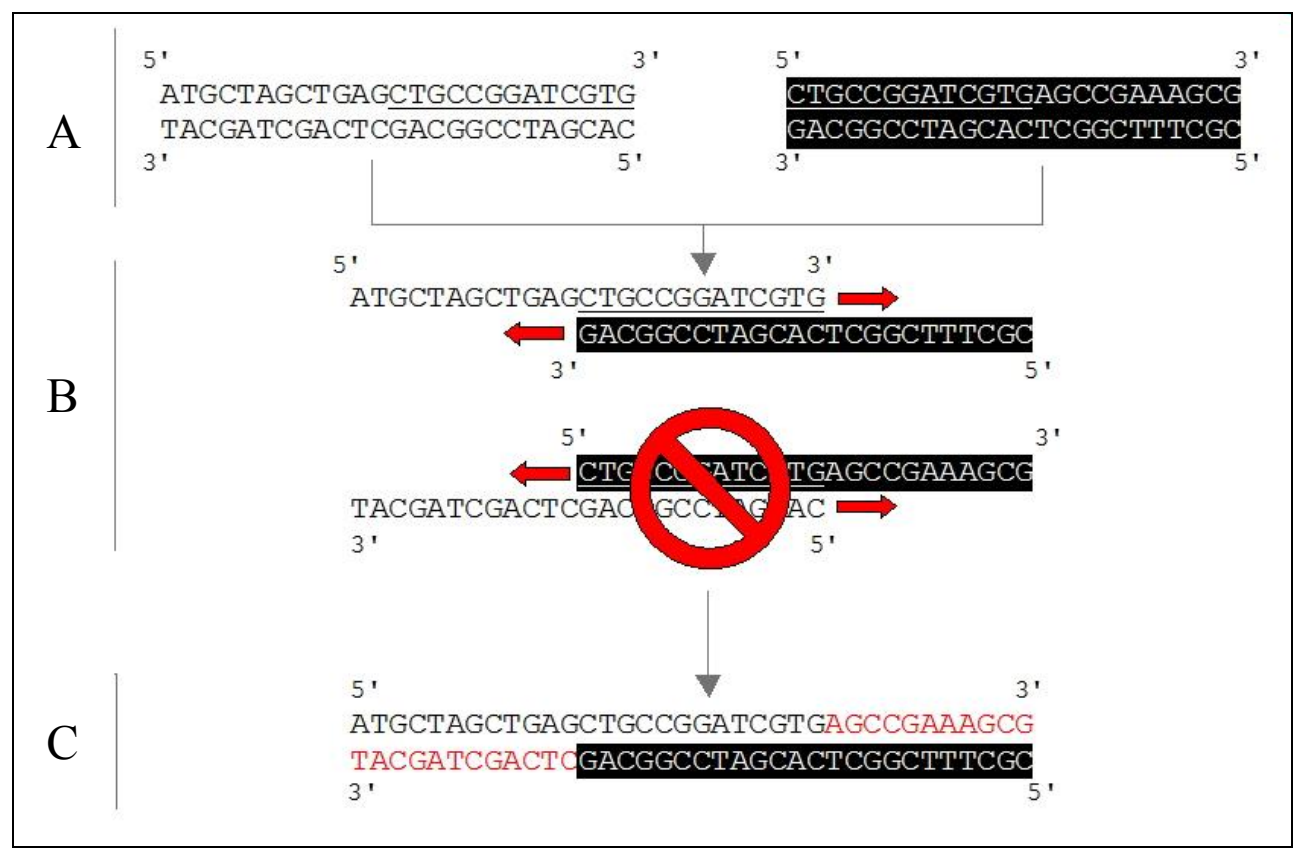

\section{Figure 2: Scheme of OE-PCR}

$\mathbf{A}=$ Two independent fragments (black and white bars) with homologous sequences (underlined) can overlap after the denaturation step of OE-PCR

B $=50 \%$ of the overlapping fragments can be filled up by an DNA polymerase

$\mathbf{C}=$ The assembly is combined to a novel fragment by self-primed upfilling of annealed fragments during PCR

The results of this work provide new insights into the applicability of OE-PCR for the construction of HP fragments. Parallel to the establishment of the HP construction by the use of OE-PCR, we applied a construction method based on conventional cloning, including restriction and ligation steps. The efficiency of gene silencing caused by intracellularyexpressed HP cassettes transformed into $V$. longisporum compared to the effort needed for the construction should give us an effective and reliable tool for the characterization of putative pathogenicity-related candidate genes of the fungi.

\section{MATERIALS AND METHODS}

\section{Bacterial and fungal stains}

V. longisporum VL43 strain was provided by Prof. Andreas von Tiedemann, (General Plant Pathology and Crop Protection, Georg-August University Göttingen, Göttingen, Germany). 
Agrobacterium tumefaciens strain AGL1 was provided by Dr. Susanne Frick (Leibniz Institute of Plant Biochemistry, Martin-Luther University Halle-Wittenberg, Halle/Saale, Germany) and was used for the transformation of $V$. longisporum.

Chemically competent Escherichia coli strain DH5 $\alpha$ and electrocompetent DH5 $\alpha$ and DH10 $\beta$ strains (New England Biolabs, Ipswich, United Kingdom) were used for cloning purposes.

\section{Plasmids and enzymes}

For A. thumefaciens-mediated transformation (AMT) of $V$. longisporum, we used the binary vector pPK2 (12) including border sequences for the AMT and a hygromycin B-resistant cassette containing the hygromycin phosphotransferase gene from E. coli (hph) for selection of positive transformants. We cloned the oliC promoter from Aspergillus nidulans and the tubA terminator from Botrytis cinerea between the border sequences of the T-DNA providing the expression of intervening HP fragments.

Two different commercially available cloning vectors were used for subcloning of HP fragments derived from OE-PCR. The first was a modified vector (23) based on pBluescript $\mathrm{SK}^{-}$(GenBank accession number X52330), containing a inserted 1620 bp spacer fragment in the multiple cloning side (MCS). Using the plasmid vector for ligation purposes, the prior preparation of insert-specific cutted vector-fragments from an agarose-gel is guaranteed due to the better separation of linerized vectors from non-sufficient cutted vector-fragments during agarose-gel electrophoresis. The resulting coherent elimination of any non-specific recirculated plasmid-vectors after ligation excludes any non-positive transformants. The second plasmid we used was the pBarn cloning vector (AppliChem GmbH, Darmstadt, Germany), including the toxic barnase gene expressing a small, highly active ribonuclease from Bacillus amyloliquefaciens (24). The disruption of the barnase gene by insertion of DNA fragments into the MCS prevents positive transformed E. coli cells being killed after transformation with the pBarn plasmid due to the toxic feature of the expressed ribonuclease.

Cloning of vectors containing HP cassettes was carried out by restriction enzymes, 'T4-DNA Ligase', 'T4- Polynucleotide Kinase' and affiliated buffers purchased from Fermentas Inc. (Fermentas, St. Leon-Rot, Germany). 
Enzymes and reagents for first strand cDNA synthesis, including 'Oligo(dT)18 Primer', 'RiboLock ${ }^{\mathrm{TM}}$ RNase Inhibitor' and 'M-MuLV Reverse Transcriptase' were also purchased from Fermentas.

Different polymerases were used for the experiments in this chapter. 'Biotaq'TM DNA Polymerase' (Bioline, Luckenwalde, Germany) was used for general amplification of fragments by PCR. 'Pfu-Polymerase' (Fermentas, St. Leon-Rot, Germany) was used for the amplification of blunt-end PCR-fragments, which in turn are intended to be used for OE-PCR and ligation purposes. High fidelity 'Phusion ${ }^{\circledR}$-Polymerase' (Fisher Scientific GmbH, Schwerte, Germany) was used for sequencing purposes and also during the construction of HP fragments by OE-PCR. The 'ABsolute Blue QPCR Fluorescin Mix' (Fisher Scientific $\mathrm{GmbH}$, Schwerte, Germany) was used for quantitative real-time PCR (qRT-PCR) to assess the silencing efficiency of $V$. longisporum mutants.

\section{Alkaline agarose gel electrophoresis}

Alkaline conditions were used for the separation and visualization of single-stranded DNA (ssDNA) fragments in agarose gels using gel electrophoresis. The run of DNA samples on agarose gels at a $\mathrm{pH}$ that is high enough to denature double-stranded DNA (dsDNA) prevents the accretion of homologous ssDNA-sequences to dsDNA fragments. For this purpose we followed a modified protocol of Sambrook et al. (26) for alkaline gel electrophoresis by adding $\mathrm{NaOH}$ to the agarose and buffers. Samples were heated up to $98{ }^{\circ} \mathrm{C}$ for $3 \mathrm{~min}$ prior to electrophoresis to ensure complete denaturation, of dsDNA into ssDNA. Samples were immediately mixed up with a loading buffer containing $200 \mathrm{mM} \mathrm{NaOH}$ to prevent the renaturation of ssDNA to dsDNA. The sample was loaded on an agarose gel flooded with an electrophoresis buffer containing $200 \mathrm{mM} \mathrm{NaOH}$. We reduced the concentration of $\mathrm{NaOH}$ for the alkaline agarose gel electrophoresis from $300 \mathrm{mM}$, as suggested by Sambrock et al., to $200 \mathrm{mM}$ to minimize the heating up of buffers and agarose because of to the higher hydroxide ionic level of the electrophoresis buffer, which leads to an improved electric flow during electrophoresis. Staining of ssDNA fragments with ethidium bromide is relatively poor in contrast to dsDNA because of the lower ability of the fluorescent agent to intercalate into the ssDNA. Additionally, the higher $\mathrm{pH}$ levels of the gel, due to the alkaline conditions, hamper the staining with ethidium bromide. Therefore, after gel electrophoresis, the gel was 
transferred into a neutralization-puffer containing $1.5 \mathrm{M} \mathrm{NaCl}$ to compensate for the $\mathrm{pH}$ value. Also, the reduction of $\mathrm{NaOH}$ to $200 \mathrm{mM}$ during the electrophoresis process leads to a more efficient staining and a better visualization of ssDNA fragments.

\section{Extraction of genomic DNA (gDNA) and total RNA from fungal mycelium}

Total RNA for qRT-PCR and gDNA for PCR and southern hybridization were extracted simultaneously using a modified protocol of Manitatis et al. (27). Approximately $1 \times 10^{5}$ spores of $V$. longisporum strain 43 were inoculated in $20 \mathrm{ml}$ liquid potato-dextrose broth (PDB) media (Roth, Karlsruhe, Germany) and grown for approximately 10 days at $23{ }^{\circ} \mathrm{C}$ in the dark. Fungal mycelium was harvested and directly ground into a fine powder in a mortar in liquid nitrogen. The ground samples were stored at $-80{ }^{\circ} \mathrm{C}$ or immediately used for extraction. To proceed with extraction, powdered mycelium was treated with a hot extraction buffer containing $0.1 \mathrm{M}$ Tris-HCl, $0.1 \mathrm{M} \mathrm{LiCl}, 0.01 \mathrm{M}$ EDTA and $1 \%$ SDS. After phenol and chloroform/isoamylalcohol extraction, the RNA fraction was precipitated by incubating the samples overnight $(\mathrm{ON})$ along with 1 vol. of a $4 \mathrm{M} \mathrm{LiCl}$ solution on ice. After centrifugation (6000 g, $15 \mathrm{~min}, 4^{\circ} \mathrm{C}$ ) to pellet the RNA, the gDNA was purified by transferring the supernatant from the LiCl-precipitation into a new reaction tube and was incubated along with 0.7 vol. $\mathrm{NH}_{4} \mathrm{Ac}(7.5 \mathrm{M})$ and $2.5 \mathrm{vol}$. EtOH $(96 \% \mathrm{v} / \mathrm{v})$ to precipitate the gDNA and pellet it by another centrifugation. Extracted RNAs were stored at $-80{ }^{\circ} \mathrm{C}$ and gDNAs were stored in -20 ${ }^{\circ} \mathrm{C}$ freezers.

\section{Southern hybridization}

Southern hybridization was performed to check the number of copies of the genes to be silenced in the genome of near-diploid $V$. longisporum strain 43. Therefore, dioxygenin (DIG)-labelled fragments, specific for the gene of interest, were produced and used as a probe for hybridization with homologous sequences of digested gDNA from $V$. longisporum blotted on a membrane. The labelling of probes relies on the principles of PCR using DIG-tagged deoxyuridine triphosphates (DIG-dUTP) for the elongation of fragments instead of deoxythymidine triphosphate (dTTP). For this purpose the quantity of dTTP was substituted with DIG-dUTP in a proportion of $30 \%(\mathrm{w} / \mathrm{v})$ in a PCR run for 30 cycles using thermostable Taq polymerase. The probes were amplified using gDNA of $V$. longisporum as a target, and 
specific oligonucleotides as primers. The efficiency of labelling of the probes was tested by dot-blot following the manufacturer's instructions (Roche Diagnostics GmbH, Penzberg, Germany). For the digestion of gDNA of $V$. longisporum, $10 \mu \mathrm{g}$ was cut with $B g l \mathrm{II}$ and HindIII. The gDNAs and a DIG labelled DNA molecular weight marker was subsequently separated on a $1 \%$ agarose gel by gel electrophoresis at $2 \mathrm{~V} / \mathrm{cm}$ for 4 hours. The agarose gel, containing the separated gDNA, was rinsed with $0.25 \mathrm{M} \mathrm{HCl}$ for a partial depurination of high molecular DNA fragments to ensure the transfer of the entire gDNA from the agarose gel to a nylon membrane by vacuum blot. Prior to vacuum blotting, the gel was also rinsed in $0.4 \mathrm{~N}$ $\mathrm{NaOH}$ for 20 min to ensure complete denaturation of the gDNA to allow the binding of probes to homologous regions of the DNA while hybridization. After vacuum blotting using a VacuGene XL blotting apparatus (Pharmacia, Freiburg, Germany), the gDNA was fixed on Hybond N+ nylon membrane (Amersham Biosciences Europe GmbH, Freiburg, Germany) using a UV-crosslinker (Vilber Lourmat, Torcy, France). Hybridization and detection of the DIG-labeled probe, using the DIG Easy Hyb hybridization solution, was performed following the manufacturer's instructions (Roche Diagnostics GmbH, Penzberg, Germany).

\section{Transformation of $V$. longisporum}

Agrobacterium tumefaciens-mediated transformation (AMT) of $V$. longisporum was performed following a protocol for the transformation of filamentous fungi published by Utermark in 2008 (28). Artificially initiated AMT consists of three consecutive steps: Firstly, the induction of the A. thumefaciens bacterial culture carrying the transformation-plasmid; Secondly the co-incubation of the bacterial culture with fresh fungal spores to apply the transformation process; and thirdly the selection of positive transformants by the use of a selection agent. The induction of the bacterial culture implies the expression of several vir

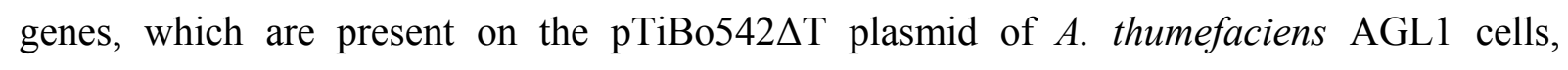
triggered by the addition of $200 \mathrm{mM}$ acetosyringone to the induction medium. The expression of vir genes leads to the transfer of a particular DNA fragment, which was inserted between the left- and right-T-region border sequences, usually carrying the T-DNA of the tumourinducing (Ti)-plasmid, into the fungal recipient. The replaced T-DNA sequence was thus incorporated into the nuclei of infected cells where it was then stably integrated into the host genome. Positive transformants were selected by the use of potato dextrose agar (PDA) plates containing $50 \mu \mathrm{g} / \mathrm{ml}$ hygromycin B (Carl Roth GmbH \& Co. KG, Karlsruhe, Germany) and 
$200 \mathrm{mM}$ cefotaxime (Carl Roth GmbH \& Co. KG, Karlsruhe, Germany) to get rid of the bacteria from the selection media.

\section{qRT-PCR}

Total RNA extracted from silencing mutants and wild type $V$. longisporum was used for twostep qRT-PCR. For first strand cDNA synthesis, 50 pmol “Oligo(dT)18 primer" was used to reverse transcribe $400 \mathrm{ng}$ of total RNA. For this purpose we incubated the RNA along with 1 mM dNTP mix, 20 U RiboLock RNAse inhibitor and 40 U M-MuLV-reverse transcriptase for 60 min at $42{ }^{\circ} \mathrm{C}$. The resulting cDNA was purified using "QIAquick PCR Purification Kit" (Qiagen, Hilden, Germany). Approximately $10 \mathrm{ng}$ of total cDNA was used to measure the expression levels of candidate genes in fungal mycelium to assess the silencing efficiency of the transformed fungi compared to wild type gene-expression. Amplification of fragments and melting curve analysis was performed using the iCycler System (BioRad, San Diego, USA). The qRT-PCR protocol starts with a $15 \mathrm{~min}$ step at $95{ }^{\circ} \mathrm{C}$ to activate the polymerase included in the "The ABsolute Blue QPCR Fluorescin Mix" and is followed by 40 cycles including a denaturation step at $95{ }^{\circ} \mathrm{C}$ for $30 \mathrm{sec}$, an annealing step at $60{ }^{\circ} \mathrm{C}$ for $30 \mathrm{sec}$ and a final elongation step at $72{ }^{\circ} \mathrm{C}$ for $30 \mathrm{sec}$. The detection of fluorescence was automatically carried out by the iCycler system during the elongation step of the PCR. The following melting curve analysis of the amplified fragments was carried out directly after the PCR run by heating the samples to $95^{\circ} \mathrm{C}$ for $1 \mathrm{~min}$, cooling them to $55^{\circ} \mathrm{C}$ for $1 \mathrm{~min}$ and then carrying out a stepwise increase of the temperature from $65^{\circ} \mathrm{C}$ to $95{ }^{\circ} \mathrm{C}$ at the rate of $1{ }^{\circ} \mathrm{C} / \mathrm{min}$. The fluorescence was continuously measured by the cycler after each temperature increase. For normalization of fungal gene expression the two housekeeping genes $\beta$-tubulin and ribosomal protein S17 (29) were applied. Statistical analysis of three biological replicas was carried out with the REST384C Version 1 (30) and efficiency normalization of PCR amplification was carried out by measuring cT values of a dilution series for each gene.

\section{Primer design}

Design and analysis of primer-sequences was carried out with the FastPCR software (25). Primers were synthesised and purchased from Invitrogen Inc. (Karlsruhe, Germany). We designed many primer-sets for the construction of HP fragments suitable for different 
candidate genes of $V$. longisporum. All primer sets were designed in a comparable manner. Primer sets for one candidate gene named Vl-12.1, which showed high homology to a zincfinger transcription factor named ACE1, are described and listed subsequently.

The first two pairs of primers amplify a sense and antisense fragment of a candidate gene suitable for OE-PCR. These primers were designed by adding a homologous sequence to the spacer on the 3 '-ends of the reverse primer to allow overlapping with the spacer during the annealing step of OE-PCR. The 5'-ends of the sense and antisense forward primers are associated with overhang sequences providing restriction sites for the directional ligation into a cloning vector. Primers for the amplification of a spacer (no. 5 and 6) were designed, amplifying a fragment comprising the sequence of a native intron from the $V$. longisporum hydrophobin gene $V l H 1$, homologous to $V d H 1$ from $V$. dahliae (GenBank Accession No. DQ026260.1). Partial sequences of the resulting PCR fragments are shown in the flow chart for OE-PCR (see page 37).

\begin{tabular}{|c|c|c|}
\hline no. & name & sequence $\left(5^{\prime} \rightarrow 3^{\prime}\right)$ \\
\hline 1 & sense-SdaI-F & TAGTGACCTGCAGGACATCGAGAGGATCGACGCCAGC \\
\hline 2 & sense-OE-R & ACAACGTACGGGTAGAGCAGTACATGTCGCCGCGCGAGCCTAC \\
\hline 3 & antisense- $A s c \mathrm{I}-\mathrm{F}$ & GAGCTCGGCGCGCCACATCGAGAGGATCGACGCCAGC \\
\hline 4 & antisense-OE-R & CCAACAATAGCAAAGAGTGCCAGGACATGTCGCCGCGCGAGCCTAC \\
\hline 5 & spacer-F & ACTGCTCTACCCGTACGTTG \\
\hline 6 & spacer-R & CCTGGCACTCTTTGCTATTGTTGG \\
\hline 9 & sense2-SdaI-F & TAGTGACCTGCAGGACATCGAGAGGATCGACGCCAGC \\
\hline 10 & antis2-AscI-F & GAGCTCGGCGCGCCACATCGAGAGGATCGACGCCAGC \\
\hline
\end{tabular}

Table 1: Primer sequences for the amplification of fragments suitable for the construction of HP

\section{fragments using OE-PCR}

Applies for all primer sequences in the following tables: restriction sites are marked in bold; primer sequences that could overlap with the spacer fragment during OE-PCR are underlined.

Primers for the amplification of sense (no.11 and 12) and antisense fragments (no. 13 and 14) for the construction of an HP fragment using conventional cloning steps were designed in a comparable manner to those designed for OE-PCR, with the difference that the homologous spacer sequences on the 3'-ends were replaced by restriction sites for the ligation with the spacer fragment. Therefore the primers (no. 15 and 16) for amplification of the spacer also contain analogue restriction sites for directional ligation with the flanking fragments. 


\begin{tabular}{|c|l|l|}
\hline no. & \multicolumn{1}{|c|}{ name } & \multicolumn{1}{c|}{ sequence $\left(\mathbf{5}^{\prime} \boldsymbol{\rightarrow} \mathbf{3}^{\prime} \mathbf{)}\right.$} \\
\hline 11 & sense-SdaI-F & TAGTGACCTGCAGGACATCGAGAGGATCGACGCCAGC \\
\hline 12 & sense- $N d e I-R$ & GATATGCATATGACATGTCGCCGCGCGAGCCTAC \\
\hline 13 & antisense- $A s c I-F$ & GAGCTCGGCGCGCCACATCGAGAGGATCGACGCCAGC \\
\hline 14 & antisense- $B g l I I-R$ & GATATGAGATCTACATGTCGCCGCGCGAGCCTAC \\
\hline 15 & spacer- $N d e I-F$ & CTATACCATATGACTGCTCTACCCGTACGTTG \\
\hline 16 & spacer-BglII-R & GATATGAGATCTCCTGGCACTCTTTGCTATTGTTGG \\
\hline
\end{tabular}

Table 2: Primer sequences for the amplification of fragments possess restriction sites suitable for the construction of an HP fragment using conventional cloning steps

Primers to amplify probes for southern hybridization (no. 19 and 20) were designed to detect the number of copies of candidate genes that are present in the genome of $V$. longisporum. Therefore, primer sequences were applied amplifying the same candidate gene sequence as we used for the construction of HP fragments, but primers lacked sequences for restriction sites.

\begin{tabular}{|c|c|c|}
\hline no. & name & sequence $\left(\mathbf{5}^{\prime} \rightarrow \mathbf{3}^{\prime}\right)$ \\
\hline 19 & SB-sense-F & ACATCGAGAGGATCGACGCCAGC \\
\hline 20 & SB-sense-R & ACATGTCGCCGCGCGAGCCTAC \\
\hline
\end{tabular}

Table 3: Primer sequences for the amplification of probes for southern hybridization

To assess the silencing efficiency of $V$. longisporum mutants using qRT-PCR, we used primers (no. 21 and 22) to amplify fragments different to those used during construction of HP fragments. Otherwise, a mass of transcripts will be measured expressed by the inserted HP cassettes under the influence of the transient oliC promoter. For normalization of fungal gene expression, primers for the amplification of the two housekeeping genes $\beta$-tubulin (no. 23 and 24) and ribosomal protein S17 (no. 25 and 26) were applied.

\begin{tabular}{|c|l|l|}
\hline no. & \multicolumn{1}{|c|}{ name } & \multicolumn{1}{c|}{ sequence $\left(\mathbf{5}^{\prime} \rightarrow \mathbf{3}^{\prime}\right)$} \\
\hline 21 & RT-sense-F & AGCGTCCTGCAAACAGACC \\
\hline 22 & RT-sense-R & TGTCAGTGGGAAAGCGATG \\
\hline 23 & tubulin-F & GTTCATCTTCAGACCGGTCAGT \\
\hline 24 & tubulin-R & CCAGACTGGCCGAAAACGAAGT \\
\hline 25 & rps $17-F$ & GCATCTGCGATGAGATCGCCA \\
\hline 26 & rps $17-\mathrm{R}$ & TCGGAGTTCTGGGTAAAGTCGAGA \\
\hline
\end{tabular}

Table 4: Primer sequences to measure silencing efficiency when silencing mutants by qRT-PCR 


\section{RESULTS \& DISCUSSION}

Many candidate genes of $V$. longisporum were efficiently silenced by RNAi, triggered by the intracellular expression of HP cassettes, during the research reported in this thesis. To indicate the encountered problems during establishment of the construction for HP fragments by the use of OE-PCR and either conventional cloning steps, we give preference to one candidate gene. The following results demonstrate our procedures to construct transformation vectors, including HP cassettes to trigger post-transcriptional silencing for the $V$. longisporum candidate gene V1-12.1. This gene was displayed by a molecular fingerprinting method, known as cDNA-AFLP (amplified fragment-length polymorphism), as a gene putatively involved in the pathogenic life cycle of the fungus during the interaction with the natural host plant B. napus (38). The ORF of this gene comprises 2328 nucleotides and one intron. The translated mRNA is predicted to encode a protein which possesses 775 amino acids. Southern hybridization was performed, showing two gene copies in the genome of $V$. longisporum.

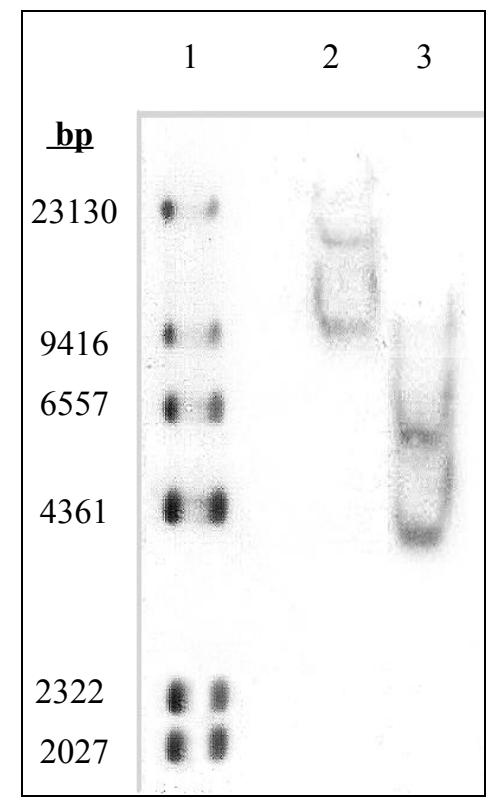

Figure 3: Southern hybridization for candidate gene Vl-12.1

1 = self-made DNA ladder comprising incorporated DIG-dUTPs

$\mathbf{2}=\mathrm{gDNA}$ cut with $B g l I \mathrm{I}$

$3=$ gDNA cut with $X b a \mathrm{I}$ 
The design of the HP fragment for V1-12.1 provides two flanking 238 bp sense and antisense fragments and a $125 \mathrm{bp}$ intervening spacer, forming the eponymous loop of the expressed HP RNA. The correctly assembled HP fragment comprises 601 bp.

\section{Construction of HP fragments using OE-PCR}

Expressing stem-loop HP RNAs were shown to efficiently silence homologous target gene expression in plants, animals and fungi (31). In regard to enabling the generation of HP RNA constructs, several vectors with a functional intervening intron spacer have been reported in literature $(32,33)$. However, these methods generally require amplification of target sequences and several rounds of restriction and ligation steps. The construction by the use of restriction enzyme-based cloning is laborious and there are inefficiencies in the assembly of some sequences to HP fragments (32). An alternative way to construct HP containing vectors takes advantage of "Gateway®" technology (Invitrogen, Karlsruhe, Germany) and facilitates easy cloning of DNA fragments but the reagents for this method are relatively expensive compared to the reagents for cloning with restriction enzymes. In this study, we tested different approaches published in recent years for the construction of HP fragments by PCRbased methods. All these methods utilize OE-PCR to assemble sense and antisense strands of a candidate gene with an intervening spacer, and do not depend on time-consuming restriction enzyme-based cloning steps or require costly consumables.

In 2005, Pawlowski et al. first reported their work on the construction of HP fragments by the use of OE-PCR (34). This method was referred to as "inverted-repeat PCR" and consisted of three consecutive PCR rounds (see flow chart on page 37 , round $1=\mathrm{A}$; round $2=\mathrm{B}$ to $\mathrm{D}$; round $3=\mathrm{E})$. The first round of PCR was determined to amplify the three fragments which are intended to overlap and therefore build up the HP fragment during OE-PCR. Therefore, sense and antisense fragments of candidate genes were amplified with primers adding sequences to the 3 '-ends homologous to the intervening spacer. This allowed overlapping during the annealing step of the following second round OE-PCR-step. 


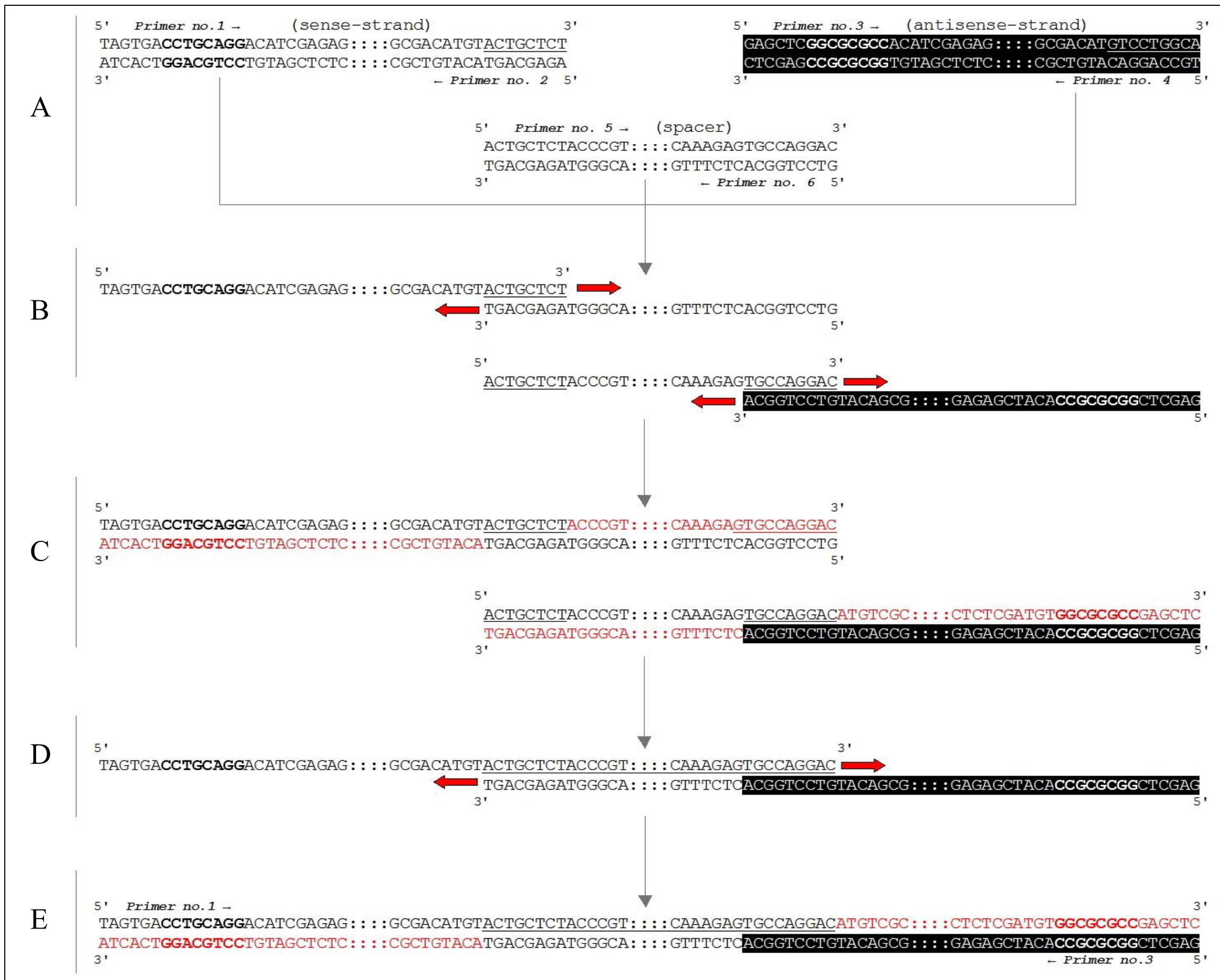

Flow chart showing the

procedure for construction of hairpin-cass ettes using OE-PCR

- Partial sequences are shown; restriction sites are marked in bold; homologous sequences to overlap with the spacer are underlined

A = round-one PCR: Sense/ antisense- and spacer-fragments were amplified using primers shown in Table 1

B = round-two PCR (OE-PCR): Denaturation of fragments and annealing of homologous regions during OE-PCR

C = round-two PCR (OE-PCR): Self-primed strandfilling of sense/intron and antisense/ intron during OE-PCR

D = round-two PCR (OE-PCR): Denaturation of fragments and annealing of homologous regions during OE-PCR

$\mathbf{E}=$ round-three PCR: Amplification of HP fragment with end terminal primer 
In the protocol given by Pawlowski et al., the use of a thermostable DNA polymerase, named after the thermophilic bacterium Thermus aquaticus (Taq), was mentioned. Taq-polymerase makes DNA products that have adenine overhangs at their 3'-ends. Therefore, the addition of dNTPs to upfill the overlapping fragments during the elongation step of OE-PCR by a DNA polymerase should be inhibited if the following base of the linker cannot form a canonical Watson-Crick DNA base pairing with the adenine overhang of the Taq-derived fragment (see Figure 4).

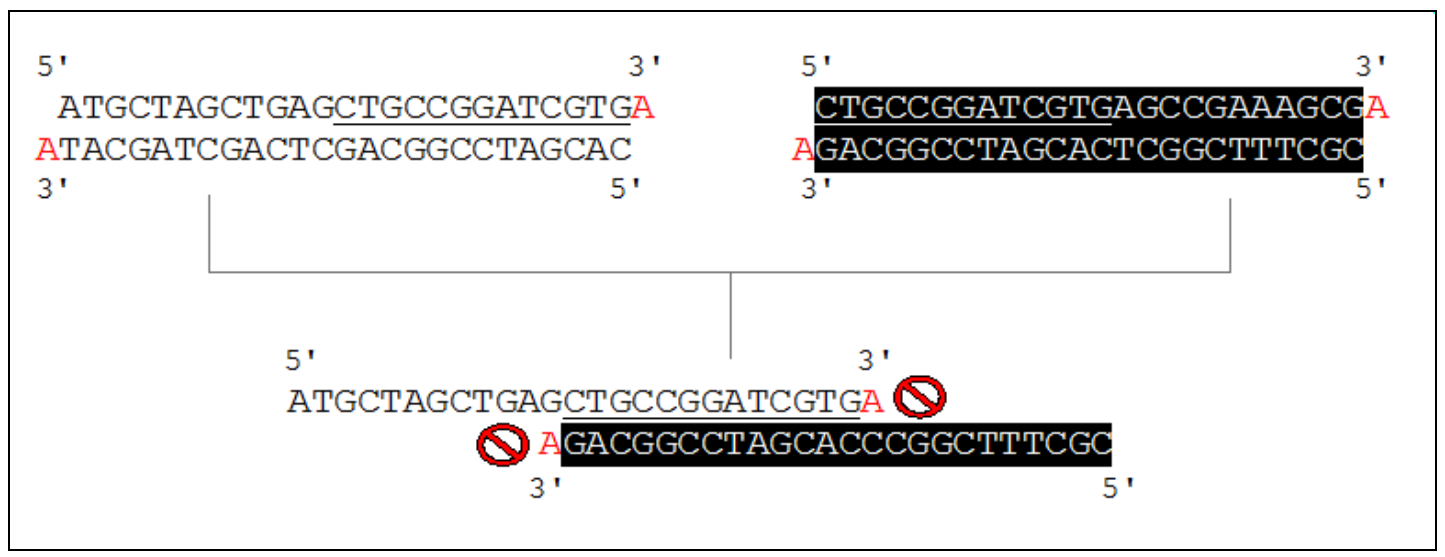

Figure 4: Inhibition of the addition of dNTPs during OE-PCR by the use of Taq-Polymerase

To provide the strand-filling of the overlapped fragments during OE-PCR we give preference to the use of a polymerase which generates blunt end fragments. The efficiency of HP assembling was tested by the use of Taq-polymerase and was then compared to high

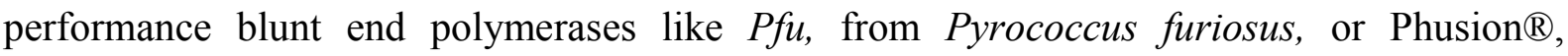
including a novel Pyrococcus-like enzyme with a processivity-enhancing dsDNA-binding domain. The error rate of Phusion ${ }^{\circledR}$ polymerase is 50 times lower than Taq-, and 6 times lower than $P f u$ polymerases (35). In our experiments, the use of both blunt end polymerases led to a higher assembly efficiency of single fragments to HP constructs than was achieved by the use of Taq-polymerase during OE-PCR (data not shown). Since the Phusion ${ }^{\circledR}$ polymerase was more expensive we decided to use a mixture of $P f u$ - and Taq-polymerase in a 1:10 ratio to benefit from the rapidity of Taq- (36) and also from the 3'- to 5'-end exonuclease proofreading activity and blunting property of $P f u$-polymerase (37).

For the first round of PCR, approximately $1 \mathrm{ng}$ of gDNA from $V$. longisporum was used to amplify the three fragments of the HP assembly. The PCR run was performed using 5 pmol of 
each primer given in Table 1 (no. 1 to 6) with a starting denaturation step at $95{ }^{\circ} \mathrm{C}$ for 5 min followed by 35 PCR cycles including a denaturation step at $95{ }^{\circ} \mathrm{C}$ for $30 \mathrm{sec}$, an annealing step at $60{ }^{\circ} \mathrm{C}$ for $30 \mathrm{sec}$, and an elongation step at $72{ }^{\circ} \mathrm{C}$ for $30 \mathrm{sec}$. The PCR run finished with a final elongation step at $72{ }^{\circ} \mathrm{C}$ for 5 min. PCR products were run on a $1.7 \%$ agarose gel to visualize the amplicons and to measure product amounts.

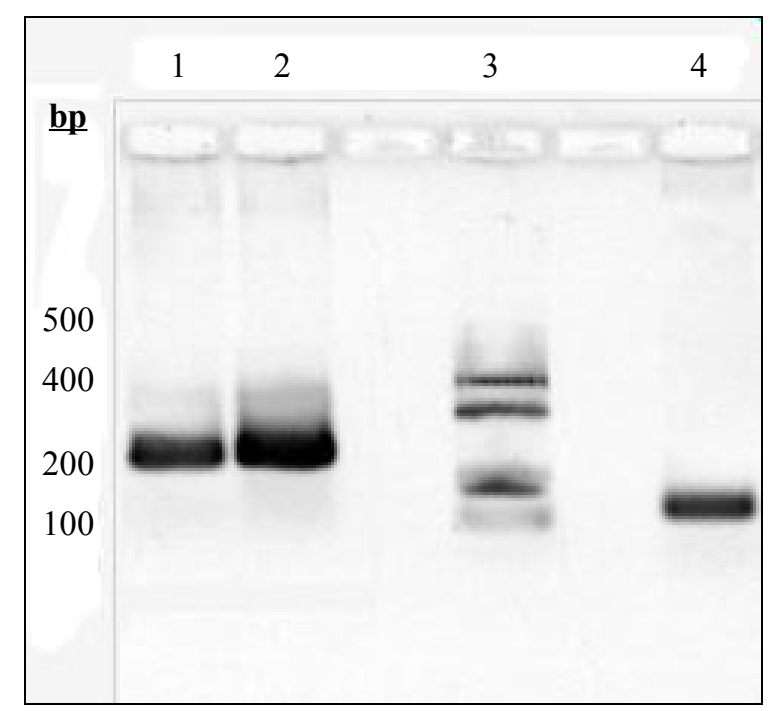

Figure 5: Agarose gel electrophoresis of the first round of PCR showing amplicons intended for OE-PCR $\mathbf{1}=$ sense fragment of candidate gene amplified using primers 1 and 2 (Table 1)

$\mathbf{2}=$ antisense fragment amplified with primers 3 and 4 (Table 1)

$\mathbf{3}=$ self-made marker-fragments for agarose gel electrophoresis

$\mathbf{4}=$ spacer amplified with primers 3 and 4 (Table 1)

Amplicons from round one PCR were purified from agarose gel using "QIAquick Gel Extraction Kit" (Qiagen, Hilden, Germany). For the second round of PCR, approximately 5 ng from the first round PCR-product was used in equal molar ratio for the three fragments. This round of PCR is what gives the name OE-PCR to this method and was performed according to the author's recipe without the use of any primers to allow annealing of homologous overhangs of sense and antisense fragments to the spacer, and consequent selfprimed strand-filling by the DNA polymerase. OE-PCR was initiated with a treatment of 95 ${ }^{\circ} \mathrm{C}$ for $5 \mathrm{~min}$, then $8 \mathrm{PCR}$ cycles $\left(95^{\circ} \mathrm{C}\right.$ for $1 \mathrm{~min}, 52{ }^{\circ} \mathrm{C}$ for $1 \mathrm{~min}$ and $72{ }^{\circ} \mathrm{C}$ for $2 \mathrm{~min}$ ), and finished with one cycle of $72{ }^{\circ} \mathrm{C}$ for $7 \mathrm{~min}$. For the visualization of annealed HP fragments due to OE-PCR, we applied an identical OE-PCR run as above with an additional 27 cycles, and we pooled 6 PCR samples to gain sufficient numbers of annealed assemblies to show. To 
demonstrate the ability of both flanking fragments to overlap with the spacer, we applied OEPCR runs adding either sense and spacer fragment, antisense and spacer fragment or sense, antisense and spacer fragments to each individual PCR mixture. The samples were loaded after PCR on a $1.7 \%$ agarose gel for electrophoresis.

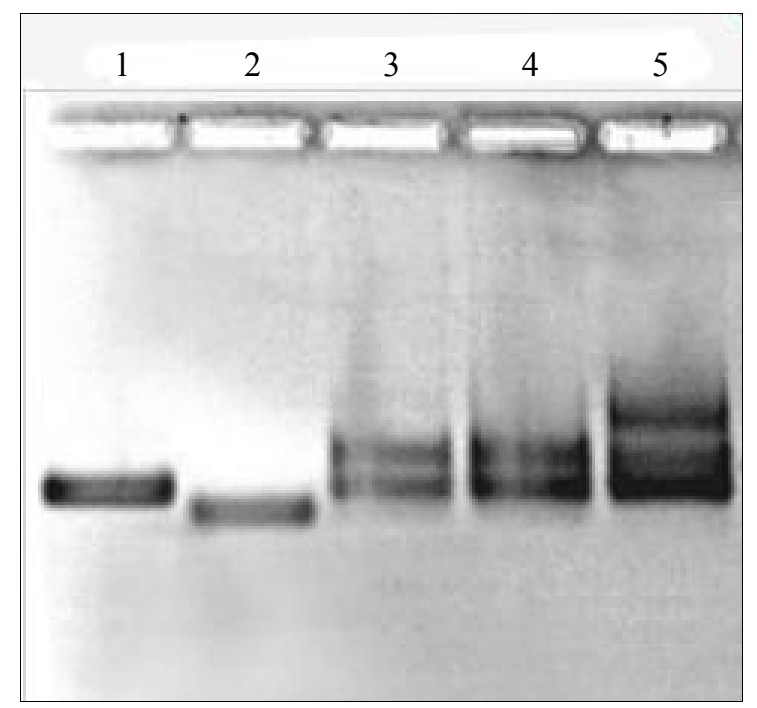

Figure 6: Agarose gel electrophoresis to show efficiency of OE-PCR to assemble HP fragments $\mathbf{1}=$ sense fragment of candidate gene

$2=$ intron spacer

$3=$ assembly of sense fragment and intron spacer after OE-PCR

$\mathbf{4}=$ assembly of antisense fragment and intron spacer after OE-PCR

$\mathbf{5}=$ assembled HP fragment by adding sense/antisense fragment and intron spacer to the OE- PCR

As proposed by the author's recipe, we used an aliquot of $5 \mu 1$ from the $50 \mu 1$ PCR sample of round two PCR (analogue as with lane 5 shown in Figure 6) and added it to the third round of PCR (see Figure 4E) to increase the number of HP fragments by amplification using 25 pmol of end terminal primers (no. 1 and 3, Table 1) to the HP fragment. The mix was run at $95{ }^{\circ} \mathrm{C}$ for $5 \mathrm{~min}$, then $30 \mathrm{PCR}$ cycles including $1 \mathrm{~min}$ at $95{ }^{\circ} \mathrm{C}, 1 \mathrm{~min}$ at $55^{\circ} \mathrm{C}$ and $2 \mathrm{~min}$ at $72{ }^{\circ} \mathrm{C}$, and finished with one cycle for $5 \mathrm{~min}$ at $72{ }^{\circ} \mathrm{C}$. The PCR sample was separated on a $1.7 \%$ agarose gel by electrophoresis. 


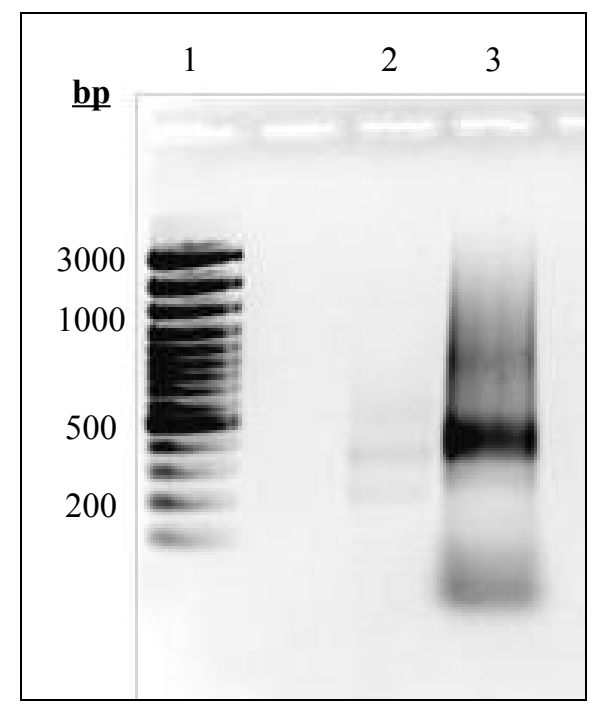

Figure 7: Agarose gel electrophoresis of amplicons from third round of PCR

$1=$ GeneRuler $^{\mathrm{TM}} 100$ bp Plus DNA Ladder (Fermentas, St. Leon-Rot, Germany)

$\mathbf{2}=$ round two PCR sample (see Figure 6, lane 5)

$\mathbf{3}=$ round three PCR sample, amplification of HP fragment with end terminal primers

For all tested candidate genes we were never able to amplify a PCR product with the calculated length for the correctly assembled HP fragments. The amplified fragments of the third PCR round were approximately as large as the fragments that emerged in the OE-PCR as a result of the overlapped sense or antisense fragments connected with the spacer. It is most likely that the homologous sequences of HP fragments, amplified during the third round of PCR, showed great affinity for annealing by pairing the sense and antisense sequences after each denaturation step of PCR and thus formed HP structures. Using this assumption, we suggest that the smaller fragment shown in lane 3 of Figure 7 may be the folded HP structure. We could show by a time course run of round three PCR, in which we removed a sample after each fifth PCR cycle, that an amplicon with the assumed length for the HP fragments appeared after 25 cycles of PCR and vanished within the next 5 cycles. PCR samples were examined by electrophoresis in a $1.7 \%$ agarose gel. 


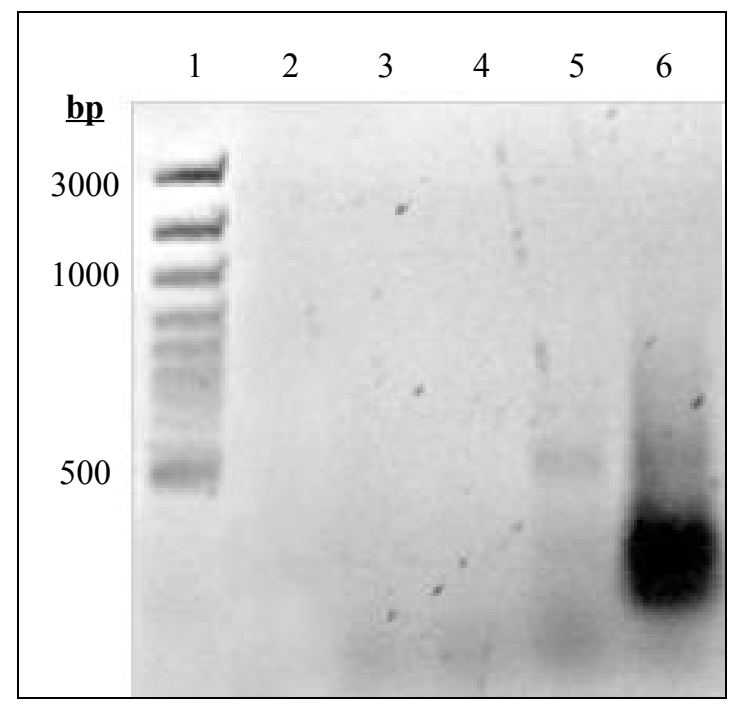

Figure 8: Agarose gel electrophoresis of amplified fragments from a time course PCR

1 = GeneRulerTM 100 bp Plus DNA Ladder

$\mathbf{2}=$ round three PCR stopped after 10 cycles

$\mathbf{3}=$ round three PCR stopped after 15 cycles

$\mathbf{4}=$ round three PCR stopped after 20 cycles

$\mathbf{5}=$ round three PCR stopped after 25 cycles, amplicon with assumed length for HP fragment appears

$\mathbf{6}=$ round three PCR stopped after 30 cycles, previous amplicon vanishes and the smaller fragment emerges

We made a great effort to accomplish the amplification of the HP fragment during the third round of PCR by varying PCR conditions and by the use of extended primer sequences (Table 1, primer no. 7 and 8). Neither the use of increased primer concentration, nor changes in the PCR conditions, such as varying the $\mathrm{MgCl}_{2}$ concentration or modification of incubation times for the different PCR steps, led to any improvement in the amplification of HP fragments. We proposed that the use of end terminal primers with extended sequences from the candidate gene would be more effective in binding to the homologous sequences of the HP fragments, and thus lead to an interfering apposition of HP fragments to HP structures and therefore allows amplification of the assembly. The PCR run with extended end terminal primers was done in the same way as the previous PCR run. The PCR sample was loaded in a $1.7 \%$ agarose gel and the amplicons were separated by electrophoresis. 


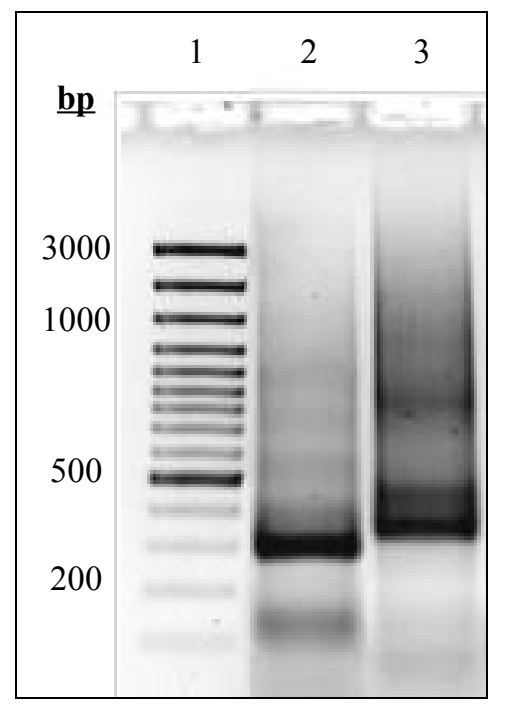

Figure 9: Agarose gel electrophoresis of round three PCR with extended primers

1= GeneRuler ${ }^{\mathrm{TM}} 100$ bp Plus DNA Ladder

$\mathbf{2}=$ round three PCR sample, amplification of HP fragment with end terminal primers (see Figure 7, lane 3)

$3=$ round three PCR sample, amplification of HP fragment with extended end terminal primers

Interestingly, the use of the extended end terminal primers for the third round of PCR led to an altered band pattern visualized on an agarose gel, but again not the expected amplicon for the HP fragment appears. Presumably, the larger size of the fragment that appeared after the third round PCR with extended primers was due to the fact that the end terminal primers can effectively bind in both PCR runs to the HP fragments but cannot prevent the folding of the HP structure, which consequently slows down the mobility of the fragment in passing through the agarose gel during electrophoresis, and results in the altered band pattern because of the larger extended primers used for PCR. To discover if the HP fragments were indeed amplified through the third round of PCR but instantly folded to HP structures, we applied agarose gel electrophoresis at a $\mathrm{pH}$ that was sufficiently high to denature dsDNA. This alkaline agarose gel electrophoresis can visualize ssDNAs by adding $\mathrm{NaOH}$ to agarose and buffers for electrophoresis. Therefore, we used both third round PCR samples for alkaline agarose gel electrophoresis and separated them at $1 \mathrm{~V} / \mathrm{cm}$ for $2 \mathrm{~h}$. 


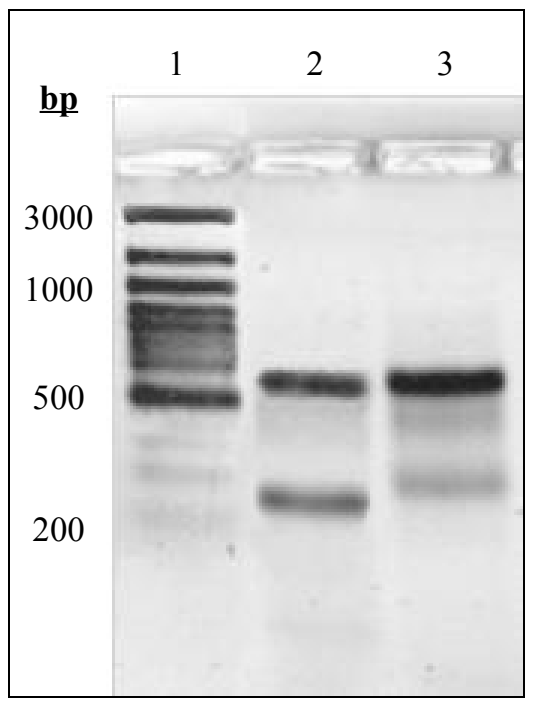

Figure 10: Alkaline agarose gel electrophoresis of samples from third round PCR

$1=$ GeneRuler $^{\mathrm{TM}} 100$ bp Plus DNA Ladder

$\mathbf{2}=$ round three PCR sample using end terminal primers

$\mathbf{3}=$ round three PCR sample using extended end terminal primers

For both PCR samples, using end terminal and extended end terminal primer sets, we could visualize a band with the calculated length for the HP fragment of candidate gene Vl-12.1 by alkaline agarose gel-electrophoresis. Therefore, we propose that the folded HP structure that we suggested after the third round of PCR was separated into ssDNA HP fragments due to alkaline conditions. We were also able to reform the HP structure by heating the purified fragments from the alkaline agarose gel up to $60{ }^{\circ} \mathrm{C}$ for $5 \mathrm{~min}$ and then cooling them down before loading the samples on a normal agarose gel to separate them again by electrophoresis. The band pattern for both PCR samples was nearly identical to that shown in Figure 9 in lane 2. There was no band shift visible due to the PCR with extended primers as shown before. The primers to bind on the HP fragments were probably removed by gel extraction, thus both PCR samples of the third round PCR showed the folded HP without any bound primers. Unfortunately, no dsDNA of HP fragments, which could be used to proceed with ligation into a cloning vector, could be obtained due to reapposition of ssDNA to dsDNA. Attempts to use the assembly gained from round two PCR (see Figure 6, lane 5) for subcloning failed due to the insufficient amounts of DNA that could be obtained after purification and prior digestion of the insert to ligate into the vector. As mentioned in the introduction, the ability to upfill overlapping DNA strands during OE-PCR is reduced to $50 \%$ (see Figure 2). The construction of an HP fragment requires two independent consecutive steps of OE-PCR to perform 
successive upfilling of the overlapping sense or antisense fragment with the spacer, and subsequent upfilling of the overlapping sense/spacer with antisense/spacer assemblies to the HP fragment (see flow chart on page 37, B and D). This leads to a reduction of $75 \%$ from the inserted DNA while OE-PCR to fulfil HP fragment assembly. Therefore, a third PCR round to enhance the HP fragment, and to gain sufficient amounts of insert suitable for subcloning, is inevitable.

To accomplish the amplification of HP fragments we made another attempt in compliance with a paper which was published in 2009 (39) performing an OE-PCR run by adding three pairs of primers in an asymmetric manner (see flow chart on page 46, A). The concept behind this method is to provide large numbers of fragments (see flow chart, B), amplified by all primers that have been previously utilized to amplify the three fragments in round one of PCR. This accomplishes HP fragment apposition due to assembling of fragments by base pairing of homologous sequences and consequent self-primed strandfilling. The authors suggested merging the second round with the third round of PCR by the use of primers for OE-PCR so that a third round of PCR with end terminal primers was no longer needed. As shown on page 46, end terminal primers were used for asymmetric OE-PCR in a concentration twenty times higher than the non-end terminal primers. On the one hand, this was done to ensure the amplification of HP fragments, as in the third round of PCR, by the use of large numbers of end terminal primers as we did before. On the other hand, it was also done to prevent the non-end terminal primers interfering with the binding of homologous sequences of the HP assembly by competing with the binding sites of the overlapping fragments. During asymmetric OE-PCR, the given primers are able to amplify various fragments, including sense, antisense, sense/spacer, antisense/spacer fragments that are intended to overlap and build up the HP fragments (see flow chart, C).

We tried to perform asymmetric OE-PCR by adding the three fragments from round one PCR and also, following a protocol published in 2010 (40), by adding gDNA from $V$. longisporum, as a template for primers during PCR. Thereby, the given primers in the PCR mixture should be able to amplify the fragments which are intended for assembling the HP fragments. 


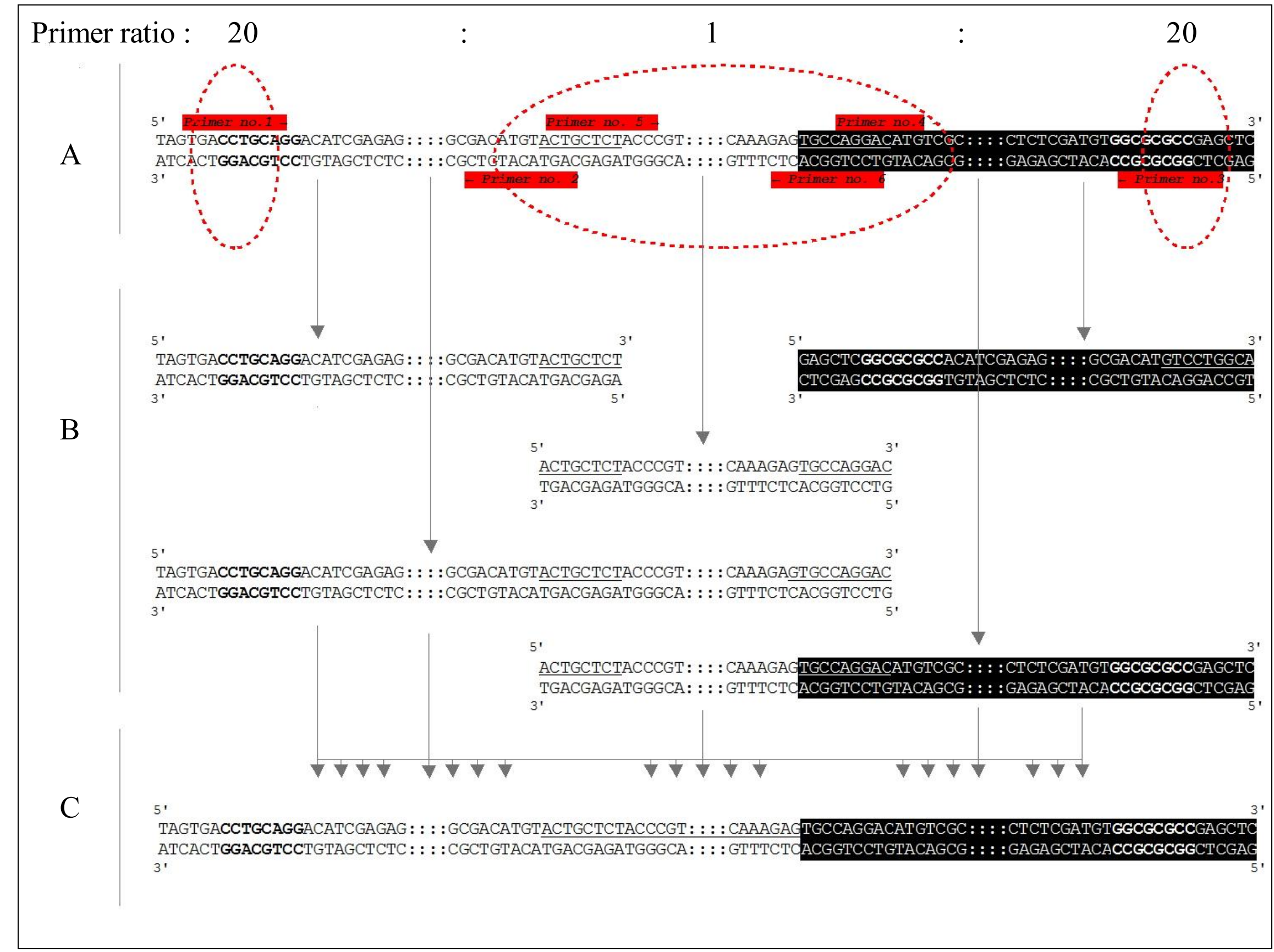

Flow-chart of asymetric OE-PCR for the construction of hairpincassettes

Partial sequences are shown; restriction sites are marked in bold; homologous sequences to overlap with the spacer are underlined

A = asymetric OE-PCR: along with the template for OE-PCR, primers shown in table 1 were used in a molar ratio of 20:1 as displayed to reach HP-fragment amplification

B = asymetric OE-PCR: severa amplified fragments thus can overlap with each other during annealing step of PCR and get filled up by a DNA-polymerase during elongation step

C = asymetric OE-PCR: large amounts of HP-fragments should be obtained by asymetric OR-PCR 
Amplification of round one PCR fragments was performed according to the protocol given on page 37. For the asymmetric OE-PCR, 1 ng of the first round PCR products was used in equal molar ratio. For the amplification of HP fragments directly from gDNA, $10 \mathrm{ng}$ from the gDNA of $V$. longisporum was used. Asymmetric OE-PCR was done using 25 pmol of end terminal primers and $1.25 \mathrm{pmol}$ from the others in a $50 \mu \mathrm{l}$ sample. The reaction started at 95 ${ }^{\circ} \mathrm{C}$ for $5 \mathrm{~min}$, followed by 40 cycles of $95{ }^{\circ} \mathrm{C}$ for $30 \mathrm{sec}$., $55{ }^{\circ} \mathrm{C}$ for $30 \mathrm{sec}$. and $72{ }^{\circ} \mathrm{C}$ for 2 min. The PCR run finished with one cycle for 5 min at $72{ }^{\circ} \mathrm{C}$. Both PCR samples were examined by electrophoresis on a $1.7 \%$ agarose gel.
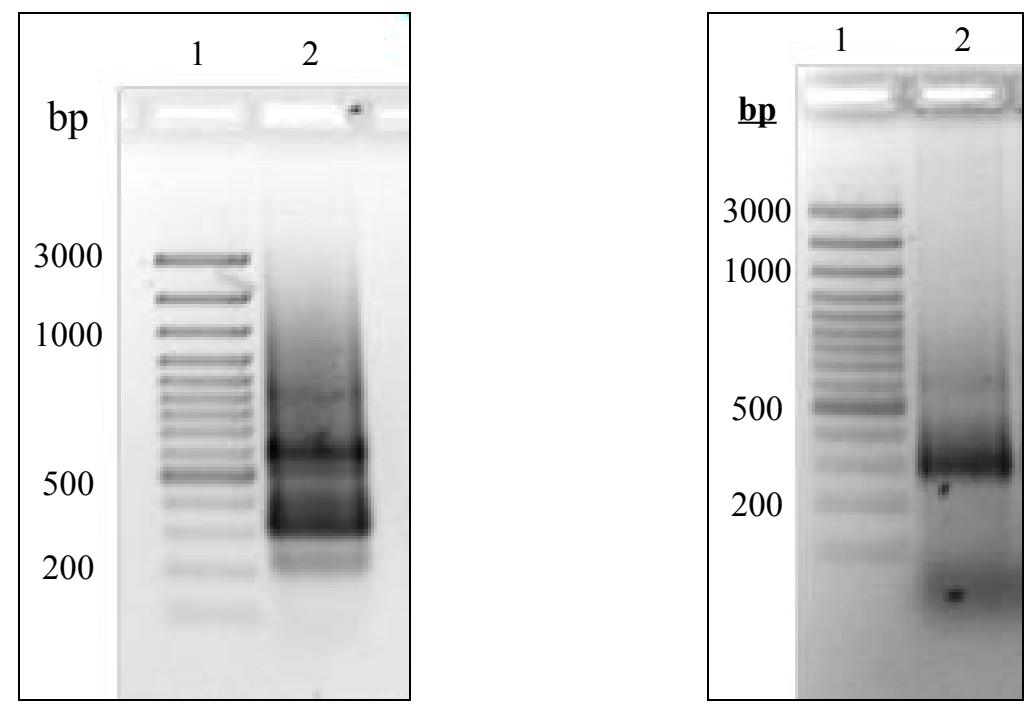

Figure 11-12: Agarose gel electrophoresis of asymmetric OE-PCR using round one PCR products (Figure 12: left side) or gDNA (Figure 13: right side)

$1=$ GeneRuler ${ }^{\mathrm{TM}} 100 \mathrm{bp}$ Plus DNA Ladder

$\mathbf{2}=$ PCR sample amplified by using PCR products from round one PCR or gDNA as template for asymmetric OE-PCR

For both samples of asymmetric OE-PCR, the band pattern of the stained agarose gels showed a fragment with the length to be assumed for HP fragments of the candidate gene Vl-12.1. We could also observe that a more intense band was visualized which could probably be attributed to the formerly proposed folded HP structure as shown in Figure 7. Due to the larger amount of amplified HP fragments, we purified the distinct band for the calculated length of HP fragment from the agarose gel and used it for subcloning into a cloning vector.

Due to the amplification of HP fragments by a mixture of $P f u$ - and Taq-polymerase by OEPCR, we were able to use the resulting blunt end amplicons directly for ligation into vectors, 
which were linearized with restriction enzymes showing blunt end facilities. Linearized pBarn cloning vector was provided with removed phosphate groups of the EcoRV restriction sites to avoid recircularization of the vector while ligation. Therefore, we used a T4-polynucleotide kinase to perform 5'-phosphorylation of the insert to ensure proper ligation effectiveness. Besides the ligation into the pBarn cloning vector without any prior restriction of the insert, we also tried to ligate the purified fragment into the MCS of a modified vector base on pBluescript $\mathrm{SK}^{-}$by cutting the vector and the insert by incubating the samples along with $10 \mathrm{U}$ $S d a \mathrm{I}$ and $5 \mathrm{U} A s c \mathrm{I}$ for $2 \mathrm{~h}$ at $37^{\circ} \mathrm{C}$ prior to ligation. For both subcloning into pBarn and the modified pBluescript $\mathrm{SK}^{-}$, ligation was carried out using a 1:5 molar ratio of vector to insert. Approximately $50 \mathrm{ng}$ of vector DNA was used for subcloning. The ligation was done in a total volume of $20 \mu \mathrm{l}$, containing $5 \mathrm{U}$ of T4-DNA ligase and $2 \mu \mathrm{l}$ of $50 \%$ PEG 4000 . Incubation was carried out at $37^{\circ} \mathrm{C}$ for $16 \mathrm{~h} .10 \mu \mathrm{l}$ of the mixture was used for transformation of chemically competent $E$. coli cells and then plated on lysogeny broth (LB) agar media containing appropriate antibiotics for selection of positive transformants. Sequencing of transformants was carried out by "Eurofins MWG Operon” (Ebersberg, Germany).

Cloning of putative HP fragments turned out to be very difficult and resulted in a wide variety of non-positive transformants. Sequence analysis of assumed positive plasmids showed a mass of non-specific inserted fragments comprising repetitive sequences resulting from the apposition of parts of the three fragments that were intended to be assembled by OE-PCR. Out of more than 100 tested colonies, we only succeeded in subcloning one HP fragment into a modified pBluescript $\mathrm{SK}^{-}$vector. Therefore, we decided to reject the construction of $\mathrm{HP}$ fragments by OE-PCR and establish a method using conventional cloning steps for the design of transformation vectors carrying HP fragments.

\section{Construction of HP fragments using conventional cloning steps}

To facilitate generation of HP constructs, several generic vectors with a functional intron have been reported $(13,16)$. The common approaches, which take advantage of the commercially available pHELLSGATE vector, utilizing Gateway ${ }^{\circledR}$ recombinational cloning (Invitrogen, Karlsruhe, Germany) for high throughput construction of HP vectors, are often too expensive to use in laboratories working in the molecular field. Normally, construction of transformation vectors containing HP fragments, following conventional cloning steps, is carried out in three 
cloning steps of the desired stem loop structure, which ensures HP formation by the intracellular expression of the HP cassette.

Here we report our experimental procedure comprising two cloning steps for the construction of pPK2-vector containing HP fragment (pPK2-HP) for the $V$. longisporum candidate gene Vl-12.1. An attempt to realize the construction of the HP fragment in one step with a threeparental ligation and the subsequent amplification of the assembly failed due to the formation of HP structure during amplification, as noted in the previous OE-PCR part. Transformation vectors were constructed using standard molecular techniques. Primers for PCR are listed in Table 2. The basis for the ligation with the HP fragment is the binary vector pPK2, which originates from the vector pPZP-201 (41) which was developed for the AMT of plants. Restriction sites for the ligation of fragments were available in the pPK2-vector due to further cloning of a fragment between oliC promoter and the $t u b \mathrm{~A}$ terminator comprising sequences that can be recognized by restriction enzymes (see Figure 13) suitable for assembly of the HP fragment in two cloning steps.

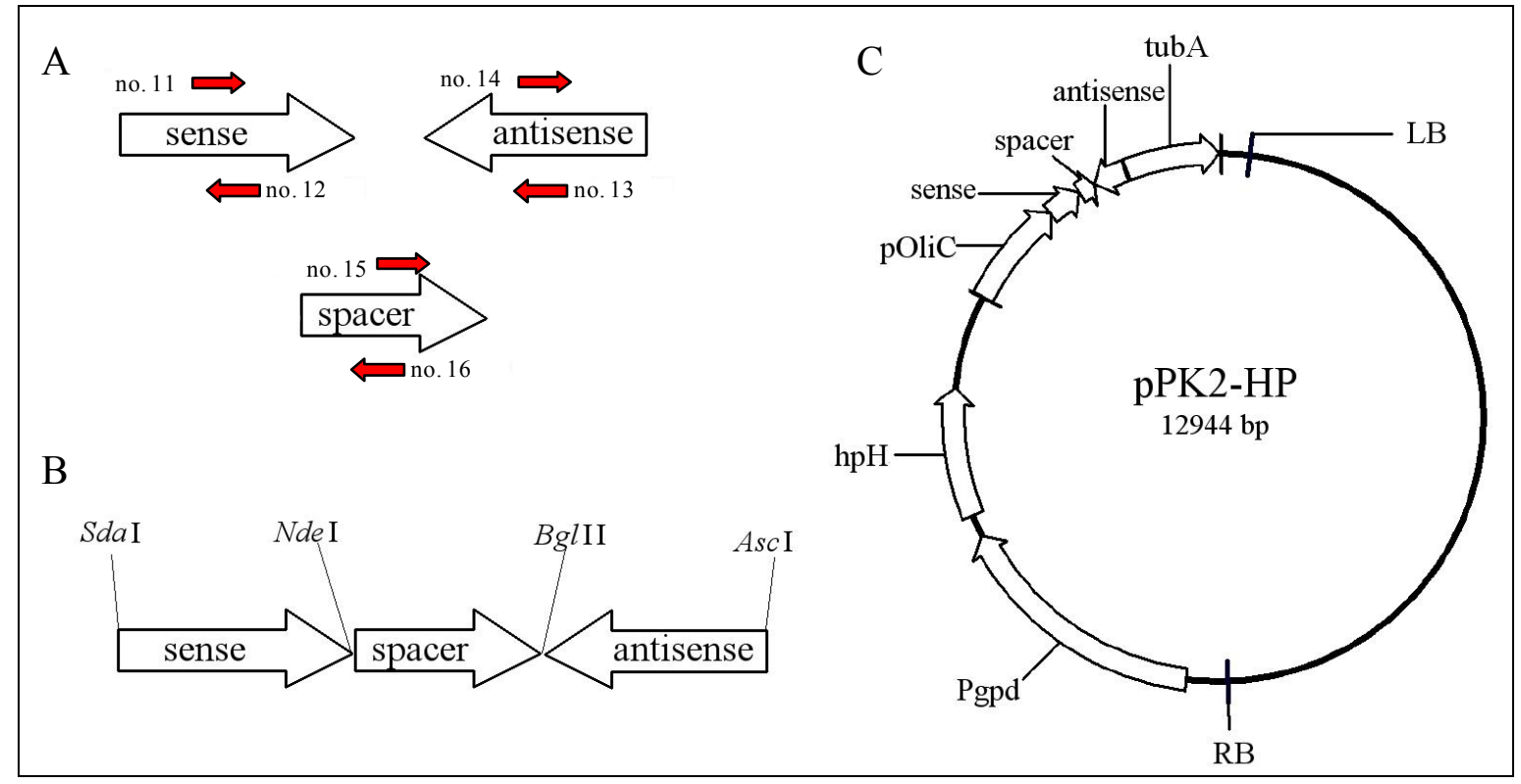

\section{Figure 13: Designed HP fragment for the transformation into binary pPK2 vector}

$\mathbf{A}=$ single amplicons for the construction of HP fragments are shown. Primers used for amplification by PCR are highlighted in red $\mathbf{B}=$ Assembled HP fragment showing restriction sites which were intended to be used for ligation of the single amplicons for building up the HP fragment $\mathbf{C}=p$ PK2-HP vector comprising left (LB) and right boarder $(\mathrm{RB})$ for the AMT and a hygromycin B resistance cassette $(\mathrm{hpH})$ under the control of constitutive promoter from $A$. nidulans (Pgpd) for the selection of transformants; included HP cassette comprises oliC promoter from A. nidulans and tubA terminator from B. cinerea 


\section{Cloning step one}

Prior to the first cloning step, we amplified fragments comprising a 238 bp sequence of the Vl-12.1 gene in the sense orientation and a $125 \mathrm{bp}$ sequence covering the native intron from the $V$. longisporum hydrophobin gene $V l H l$ by the use of Taq-polymerase. Primers were associated with overhang sequences providing restriction sites for the directional ligation of the fragments to the HP assembly and for the ligation into the binary vector pPK2. A PCR run was carried out following the method noted on page 36 for the amplification of fragments used for the construction of HP fragments by OE-PCR. $500 \mathrm{ng}$ of each purified PCR product was incubated along with $5 \mathrm{U}$ of $\mathrm{NdeI}$ for $2 \mathrm{~h}$ at $37^{\circ} \mathrm{C}$. Fragments were purified from agarose gel and used for ligation in equal molar ratio. The assembly of directionally ligated sense fragments of V1-12.1 associated with the VlH1 intron spacer was used as a template for PCR to generate sufficient amounts of DNA for cloning into pPK2 vector. Amplification of the sense/intron assembly was done using primers no. 11 and 16 with approximately $1 \mathrm{ng}$ of the DNA as a template. The resulting amplicon was purified and $500 \mathrm{ng}$ were subsequently double-digested along with $1 \mu \mathrm{g}$ of the pPK2-vector using $5 \mathrm{U}$ of each of the $S d a \mathrm{I}$ and $B g l \mathrm{II}$ restriction enzymes by incubation for $2 \mathrm{~h}$ at $37{ }^{\circ} \mathrm{C}$. After digestion, both insert and vector were purified from agarose gel, and the amount of DNA was estimated by spectral measurement and quantification using a NanoDrop spectrophotometer (Thermo Scientific, Willmington, USA). Ligation of the sense-intron assembly with the linearized pPK2-vector was carried out using a 1:3 molar ratio of vector to insert. After $\mathrm{ON}$ incubation of the samples, along with $5 \mathrm{U}$ of T4-DNA ligase, the mixture was directly used for electroporation into $E$. coli strain DH5 $\alpha$. Therefore, we used $1 \mu \mathrm{l}$ from the $20 \mu \mathrm{l}$ ligation mixture to mix with $50 \mu \mathrm{l}$ of electrocompetent cells and electroporated it at $1700 \mathrm{~V}$ and $25 \mathrm{mF}$ using the Gene Pulser II System (Biorad, Hercules, USA). Instantly, $800 \mu \mathrm{l}$ of prewarmed SOC medium (26) was added to the cells and incubated for $1 \mathrm{~h}$ at $37^{\circ} \mathrm{C}$ in a rotary shaker. Then, 600 and $200 \mu 1$ of the mixture were spread on agar plates containing $30 \mathrm{mg} / \mathrm{ml}^{-1}$ kanamycin. The plates were incubated $\mathrm{ON}$ at $37^{\circ} \mathrm{C}$. Grown E. coli colonies were tested by colony PCR. Prior to colony PCR, colonies were picked up using a sterile pipette tip and dissolved in $50 \mu$ of doubledistilled $\mathrm{H}_{2} \mathrm{O}\left(\mathrm{ddH}_{2} \mathrm{O}\right)$. The mixture was heated up to $100{ }^{\circ} \mathrm{C}$ for $5 \mathrm{~min}$ to release plasmid DNA, and $2 \mu 1$ was used for colony PCR with primers amplifying the sense/intron assembly. Positive tested transformants were grown in $5 \mathrm{ml}$ liquid LB medium containing $30 \mathrm{mg} / \mathrm{ml}^{-1}$ 
kanamycin. Plasmids were isolated from the grown E. coli cells following a protocol for extraction referred to as the "rapid boiling method" (42).

\section{Cloning step two}

For the second cloning step, we applied the pPK2-vector comprising the sense/intron assembly (pPK2-SI) constructed by cloning step one. An amplified antisense fragment of the candidate gene was double-digested along with pPK2-SI using $5 \mathrm{U}$ of each of the restriction enzymes $A s c \mathrm{I}$ and BglII. All the following steps were accomplished as described for cloning step one.

We had very little difficulty achieving positive transformants carrying pPK2 vector with the assembled HP fragment, probably because of the minor transformation efficiency due to the large pPK2-vector. Therefore, we applied E. coli strain DH10 $\beta$ for electroporation, which is described as being optimized for high efficiency transformation with a guaranteed increased efficiency of the accommodation of large plasmids as compared to DH5 $\alpha$. The success of $E$. coli transformation with pPK2-HP was tested by colony PCR and restriction analysis of the extracted plasmids by cutting out the HP fragments. All vectors used for further experiments showed the calculated lengths of HP fragments for candidate genes on agarose gels after digestion with restriction enzymes $S d a \mathrm{I}$ and $A s c$ I. Furthermore, we were able to induce HP structure formation by heating up the digested samples to $100{ }^{\circ} \mathrm{C}$ for $5 \mathrm{~min}$ and cooling them down before loading them on an agarose gel for electrophoresis. The emerging gel shift demonstrates the ability of the HP fragment to form HP RNA after intracellular expression in $V$. longisporum (see Figure 14). 


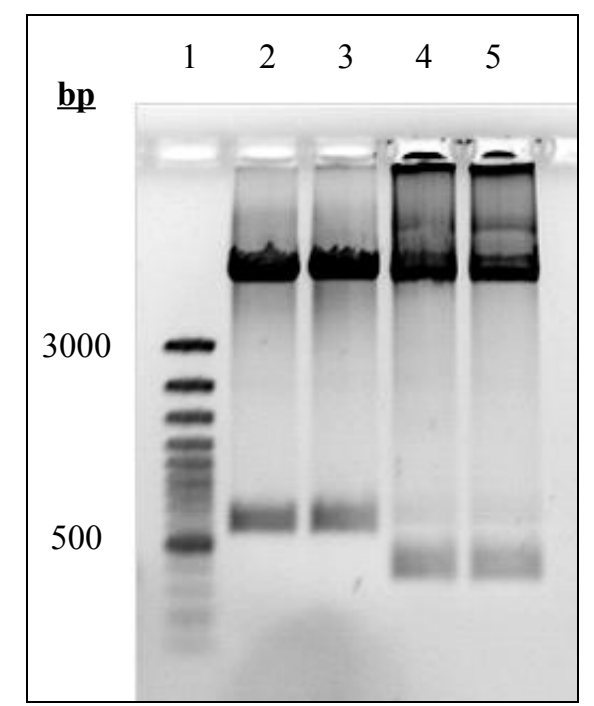

Figure 14: Agarose gel electrophoresis showing insertion of HP fragments into pPK2 by restriction analysis and functionality of HP formation

$1=$ GeneRuler ${ }^{\mathrm{TM}} 100$ bp Plus DNA Ladder

$\mathbf{2}=$ pPK2-HP for candidate gene V1-12.1 digested with SdaI and AscI

$3=$ same as above

$4=$ pPK2-HP for candidate gene V1-12.1 digested with $S d a \mathrm{I}$ and $A s c \mathrm{I}$, heated up to $100^{\circ} \mathrm{C}$ before loading $\mathbf{5}=$ same as above

So far, we have succeeded in constructing several HP constructs cloned in the pPK2-vector for different candidate genes. The pPK2-HP vectors were transformed into $A$. thumefaciens to accomplish AMT of $V$. longisporum. For this we used $1 \mathrm{pg}$ of vector DNA and mixed it along with $50 \mu 1$ of electrocompetent AGL1 cells, and electroporated them according to the method used for transformation of $E$. coli cells. Deviating from this, the incubation time for the recovery in SOC medium was prolonged to $3 \mathrm{~h}$ and the incubation temperature was reduced to $28{ }^{\circ} \mathrm{C}$, which was appropriate for the growth of A. thumefaciens strain AGLI. The mixture was spread on agar plates containing $30 \mathrm{mg} / \mathrm{ml}^{-1}$ kanamycin for the selection of pPK2-HP vector and $25 \mathrm{mg} / \mathrm{ml}^{-1}$ carbenicillin and $50 \mathrm{mg} / \mathrm{ml}^{-1}$ rifampicin for the selection of AGLI carrying Ti-plasmid pTiBo542 $\Delta \mathrm{T}$. Positive transformants were used for the AMT of $V$. longisporum following the protocol for the transformation of filamentous fungi published by Utermark in 2008 (28). Fungi that grew on the selection media after AMT were tested by PCR with primer for the hygromycin cassette and also by southern hybridization to show if the constructs had been successfully inserted into the genome of $V$. longisporum. Southern 
hybridizations show additional signal for the candidate gene on the blot due to the inserted HP fragment (data not shown, see Chapter 3 and 4).

Silencing efficiencies of transformed fungi were assessed by the use of qRT-PCR using cDNA of silencing mutants as a template for primers specific for the candidate genes. Therefore, cDNA was transcribed from extracted RNA which was isolated from fungal cultures grown in liquid SXM (simulating xylem sap) medium (43), which imitates the general nutritional environment existing in the xylem, using Oligo(dT)18 Primer which binds to the poly(A) tail present at the 3'-end of eukaryotic mRNA.

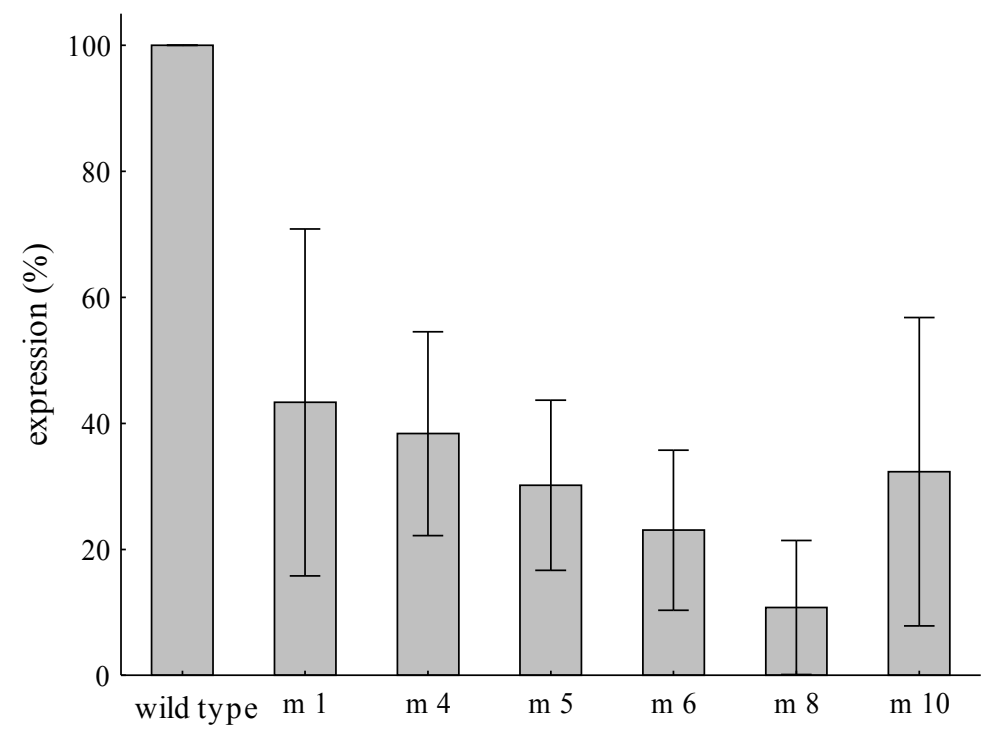

Figure 15: Efficiency of gene silencing triggered by the intracellular expression of a HP cassette for $V$. longisporum candidate gene Vl-12.1

For $V$. longisporum mutants carrying HP cassettes for gene-silencing of candidate genes, we could show a reduction in specific gene expression on up to $98 \%$ at best compared to wild type expression (see Chapter 3). Mutants with a silencing efficiency of at least $80 \%$ were used for further characterization of candidates' gene function to evaluate their role in the life cycle of $V$. longisporum (see Chapter 3 and 4). 


\section{CONCLUSIONS}

Our goal was to establish a method for post-transcriptional silencing by triggering RNAi in $V$. longisporum to decrease the expression of several candidate genes that were found (38) to be putatively involved in the pathogenic life cycle of the phytopathogenic fungus. Different intracellulary-expressed constructs showing the ability to release the production of siRNA have been tested in recent years, working as precursors of RNAi. Plasmid constructs expressing sense, antisense, or hairpin RNAs were reported to be potent triggers for downregulation of corresponding genes. In the plant pathogenic ascomycota fungus Magnaporthe oryzae, it was shown that transformants were silenced much more efficiently by HP RNA than by other RNA species (44). Additionally it was shown that the choice of an appropriate spacer, to form the loop of the HP, is of great significance. As reported, spacers are necessary for the stability of the HP structure. However, using a functional intron sequence of the host as spacer for HP fragment constructing, was shown to increase the silencing efficiency from approximately 50 to about $100 \%$ (11). Flanking sense and antisense arms ranging from 98 to $853 \mathrm{bp}$ were reported to be potent triggers for efficient silencing. It was also shown in $M$. oryzae that a silencing vector with a native intron spacer of $147 \mathrm{bp}$ length had a higher silencing efficiency than did those with a longer intron spacer of $850 \mathrm{bp}$ (45). During the research reported in this thesis we designed HP fragments consisting of flanking sense and antisense arms ranging from 180 to 696 bp length and an intervening 125 bp spacer of the native intron from the $V$. longisporum hydrophobin gene $V l H 1$. For all generated silencing-mutants of $V$. longisporum candidate genes, we could show a reduction in candidate gene expression of at least $90 \%$.

In addition to silencing due to HP RNA expression, another method was tested in our lab (46). This relied on the intracellular expression of an antisense RNA (AS-RNA) strand to inhibit gene function on a post-transcriptional level. Constructed AS-RNA-cassettes were designed complementary to the specific mRNA of the candidate gene to inhibit the translation process by expressing an RNA sequence in antisense orientation to the specific target gene. This bound the mRNA of the target gene, forming RNA-RNA-hybrids, thereby causing obstruction of the translation machinery (19). Naturally expressed AS-RNAs were first discovered in 1981 and were reported to control the copy numbers of two E. coli plasmids $(20,21)$. In most cases, AS-RNAs are naturally transcribed by a promoter that is located on the opposite strand 
of the DNA molecule coding for the sense mRNA. Therefore, they are completely complementary to the mRNA expressed from the sense strand. To date, AS-RNA has been found to control regulation of gene expression in many other species. In humans, more than 1600 AS-RNAs are known such as the insulin-like growth factor 2 receptor (22). $V$. longisporum mutants carrying cassettes for the expression of AS-RNAs show a moderate silencing effect on up to $70 \%$ of the corresponding candidate gene.

Our success in achieving HP fragments by the use of OE-PCR was not worth the effort needed to correctly assemble sense and antisense fragments with the spacer. We showed that the assembled HP fragment has a strong tendency to anneal after each denaturation step of the third round of PCR, forming HP structures by pairing of homologous sequences of sense and antisense ssDNA fragments. We made many adjustments to PCR runs to facilitate the amplification of the HP fragments and to suppress the formation of HP structure but could make no improvements. We propose that the amplification of HP fragments during the third round of PCR with end terminal primers may succeed with the use of a larger intervening spacer which would result in spatial separation of the sense and antisense strand and would consequently slow down the formation of the HP structure, allowing the amplification of HP fragments. Pawloski et al. used a 1060 bp $\beta$-glucuronidase (GUS) spacer to achieve HP fragments by OE-PCR and still reported "very few difficulties using OE-PCR to assemble RNAi constructs with the desired gene targeting sequence" (34). We decided not to elongate the spacer sequence to achieve better results during amplification of HP fragments, and instead to establish a construction method based on conventional cloning steps to take advantage of higher silencing efficiency due to short spacers.

The use of asymmetric OE-PCR led to one correctly assembled HP fragment out of more than one hundred attempts. We sequenced many putatively positive plasmids showing a signal during analysis of colony PCR with the corresponding E. coli cells. As turned out later, all sequenced non-positive fragments showing a variety of unspecific assembled parts of the three fragments that were intended to form the HP fragments. The mass of inserted primers into asymmetric OE-PCR and the resulting amplicons probably lead to a large number of options to assemble to unspecific fragments. Separated samples after asymmetric OE-PCR by agarose gel-electrophoresis show a smeary band pattern, putatively due to the unspecific formation of assemblies. We were able to re-amplify any fragment length which was sliced 
out and purified from any position of the smear on the agarose gel, using end terminal primers for the HP fragment. Nevertheless, we used specific HP fragment length, purified from the agarose gel, to perform subcloning into vectors and still succeeded in subcloning for only one sample. It can be assumed that many of the reported problems during construction of HP carrying vectors are due to a hampered DNA replication of plasmids in E. coli. It is most likely that a vector which carries an HP fragment has a strong tendency to form the HP structure after winding up of the plasmid DNA to ssDNA during the first step of DNA replication, forming the replication fork by breaking the hydrogen bonds which hold the two DNA strands together. The folded HP structure created during DNA replication would thereby obstruct the replication process by stopping the reading of DNA polymerase. This suggests, and would also explain, our tremendous problems during the second ligation step for conventional cloning of HP fragments. Nevertheless, we established a repeatable method for the conventional cloning of HP vectors by the use of standard molecular techniques.

We could demonstrate in our lab that both the HP RNA and AS-RNA methods are capable of inducing gene silencing in the ascomycota fungus $V$. longisporum. As mentioned in the literature, we could prove that HP RNA triggers RNAi more efficiently as compared to ASRNA-effected silencing, with a moderate reduction in the expression level of candidate genes. Therefore, we achieved an effective and reliable tool for the characterization of putative pathogenic-related genes of $V$. longisporum.

\section{ACKNOWLEDGMENTS}

The author would like to thank the following people for their outstanding assistance with this chapter:

Prof. Petr Karlovsky for his continuous assistance with scientific problems. Dr. Arne Weiberg for the remarkable help with work on construction of HP cassettes. Haiquan Xu for the construction of $V$. longisporum AS cassettes. 


\section{REFERENCES}

1. Crick F. (1958). On Protein Synthesis. Symp. Soc. Exp. Biol. XII, PMID 13580867.

2. Terman DS., Ogden D., Petty D. (1976). Removal of Circulating Antigen and Immune Complexes with Immunoreactive Collodion Membranes, FEBS Letters, vol. 68, No. 1, pp. 89-94.

3. Capecchi M. (1989). Altering the genome by homologous recombination, Science, Vol. 244, no. 4910, pp. 1288-1292.

4. Barbara D.J., Clewes E. (2003). Plant pathogenic Verticillium species: how many of them are there? Mol. Plant Pathol. 4:297-305.

5. Fahleson J., Lagercrantz U., Hu Q., Steventon L.A., Dixelius C. (2003). Estimation of genetic variation among Verticillium isolates using AFLP analysis. Eur. J. Plant Pathol. 109:361-371.

6. Fire A, Xu S, Montgomery MK, Kostas SA, Driver SE, Mello CC. (1989). Potent and specific genetic interference by double-stranded RNA in Caenorhabditis elegans. Nature. 1998 Feb 19;391(6669):806-11.

7. Ratcliff FG, MacFarlane SA, Baulcombe DC. (1999). Gene silencing without DNA. RNA-mediated cross-protection between viruses Plant Cell 11(7): 1207-16.

8. Hammond SM, Bernstein E, Beach D, Hannon GJ. (2000). An RNA-directed nuclease mediates post-transcriptional gene silencing in Drosophila cells. Nature. 2000 Mar 16;404 (6775): 293-6.

9. Hamilton A.J., Baulcombe D.C. (1999). A species of small antisense RNA in posttranscriptional gene silencing in plants. Science. 286, Nr. 5441 pg. 950-952.

10. Smith NA, Singh SP, Wang MB, Stoutjesdijk PA, Green AG, Waterhouse PM. (2000). Total silencing by intron-spliced hairpin RNAs. Nature. 407(6802): 319-20.

11. Wesley SV, Helliwell CA, Smith NA, Wang MB, Rouse DT, Liu Q, Gooding PS, Singh SP, Abbott D, Stoutjesdijk PA, Robinson SP, Gleave AP, Green AG, Waterhouse PM. (2001). Construct design for efficient, effective and highthroughput gene silencing in plants. Plant J. Sep;27(6):581-90.

12. Andrew Eamens, Ming-Bo Wang, Neil A. Smith and Peter M. Waterhouse (2001). RNA Silencing in Plants: Yesterday, Today, and Tomorrow. 
13. Wang, M.B. and P.M. Waterhouse (2001). Application of gene silencing in plants. Curr. Opin. Plant Biol. 5:146-150.

14. Miki, D., R. Itoh, and K. Shimamoto (2005). RNA silencing of single and multiple members in a gene family of rice. Plant Physiol. 138:1903-1913.

15. Liu, Q., S.P. Singh, and A.G. Green (2002). High-stearic and high-oleic cottonseed oils produced by hairpin RNA-mediated posttranscriptional gene silencing. Plant Physiol. 129:1732-1743.

16. Cejka D, Losert D, Wacheck V. (2006). Short interfering RNA (siRNA): tool or therapeutic? Clinical Sciences (London). 2006 Jan;110 (1): 47-58.

17. Singh S. (2008). Study of genes of the phytopathogenic fungus Verticillium longisporum involved in the colonization of xylem vessels of its host Brassica napus, Dissertation, Georg-August Universität Göttingen.

18. Higuchi R, Krummel B, Saiki R (1988). A general method of in vitro preparation and specific mutagenesis of DNA fragments: study of protein and DNA interactions. Nucleic Acids Res 16 (15): 7351-67.

19. Weiss, B., Davidkova, G., and Zhou, L-W. (1999). Antisense RNA gene therapy for studying and modulating biological processes. Cell. Mol. Life Sci. , 55: 334-358.

20. Tomizawa, J., Itoh, T., Selzer, G., Som, T. (1981). Inhibition of ColE1 RNA primer formation by a plasmid-specified small RNA. Proc. Natl. Acad. Sci. U.S.A. 78: 14211425 .

21. Stougaard, P., Molin, S. \& Nordström, K. (1981). RNAs involved in copy-number control and incompatibility of plasmid R1. Proc. Natl. Acad. Sci. U.S.A. 78: 60086012 .

22. Oshima A, Nolan CM, Kyle JW, Grubb JH, Sly WS (1988). The human cationindependent mannose 6-phosphate receptor. Cloning and sequence of the full-length cDNA and expression of functional receptor in COS cells. J. Biol. Chem. 263 (5): $2553-62$.

23. Koopmann B. and Karlovsky P. (2001) unpublished.

24. Yazynin S.A., Deyev S.M., Jucovic M., Hartley R.W. (1996). A plasmid vector with positive selection and directional cloning based on a conditionally lethal gene. Gene, Volume 169, Number 1, 22 February 1996, pp. 131-132. 
25. Kalendar R, Lee D, Schulman AH. (2009). FastPCR Software for PCR Primer and Probe Design and Repeat Search. Genes, Genomes and Genomics, 3(1): 1-14.

26. Sambrook J., Russell DW. (1989). Molecular Cloning: A Laboratory Manual $2^{\text {nd }}$ Edition, Trade paperback, Cold Spring Harbor Laboratory Press.

27. Maniatis T., Fritsch EF., Sambrook J. (1982). Molecular Cloning: A Laboratory Manual. Trade paperback, Cold Spring Harbor Laboratory Press.

28. Utermark J. (2008). Genetic transformation of filamentous fungi by Agrobacterium tumefaciens. Nature Protocols, Published online.

29. Yamamoto I., Numao M., Sakaguchi Y., Tsushima N., Tanaka M. (2007). Molecular characterization of sequence and expression of chicken GPR39. General and Comparative Endocrinology 151:128-134.

30. Pfaffl, M.W., Horgan, G.W., Dempfle, L. (2002). Relative expression software tool (REST) for group-wise comparison and statistical analysis of relative expression results in real-time PCR. NAR 30, e36.

31. Baulcombe D. (2004). RNA silencing in plants. Nature, 2004 Sep 16;431 (7006): 356-63.

32. Wesley, S.V., C.A. Helliwell, Smith NA., Wang M., Rouse DT., Liu Q., Gooding PS., Singh SP., et al. (2001). Construct design for efficient, effective and highthroughput gene silencing in plants. Plant J. 27:581-590.

33. Miki D, Shimamoto K. (2004). Simple RNAi vectors for stable and transient suppression of gene function in rice. Plant Cell Physiol.; 45(4): 490-5.

34. Pawloski LC, Deal RB, McKinney EC, Burgos-Rivera B, Meagher RB (2005). Inverted repeat PCR for the rapid assembly of constructs to induce RNA interference. Plant Cell Physiol.; 46(11): 1872-8.

35. Frey \& Suppmann (1995). Biochemica 2, 34-35.

36. Lawyer FC, Stoffel S, Saiki RK, et al. (1993). High-level expression, purification, and enzymatic characterization of full-length Thermus aquaticus DNA polymerase and a truncated form deficient in 5' to $3^{\prime}$ exonuclease activity. PCR Methods Appl.. 2, Nr. 4, Mai 1993, pg. 275-87.

37. Lundberg KS, Shoemaker DD, Adams MW, Short JM, Sorge JA, Mathur EJ. (1991). A High Fidelity Thermostable DNA Polymerase Isolated from Pyrococcus furiosus. Gene, 12, 108(1): 1-6. 
38. Weiberg, A. (2008). Identifizierung von Xylemsaft-induzierten Genen im vaskulären Pathogen Verticillium longisporum mittels einer verbesserten cDNA-AFLP Methode für transkriptomweite Expressionsstudien. Dissertation, Georg-August Universität Göttingen.

39. Yan P, Wang S, Shen W, Gao X, Wu J, Zhou P. (2010). Simple construction of chimeric hairpin RNA for virus resistance in plants. J Virol Methods. 166(1-2): 101-5.

40. Xiao YH, Yin MH, Hou L, Pei Y. (2006). Direct amplification of intron-containing hairpin RNA construct from genomic DNA. Biotechniques, 41(5): 548, 550, 552.

41. Hajdukiewicz P., Svab Z., and Maliga P. (1994). The small, versatile pPZP family of Agrobacterium binary vectors for plant transformation. Plant Molecular Biology, 25(6):989994.

42. Riggs MG. and McLachlan A. (1986). A simple screening procedure for large numbers of plasmid mini-preparations. Biotechniques, 4(4):310313.

43. Neumann M.J., Dobinson K.F. (2003). Sequence tag analysis of gene expression during pathogenic growth and microsclerotia development in the vascular wilt pathogen Verticillium dahliae. Fung. Genet. Biol. 38:54-62.

44. Kadotani N., Nakayashiki H., Tosa Y., Mayama S. (2003). RNA silencing in the phytopathogenic fungus Magnaporthe oryzae. Mol Plant Microbe Interact. 2003 Sep;16(9):769-76.

45. Nakayashiki H., Hanada S., Nguyen BQ., Kadotani N., Tosa Y, Mayama S. (2005). RNA silencing as a tool for exploring gene function in ascomycete fungi. Fungal Genet Biol. 2005 Apr;42(4):275-83.

46. Xu H. (2011). Dissertation, Georg-August University of Goettingen. 


\section{APPENDIX}

\section{Vl-12.1}

\section{gDNA sequence}

1 ATGTCGTGCCAGAACCCTCGCCGCAGGTCCCCTGTGACCCGCGTCGGCGA

51 CGCTTCCAGCAATGGCCTCACCAGCCTTAAGACCAACATGACCCTGCGCA

101 AGGGGGCCACCTTCCACTCGCCCACCTCTCTCGACTCTTCATCCATCGAC

151 GCCTTCATCCCCCCAGCTCTTGGTCGTATCTCAGACCAATCTTGAAGACG

201 TGTCGGCGCTCACGTCCGCCGCATGGAGATGATCGTCAGCGGCATCGAGA

251 CATCACTCAATCTGAATGATACCCCAAGGCCGGCCTCCAAGCCTTCGCGT

301 GACGAGTGCCTGCCTCGCACAAACGGCTTCCTCGGCCGCCCTACTGTCGA

351 CCCCGCCATGGCAAAAGACACCAAGACCAGCGGGGAGCGCCGCGTTTTGC

401 GCCCAAGACATCGTCGCTCATCGGAGCAGCACGCTTCGGACAGCGGTCTC

451 GGCACCTCTCTGGCCTCTTCCGTCGAGAAGCAAGCCCCCAGCATCACCTC

501 CAAGACCAGCAAGGCATCCGCCATTACACGCTCTGCCGCCGCTCCTTCCA

551 ACACCATGACCAAGGTCTCTGGCCTGAGCTCCAAGGCGGTCAGCCGTGTT

601 CACGAACACGTTCTTCGCCCCCTTCGTGCCAAGCCTGAGTTGAAGGACTT

651 CGAGCCCATCGTCCTGGACATTCCCAGGCGAATCCGTGACAAGGAAATCA

701 TCTGCCTCAGGGATCTTGAGAAGACTTTGATCTTCATGGCACCGGTAAGT

751 CAACTCTTGTATCAACGCAGCGTTTGGGGAGATACTTATCGGTCGTTGAT

801 GAAGGAGAGGGCCAAGACCGCCGCCTTGTACCTCGATTTCTGCCTGACGT

851 CCATTCGATGCATTCAAGCCACCGTCGAATACCTCAGCGACCGCGAACAA

901 ATTAGACCGGCCGACCGACCATACACTAACGGATACTTCATTGATCTCGT

951 CGAACAGATTCGCCAATACGCCGGACAACTGGCCACTGCCAAGGAAGCCG

1001 GAGTCGAGGGGCGTGAGATGGACGTCGACCCCACCGACGAGGTTAAGCTG

1051 TTCGGTGGCATCTCGCAGAACGGCCGCCCCGCCGAGCTTGTCCGCGTCAG

1101 AAAGGACGGTCAAGCCATCTCCATGGCCACTGGCCTCCCCGTTGACATGG

1151 ATGAGGACGGCAAGGATTTCCCCAGACTGAAGCGCTCCCTGAGCCAGCAG

1201 CTGGCAGACGACGAGGAGATCATGCGGTCCATGGCTCGCAGGAAGAAGAA

1251 CGCTGCGCCGGAGGAGCTCGCGCCCAAGAAATGCCGCGAGCCTGGCTGCA

1301 ACAAGGAGTTCAAGCGTCCCTGTGACCTGACCAAGCACGAGAAGACTCAC

1351 TCTCGTCCCTGGAAGTGCCCTGTCAAGACGTGCAAGTACCACGAGTACGG

1401 CTGGCCCACCGAGAAGGGGATGGACCGCCATCACAACGACAAGCACTCCT

1451 CAGCGCCCCCCATGCACGAGTGCCTGTTTAAGCCTTGCCCTTACAAGTCG

1501 AAGCGCGAGTCAAGCTGCAAGCAGCACATGGAGAAGGCCCACGGATGGCA

1551 GTACGTCCGCACCAAGACCAACGGCGGCAAGAAGGCGCCCAGCGTTGCTG

1601 GAAGCTCGGCACAGCCGACCCCTCAGCTTGGCAACATGGCAACGCCCTCG

1651 AGCAGCCACAGTATTGCTACGCCGCCCGAGGAGAGCACCAGCCTCTTCCC

1701 GCCTTTTAACCACGATGACTTCCCTCACTACGTCCCGGCCGAGGAGTTTG

1751 CTGACACCTGCCTCGGGCCCATGGGACAGCCGCCCATGACGCTCGAGGGT

1801 ATCGACTTTAACGACCTTGGCGTGTCTCCCACTGATTACAACACCCCTTC

1851 TACCGACACATCCTACCCATACACCTCTTACCAGGATGGACCCGAGTTTG

1901 TCATCAACAACGATGACATTTACGGCGCCCGTGTCCAGATCCCGACACCG

1951 GCGTGGCCCGAAAAGATGATGGCTGGCATGCAGAACTACGCCCCAGTGTC

2001 TGCATGCCAACCTCAGATGATGCCCGAGCCGCTCGCCCCACACATCTCCC

2051 CGATAGGTCAGGGGAACGCCATGCTCTTCACGCCCAACTCGTTGGCCGAG

2101 GTTGACGAAGGCTTTGATGATTTCGGCGGCTGTGGTGATGATTTCACCTT

2151 GTTCCCCGTCAACGGGCTCGACAAGGACGCACAATTCCAGACTCTGTTCG

2201 GCAGCGAGATGCCCAGCAGCGGCCTCGGCTTGTCTCAGGGCGCCTCCCAG

2251 GACTTCTTTGGGAACGGCATGGACTGGTCCAGCATGGAATACCACACCTA

2301 CTCCCAGCAGCCCCAGCACCAGCAGTAG 


\section{amino acid sequence}

1 MSCQNPRRRSPVTRVGDASSNGLTSLKTNMTLRKGATFHSPTSLDSSSID

51 AFIPPALGRISDQSRRVGAHVRRMEMIVSGIETSLNLNDTPRPASKPSRD

101 ECLPRTNGFLGRPTVDPAMAKDTKTSGERRVLRPRHRRSSEQHASDSGLG

151 TSLASSVEKQAPSITSKTSKASAITRSAAAPSNTMTKVSGLSSKAVSRVH

201 EHVLRPLRAKPELKDFEPIVLDIPRRIRDKEIICLRDLEKTLIFMAPERA

251 KTAALYLDFCLTSIRCIQATVEYLSDREQIRPADRPYTNGYFIDLVEQIR

301 QYAGQLATAKEAGVEGREMDVDPTDEVKLFGGISQNGRPAELVRVRKDGQ

351 AISMATGLPVDMDEDGKDFPRLKRSLSQQLADDEEIMRSMARRKKNAAPE

401 ELAPKKCREPGCNKEFKRPCDLTKHEKTHSRPWKCPVKTCKYHEYGWPTE

451 KGMDRHHNDKHSSAPPMHECLFKPCPYKSKRESSCKQHMEKAHGWQYVRT

501 KTNGGKKAPSVAGSSAQPTPQLGNMATPSSSHSIATPPEESTSLFPPFNH

551 DDFPHYVPAEEFADTCLGPMGQPPMTLEGIDFNDLGVSPTDYNTPSTDTS

601 YPYTSYQDGPEFVINNDDIYGARVQIPTPAWPEKMMAGMQNYAPVSACQP

651 QMMPEPLAPHISPIGQGNAMLFTPNSLAEVDEGFDDFGGCGDDFTLFPVN

701 GLDKDAQFQTLFGSEMPSSGLGLSQGASQDFFGNGMDWSSMEYHTYSQQP

751 QHQQ

Table 5: gDNA and amino acid sequence of candidate gene Vl-12.1 


\title{
Chapter 3: Characterization of NEP like proteins of Verticillium longisporum according to their relevance for pathogenicity in Brassica napus
}

\author{
Malte Beinhoff, Arne Weiberg, Mona Quambusch, Haidi Yin*, Ruth Pilot, Haiquan Xu, \\ Christian Loefke, Richard Splivallo and Petr Karlovsky \\ Molecular Plant Pathology and Mycotoxin Research Unit, Department for Crop Sciences, \\ Georg-August University of Goettingen, Grisebachstrasse 6, 37077 Goettingen, Germany. \\ *College of Life Sciences, Peking University, Beijing, China
}

\begin{abstract}
Verticillium longisporum is a soil-borne fungal pathogen showing major yield losses on the rapeseed plant Brassica napus in the northern hemisphere. Because of the variety of investigations on the pathosystem of several Verticillium spp. to their host plants, the species is on the way to becoming a model system for studying diseases caused by plant pathogenic fungi. Little is known about phytotoxic metabolites of $V$. longisporum which allow the successful host colonization by the induction of plant cell death during the saprophytic phase of the hemi-biotroph fungus to metabolise nutrients released by dead plant tissue. Recently a family of small phytotoxic peptides have been described, referred to as necrosis and ethyleneinducing peptides (NEPs). These have been shown to trigger cell death and the activation of defense signaling reactions in dicotyledonous plants. NEPs are dominantly present in plant pathogenic species with a hemibiotrophic or a necrotrophic life cycle. In this study, five different NEP orthologs from $V$. dahliae were identified in the genome of $V$. longisporum (V1NEP-1 to 5). Three of them were proved to be strongly upregulated in $V$. longisporuminfected host plant B. napus as compared to the expression measured in vitro. We functionally analysed the impact of Vl-NEP-1 in the pathogenic life-cycle of the fungus. Our findings strongly suggest that Vl-NEP-1 is a true virulence factor of $V$. longisporum during infection of B. napus.
\end{abstract}




\section{INTRODUCTION}

Plant-pathogenic microbes release a large variety of chemical compounds facilitating their infection of host plants. Some of these compounds are elicitors, whose presence is perceptible by plant cell wall receptor molecules as the first step in pathogen recognition, followed by the activation of innate plant immunity (1). Beside elicitors, disease symptoms can also be caused by cytotoxic compounds (phytotoxins) produced by the pathogen. These can damage and kill plant cells without any activation of programmed cell death $(2,3)$.

In 1995, Bailey et al. first described a protein purified from culture filtrates of Fusarium oxysporum f.sp. erythroxyli (4) which is capable of triggering ethylene production and necrosis in numerous dicotyledonous plants and is therefore known as a necrosis and ethylene-inducing protein 1 (NEP-1). This is the first representative of what is currently known to be the large family of NEP-like proteins (NLPs). The predominant presence of NLPs in oomycete, fungal and bacterial species (5), especially for plant pathogenic organisms that have a hemibiotrophic or necrotrophic lifestyle, and the absence in higher eukaryotes including plants and animals, suggests that these proteins are a common feature of microbial organisms and are thus likely to play a role in plant-pathogen interactions (6). The group of NLPs includes small $(25-35 \mathrm{kDa})$, secreted peptides that have the ability to trigger plant responses on host plants $(15,16)$. In contrast to other known elicitors or phytotoxins, NLPs are taxonomically widespread $(16,17)$ and are found both in gram-positive and gram-negative bacteria (18) as well in oomycetes $(15,19,20)$, ascomycetes $(4,21,22,23,24)$ and basidiomycetes (25). In spite of the taxonomical prevalence of NLPs, it was shown that functional orthologs, demonstrated by an oomycete NLP, expressed in a NLP-deficient Pectobacterium carotovorum mutant, complement partial restoration of virulence (17), suggesting that NLPs of eukaryotic and prokaryotic origins are orthologous proteins. All NLPs share a highly conserved stretch called the necrosis-inducing Phytophthora protein 1 (NPP1) domain. This domain comprises the amino acids $\operatorname{GHRHDWE}(16,17)$ in the centre of the peptide and shows no significant similarity to any currently known protein sequence and so provides no reference to NLP function. The conserved domain is supposed to interact with two or four cysteine residues upstream to the domain to execute membrane-disintegrative activity $(17,26,27)$. Furthermore, it was shown, that the ability of a NLP from Phytophthora parasitica to trigger phytoalexin production and necrotic lesion formation in tobacco leaves 
was impaired by site-directed mutagenesis of two conserved cysteine residues to serine. Using the conserved cysteines, NLPs were classified into subgroups comprising Group I, which exhibits two cysteines upstream from the conserved domain, and Group II, which harbours four cysteines (28).

The functionality of NLPs is a controversial issue in that there is still discussion about whether to classify the peptides as functional elicitors (29) or as phytotoxins (5). The elucidation of the crystal structure of a NLP from the phytopathogenic oomycete Pythium aphanidermatum shows great similarity to cytolytic toxins produced by marine organisms (30). This report is strengthened by the results of former studies showing cytolytic effects on plants triggered by NLPs expressed by ten different phytopathogenic organisms $(5,28)$. Immunolocalization results show that NLPs are mainly localized in the plant cell wall and in the cytosol on cellular level (23). Additionally it was shown, that NLP-induced necrosis requires interaction with a target site that is unique to the extracytoplasmic side of dicotyledonous plant plasma membranes. A GFP-fused NLP was found to be associated with the phospholipid bilayers of plasma membrane and the nuclear envelop (26). Additionally, Qutob et al. (5) demonstrated that NLPs have an affinity for lipid bilayers, and their phytotoxic activity and specificity for dicots do not require the presence of a cell wall.

Plant-responses triggered by NLPs are strictly limited to dicotyledonous plants; all monocotyledonous plants or other organisms tested so far are insensitive to NLP exposure (4, $24,26)$. Sensitive plants respond with a large variety of modes of action due to NLP exposure such as: up-regulation of defence-related genes $(6,31)$, transcriptome profiling indicating large-scale reprogramming of plant gene expression $(5,22,23)$, the de-novo synthesis of phytyoalexins $(6,19)$ and phenolic compounds $(15)$, production of ethylene $(6,21)$, initiation of an oxidative burst by nitric oxide and reactive oxygen species (ROS) $(5,18,30)$, induction of apoptosis $(20,31), \mathrm{Ca}^{2+}$ influx (6) and callose deposition into plant cell walls (32). All these effects on plants act in a dose-dependent manner $(6,15)$. NLPs might play dual roles in plant-pathogen interactions as toxin-like virulence factors and as triggers of innate plant immune responses (5). This is supported by the findings that NLP-induced apoptosis was not stopped by specific inhibitors (25). Whether NLPs can act as true virulence factors remains doubtful. Pathogenicity assays with NLP-disfunctional mutants showed no arrest in pathogen spread and limit infection, which was tested in F. oxysporum in cocoa (33) and Erwinia 
carotovora ssp. carotovora in different solanaceanous plants $(16,18)$. Although the presence of NLPs has been deeply investigated in the oomycete genera Phytophothora, Pythium and in the ascomycetes Fusarium oxysporum and Botrytis spp., nothing is known about the presence and putative contribution of NLPs regarding the pathogenic life cycle of $V$. longisporum. The first representative of an NLP for the genus Verticillium was reported by Wang in 2004 . He found an NLP in $V$. dahliae, named Vd-NEP, which triggers typical wilting in leaves of the natural host plant, cotton (31).

The soil-borne fungi Verticillium longisporum, in contrast to other plant pathogenic Verticillium spp. has a limited host range and infects only Brassica and other cruciferous plants (7). The pathogenic life cycle of $V$. longisporum starts with the penetration of the host plant via the roots, and proceeds with the colonization of the vascular system (8). During this first stage of infestation, the fungus stays biotrophic and strictly remains in the vessel system of the plant. In a later stage of infection the pathogen changes its life style into that of a necrotrophic-living organism. In this saprophytic stage, the fungus metabolises nutrients released by dead plant tissue. In contrast to other plant-pathogenic Verticillium spp., $V$. longisporum is not indicated by wilting of host-plants $(9,10,11,12)$, which is usually a typical feature of the disease, and is known as Verticillium-wilt. In addition to this distinctive feature, $V$. longisporum also causes stunting, chlorosis and anthocyanin accumulation, which affects the flowering time and triggers early onset of senescence on host plants $(13,14)$. In this study we identified five NLP genes from $V$. longisporum, designated as V1-NEP-1 to 5, by molecular techniques.

\section{MATERIALS AND METHODS}

\section{Fungal and bacterial strains}

$V$. longisporum VL43 strain was provided by the Department of Crop Sciences, Section Plant Pathology and Crop Protection, (University of Goettingen, Goettingen, Germany) and was used for all experiments in this chapter. The isolate originated from oilseed rape plants 
collected in Northern Germany (34). The optimal growth temperature is between 20 and 23

${ }^{\circ} \mathrm{C}$ and this was therefore used for all experiments using $V$. longisporum.

Agrobacterium tumefaciens strain AGL1 was provided by Dr. Susanne Frick (Leibniz Institute of Plant Biochemistry, Martin-Luther University Halle-Wittenberg, Halle/Saale, Germany) and was used for the transformation of $V$. longisporum.

Protease-deficient Escherichia coli strain BL21 (New England Biolabs, Ipswich, United Kingdom) was used for overexpression of V1-NEP-1 protein.

Chemically competent E. coli strain DH5 $\alpha$ and electrocompetent DH10 $\beta$ strains (New England Biolabs, Ipswich, United Kingdom) were used for cloning purposes.

\section{Preparation of spore suspensions}

One hundred $\mu 1$ of a spore solution containing $1 \times 10^{6}$ spores was spread on a potato-dextrose agar (PDA) plate and incubated at $23{ }^{\circ} \mathrm{C}$ for 10 days in the dark. The plate was subsequently flooded with $15 \%$ glycerine suspension and the spores were released from the conidiophores by scratching the mycelium with a spatula. The suspension was filtered through a sterile gauze and the spore concentration was estimated using a Thoma hemacytometer with a depth of $0.1 \mathrm{~mm}$ (Roth $\mathrm{GmbH}$, Karlsruhe, Germany). The spore suspension was diluted to $1 \times 10^{7}$ spores per $\mathrm{ml}^{-1}$ with a $15 \%$ glycerine solution.

\section{Plant material}

The seed material of 'rapid cycle rape' (Brassica napus var. napus, Genom ACaacc) (35) was provided by the Department of Crop Sciences, Section Plant Pathology and Crop Protection, (University of Goettingen, Goettingen, Germany).

Seeds of Arabidopsis thaliana ecotypes Burren (Bur) (36), Columbia (Col-0) (37) and Landsberg erecta (Ler) (38) were provided by Prof. Volker Lipka (Department of Plant Cell Biology, Georg-August University of Goettingen, Goettingen, Germany). 
Seed material of Nicotiana tabacum was provided by the Department of Crop Sciences, Section Plant Pathology and Crop Protection, (University of Goettingen, Goettingen, Germany).

\section{Plasmids}

For A. thumefaciens-mediated transformation (AMT) of $V$. longisporum, we used the binary vector pPK2 (12) including border sequences for the AMT, and a hygromycin B resistance cassette containing the hygromycin phosphotransferase gene from E. coli (hph) for selection of positive transformants.

The plasmid pET21a (MERCK, San Diego, CA, USA) was used for overexpression of V1NEP-1 protein in E. coli strain BL21.

The plasmid pUC57 (Fermentas, St. Leon-Rot, Germany) was used for the construction of a $V$. longisporum genomic library.

\section{Enzymes}

For the construction of pPK2 vector containing hairpin (HP)-cassettes, suitable for triggering post-transcriptional gene silencing by RNA interference (RNAi), we used restriction enzymes, 'T4-DNA Ligase' and affiliated buffers purchased from Fermentas Inc. (Fermentas, St. LeonRot, Germany).

Enzymes and reagents for first strand cDNA synthesis, including 'Oligo(dT)18 Primer', 'RiboLock ${ }^{\mathrm{TM}}$ RNase Inhibitor' and 'M-MuLV Reverse Transcriptase' were purchased from Fermentas.

'Biotaq ${ }^{\mathrm{TM}}$ DNA Polymerase' (Bioline, Luckenwalde, Germany) was used for general amplification of fragments by polymerase chain reaction (PCR) and quantitative real time PCR (qPCR) to assess the amount of fungal DNA in plant tissue

The 'ABsolute Blue QPCR Fluorescin Mix' (Fisher Scientific GmbH, Schwerte, Germany) was used for qRT-PCR to assess the silencing efficiency of $V$. longisporum mutants. 
The 'HotStart-IT SYBR Green One-Step qRT-PCR Master Mix Kit' (Affymetrix UK Ltd., High Wycombe, UK) was used for one-step qRT-PCR for the analysis of the expression of pathogenesis-related genes in B. napus.

\section{Genomic library of $V$. longisporum}

For the construction of a $V$. longisporum genomic library, $20 \mu \mathrm{g}$ of isolated gDNA was partially digested with 0.4 U Bst 143 I for 30 minutes. Digested DNA was electrophoretically separated on a $0.6 \%$ agarose gel at $0.5 \mathrm{~V} / \mathrm{cm}$ overnight. DNA fragments of $8-14 \mathrm{~kb}$ were excised and purified from the agarose gel using 'QIAquick Gel Extraction Kit' (Qiagen, Hilden, Germany) and ligated into pUC57 vector. For library construction, cloned fragments were transformed into electrocompetent E. coli DH5 $\alpha$ cells. The library contained a total number of 9600 single clones placed in 100 microtiter plates with a 96 well format. About 50 $\%$ of the clones were determined by electrophoresis to contain circularized plasmid without any insert. For the screening of clones comprising full gene sequences (and flanked regions) a stepwise strategy of, in total, 40 PCRs with gene-specific primers was chosen to pinpoint single clones carrying an insert that contained the sought gene sequence. In a first PCR round, pooled clones of ten microtiter plates were used per PCR reaction and subsequently analysed by electrophoresis on a $1.7 \%$ agarose gel. Positive clone pools, which showed a gene-specific PCR product, were used for another round of 10 PCRs, in which pooled clones of single microtiter plates were analysed. A third PCR round of 20 PCRs was performed to dissect the positive tested microtiter plate by analysing pooled clones of each row and each line of the microtiter plate. This resulted in a single positive tested row and a single positive tested line, and the crossing point localized the position of the positive single clone used to sequence the insert.

\section{Vl-NEP-1 gene silencing}

Construction of pPK2-HP vector, containing a V1-NEP-1 specific HP-cassette, was performed as described in Chapter 2 (Construction of HP-fragments using conventional cloning steps, from page 48). The procedure comprised two cloning steps for the construction of pPK2-HP for the $V$. longisporum candidate gene V1-NEP-1. Fragments for the construction were PCR amplified using primers (see Table 10 in the Appendix) for sense- and antisense-sequences of 
the Vl-NEP-1 gene and intron-fragments comprising the sequence of a native intron from the $V$. longisporum hydrophobin gene $\mathrm{VlH1}$, homologous to VdH1 from V. dahliae (GenBank Accession No. DQ026260.1). All amplicons were associated with suitable restriction sites for directional cloning.

\section{Transformation of $V$. longisporum}

Agrobacterium tumefaciens-mediated transformation (AMT) of $V$. longisporum was performed as described in Chapter 2 (see page 31) using a protocol published by Utermark (39).

\section{Southern hybridization}

To analyse the number of Vl-NEP-1 gene-copies present in the genome of wild type $V$. longisporum and to determine the number of copies in the transformed mutants compared to the wild type, southern hybridization was performed as described in Chapter 2 (see page 30).

\section{Plant pathogenicity assay using Vl-NEP-1 silencing mutants}

Seeds of 'rapid cycle rape' were surface sterilized in $70 \%$ ethanol for $15 \mathrm{sec}$ and rinsed three times in sterile tap water before sowing in sterile silica sand. The silica substrate was carefully rinsed from the rape plants seven days after sowing. The cleaned roots were dip inoculated for $45 \mathrm{~min}$ in a spore suspension $\left(1 \times 10^{6}\right.$ spores $\left.\mathrm{ml}^{-1}\right)$ of $V$. longisporum wild type and V1-NEP-1 knock-down mutants. In all experiments, 60 plants were either water inoculated (mock) or inoculated with $V$. longisporum wild type or Vl-NEP-1 silencing mutants. Subsequently, plants were transferred into an autoclaved earth/sand mixture $(1 / 1 \mathrm{v} / \mathrm{v})$ and raised under constant conditions in a climatic chamber with a day/night length of $16 / 8 \mathrm{~h}, 23^{\circ} \mathrm{C}$ at daylight and $20^{\circ} \mathrm{C}$ at night conditions. After 14,21 and $28 \mathrm{dpi}$, plant symptoms were evaluated by measuring the plant shoot lengths and by the assessment of a disease score according to Zeise et al. (40). Plants were harvested at different time points depending on the corresponding experiment for measurement of parameters and for extraction of total RNA, gDNA or phytohormones. 


\section{Extraction of gDNA and total RNA}

Total RNA for qRT-PCR and gDNA for PCR, qPCR, southern hybridization or for the construction of a $V$. longisporum genomic library were extracted from fungal mycelium or plants as described in Chapter 2 (see page 30) using a modified protocol of Maniatis et al. (41).

\section{qRT-PCR}

Total RNA from fungal mycelium was used for gene expression analysis. Polyadenylated RNA (mRNA) was purified from total RNA extractions using Oligotex $\subset$ mRNA Mini kit (Qiagen, Hilden, Germany) for analysing fungal transcripts in samples of infected plants. QRT-PCR was performed as described in Chapter 2 (see page 32).

\section{qPCR}

QPCR was used to quantify fungal DNA in plant tissue by real-time PCR using SybrGreen. PCR runs were performed using an iCycler detection system (BioRad, Hercules, CA, USA). Approximately $50 \mathrm{ng}$ of extracted gDNA from infected plants was used for qPCR including $0.25 \mathrm{U}$ Taq-polymerase, $3 \mathrm{mM} \mathrm{MgCl}_{2}, 200 \mathrm{mM}$ dNTPs and primers OLG 70 and OLG 71 (see Table 11 in the Appendix) to amplify a $261 \mathrm{bp}$ fragment of an ITS region from $V$. longisporum. As a passive reference-dye for well-factor collection with the iCycler detection system, $10 \mathrm{nM}$ fluorescein was used during PCR. SybrGreen I (Invitrogen, Karlsruhe, Germany) diluted 100,000 times, was added to the reaction tube. The qPCR protocol starts with a 2 min step at $95{ }^{\circ} \mathrm{C}$ and is followed by 40 cycles including a denaturation step at $95^{\circ} \mathrm{C}$ for $20 \mathrm{sec}$, an annealing step at $59{ }^{\circ} \mathrm{C}$ for $30 \mathrm{sec}$ and an elongation step at $72{ }^{\circ} \mathrm{C}$ for $40 \mathrm{sec}$. The detection of fluorescence was automatically measured by the cycler during the elongation step of the PCR. The following melting curve analysis of the amplified fragments was directly carried out after the PCR run by heating the samples to $95^{\circ} \mathrm{C}$ for $1 \mathrm{~min}$, cooling them to $55^{\circ} \mathrm{C}$ for $1 \mathrm{~min}$, and carrying out a stepwise increase of the temperature from $65^{\circ} \mathrm{C}$ to $95^{\circ} \mathrm{C}$ at the rate of $1{ }^{\circ} \mathrm{C} / \mathrm{min}$. The fluorescence was continuously measured by the cycler after each temperature increase. The absolute amount of fungal DNA in the plant matrix was derived from a calibration curve constructed from a dilution series of gDNA from $V$. longisporum. 


\section{Measurement of ethylene $\left(\mathrm{C}_{2} \mathrm{H}_{4}\right)$-production of $\mathrm{V}$. longisporum}

We quantified ethylene concentrations of the wild type and Vl-NEP-1 silencing mutants of $V$. longisporum. Therefore, $1 \times 10^{4}$ fungal spores were added to $5 \mathrm{ml}$ liquid potato dextrose broth (PDB) medium (Roth GmbH, Karlsruhe, Germany) in $20 \mathrm{ml}$ solid-phase microextraction (SPME) vials, closed and made airtight with a silicon/polytetrafluoroethylene septum, and grown for 5 days at $23{ }^{\circ} \mathrm{C}, 16 \mathrm{~h}$ photoperiod. The air from the vials including grown fungus in PDB without or with $5 \mathrm{mM}$ L-methionine (added through a sterile filter after autoclaving to the cooled down PDB) was injected into a gas chromatography (GC)-flame ionization detector, and ethylene production was measured and calculated for each treatment using four replicates.

\section{High-performance liquid chromatography-mass spectrometry (HPLC-MS)}

For the analysis of the phytohormones salicylic acid (SA), salicylic acid glycoside (SAG), jasmonic acid (JA), abscisic acid (ABA), and auxin (IAA) in B. napus, $100 \mathrm{mg}$ of hypocotyl samples were milled in liquid nitrogen. Phytohormones were co-extracted using a modified protocol according to Xiangqing et al. (43) by replacing dichloromethane with 1 Vol. of diethylether as an extraction solvent. After extraction, the organic phase was dried in a speed vacuum centrifuge (Heidolph $\mathrm{GmbH}$, Kelheim, Germany) and the pellet was resolved into $200 \mu \mathrm{l}$ of $\mathrm{H}_{2} \mathrm{O}$ / methanol mixture 1:1 (v/v) and $7 \mathrm{mM}$ acetic acid. Then, $20 \mu \mathrm{l}$ of the extracts were injected into HPLC-MS for analysis.

\section{Confocal laser scanning microscopy (CLSM)}

Seeds of 'rapid cycle rape' were double surface sterilized by sequential immersion in $70 \%$ ethanol for $2 \mathrm{~min}$ and subsequently in $1 \%$ sodium hypochlorite containing $0.1 \%$ Tween-20 for $15 \mathrm{~min}$ (44). The sterilized seeds were rinsed three times in sterile tap water before sowing on water agar in $24 \times 24 \mathrm{~cm}$ petri dishes. Autoclaved cellophane membranes (Folia Bringmann, Wendelstein, Germany) were previously placed on the agar to prevent roots growing into the medium, and this allowed easy analysis of the interaction between plant roots and the fungus using CLSM. After five days of incubation in a climate cabinet (settings: 14/10 h (light/dark), $23 / 20{ }^{\circ} \mathrm{C}$ (day/night)), germinated seedlings with a well developed branched root system were treated with a spore suspension $\left(1 \times 10^{6}\right.$ spores $\left.\mathrm{ml}^{-1}\right)$ of $V$. 
longisporum wild type and Vl-NEP-1 knock-down mutants to assess any changes in the ability to enter the roots of B. napus. After 12, 24, 36, 48, 72, 96 and $120 \mathrm{~h}$, two roots were harvested from each approach and used for histological staining prior to CLSM. Staining was performed using a protocol published by Eynck et al. (45). Deviating from this protocol, we dispensed with the use of lactophenol due to the toxicity of the substance. This allowed easy handling of the samples. As a result of the treatment with $0.05 \%$ acid fuchsin, a strong staining of all fungal structures and a weaker staining of plant cell walls was achieved. Microscopic analyses were performed using a Leica TCS SP2-CLSM (Leica, Mannheim, Germany). Digital images were acquired by scanning with settings for acid fuchsin fluorescence (absorption: $543 \mathrm{~nm}$, emission: 560-620 nm).

\section{Purification of Vl-NEP-1 protein using pET21 system}

The Vl-NEP-1 gene was amplified by PCR using primers which amplify the complete exon sequence of the gene (see Table 12 in the Appendix) and ligated into NdeI/BamHI-digested pET21a, resulting in the V1-NEP-1 expression vector, pET21a-Vl-NEP-1 (6.9 kb) including a polyhistidine-tag (his-tag) required for protein-purification. Digestion of vector and insert was performed by incubating the samples along with $5 \mathrm{U} \mathrm{NdeI}$ and $5 \mathrm{U}$ Bam HI for $2 \mathrm{~h}$ at $37{ }^{\circ} \mathrm{C}$. Ligation was performed in a total volume of $20 \mu 1$, containing $5 \mathrm{U}$ of T4-DNA ligase. The reaction mixture was then incubated at $37{ }^{\circ} \mathrm{C}$ for approximately $12 \mathrm{~h}$. Ten $\mu \mathrm{l}$ of the mixture was used for transformation of chemically competent E. coli BL21 cells and plated on lysogeny broth (LB) agar-media containing $50 \mathrm{mg} / \mathrm{ml}^{-1}$ ampicilin for selection of positive transformants. Transformants that were tested positive in PCR were sequenced by 'Eurofins MWG Operon' (Ebersberg, Germany). The protein was over expressed by induction of the lac operon using $1 \mathrm{mM}$ IPTG and subsequently purified. Purification of Vl-NEP-1 protein from bacterial cells was performed using TALON His-Tag Purification Resin (Clontech-Takara Bio Europe, Saint-Germain-en-Laye, France) following the manufacturer's instructions. The protein was concentrated using Sartorious Vivaspin 20 (Sartorius Stedim Biotech GmbH, Göttingen, Germany). 


\section{Sodium dodecyl sulfate poly acrylamide gel electrophoresis (SDS page)}

Tris SDS gradient gels (12-19\%) with a discontinuous buffer system (46) were poured using SG 15 gradient maker (Hoefer Inc., Holliston, USA), Rotiphorese ${ }^{\circledR}$ Gel A (30 \% acrylamide solution) and Rotiphorese ${ }^{\circledR}$ Gel B (2 \% bisacrylamide solution) (both: Roth $\mathrm{GmbH}$, Karlsruhe, Germany) and were polymerised by adding $30 \mu \mathrm{l}$ of a $10 \%$ ammonium persulfate solution and $5 \mu 1$ TEMED. Gels were cast in the multiple gel caster Hoefer SE 215 (Hoefer Inc., Holliston, USA). The stacking gel contained $4 \%$ acrylamide, $0.125 \mathrm{M}$ Tris-HCL, $0.1 \%$ SDS, $0.1 \%$ APS w/v, and $1 \%$ TEMED v/v. Samples were mixed with loading buffer $(12.5 \%$ glycerol, $25 \mathrm{mM}$ Tris, $5 \%$ SDS, $2.5 \%$ Mercaptoethanol and $0.0625 \%$ bromophenol blue) and loaded along with the molecular weight standard Roti®-Mark 10-150 PLUS (Roth $\mathrm{GmbH}$, Karlsruhe, Germany) on the gel. Electrophoresis was conducted at $6 \mathrm{~V} / \mathrm{cm}$ for $90 \mathrm{~min}$ with tris glycine buffer (0.025 M Tris base, $0.192 \mathrm{M}$ glycine, $0.1 \%$ SDS buffer). Gels were stained using silver nitrate according to Blum et al. (47).

\section{Leaf-infiltration assay with Vl-NEP-1 protein}

Seeds of B. napus and N. tabacum were surface sterilized in $70 \%$ ethanol for $15 \mathrm{sec}$ and rinsed three times in sterile tap water before being sown in an autoclaved earth/sand mixture $(3 / 1 \mathrm{v} / \mathrm{v})$. The plants were used after approximately 20 days of growth to allow the purified V1-NEP-1 protein to infiltrate the leaves. Different concentrations of the protein, dissolved in $25 \mathrm{mM}$ HEPES, were infiltrated into abaxial leaf tissue by using $1 \mathrm{ml}$ plastic syringes (Roth, Karlsruhe, Germany). A $25 \mathrm{mM}$ Hepes solution was infiltrated as a negative control. Boilded protein $\left(5 \mathrm{~min}\right.$ at $\left.95^{\circ} \mathrm{C}\right)$ was used as a second negative control. The leaves were photographed $24 \mathrm{~h}$ after infiltration to monitor putative lesion formation.

\section{Seedling growth and root development assay}

The seeds of different ecotypes from A. thaliana and 'rapid cycling rape' were surface sterilized using $70 \%$ ethanol ( $2 \mathrm{~min}), 1 \%$ hypochloride and $0.1 \%$ Triton solution (15 min) and subsequently washed twice with sterile tap water before treatment with the purified protein to assess the effects of V1-NEP-1 protein on plant growth. The seeds were then left to grow on $0.8 \%$ agar (1 \% Sucrose, $0.5 x$ Murashige and Skoog (MS) basal salts) supplemented with different concentrations of purified Vl-NEP-1 protein, and then grown in a growth 
chamber at $23{ }^{\circ} \mathrm{C}$ on a regular cycle including 18 hours daylight. At different time points, plants were monitored to note any changes compared to non-treated plants.

\section{Western hybridization}

Western blotting was used to detect Vl-NEP-1 protein in the supernatant of the $V$. longisporum growth medium, mycelium, and also in the protein samples from the infected plants. Both were extracted using a trichloroacetic acid (TCA)/acetone method. Fungi were grown in erlenmeyer flasks with $10 \mathrm{ml}$ liquid PDB medium inside, inoculated with $1 \times 10^{4}$ spores of $V$. longisporum wild type and Vl-NEP-1 silencing mutants and incubated at $23{ }^{\circ} \mathrm{C}$ for 10 days. Fungal mycelium was harvested and ground to a fine powder using liquid nitrogen. B. napus plants were infected with $V$. longisporum as described on page 68 . Hypocotyl material was harvested after 28 dpi and ground in liquid nitrogen to a fine powder. Sample powders were added to three volumes of a $10 \% \mathrm{TCA} /$ acetone extraction solution and incubated $\mathrm{ON}$ at $-20{ }^{\circ} \mathrm{C}$. After centrifugation $\left(15000 \mathrm{rpm}, 15 \mathrm{~min}, 4{ }^{\circ} \mathrm{C}\right)$, the precipitate was washed three times with acetone. Subsequently, the pellet was dried and dissolved in a solution containing $7 \mathrm{M}$ Urea, $2 \mathrm{M}$ Thiourea and $2 \%$ CHAPS. Protein concentrations were determined by the method of Bradford et al. (48). Then $10 \mu \mathrm{g}$ of total protein was loaded per well on the gel for SDS page. Separated proteins were spotted on a polyvinylidene fluoride (PVDF)-membrane (Roth, Karlsruhe, Germany) using Hoefer TE22 mini-gel tank (Hoefer Inc., Holliston, USA) and Towbin Buffer (Serva Electrophoresis GmbH, Heidelberg, Germany) for electrotransfer at $600 \mathrm{~mA}$ for $1 \mathrm{~h}$. Western hybridization was performed using Vl-NEP-1 polyclonal antiserum (Biogenes $\mathrm{GmbH}$, Berlin, Germany) from rabbit followed by an incubation with goat anti-rabbit IgG horseradish peroxidase conjugate (Sigma-Aldrich Chemie GmbH, Munich, Germany). Immunodetection was performed using CDP-Star from Roche diagnostics (Penzberg, Germany).

\section{Immunofluorescence microscopy}

Seeds of 'rapid cycle rape' were double surface sterilized by sequential immersion in $70 \%$ ethanol for $2 \mathrm{~min}$, and subsequently washed three times in sterile tap water before being sown in an autoclaved earth/sand mixture (3/1 v/v). Plant parts (root, hypocotyl and stem) were harvested at different time points and fixed using $5 \%$ glutaraldehyde solution. Subsequently, 
samples were transferred into a solution of glutaraldehyde and then degassed using a water pump. Fixation using Roti ${ }^{\circledR}-$ Histol and Roti ${ }^{\circledR}-$ Plast (both: Roth, Karlsruhe, Germany) was performed as described in the following table.

\begin{tabular}{|c|c|c|c|}
\hline step & solution & temperature & treatment \\
\hline 1 & PBS & room temperature $(\mathrm{RT})$ & $5 \mathrm{~min}$ \\
\hline 2 & $50 \% \mathrm{EtOH}$ & RT & $30 \mathrm{~min}$ \\
\hline 3 & $70 \% \mathrm{EtOH}$ & RT & $30 \mathrm{~min}$ \\
\hline 4 & $90 \% \mathrm{EtOH}$ & Rt & $30 \mathrm{~min}$ \\
\hline 5 & $96 \% \mathrm{EtOH}$ & $\mathrm{RT}$ & $30 \mathrm{~min}$ \\
\hline 6 & EtOH/Roti ${ }^{\circledR}-H i s t o l ~ 3: 1$ & $\mathrm{RT}$ & $30 \mathrm{~min}$ \\
\hline 7 & EtOH/Roti ${ }^{\circledR}-H i s t o l ~ 1: 1$ & RT & $30 \mathrm{~min}$ \\
\hline 8 & EtOH/Roti ${ }^{\circledR}-$ Histol 1:3 & $\mathrm{RT}$ & $30 \mathrm{~min}$ \\
\hline 9 & Roti ${ }^{\circledR}$-Histol & $\mathrm{RT}$ & $45 \mathrm{~min}$ \\
\hline 10 & Roti ${ }^{\circledR}$-Histol & RT & $45 \mathrm{~min}$ \\
\hline 11 & Roti ${ }^{\circledR}-$ Histol/Roti ${ }^{\circledR}-$ Plast saturated RT & RT & $60 \mathrm{~min}$ \\
\hline 12 & Roti ${ }^{\circledR}$-Histol/Roti ${ }^{\circledR}$-Plast saturated $40^{\circ} \mathrm{C}$ & $40^{\circ} \mathrm{C}$ & $60 \mathrm{~min}$ \\
\hline 13 & Pure melted Roti ${ }^{\circledR}$-Plast & $60{ }^{\circ} \mathrm{C}$ & $\mathrm{ON}$ \\
\hline
\end{tabular}

Table 1: Fixation procedure of plant samples for immunofluorescence microscopy

Samples were embedded in pure paraffin and stored at $4{ }^{\circ} \mathrm{C}$ until use. Prior to microscopy, the embedded samples were cut to 20-30 $\mu$ m thick slices using microtome HM 335 E (Microm International GmbH, Walldorf, Germany) and placed on a 75 x $25 \mathrm{~mm}$ gelatinised microscopy slide at $40{ }^{\circ} \mathrm{C}$. Paraffin was removed from the samples by using Roti ${ }^{\circledR}-$ Histol at RT for 30 min and subsequently washing the samples with different ethanol concentrations $(96 \%, 90 \%$, $70 \%$ and $50 \%$ ) for $5 \mathrm{~min}$. The samples were rinsed in $\mathrm{ddH}_{2} \mathrm{O}$ before the antigen retrieval procedure was carried out. Antigen retrieval was performed following a protocol published by Shi et al. (49) using citrate buffer (0.05\% Tween 20, pH 6.0). Finally the samples were incubated with Vl-NEP-1 polyclonal antiserum and fluorescein isothiocyanate (FITC)labelled antibodies (Sigma-Aldrich Chemie GmbH, Munich, Germany) and trypan blue. We used a laser-scanning microscope Leica DM5000 CS (Leica, Mannheim, Germany) for imaging of the samples (absorption: $488 \mathrm{~nm}$, emission Cy3: 540-590 nm, emission trypan blue: $620-720 \mathrm{~nm})$. 


\section{Statistical analysis}

For statistical analysis and creation of graphs we used the statistical analysis software STATISTICA (StatSoft GmbH, Hamburg, Germany). Data are presented as means \pm standard deviation. Differences of data sets obtained from experiments using $V$. longisporum wild type and silencing mutants were determined using one way analysis of variance (ANOVA) followed by a post hoc test using "Fisher's Least Significant Difference (LSD) test" to show which differences were significant.

\section{RESULTS AND DISCUSSION}

\section{NLP orthologs of $V$. longisporum}

NLPs are widely distributed among microbes reported to be excreted by diverse pathogens and to induce ethylene production and necrosis in dicot plants. All proteins of this family range from 24-35 $\mathrm{kDa}$ in mass and comprise a highly conserved amino acid region, namely a GHRHDWE motif in the centre of the peptide and two to four N-terminal cysteine residues supposed to be relevant for peptide activity. $V$. dahliae and $V$. albo-atrum are closely related species to $V$. longisporum. We inspected the $V$. dahliae genome for NLP genes considering molecular weight, the conserved motif and likelihood of it having a signal peptide. Consequently, we identified eight distinctive sequences (Vd-NEP type A - H) of putative ORFs. Genes were found to be randomly distributed in the $V$. dahliae genome localized on different chromosomes, which makes a co-regulation of the Vd-NEP genes unlikely.

\begin{tabular}{|c|c|c|c|c|c|}
\hline $\begin{array}{c}\text { Vd-NEP } \\
\text { genes }\end{array}$ & Database entry & Putative peptide size & $\begin{array}{c}\text { Chromosomal } \\
\text { locus }\end{array}$ & $\begin{array}{c}\text { Signal } \\
\text { peptide }\end{array}$ & $\begin{array}{c}\text { Cleavage site } \\
(\text { aa }) / \mathrm{p} \text {-value }\end{array}$ \\
\hline type-A & gb: AY524789.1x* & 233 aa / 25,876 Da & $\begin{array}{c}\text { Chromosome 3 } \\
\text { Chromosome 5 }\end{array}$ & YES & $18 / 0.991$ \\
\hline type-B & VDAG_01995.1 & $239 \mathrm{aa} / 25,116 \mathrm{Da}$ & Chromosome 7 & YES & $24 / 0.592$ \\
\hline type-C & VDAG_04550.1 & $256 \mathrm{aa} / 27,358 \mathrm{Da}$ & Chromosome 1 & YES & $20 / 0.962$ \\
\hline type-D & VDAG_03497.1 & $283 \mathrm{aa} / 32,384 \mathrm{Da}$ & Chromosome 6 & YES & $23 / 0.980$ \\
\hline type-E & VDAG_09117.1 & 277 aa / 31,043 Da & Chromosome 4 & YES & $18 / 0.859$ \\
\hline type-F & VDAG_08022.1 & 308 aa / 35,342 Da & Chromosome 2 & YES & $20 / 0.783$ \\
\hline
\end{tabular}




\begin{tabular}{|c|c|c|c|c|c|}
\hline type-G & VDAG_07972.1 & 264 aa / 29,420 Da & Chromosome 2 & YES & $21 / 0.609$ \\
\hline type-H & VDAG_02984.1 & 185 aa / 21,310 Da & Chromosome 3 & NO & - \\
\hline
\end{tabular}

Table 2: Putative NLPs identified in the $V$. dahliae genome

Chromosome locus according to Verticillium genome database information (The Broad Institute Verticillium group database (50)) and from the *NCBI Genbank (51). Signal peptide and cleavage site was predicted by SignalP $3.0(52)$.

Sequence alignment of all identified Vd-NEP genes was done using ClustalWl (53) to show the conserved GHRHDWE motif and cysteine residues.

\begin{tabular}{|c|c|}
\hline EP-A & --LVGSALAQQPP------KVNHDS INPVRD--TLGPNGDMIRKF \\
\hline d-NEP-B & IFSTLASIALVAAGPVSLRA------VVPHDSLNPVTQRVQTGAIGDAIAKF \\
\hline Vd-NEP-C & -MQHTLLSTAALLGALSAVNASPAP------ILRRDIITALP----- \\
\hline Vd-NEP-D & -MPSLRTASFSAVAALLLLPAVIATPLPDTPTTKLIRRDLLQPLG-----GSAW \\
\hline Vd-NEP-E & AVIQARQDDPEN-PPRDF \\
\hline Vd-NEP-F & -MLFLQNIAVVTAMVLSVPSTASVMRRQNNSSRILSESPALEPIVN--GHDFAYYFEVKF \\
\hline Vd-NEP-G & ----MYHKILLVGVLATLTGLTSANDA I PGSAFENSGHEAAIAGAPMYHFGRSWDRKPCY \\
\hline$-\mathrm{NEP}-\mathrm{H}$ & ALVHPSNCSVI \\
\hline
\end{tabular}

Vd-NEP-A Vd-NEP-B Vd-NEP-C Vd-NEP-D Vd-NEP-E Vd-NEP-F Vd-NEP-G

$\begin{array}{lll}\text { QPLLHIAHG-CQPYSAVNTRGEVNAGLQDSGT---TAGGCKETS---KGQTYARSMTLNG } & 99 \\ \text { NPLLHIANG-CQPYTAVNDAGDTSGGLQDSGN---ISAGCRDQS---KGQTYARAKVVNG } & 103 \\ \text { QPILDFDTDGCYNTAAIDPDGNINPGKGATGTP---QGDCRDPPQLENSNVYSRRRCNNG } & 102 \\ \text { CPALDYDTDSCYNTVAISPSGQLNAGQDETKSAGEILGWCRKEVRLQQTNIYVRSRCNNG } & 114 \\ \text { QPALDFDTDSCYNVPAIGPNGDLAIGMFPFEWP--PQAGCRNEEMLDRGNVYSRQRCNNG } & 112 \\ \text { QPLVDFDTDSCYSVPAMTMDGTASEGLSPSD----DVGPCRPRSALDRTNVYVRGRCNRG } & 113 \\ \text { PEAGQTDGVKTDGVDSDLCFSSQNGGCADPGP-----WNGVNSPGNPFPVYYTVRQCNDN } & 111 \\ \text { QPALDFDTDSCYNVPAIGCDGKIAEGLEPDG----TTKDYRDLADLDNTNVYSRQRCNSG } & 114\end{array}$

Vd-NEP-A Vd-NEP-B Vd-NEP-C Vd-NEP-D Vd-NEP-E Vd-NEP-F

Vd-NEP-A Vd-NEP-B

Vd-NEP-C Vd-NEP-D Vd-NEP-E QLAIMYS FYMPKDQPIAGN-VAGGHRHDWENVVVFVDDPAAN--AAPGLLGGAASGHGEY 160 MYEEDQSVSGSF-AGGHI GHRHDWENVVVFARGDTI-----VRVAPSCHGGYDG- 155 HMYDYYFEADFGWG------AHRHDWEHIAVWVQHGQL-----KFVSISQHGKWDIR 163 IFYAYYFQKDTATP----IDGHRHDWEHIAVWVRQSDS---FVTHVAVSQHKGYEIR 165 YYFQMDWAWSWPVSGYNHRHDWEHVVVWAKEGKV-----RGVSVSQHGGYESR 168 EWRVAYS IYYKK--------DSGHKNDWENS IVIWNGDGAGGWKRSGTLLGWHSGWDY I 162 WCAYMYDYYFEKDHAD-----IGAHKHDWEHI IVWVTDDRTK--NKKYACVSQHGEWLCH 167

KKVNNPQRNN-----------------NNLHVEYFTSLGKNHELQFKTSPG------- 189 KKTATPDREG------------------DSVKVEYFTTFPTNHELQFTATTG------- 194 -----ASNEFPADG-------------TSPQMVYHKDSAGTHCFRFANDADIGGVENF 195 ILDGRTAAPRFEHG-------------THPKVVYHKDGALTHAFRWANGGDEP-PENH 207 ENSQVTWTAAEN----------------GKPAIVYHKDSILTHCFRFGNGADAGGPGPE 208 VAEDQRLRFDYTPKEFPYPAWDPMPTSVAMHPKVVFHKDGARTHCFRFAKDSD-DYEGQE 227 AWGDIQNTVNNDGD----------LFDQGAKDRNHAKVYQGFYYHATFSTRKTSLNTC 210

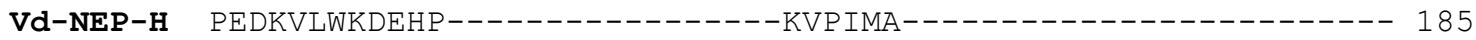

Vd-NEP-A $\mathrm{Vd}-\mathrm{NEP}-\mathrm{B}$ Vd-NEP-C Vd-NEP-D Vd-NEP-E Vd-NEP-F Vd-NEP-G $\mathrm{Vd}-\mathrm{NEP}-\mathrm{H}$

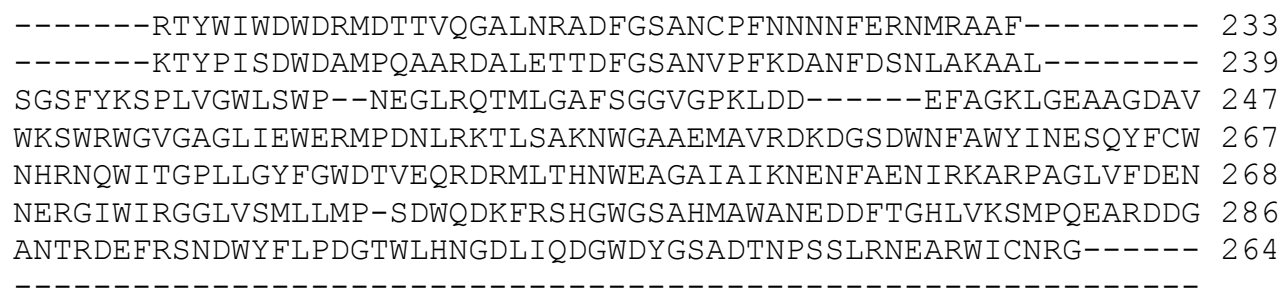




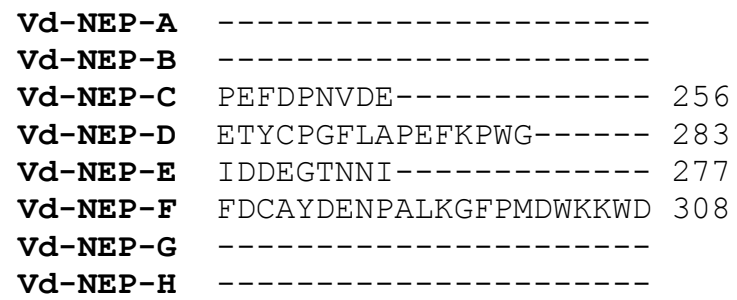

Figure 1: Sequence alignment of putative Vd-NEP genes

Black letters indicate the conserved features GHRHDWE and cysteine residues, grey letters indicate amino acid exchanges in the conserved parts.

To check, whether we could find orthologous genes to Vd-NEP type A- H in the genome of $V$. longisporum, we designed primer oligonucleotides (see Table 6 in the Appendix) derived from the putative NLP gene sequences of $V$. dahliae. The forward primers were localized approximately 100 nucleotides upstream of the putative start, and the reverse primers 100 nucleotides downstream of the putative stop codon to obtain the complete open reading frames (ORFs) by direct sequencing of PCR products amplified from gDNA of $V$. longisporum. PCR fragments were sequenced (Eurofins MWG Operon, Ebersberg, Germany) using the amplification primers. We succeeded in amplification of PCR-products either directly using gDNA of $V$. longisporum or by the use of a constructed genomic library of $V$. longisporum. The genomic library of $V$. longisporum was also utilized to identify clones for sequencing that carried a genomic fragment including a NLP gene. It did this by applying the same pairs of primers used for direct amplification. All amplicons were sequenced to prove homology to their corresponding Vd-NEP gene orthologs. Subsequently, specific primers for the Vl-NEP genes (Vl-NEP-1 -5) were designed. The sequence alignments of all identified Vl-NEP genes are given below.

\begin{tabular}{|c|c|}
\hline $1-N E P-1$ & -MLPSTIFSVFALVGSALAQHPPKVNHDSINPVRDTLGPNG--------DMIRKFQPL \\
\hline $\mathrm{V} 1-\mathrm{NEP}-2$ & ---MQHTLLSTAALLGALSAVNASP---APILRRDIITALPG-----SADEIENKFQPI \\
\hline $11-\mathrm{NEP}-3$ & -MLFSVGLLALAALPSSFGAVIQARQDDPENPPRDPQPPPPGPI-FGRAP \\
\hline VI-NEP-4 & ILSLRNIAVVTAMVLSVPSTASVMRRQSNSSRILSDSQALEPIVGGHDFAY \\
\hline VI-NEP-5 & --- MYHKILLVGVLATLTGLTSANDAIPGSAFEN \\
\hline $1-\mathrm{NEP}-1$ & DSGTTAGGCKETS---KGQTYARS \\
\hline $1-\mathrm{NEP}-2$ & TGTPQGDCRDPPQLENS \\
\hline T1-NEP-3 & DFDTDSCYNVP \\
\hline T1-NEP-4 & VDIDTDSC \\
\hline $\mathrm{V} 1-\mathrm{NEP}-5$ & PEAGQTDG̈VKTDGVDSDLCFSSQNGGCADPGPWNG̈VNSPGNPFPVYYTVRQCNDNEW̄RVA \\
\hline $1-N E P-1$ & YAWYV \\
\hline $1-N E P-2$ & $\mathrm{~N}-\mathrm{VV}$ \\
\hline T1-NEP-3 & -SFVTHVAVSQH \\
\hline $1-N E P-4$ & AWSWPVSSYNHR \\
\hline $1-N E P-5$ & GTLLGWF \\
\hline
\end{tabular}



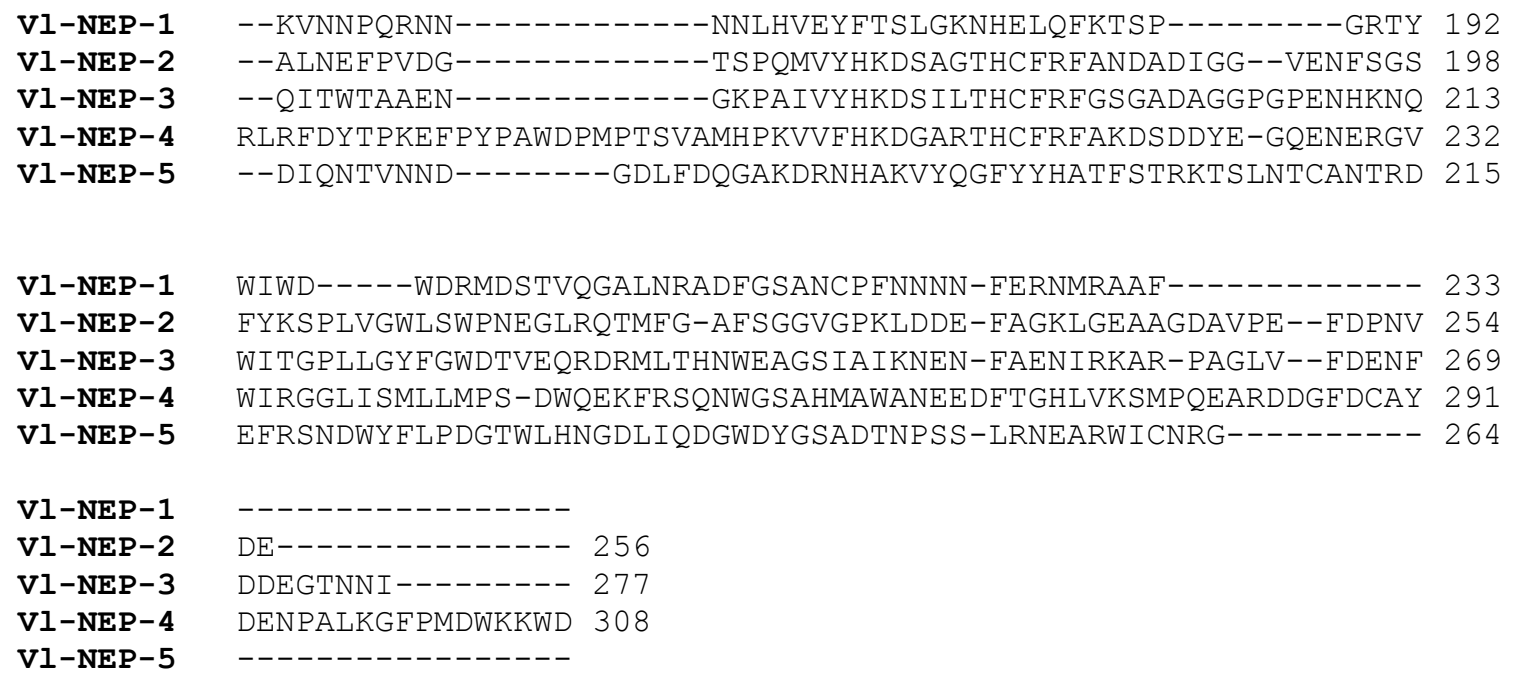

\section{Figure 2: Sequence alignment of Vl-NEP orthologs}

Black letters indicate the GHRHDWE motif and cysteine residues, grey letters indicate amino acid exchanges in the conserved parts.

The deduced protein sequences were multiply aligned showing the conserved domains of the cysteine residues and the GHRHDWE motif. According to the definition of Gijzen and Nürnberger (54) the identified Vl-NEP orthologs can be subdivided into type I NLPs harbouring two conserved C-residues including Vl-NEP-1, which is the ortholog of Vd-NEPA, and type II with 4 C-residues including Vl-NEP-2 (ortholog of Vd-NEP-C), Vl-NEP-3 (ortholog of Vd-NEP-E), and V1-NEP-4 (ortholog of Vd-NEP-F). Comparable to Vd-NEP-G, which is the ortholog from $V$. dahliae, V1-NEP-5 only harbours one conserved cysteine residue and is therefore not classifiable. Sequence alignments of corresponding orthologs for one NLP gene of $V$. dahliae and $V$. longisporum are given in the following.

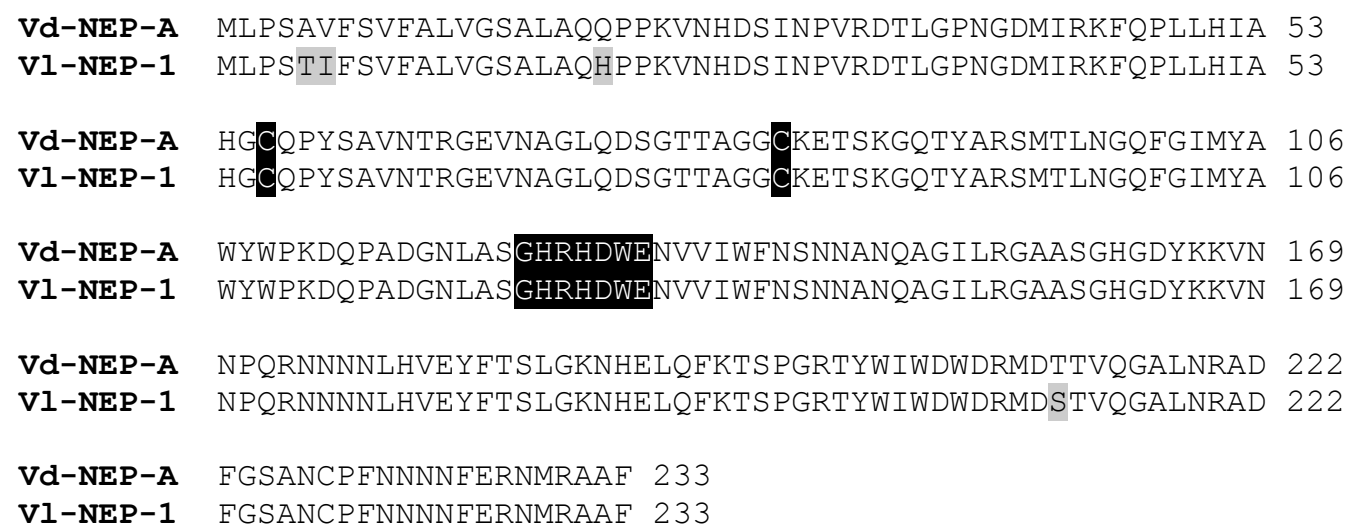

Figure 3: Sequence alignment of Vd-NEP-A with Vl-NEP ortholog 
Black letters indicate the conserved GHRHDWE motif and cysteine residues, grey letters indicate amino acid exchanges in the $V$. longisporum sequence compared to the $V$. dahliae sequence.

The identity of both proteins is equal except for four amino acids. Sequence properties for all identified Vl-NEP genes including ORF/protein size, molecular weight of the protein, intron positions and the calculated protein identities to corresponding NLPs of $V$. dahliae and $V$. albo-atrum are given in the following table.

\begin{tabular}{|c|c|c|c|c|c|c|}
\hline Ortholog & $\begin{array}{c}\text { ORF } \\
\text { (nt) }\end{array}$ & $\begin{array}{c}\text { Protein } \\
\text { size (aa) }\end{array}$ & $\begin{array}{c}\text { Molecular weight } \\
(\mathrm{Da})\end{array}$ & $\begin{array}{c}\text { Intron } \\
\text { positions }\end{array}$ & $\begin{array}{c}\text { aa sequence identity to } \\
\text { V. dahliae }\end{array}$ & $\begin{array}{c}\text { aa sequence identity } \\
\text { to } \text {. albo-atrum }\end{array}$ \\
\hline Vl-NEP-1 & 760 & 233 & 25,986 & $207-267$ & $229 / 233(98 \%)^{*}$ & $224 / 233(96 \%)$ \\
\hline V1-NEP-2 & 831 & 256 & 27,361 & $321-380$ & $251 / 256(98 \%)$ & $234 / 267(88 \%)$ \\
\hline Vl-NEP-3 & 834 & 277 & 31,040 & - & $262 / 283(93 \%)$ & $269 / 277(97 \%)$ \\
\hline Vl-NEP-4 & 927 & 308 & 35,327 & - & $292 / 308(95 \%)$ & $283 / 296(96 \%)$ \\
\hline & & & & $92-149$ & & \\
Vl-NEP-5 & 970 & 264 & 29,420 & $577-631$ & $264 / 264(100 \%)$ & $185 / 295(63 \%)$ \\
& & & & $829-890$ & & \\
\hline
\end{tabular}

\section{Table 3: Sequence properties of Vl-NEP orthologs}

Protein sequence of $V$. dahliae and $V$. albo-atrum for identity scoring were downloaded from the genome sequence database (The Broad Institute, Verticillium group database), except the protein sequence of the $V$. dahliae gene homologous to Vl-NEP 1 which was downloaded from the *NCBI database'. Molecular weight was calculated using the Peptide Property Calculator (http://www.basicnorthwestern.edu/biotools /proteincalc.html). Introns were determined by sequencing of corresponding cDNA.

We calculated identity scores by pairwise alignments among all Vl-NEP types. A redundant gene function of several homologs was not assumed due to the low sequence identities among Vl-NEP genes.

\begin{tabular}{|c|c|c|c|c|}
\hline & Vl-NEP-2 & Vl-NEP-3 & Vl-NEP-4 & V1-NEP-5 \\
\hline Vl-NEP-1 & $27.8 \%$ & $24.0 \%$ & $19.9 \%$ & $17.5 \%$ \\
\hline V1-NEP-2 & - & $35.6 \%$ & $32.0 \%$ & $20.6 \%$ \\
\hline V1-NEP-3 & - & - & $32.2 \%$ & $17.6 \%$ \\
\hline Vl-NEP-4 & - & - & - & $18.8 \%$ \\
\hline
\end{tabular}

Table 4: Sequence identity among Vl-NEP orthologs

Alignment and identity scoring was performed using the Global Pairwise Alignment Algorithm, EMBOSS (55). 
The rising numbers for the genome sequence release of microbes revealed a varying number of NLP gene copies in different organisms, a single Mg-NLP copy in Mycosphaerella graminicola (56), two copies of NEP-1 and -2 in Botrytis spp. (24) and multi-copied NPP genes in the oomycete genera Pythium and Phytophthora (23). In Botrytis spp. the presence of two NLP gene copies may have adaptive significance and some evolutionary changes in NLP genes are presumably driven by positive selection (24). A phylogenetic tree showing the inferred evolutionary relationships among various biological species of protein alignments of all Vl-NEPs, including several ascomycetes, five oomycetes and nine bacteria, was created using the bottom-up clustering neighbour-joining method (57).

The phylogram (see page 81) shows that the Vl-NEPs are subdivided into four distinctive clades. V1-NEP-1 was found to be clustered in the largest group (C), exclusively representing the oomycete sequences, but also including ascomycota, and bacilli. V1-NEP-2 and Vl-NEP-5 were both clustered in small groups $(\mathrm{B}, \mathrm{E})$ consisting only of ascomycota representatives. V1NEP-3 and Vl-NEP-4 built up a common cluster (A) including ascomycota and bacteria of the genus Bacillus, Streptomyces and Micromonospora. 


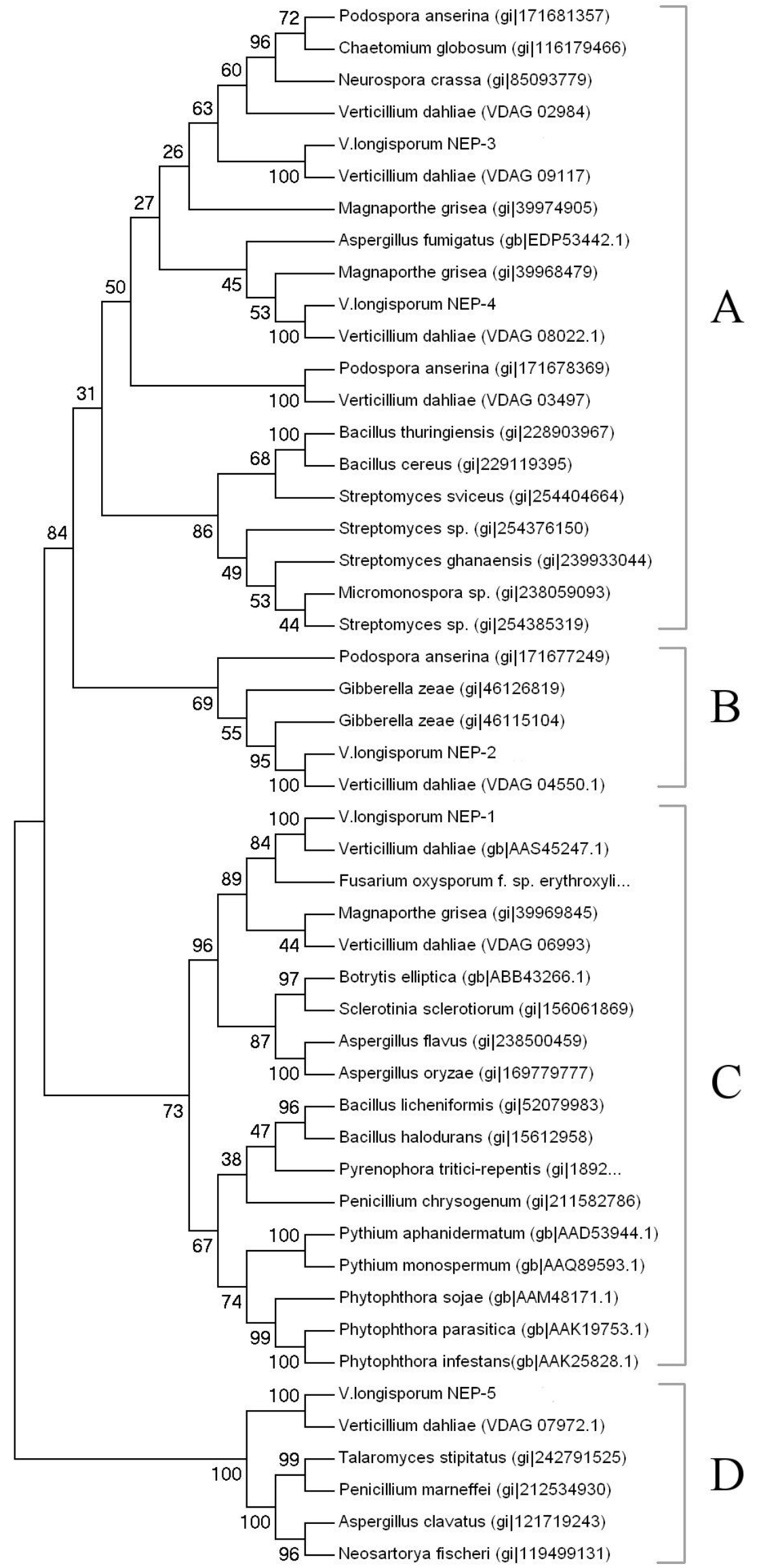

Figure 4: Phylogenetic relationship of microbial NLP orthologs

An evolutionary tree of 49 taxa in NLP orthologs is given. The evolutionary history was inferred using the Neighbour-Joining method. The optimal tree with the sum of branch length = 10.46564852 is shown. The percentage of replicate trees in which the associated taxa clustered together in the bootstrap test $(1000$ replicates) is shown next to the branches (58). The evolutionary distances were computed using the Poisson correction method (59) and are in the units of the number of amino acid substitutions per site. All positions containing gaps and missing data were eliminated from the dataset (Complete deletion option). There were a total of 100 positions in the final dataset. Phylogenetic analyses were conducted in MEGA4 (60). Four distinct clades of relations (A-D) were identified. 


\section{Expression of Vl-NEP orthologs}

Expression levels of the five identified Vl-NEP genes were measured by qRT-PCR using gene specific primers (see Table 7 in the Appendix). For normalization of expression levels, the housekeeping gene $\beta$-tubulin was used. We determined the expression of Vl-NEP genes under in vitro conditions of mycelium grown for 10 days in artificial simulating xylem (SXM) medium in standing cultures with $12 \mathrm{~h}$ day/night change. The SXM medium simulated the basic nutritional condition of a xylem environment (61). Secondly we measured the expression levels of these Vl-NEP genes in B. napus plant samples root-infected with $V$. longisporum and grown under climate chamber conditions. The Vl-NEP transcripts were quantified in hypocotyl/root mixed samples at 14, 21, 28 and 35 dpi. Figure 5 shows the time course of $\log _{2}$ relative expression values of the Vl-NEP genes in planta given in relation to the measured in vitro expression levels.

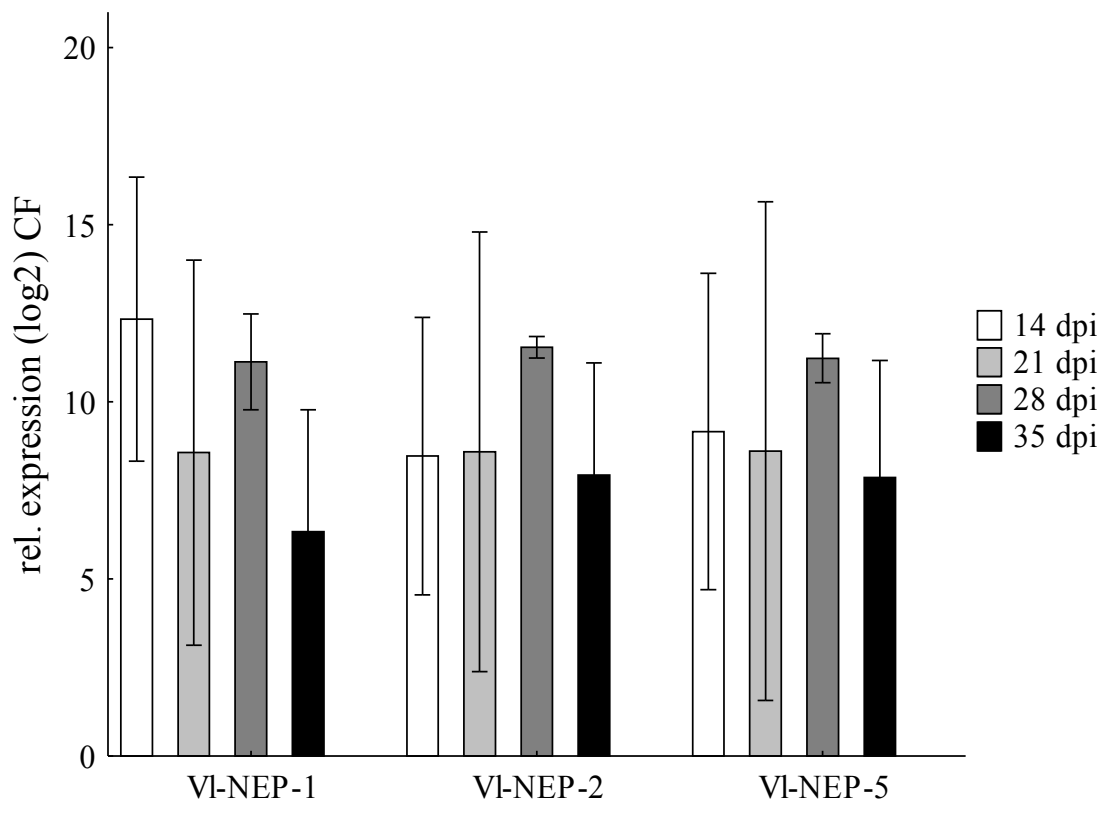

\section{Figure 5: Gene expression analysis of Vl-NEP orthologs}

Error bars indicate the standard error of 3 biological replicas.

We were able to detect transcripts of Vl-NEP-1, Vl-NEP-2, and Vl-NEP-5 in vitro by qRTPCR as well as in samples of infected plants. V1-NEP-3 and Vl-NEP-4 were neither detected in vitro nor in planta, even with the gene specific primers we used for reverse transcriptation of RNA prior to qRT-PCR. We postulate that these genes may be pseudogenes, as reported for many other organisms comprising several NLP genes $(62,54,63)$. For all three expressed 
Vl-NEP genes (Vl-NEP-1, -2, -5) significant higher expression levels were found in the analysed time points of infection than in SXM cultured $V$. longisporum samples. We have chosen Vl-NEP-1 for further analysis because its orthologs from other fungi have been described to show effects of necrosis, cell death and activation of plant defence on hosts (19, $31,32)$.

\section{Gene silencing of Vl-NEP-1}

In general, NEP-encoding genes are found in single copy, and in two and four copies. The highest numbers of copies were identified in P. aphanidermatum and in P. parasitica, respectively $(19,32)$. The species $V$. longisporum is described as being near-diploid (64) as a result of a parasexual event of parental $V$. dahliae and $V$. albo-atrum (65); therefore $V$. longisporum probably possesses two copies of the V1-NEP-1 gene in the genome. By southern hybridisation using a PCR amplified digoxigenin-labeled hybridization probe specific for V1NEP-1 (primers see Table 8 in the Appendix), two copies of the Vl-NEP-1 gene were detected in the $V$. longisporum genome which confirmed the diploidy of Vl-NEP-1 in the genome of amphihaploid $V$. longisporum (data not shown).

Because phenotypic effects determined by Vl-NEP-1 are likely to be genetically dominant and cannot be eliminated by a single mutation event, and the generation of homozygous VlNEP-1 mutants by crossing of $V$. longisporum is not available, a strategy based on RNAimediated post-transcriptional gene silencing was chosen for the inactivation of V1-NEP-1 in $V$. longisporum. For gene silencing, a V1-NEP-1 gene sequence-specific double stranded HPfragment was constructed because in recent studies its use was demonstrated to be the most effective strategy for triggering RNAi in fungi $(66,67)$. The fungus was transformed with the pPK2-V1-NEP-1 vector carrying the HP-fragment using AMT to allow intracellular overexpression of a Vl-NEP-1 silencing cassette forming an HP-structure triggering RNAi in the fungus. 


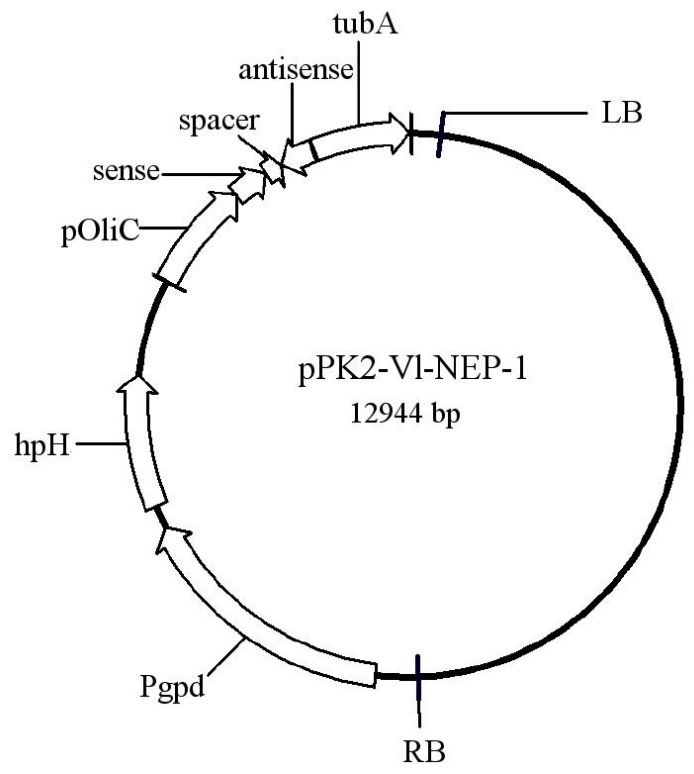

Figure 6: Physical map of binary vector constructed for HP-RNA expression of Vl-NEP-1

pPK2-HP vector comprising left (LB) and right boarder (RB) for the AMT and a hygromycin B resistance cassette $(\mathrm{hpH})$ under the control of constitutive promoter from A. nidulans (Pgpd) for the selection of transformants; included HP cassette comprises oliC promoter from $A$. nidulans and tubA terminator from $B$. cinerea

Seven positive transformants $(\mathrm{m} 4, \mathrm{~m} 9, \mathrm{~m} 10, \mathrm{~m} 11, \mathrm{~m} 16, \mathrm{~m} 19, \mathrm{~m} 23)$ were identified on a hygromycin-selective medium and checked by PCR and southern hybridization for the success of transformation. PCR analysis was performed using gDNA extracted from $V$. longisporum mutants as a template, and using primers for the amplification of the hygromycin cassette. Additionally, southern hybridisation was performed to determine the number of V1NEP-1 gene copies in the transformed mutants compared to the wild type $V$. longisporum strain.
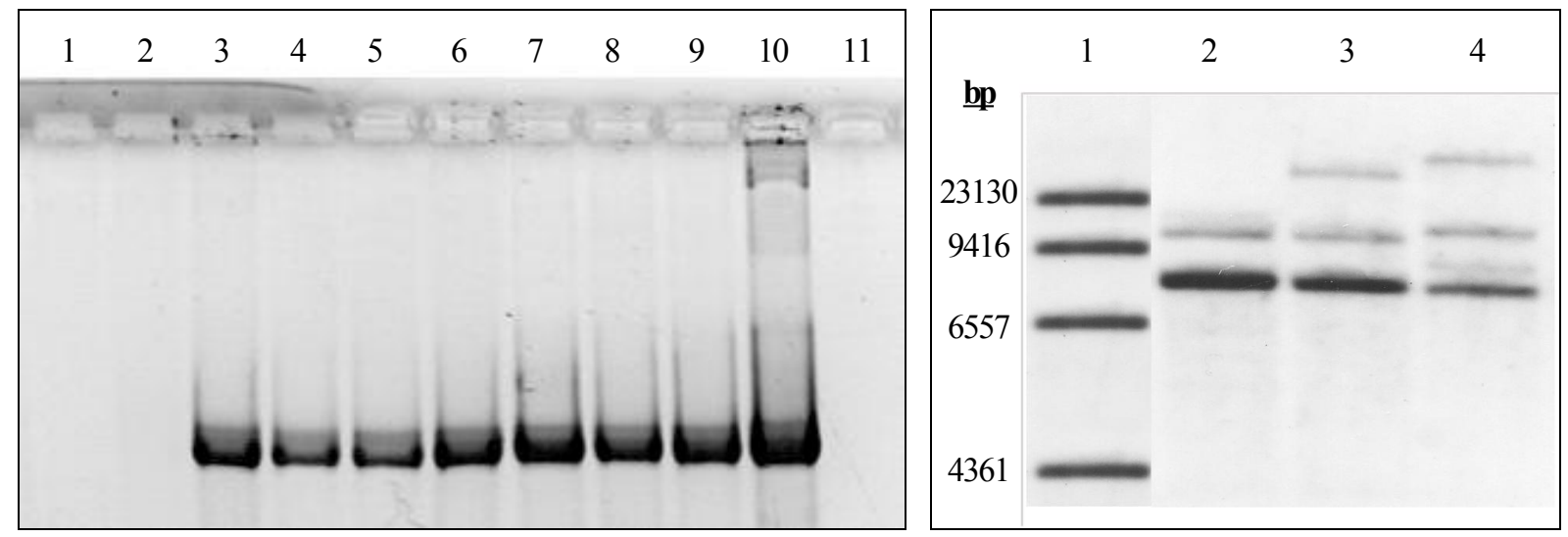

Figure 7-8: Analysis of $V$. longisporum Vl-NEP-1 transformants

Figure 7 (left side): PCR analysis using primers for the amplification of the hygromycin cassette.

1-2 = wild type $\quad 3-9=$ Vl-NEP-1 mutants $\quad \mathbf{1 0}=$ positive control $\quad \mathbf{1 1}=$ negative control

Figure 8 (right side): Southern hybridisation of $V$. longisporum Vl-NEP-1 transformants (gDNA cut with $N c o l$ ) $\mathbf{1}=$ self-made DNA-ladder comprising incorporated DIG-dUTPs $\mathbf{2}=$ wild type $\mathbf{3}=$ Vl-NEP mutant $19 \mathbf{4}=\mathrm{m} 23$ 
All tested mutants showed a positive signal on the agarose gel after electrophoresis. Southern hybridisation of mutants $\mathrm{m} 19$ and $\mathrm{m} 23$ using a probe, amplified with primers for a V1-NEP-1fragment, detected an additional third signal accompanying the insertion of the HP-fragment into the genome of the fungus.

To assess the efficiency of silencing, all mutants were cultivated in SXM liquid medium for 10 days. RNA was extracted and used for qRT-PCR to measure the transcript accumulation of Vl-NEP-1 mutants in comparison to $V$. longisporum wild types.

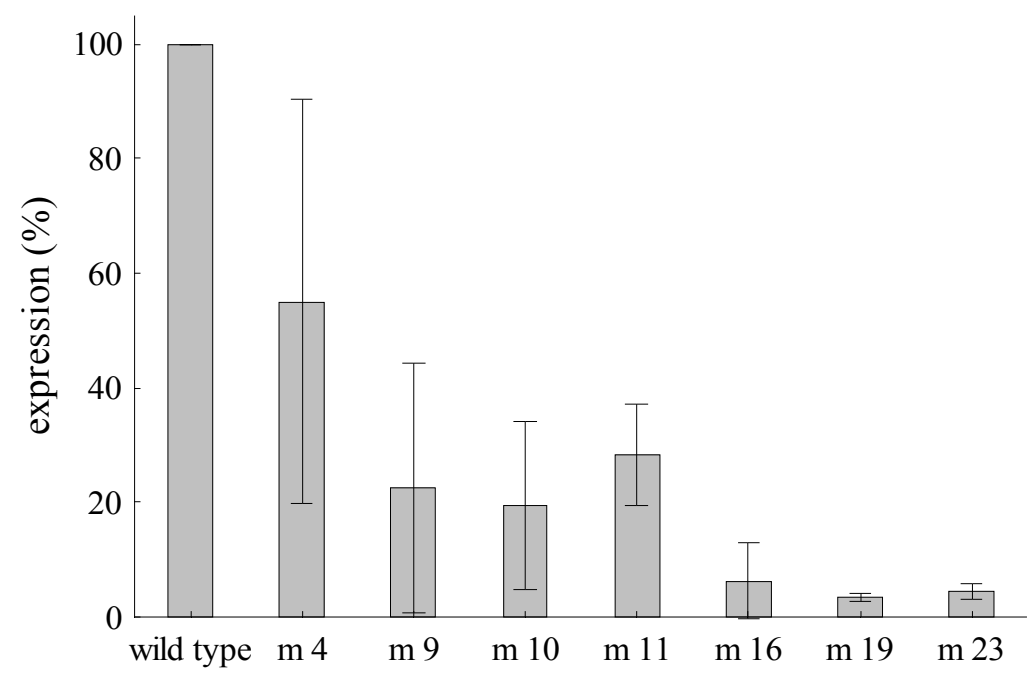

Figure 9: Gene silencing efficiency in Vl-NEP-1 transformants

Assessment of silencing efficiency in seven mutants (m4, m9, m10, $\mathrm{m} 11, \mathrm{~m} 16, \mathrm{~m} 19$, and $\mathrm{m} 23)$ were done in reference to wild type $V$. longisporum by qRT-PCR

Expression of the Vl-NEP-1 gene was shown to be reduced in a range between 47 to $98 \%$ in Vl-NEP-1 silencing mutants as compared to the expression in $V$. longisporum wild type. As proven by qRT-PCR, Vl-NEP-2 and 5, which are also expressed by $V$. longisporum wild type in Brassica plants, were not silenced by the expression of Vl-NEP-1 specific HP cassette in generated mutants (data not shown); therefore all phenotypic effects should be linked to V1NEP-1 gene suppression.

All transformants were grown in vitro on PDA plates to evaluate any ectopic effects on the growth rate and spore germination efficiency in comparison to the wild type by random integration of the silencing cassette into the fungal genome. Single spores of $V$. longisporum 
wild type and of each transformant were plated three times, and growth rates were measured every second day for 14 days. For the evaluation of the spore germination rate of $V$. longisporum wild type and the transformants, 50 spores were plated three times, as estimated by a Thoma hemacytometer. The number of fungal colonies was counted after five days of cultivation. For both growth rate and spore germination efficiency, no difference was detected in any transformant regarding the wild type of $V$. longisporum (data not shown), thus we selected two transformants, $\mathrm{m} 19$ and $\mathrm{m} 23$, which showed strong silencing efficiency, to test for pathogenicity in B. napus plants.

\section{Plant pathogenicity assay using Vl-NEP-1 silencing mutants}

NLPs are known to be involved in infection processes of plant pathogenic microbes supposed to act as elicitors or phytotoxins. In several pathosystems, activation of plant defence mechanisms was shown, while purified NLPs infiltrated into plant tissue can trigger diseaselike symptoms. Vl-NEP-1 is also supposed to play an active role in the pathogenesis of $V$. longisporum during infection of the host plant B. napus, as indicated by strong upregulation of Vl-NEP-1 gene expression as shown previously (see Figure 5). To investigate the significance of Vl-NEP-1 during the pathogenesis and symptom development we infected rape plants with $V$. longisporum wild type and with the two V1-NEP-1 knock-down mutants, $\mathrm{m} 19$ and $\mathrm{m} 23$. Symptoms were evaluated by measuring the plant shoot lengths and by the assessment using a disease score according to Zeise et al. (40).

\begin{tabular}{|c|l|}
\hline Disease score & Disease symptoms \\
\hline 1 & no symptoms \\
\hline 2 & slight symptoms on the oldest leaf (yellowing, black veins) \\
\hline 3 & slight symptoms on the next youngest leaves \\
\hline 4 & about $50 \%$ of the leaves show symptoms \\
\hline 5 & more than $50 \%$ of the leaves show symptoms \\
\hline 6 & up to $50 \%$ of the leaves are dead \\
\hline 7 & more than $50 \%$ of the leaves are dead \\
\hline 8 & only apical meristem is still alive \\
\hline 9 & the plant is dead \\
\hline
\end{tabular}

Table 5: Disease score according to Zeise et al. 


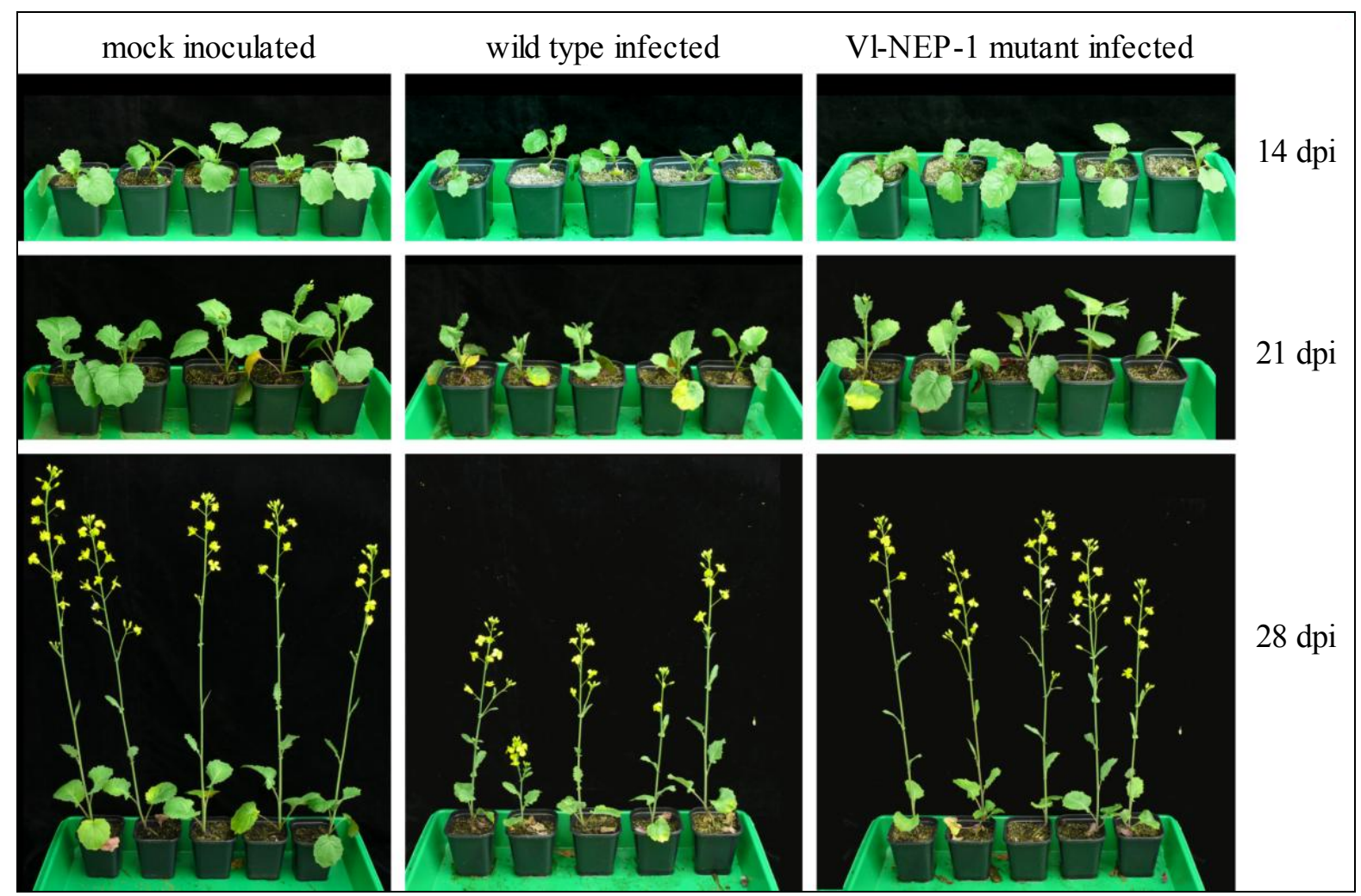

Figure 10: B. napus pathogenicity assay with Vl-NEP-1 silenced $V$. longisporum

Photography of mock, wild type, and m23 inoculated plants at time points 14, 21, and 28 dpi.

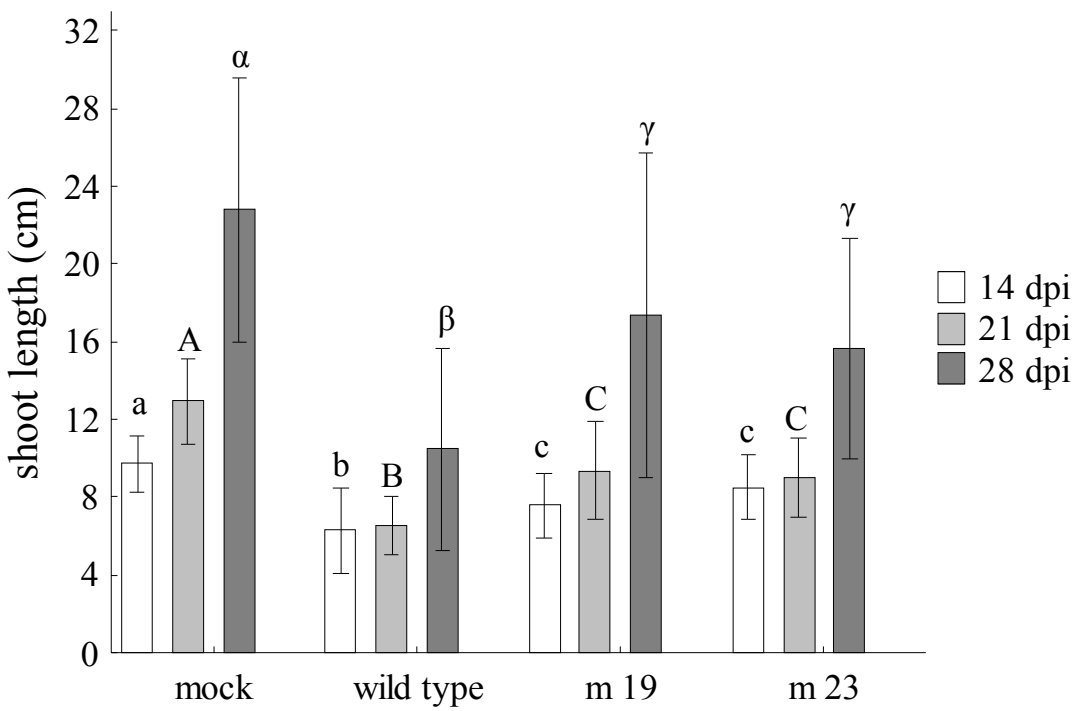

Figure 11: Measured shoot length of Brassica plants non-inoculated, wild type inoculated, m19, and m23 inoculated at 14, 21, and 28 dpi.

Applies for all following figures: Values marked by the same letter over the bars do not differ on a significance level of $p \leq 0.05$ (LSD). 


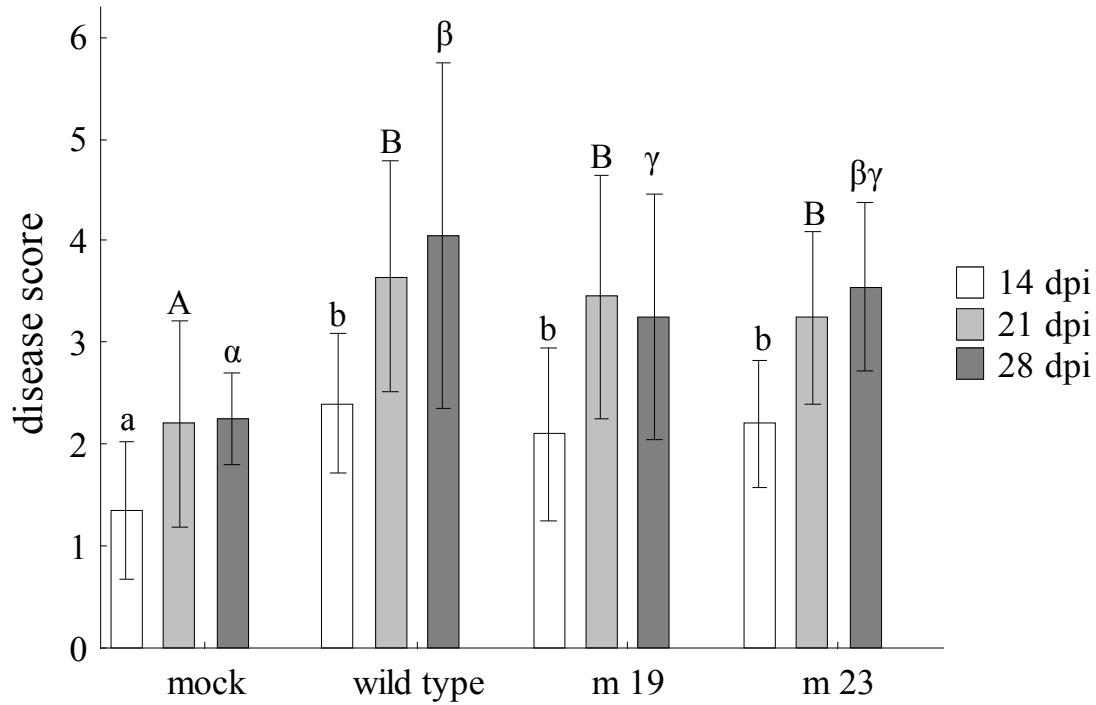

Figure 12: Disease scores of plants according to Zeise.

After 14 dpi a reduction in symptom severity was initially observed regarding the Vl-NEP-1 mutants compared to the wild type infected plants. The altered phenotype became significant at 21 dpi and 28 dpi for both Vl-NEP-1 mutants $\mathrm{m} 19$ and $\mathrm{m} 23$. Plants infected with the mutants showed less stunting and lower disease scoring than wild type infected Brassica plants. Infection assays were conducted four times, each with the same results. A plant pathogenicity assay on $A$. thaliana using Vl-NEP-1 silencing mutants was performed by the 'Department of General and Developmental Plant Physiology' (Albrecht von Haller Institute for Plant Sciences, University of Goettingen, Goettingen, Germany). No changes in symptom severity were observed during this experiment. We clearly proved that the inoculum, containing $1 \times 10^{6} \mathrm{ml}^{-1}$ fungal spores for the plant infection, indeed comprises the same number of spores for both wild type and Vl-NEP-1 mutants. We obtained this proof by plating the solutions on PDA plates and counting the germinated spores after five days of incubation at $23{ }^{\circ} \mathrm{C}$. Slight deviations were negligible due to the fact that the symptom severity caused by the infection with $V$. longisporum was consistently in a range between $1 \times 10^{5} \mathrm{ml}^{-1}$ to $1 \times 10^{7}$ $\mathrm{ml}^{-1}$, as proven by plant infection assays using different spore-concentrations (data not shown). We also proved that the reduced symptom severity was not connected to a potential disruption of a non-specific anonymous gene because of the the random insertion of Vl-NEP1 silencing cassettes by AMT. This proof was obtained by using several silencing mutants in a first pathogenicity assay on $B$. napus to exclude any effects not related to Vl-NEP-1 
disruption. Additionally, mutants did not show any changes in the ability to grow or in the ability to sporulate compared to the wild type

We measured the amount of Verticillium-DNA in the infected Brassica plants by qPCR to find out if the reduction in symptom development, compared to wild type infection, while undergoing Brassica-infection with V1-NEP-1 mutants was due to a reduction of fungal DNA in the plant. Therefore, the biomass of $V$. longisporum wild type strain and V1-NEP-1 silenced mutants $\mathrm{m} 19$ and $\mathrm{m} 23$ were measured using gDNA extracts from root-inoculated B. napus plants by qPCR analysis. The cT values of the qPCR were recorded from $100 \mathrm{mg}$ of hypocotyl tissue and the DNA quantity was derived from a linear correlation curve constructed with a $V$. longisporum DNA concentration series. The fungal biomass was measured at time points 14,21 , and 28 dpi.

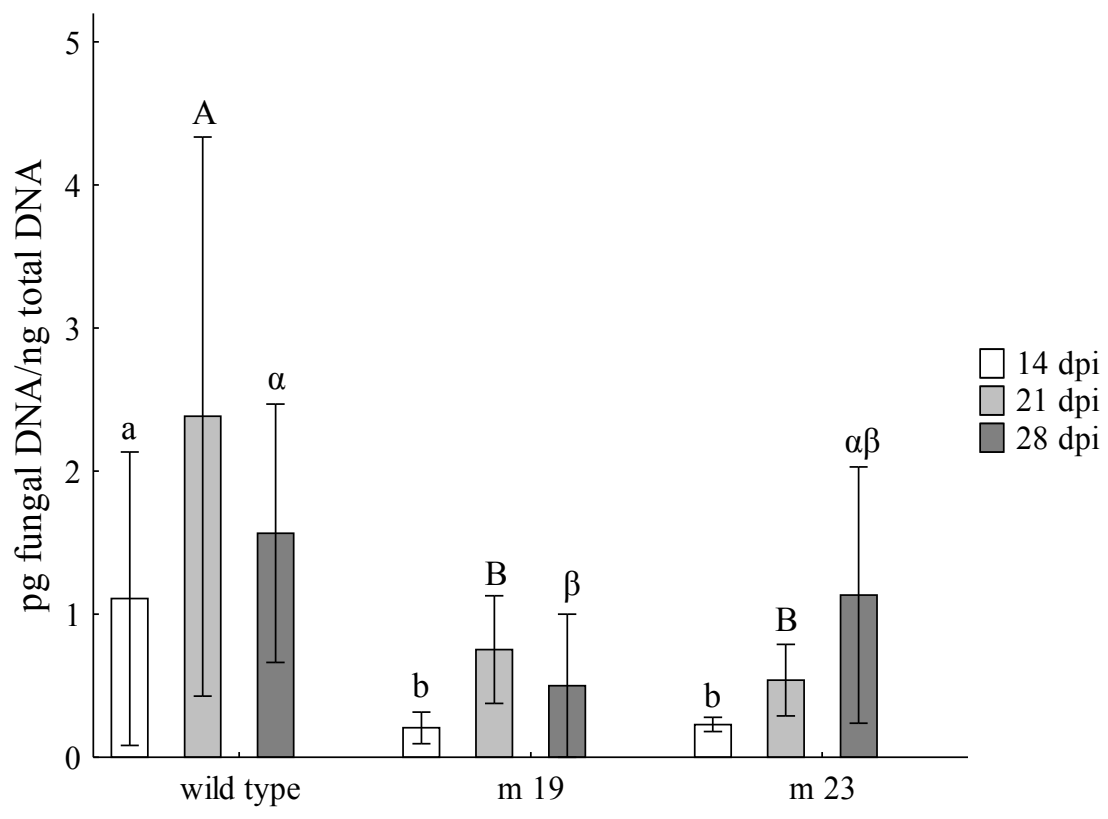

Figure 13: V. longisporum biomass in hypocotyl tissue of inoculated B. napus plants

Each sample included three biological replicas. Error bars indicate the standard deviation.

The biomass of the Vl-NEP-1 mutants $\mathrm{m} 19$ and $\mathrm{m} 23$ was significantly less than in the wild type infected Brassica plants after 14 dpi and 21 dpi in the hypocotyl. At 28 dpi, levels of fungal biomass in the wild type and in the mutant $\mathrm{m} 23$ were similar, but for the mutant $\mathrm{m} 19$ still lower levels were measured. To investigate whether reduced fungal DNA in the plants infected with silencing mutants compared to wild type infected plants was due to a hampered 
ability of Vl-NEP-1 silencing mutants to enter the plant over the roots of B. napus, we used CLSM using the conventional fluorescence dye acid fuchsin. Infection status was observed every 12 hours for five days.
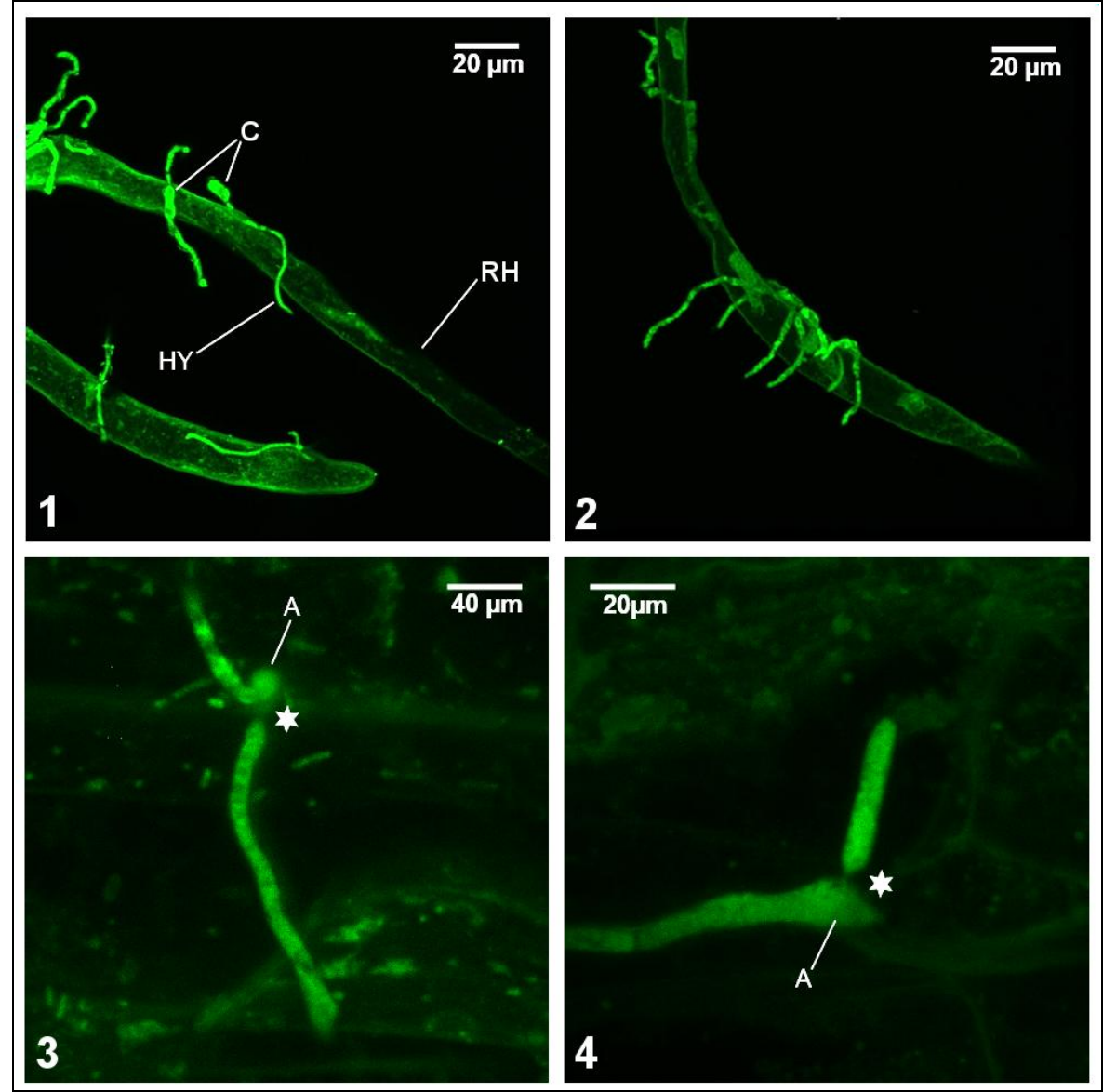

Figure 14: CLSM images of wild type and Vl-NEP-1 silencing mutants infected plants

( $\mathrm{RH}=$ root hair; $\mathrm{C}=$ conidia; $\mathrm{HY}=$ hyphae; $\mathrm{A}=$ appressoria-like formation; stars = penetration point)

$\mathbf{1}=$ wild type infected, $12 \mathrm{hpi}$

$2=$ Vl-NEP-1 mutant infected, 12 hpi

$\mathbf{3}=$ wild type infected, $72 \mathrm{hpi}$

$4=$ Vl-NEP-1 mutant infected, 72 hpi

After 12 hpi, the fungal spores of wild type and silencing mutants had both visibly germinated (see Figure 14-1 and -2). In addition to the primary germination tube with an approximate length of 50 to $200 \mu \mathrm{m}$, a secondary tube formed on the opposite side of the spore. After 24 hpi, all grown hyphae expanded in the direction of the lateral roots along the root hairs. After 36 hpi, the hyphae built a dense grid around the root hairs and came into contact with the root cortex but no penetration of the cell wall could be observed. After 72 hpi to 120 hpi, the whole root surface was covered with hyphae (see Figure 15-1 and -2) and first started to 
penetrate into the epidermal cells of the root-cortx (see Figure 15-3 and -4). Apressoria-like structures were observed at the penetration points of the hyphae.
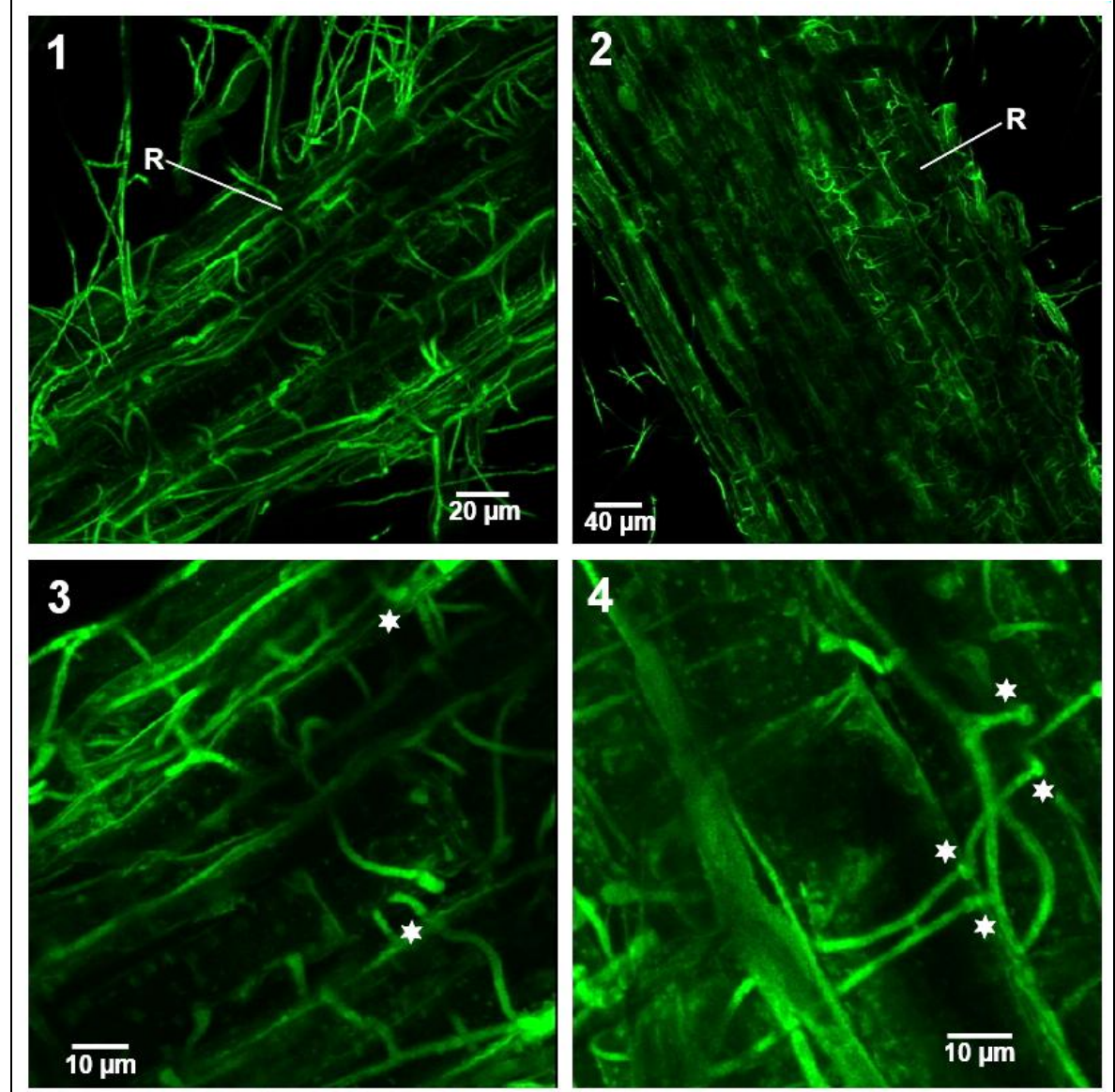

Figure 15: CLSM images of wild type and Vl-NEP-1 silencing mutants infected plants

$(R=$ root; stars = penetration point $)$

$\mathbf{1}=$ wild type infected, $120 \mathrm{hpi}$

2 = wild type infected, $120 \mathrm{hpi}$

3 = Vl-NEP-1 mutant infected, 120 hpi

4 = Vl-NEP-1 mutant infected, 120 hpi

After 120 hpi, hyphae propagated in the epidermal cells by penetrating several cell walls (see Figure 15-3 and -4). The hyphae spread in the direction of the vessel system by wrecking several cell layers. The xylem was not colonized at this stage. For all microscopic examinations, there was no evident difference visible between infection structures or speed of infection in plants infected with wild type strain and the silencing mutants of $V$. longisporum.

Nevertheless, $V$. longisporum mutants $\mathrm{m} 19$ and $\mathrm{m} 23$ showed high gene silencing efficiency of Vl-NEP-1, which correlated with a significant reduction of stunting on B. napus plants after root inoculation. Consistent with the reduced stunting effect on B. napus plants, the fungal 
biomass, quantified by qPCR, was lower in the plants infected with the silencing mutants compared to the wild type infected. This resulted in the hypothesis that Vl-NEP-1 must have a influential exercise on the fitness of the fungus in the xylem, and silencing of the gene leads to decreased growth and fungal-spreading in the plant. Therefore, the influence of V1-NEP-1 will be determined by further experiments. In previous studies it was reported that NLPs of different plant pathogens are able to activate patterns of innate plant immunity including defence mechanisms regulated by the phytohormone salicylic acid (SA). To investigate whether the gene silencing of Vl-NEP-1 has an impact on phytohormone-regulated plant defence in $B$. napus, we measured the efficiency of the $V$. longisporum wild type strain and the silenced mutants $\mathrm{m} 19$ and $\mathrm{m} 23$ in inducing hormone signalling pathways.

\section{Effects on phytohormone level}

The plant hormones jasmonic acid (JA), SA and ethylene have been implicated in various aspects of plant disease resistance signalling (68). Therefore, we measured the ability of the $V$. longisporum wild type strain and the silencing mutants $\mathrm{m} 19$ and $\mathrm{m} 23$ to induce the production of the phytohormones JA, SA, salicylic acid glycoside (SAG) and further abscisic acid (ABA), and auxin (IAA) during infection of B. napus. Ethylene production after Verticillium infection was shown to be associated with the development of disease symptoms in host plants, and was also found to be involved in resistance of A. thaliana against the fungus $(13,75,76)$. One of the eponymous features of NLPs, its capability to trigger ethylene production due to protein exposure on host plants, was often proved. Therefore, we were very interested in showing any changes, compared to wild type infection, in the ethylene production after infection with the silencing mutants. The extraction from plant material and subsequent detection by HPLC-MS of ethylene is difficult due to the volatile state of the phytohormone, therefore we investigated the expression of the ethylene biosynthesis enzymes 1-aminocyclopropane-1- carboxylate synthase (ACS) and -oxidase (ACO) by qRT-PCR to draw a conclusion on the accumulation of the phytohormone in the plants. Additionally, we determined the expression level of the SA-marker gene PR-1 as well of the JA-marker gene PDF-1.2. We harvested the hypocotyl from infected and mock inoculated plants and extracted phytohormones prior to analysis by HPLC-MS. For measurement of transcripts of phytohormone marker genes we extracted total RNA from the same plants. Both, phytohormone and gene expression analysis included three independent biological replicas. 
HPLC-MS and qRT-PCR data were measured using plant material at time points 14, 21, and 28 dpi with $V$. longisporum wild type and Vl-NEP-1 silencing mutants. The preliminary results from one measurement are shown in the following. For publishing, the data must be confirmed by two further measurements. IAA was not detectable in any of our samples.

JA is known as a phytohormone regulating plant defence by a pathway antagonistic to SA (69), and ABA is known to communicate with both during the process of activation of the plant defence response. ABA and JA were not significantly affected by $V$. longisporum after root infection of B. napus, which is consistent with the findings of Raztinger from 2008 (70), showing that both phytohormones are unaltered due to $V$. longisporum infection measured in both xylem sap and shoot extracts of B. napus by HPLC-MS. The amounts of JA in plants infected with the silencing mutants were measured and found to be slightly lower after 28 dpi as compared to wild type and mock infected samples but no significance could be shown.

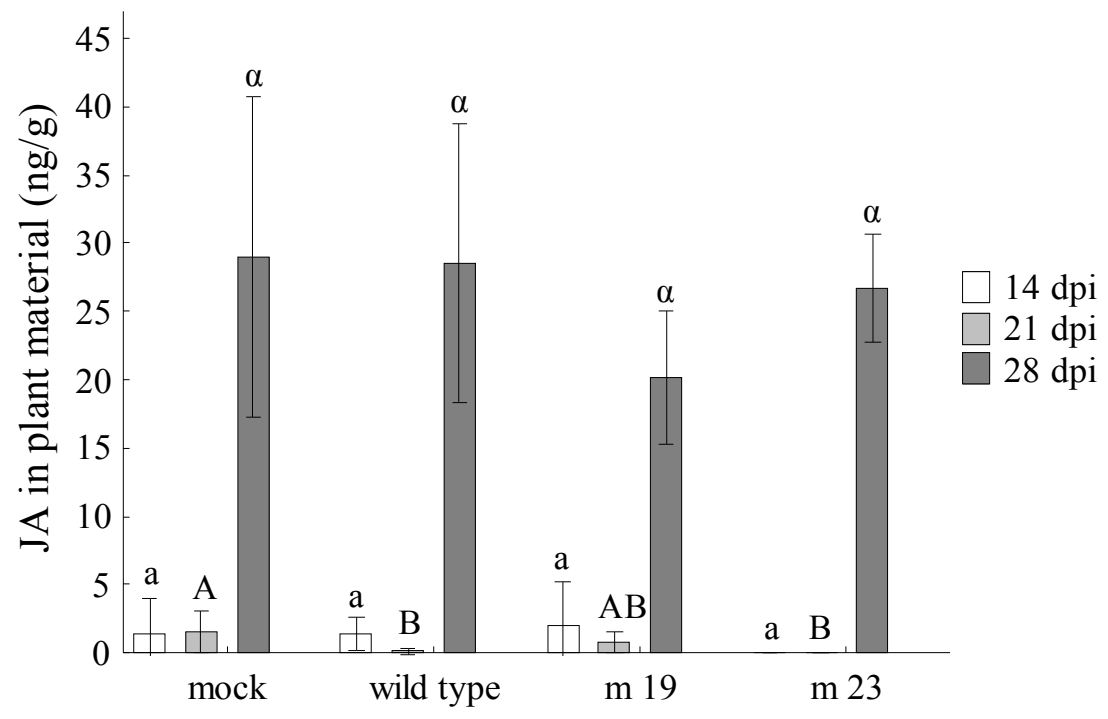

\section{Figure 16: Levels of JA in B. napus hypocotyl tissue}

Applies for all phytohormon-measurements: Analysis of phytohormons from healthy plants and $V$. longisporumwild type and Vl-NEP-1 mutant-infected plants at different time points after infection is shown. Each data point represents an average of 4 samples (each sample pooled from 5 plants). Error bars indicate standard deviation. 


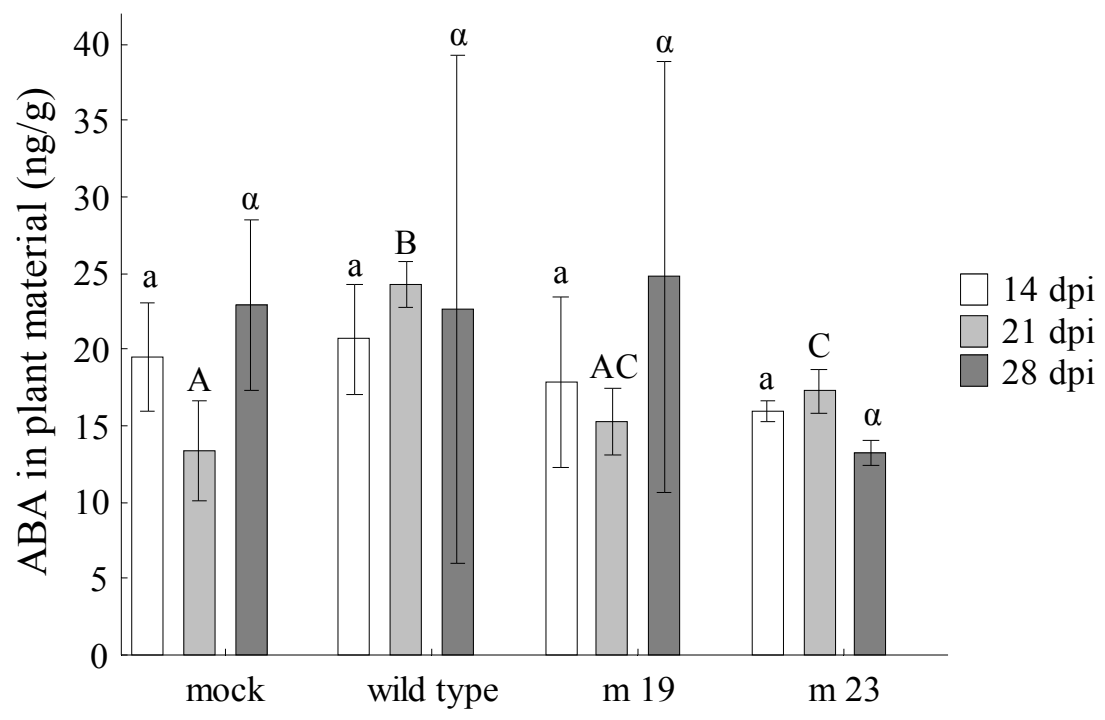

Figure 17: Levels of ABA in B. napus hypocotyl tissue

In Arabidopsis it was shown that the infection of plants by a biotrophic pathogen results in the activation of SA-mediated defence responses, wherein the infection by a necrotrophic pathogen triggers the JA and ethylene pathway of the plant (69). V. longisporum is described as a hemibiotrophic pathogen, which usually shows a biotrophic life style, and in the late stage of infection a necrotrophic life style by decomposing dead plant tissue to release nutrients and spreading of the fungus in the whole plant.

SA as well as SAG were both shown to be up-regulated in B. napus upon infection with $V$. longisporum, with a negative correlation to the stunting effect due to infection (70) as described by Ratzinger et al. in 2008. It was also shown that the accumulation of the phytohormone SA and its glucoside (SAG) seem to be unique feature in the response of $B$. napus to infection with $V$. longisporum because no changes in the level of SA and also SAG could be measured after infection with $V$. dahliae. 


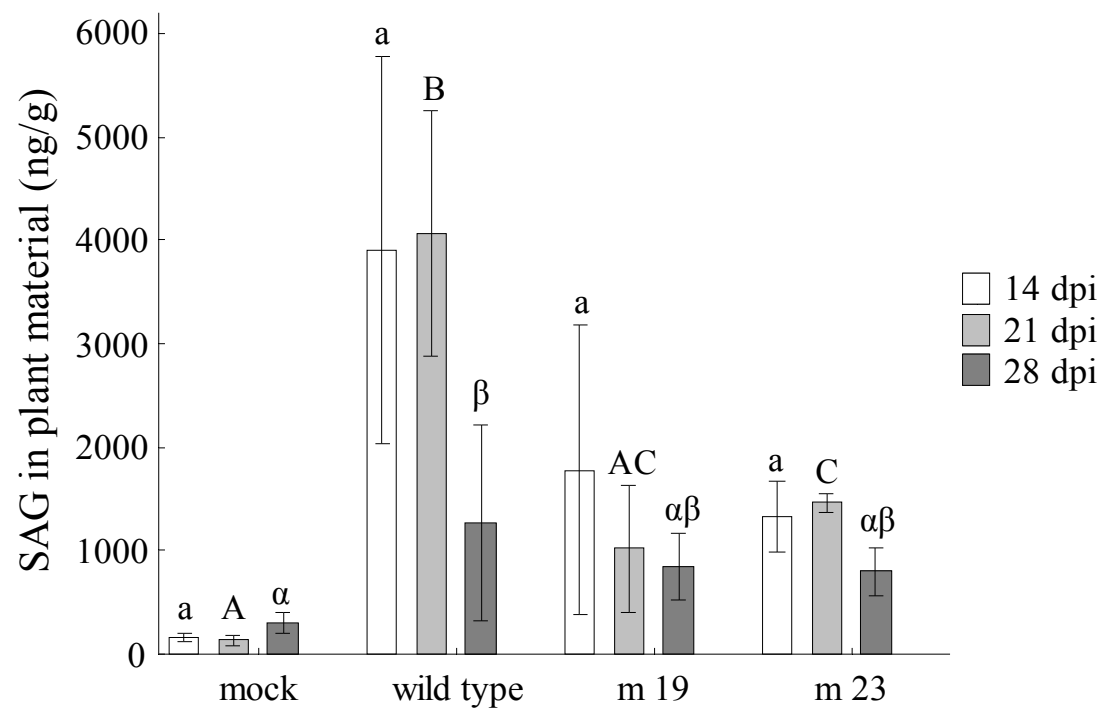

\section{Figure 18: Levels of SAG in B. napus hypocotyl tissue}

We measured a significant increase of the amount of SAG that is formed from SA by a glucosyl transferase (71) in wild type infected plants, but peculiarly, no changes in the levels of SA (data not shown). In the previous results shown by Ratzinger et al., a strong correlation between SA and SAG both in shoot tissue and xylem sap was measured. The Vl-NEP-1 mutants $\mathrm{m} 19$ and $\mathrm{m} 23$ showed a lower induction potential of SAG but an even higher accumulation of SAG than in the mock inoculated plants. The lower amount of SAG for the mutants probably corresponds to the lower levels of fungal biomass measured for the mutants (see Figure 13) and is therefore connected to the reduced stunting effect shown in the pathogenicity assay on B. napus. At 28 dpi the accumulation of SAG and also SA is in both wild type and mutants decreased as compared to the earlier time points, which is believed to be because the fungus enters the saprophytic stage of its pathogenic life cycle showing characteristics of a necrotrophic pathogen and, as shown for Arabidopsis responses, triggers the JA and ethylene pathway of the plant to counteract fungal infestation. As shown, we could not show any differences in the induction of JA after 28 dpi, therefore we proceeded with the measurements of ethylene marker-genes to discover if there were any changes in the response to wild type or mutant infection of the plant.

Ethylene production is supposed to play an active role in Verticillium pathogenesis and in symptom development. Several ethylene-deficient Arabidopsis mutants (e.g. ein2-1, ein4-1, ein6-1 or etr $1-1$ (Col-0 background)) showed enhanced susceptibility towards $V$. longisporum 
infection (13). In higher plants, ethylene is predominantly synthesized via the methionine precursor in the 'Yang' cycle $(72,73)$. S-Adenosyl-L-methionine is transformed to 5 methylthioadenosine and 1-ammino-cyclopropane-carboxylate by ACSs. The latter is transformed into ethylene by ACOs. To confirm that V1-NEP-1 induces the ethylene production in $B$. napus plants and is not synthesized by the fungus itself, we quantified ethylene concentrations of the wild type strain and the two mutants $\mathrm{m} 19$ and $\mathrm{m} 23$. Ethylene production by the fungal mycelium was measured by a gas chromatography (GC)-flame ionization detector. We ensured that no plants were present in the experimental setup in order to be certain that the ethylene detected was indeed produced by the mycelium. The fungus was grown in liquid PDB medium in SPME vials that were closed and airtight, with and without supplementation of $5 \mathrm{mM}$ methionine, and were pre-cultivated for five days.

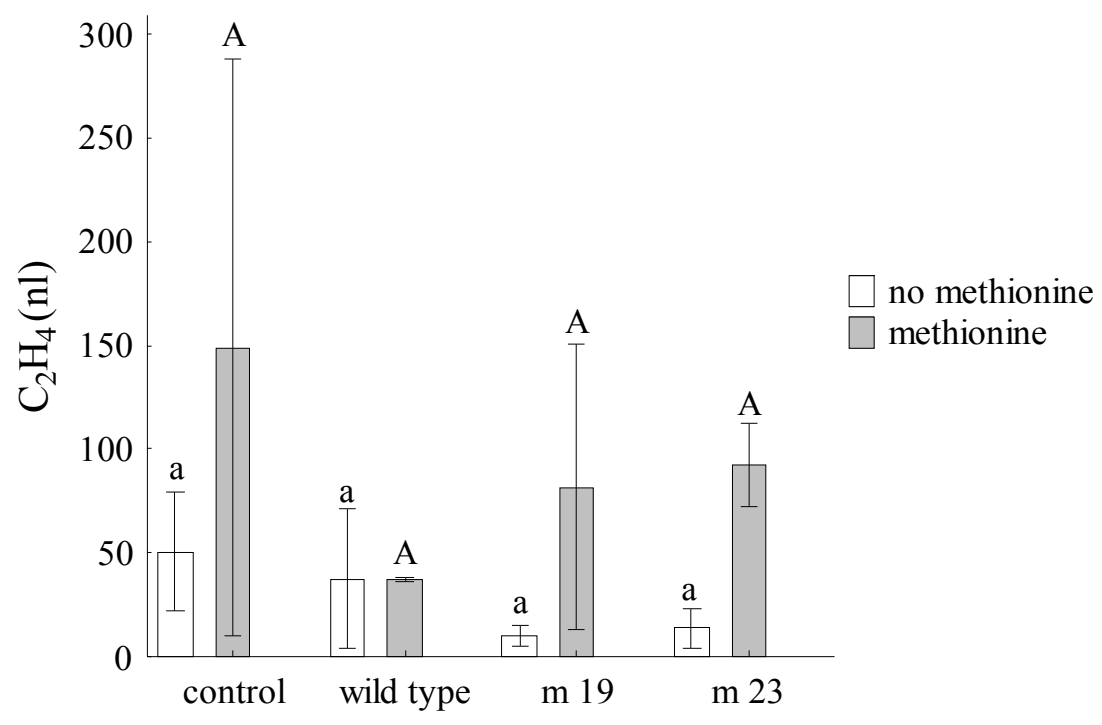

\section{Figure 19: Ethylene production of $V$. longisporum}

Results are shown as the average of four replicates (y axis indicates the amount of ethylene in the $20 \mathrm{ml}$ vial; Bars indicate standard deviation.) $\mathbf{m}$ 19/23 = Vl-NEP-1 mutants $\mathrm{m} 19$ and $\mathrm{m} 23$

The PDB medium itself (control) releases small quantities of ethylene, and neither wild type nor mutants seem to produce more ethylene than the media control $(\mathrm{P}>0.05, \mathrm{~K}-\mathrm{Wallis}$ test). No indication for ethylene production of $V$. longisporum was detected. Neither the wild type nor the mutants showed higher concentrations of ethylene compared to the medium control. Slightly lower concentrations were measured for the Vl-NEP-1 silencing mutants grown in PDB medium without methionine supplementation. 
In order to investigate the influence of Vl-NEP-1 expression on the biosynthesis of ethylene in B. napus, we measured the expression levels of the ACS-1 gene using primers derived from B. oleracea and the ACO-1 gene (gb|L27664.1) in B. napus plants infected with the wild type and the Vl-NEP-1 mutants $\mathrm{m} 19$ and $\mathrm{m} 23$ by qRT-PCR. The expression of the genes was calculated relative to the mock inoculated plants. In the literature it was shown that genes encoding ACS and ACO are strongly expressed upon treatment with an NLP from $P$. parasitica (6), but here we could not find any difference in the expression levels of the ACS and ACO in plants treated with $V$. longisporum wild type compared to the Vl-NEP-1 silencing mutant. After 28 dpi we measured a rise in the expression of the ACS-1 gene, which could be an indication of the change in the life style of the fungus, as it changed its behaviour to that of a necrotrophic pathogen, triggering ethylene induction as shown for Arabidopsis responses.

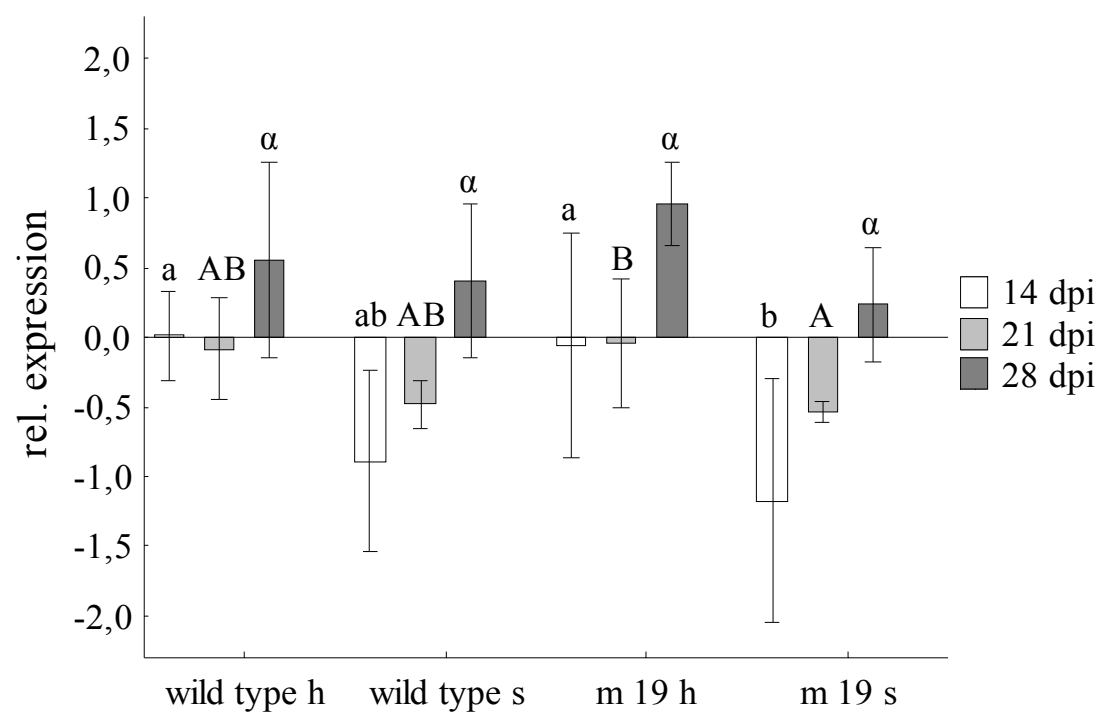

Figure 20: Induction of ACS-1 in hypocotyl and shoot samples of plants infected wild type (WT) and VINEP-1 mutant $\mathrm{m} 19(\mathrm{~h}=$ hypocotyl; $\mathrm{s}=$ shoot $)$

Applies for all marker-gene expression-level measurments: Ratios of relative expressions levels to mock inoculated plants were calculated as the mean of $\Delta \Delta \mathrm{cT}$ values of three biological replicas at each time point. Transcript levels of genes were measured and normalized using two housekeeping genes, actin and histone. 


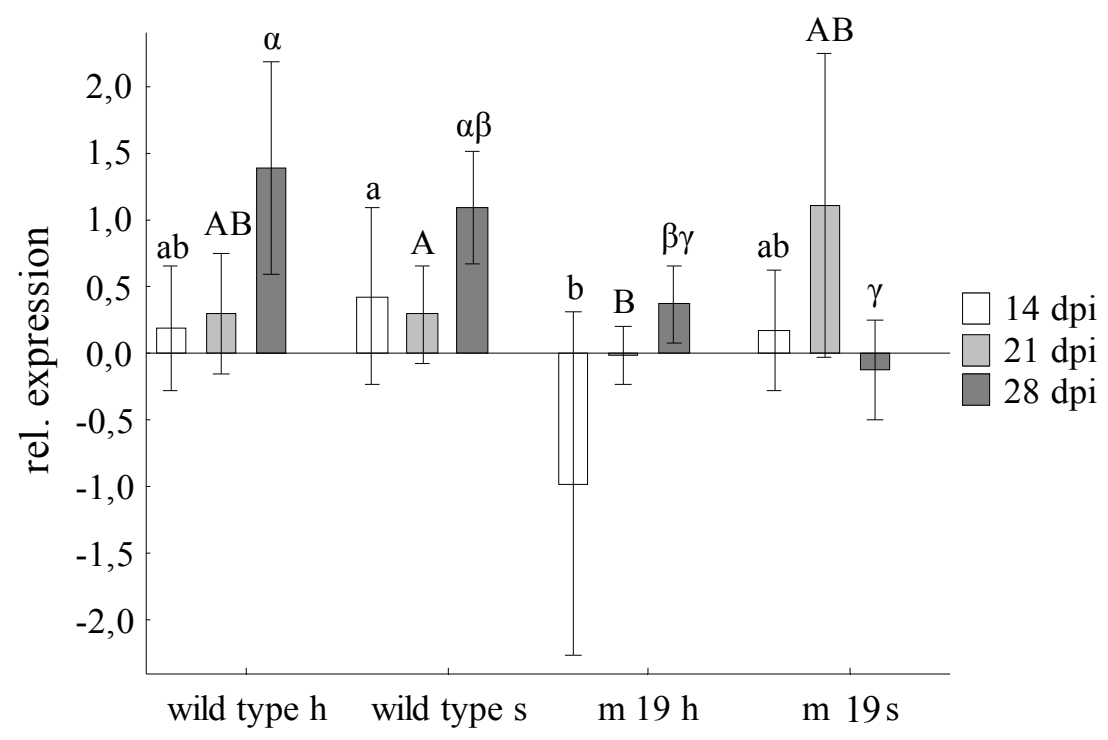

Figure 21: Induction of ACO-1 in hypocotyl and shoot samples of plants infected wild type (WT) and VlNEP-1 mutant m19

While ethylene has been mainly associated with the development of disease symptoms in Verticillium interactions with their host-plants, JA has been shown to be involved in resistance processes. For instance, JA-insensitive Arabidopsis plants have been shown to suffer more severely from infection with Verticillium $(74,75)$. Infiltration of the $V$. dahlia orthologous protein of Vl-NEP-1 into leaves of $A$. thaliana results in the activation of both SA-and JA-dependent defence pathways. Therefore, we tested the JA-marker gene PDF-1.2 to ascertain whether it was affected by the infection with $V$. longisporum Vl-NEP-1 silencing mutants. 


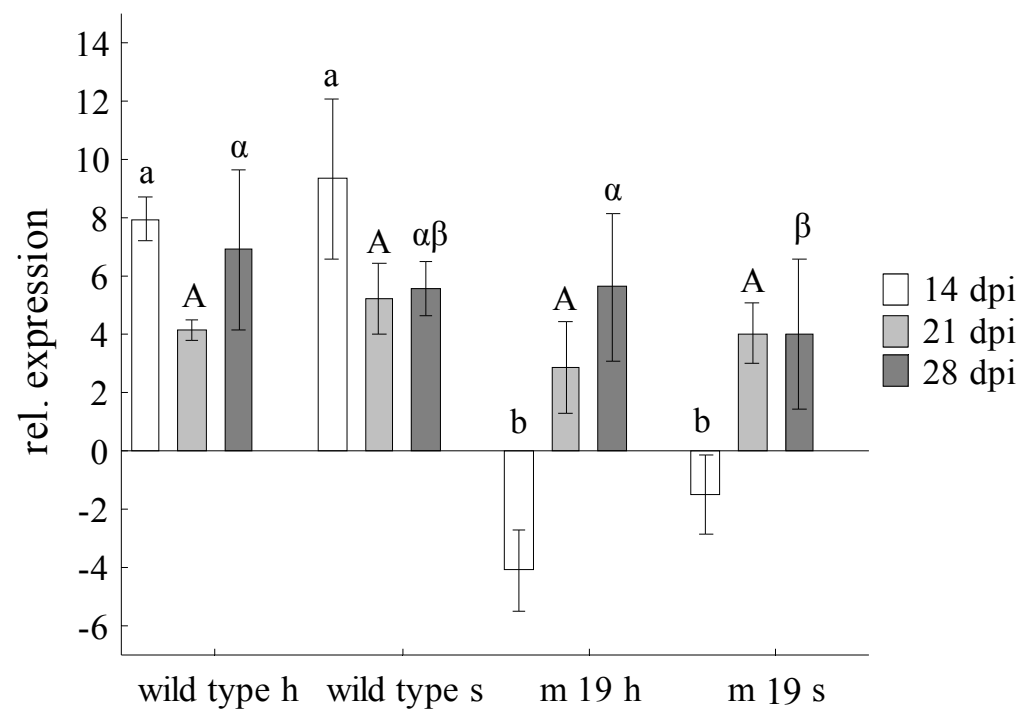

Figure 22: Induction of the JA-marker gene PDF-1.2 in hypocotyl and shoot samples of plants infected with $V$. longisporum wild type and Vl-NEP-1 mutant m19

As mentioned before, JA does not seem to be induced by the infection with $V$. longisporum. Nevertheless, we measured a significant upregulation of the expression of PDF-1.2 in wild type infected plants relative to mock inoculated ones, which indicates that the plants probably react to the infection by activating the JA-pathway to accumulate the phytohormone which probably results in the expression of defence-related genes such as pathogenicity-related (PR) genes. The significant downregulation of the PDF-1.2 gene expression that we measured in plants infected with the Vl-NEP-1 silencing mutant m19 at 14 dpi could be an indication that the mutant was not well detected by the plant and therefore did not counteract the expression of defence genes. Unfortunately, the expression analysis of the PR-1 gene could not be evaluated during this measurement; therefore further experiments must be performed to strengthen the results and to support this hypothesis.

All documented effects triggered by NLP exposure on plants, such as transcript accumulation of hormone biosynthesis enzyme-encoding genes, production of ROS and ethylene, callose apposition and HR-like cell death, were demonstrated using the purified protein for plant assays. It was reported in literature that using the purified Vd-NEP-A protein, which is the orthologous gene from $V$. dahliae to V1-NEP-1 from $V$. longisporum, for infiltration into leaves of $N$. benthamiana and A. thaliana plants, resulted in the formation of necrotic lesions and also resulted in triggering of the production of ROS and the expression of PR genes. 
Therefore, we proceeded with the purification of the Vl-NEP-1 protein to obtain detailed insights into the mode of action of the protein. This allowed us to draw conclusions on the previous results showing less fungal DNA, even though the plant-infection process by V1NEP-1 silencing mutants was not impaired compared to that of the wild type fungus, which resulted in less symptom severity of plant infection in the mutants being monitored.

\section{Overexpression and purification of Vl-NEP-1 protein and subsequent experiments}

RNA was extracted from mycelium of $V$. longisporum, grown in $10 \mathrm{ml}$ of liquid SXM medium $\left(1 \times 10^{4}\right.$ spores, $23{ }^{\circ} \mathrm{C}, 10$ days), for first strand cDNA synthesis to PCR-amplifiy VlNEP-1 gene with primers for the complete exon sequence. The amplicon was purified using 'QIAquick Gel Extraction Kit' (Qiagen, Hilden, Germany) and ligated into pET21a, resulting in the V1-NEP-1 expression vector pET21a-Vl-NEP-1 $(6.9 \mathrm{~kb})$ including a polyhistidine-tag (his-tag) required for protein-purification. The plasmid was transformed in E. coli BL21 cells, and protein expression of the Vl-NEP-1 gene was induced using IPTG. The desired protein was subsequently purified with preparative SDS-PAGE using a chromatography column with nickel beads $\left(\mathrm{Ni}^{2+}\right)$ and was concentrated, resulting in a purity of $>95 \%$ which was good enough for protein-bioassays and polyclonal antibody production for western hybridizations.

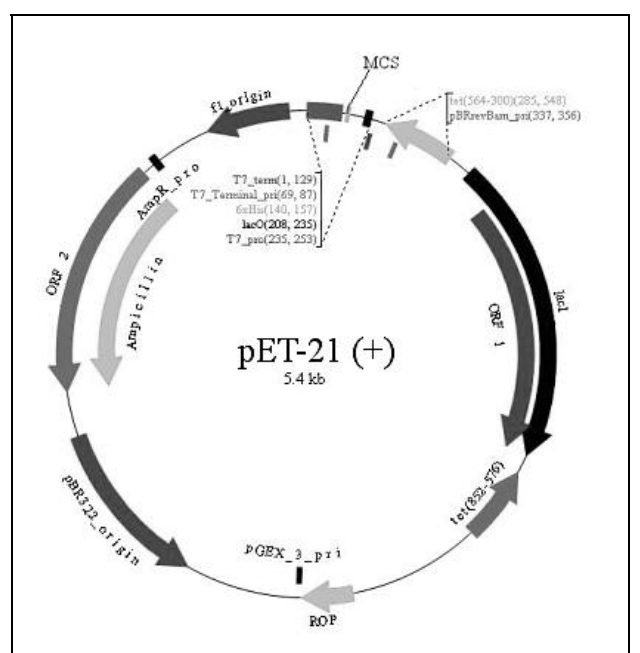

Figure 23: pET-21a expression vector

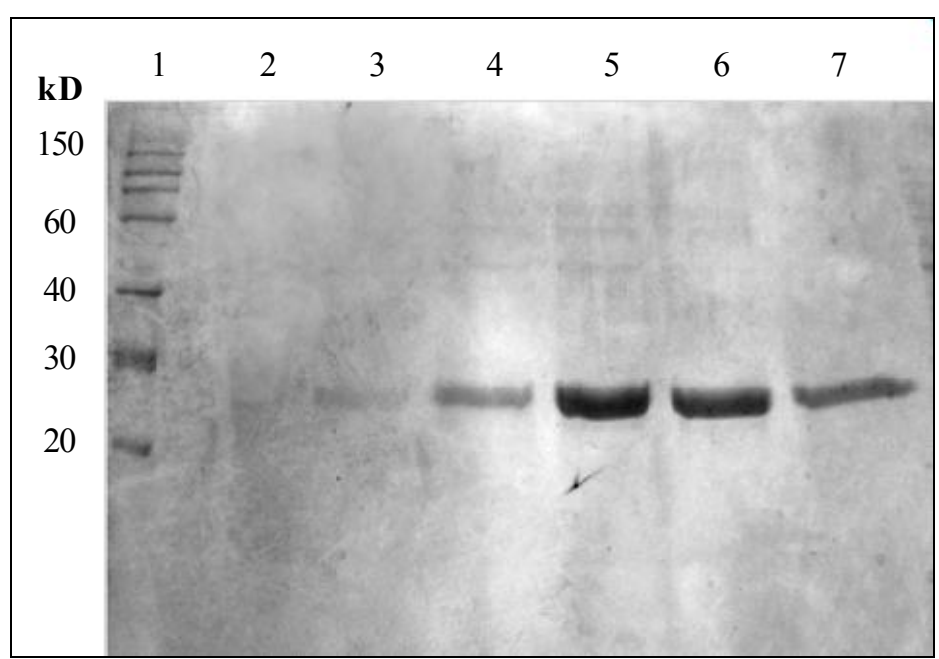

Figure 24: Purification of Vl-NEP-1 protein, expression induction using different concentrations of imidazol

$\mathbf{1}=$ Roti ${ }^{\circledR}$-Mark 10-150 PLUS $\quad \mathbf{2}-\mathbf{6}=$ different imidazol

$7=$ crude His-NEP protein concentrations $(5-50 \mathrm{mM})$ 
Plants react on NLP exposure with different responses. The way NLPs trigger these is mostly unidentified. NLPs from $P$. aphanidermatum, F. oxysporum, $P$. parasitica and $P$. sojae $(4,6$, $15,20)$ have been shown to induce necrotic responses by infiltrating the purified protein into the leaves of host plants. To study the effects of the pure protein of Vl-NEP-1 on plant organs, we infiltrated the protein through the abaxial surface, delivering it by a syringe into the leaves of B. napus and N. tabacum to visualize putative lesion formation on the leaves. Different concentrations ( 5 to $0.0005 \mu \mathrm{g}$ ) of the protein were used for infiltration to show if the protein acted in a dose-dependent manner as reported in the literature for other NLPs $(6,15)$. NLPinduced necrosis is sensitive to changes in protein structure that occur by heating the protein to $65{ }^{\circ} \mathrm{C}$; therefore we used heat-inactivated V1-NEP-1 as a negative control as confirmed by Fellbrich et al., where a reduced activity of up to $92 \%$ (19) was shown.
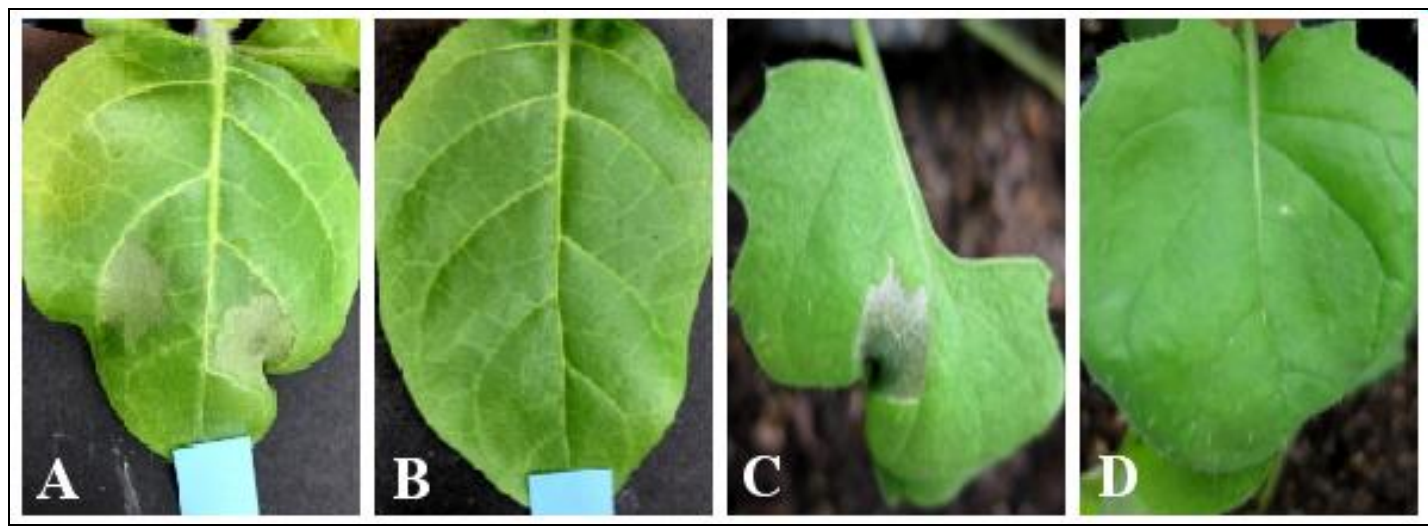

Figure 25: Effects on leaves of B. napus and . tabacum infiltrated with VI-NEP-1 protein

$\mathbf{A}=N$. tabacum treated with native Vl-NEP-1 $(5 \mu \mathrm{g})$

$\mathbf{B}=N$. tabacum treated with boiled Vl-NEP-1

$\mathbf{C}=$ B. napus treated with native Vl-NEP-1 $(5 \mu \mathrm{g})$

$\mathbf{D}=$ B. napus treated with boiled Vl-NEP-1

We could demonstrate that Vl-NEP-1 protein caused leaf necrosis in both plants. The necrotic lesions were visually apparent within 12 days post-infiltration in a dose-dependent manner. The threshold of necrosis induction is between $0.0005 \mu \mathrm{g}$ and $0.005 \mu \mathrm{g}$. Additionally, we could show that susceptibility to necrosis was also leaf age-dependent after testing on different old leaves (see Figure 26). Younger leaves showed a more severe necrosis formation as compared to older leaves treated with the same concentration of the protein. 


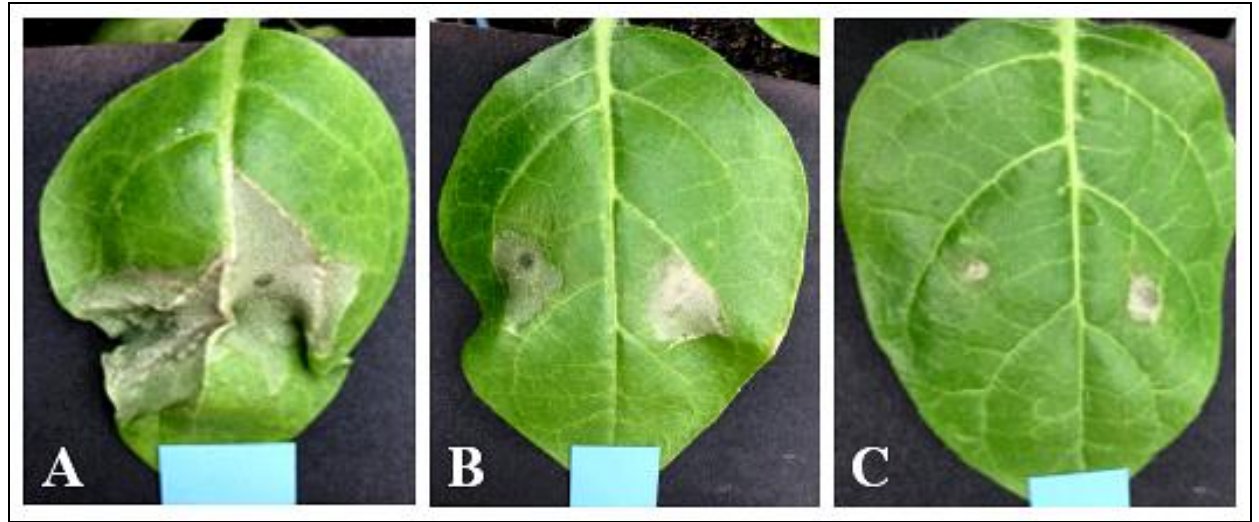

Figure 26: Effects on leaves with different age of $N$. tabacum infiltrated with Vl-NEP-1 protein $\mathbf{A}=$ third leaf of $N$. tabacum plant treated with native Vl-NEP-1 $(2,5 \mu \mathrm{g})$

$\mathbf{B}=$ fourth leaf of $N$. tabacum plant treated with native Vl-NEP-1 $(2,5 \mu \mathrm{g})$

$\mathbf{C}=$ fifth leaf of $N$. tabacum plant treated with native Vl-NEP-1 $(2,5 \mu \mathrm{g})$

To assess the effects of Vl-NEP-1 protein on plant growth, seedlings of 'rapid cycling rape' and Arabidopsis ecotypes Bur, Col-0 and Ler were treated with the purified protein. It is known from literature that an ecotype-specific genetic variability exists in Arabidopsis (77, 78). Ecotype Bur is known to be more resistant to $V$. longisporum infection as compared to Ler or Col-0 (79). For protein treatment, seedlings were grown on agar plates supplemented with increasing concentrations (50 to $5 \mu \mathrm{g} / \mathrm{ml}$ ) of purified Vl-NEP-1. Exposure of purified NLPs from P. sojae to Arabidopsis ecotype Col-0 (23) and a NLP from F. oxysporum tested on 17 different ectopies (5) was shown to result in a significant reduction of root growth. Here we tested for the first time the effect of an NLP from $V$. longisporum to show the effects of natural host plant B. napus.

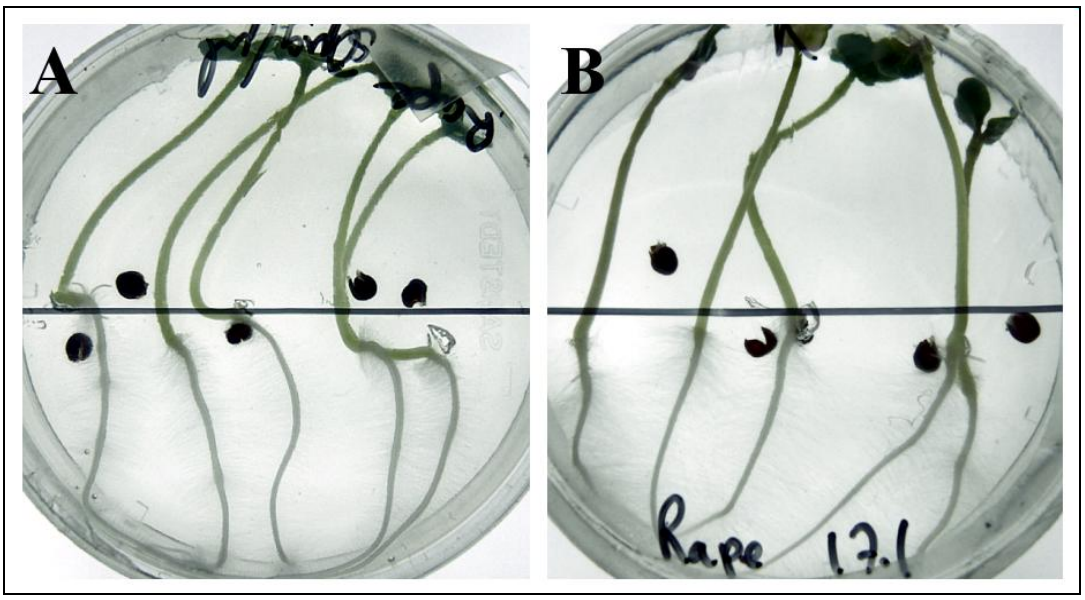

Figure 27: Effects on seedlings of $B$. napus treated with Vl-NEP-1 protein

A = seedlings grown for 4 days in agar supplemented with 50 $\mu \mathrm{g} / \mathrm{ml}$ Vl-NEP-1 protein $\mathbf{B}=$ seedlings grown for 4 days in agar without the protein 
When Brassica seedlings were treated with Vl-NEP-1, the growth of roots and cotyledons were not inhibited for any of the tested protein concentrations. The plants showed no disease symptoms as reported for NLP exposure on Arabidopsis. We could also prove that Vl-NEP shows effects on the growth of Arabidopsis roots. The inhibition-effect on the root-length was severe and showed a significant reduction for all tested concentrations on all tested ecotypes. The Arabidopsis ecotype Bur seemed to recover after approximately 8 dpi, showing similar root length compared to non-treated control plants.

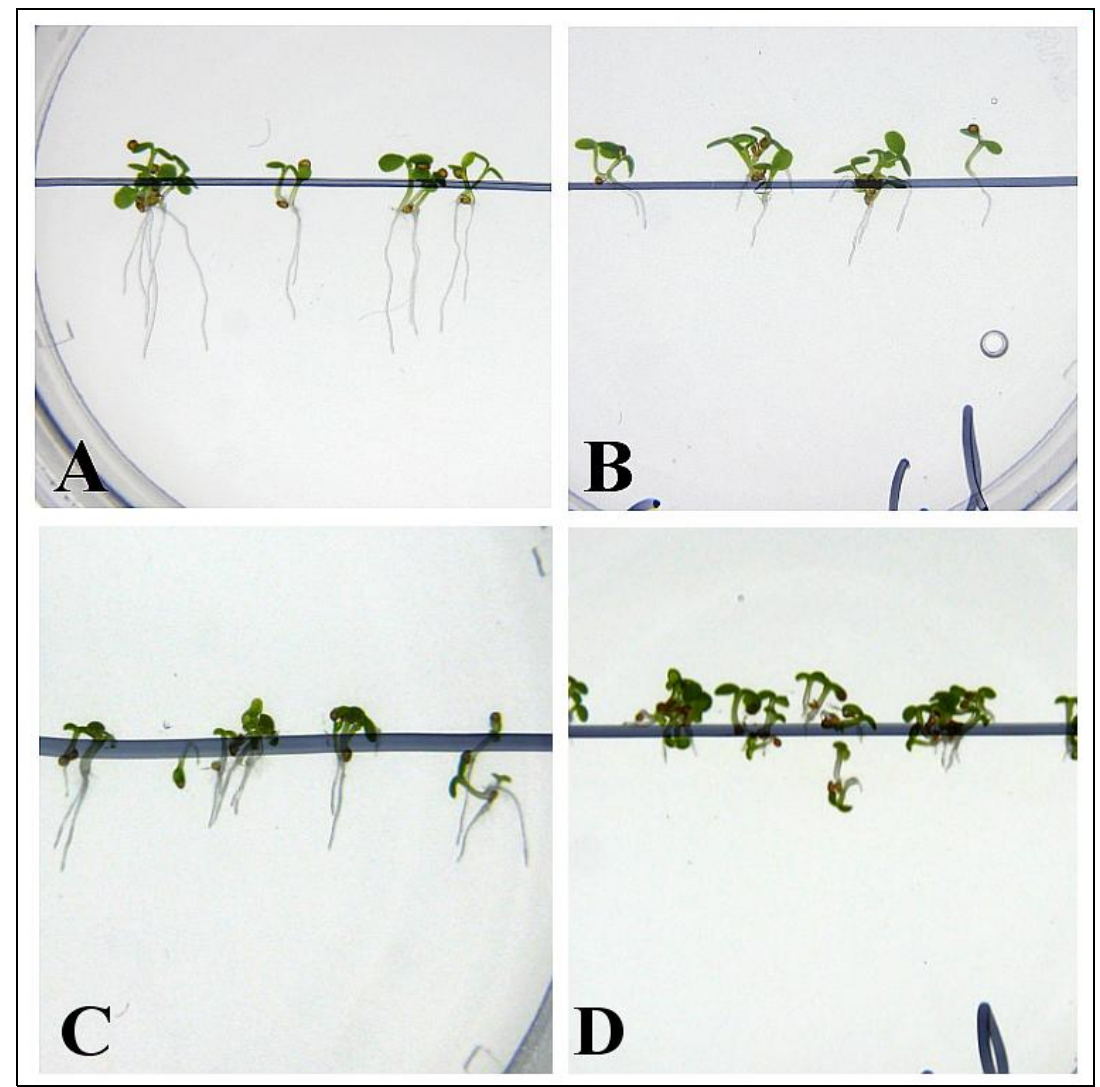

Figure 28: Effects on seedlings of Arabidopsis ecotypes Ler and Bur treated with Vl-NEP-1 protein $\mathbf{A}=$ seedlings (Ler) grown for 4 days in agar without the protein

$\mathbf{B}=$ seedlings (Ler) grown for 4 days in agar supplemented with $50 \mu \mathrm{g} / \mathrm{ml}$ Vl-NEP-1 protein $\mathbf{C}=$ seedlings (Bur) grown for 4 days in agar without the protein $\mathbf{D}=$ seedlings (Bur) grown for 4 days in agar supplemented with $50 \mu \mathrm{g} / \mathrm{ml}$ Vl-NEP-1 protein

In 2006, Bae et al. reported on the further effects on Arabidopsis plants as a result of treatment with an NLP from $F$. oxysporum. Besides the already mentioned inhibition effect on the root growth, he showed necrotic lesion formation on cotyledons, inhibition of the formation of root hairs, and damaged root tips due to protein exposure. Interestingly, VI-NEP- 
1 treatment resulted in the induction of the formation of root hairs of Arabidopsis ecotypes Bur, Ler and Col-0, which stands in complete contradiction to the observations shown for the NLP of F. oxysporum (23).

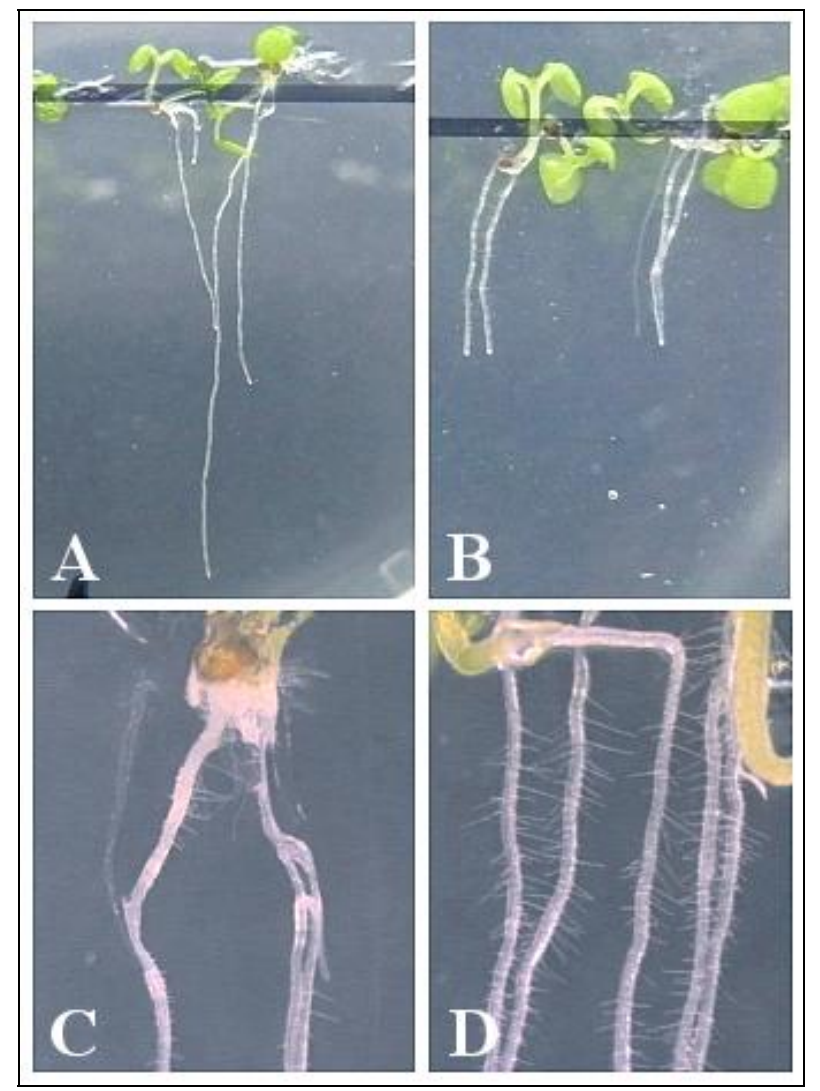

Figure 29: Effects on seedlings of Arabidopsis ecotypes Ler and Bur treated with Vl-NEP-1 protein A $=$ seedlings (Ler) grown for 4 days in agar without the protein

$\mathbf{B}=$ seedlings (Ler) grown for 4 days in agar supplemented with $50 \mu \mathrm{g} / \mathrm{ml}$ Vl-NEP-1 protein $\mathbf{C}=$ seedlings (Bur) grown for 4 days in agar without the protein D $=$ seedlings (Bur) grown for 4 days in agar supplemented with $50 \mu \mathrm{g} / \mathrm{ml} \mathrm{Vl}-\mathrm{NEP}-1$ protein

The plant material was collected from both experiments for further phytohormone measurements by HPLC-MS and expression analysis of hormone biosynthesis enzymeencoding genes for different plant defence pathways by qRT-PCR to prove the influence of Vl-NEP-1 on the phytohormone level during infection with the fungus.

To ensure that the Vl-NEP-1 protein is synthesized and secreted in the plant by $V$. longisporum wild type and repressed in the Vl-NEP-1 knock-down mutants, we analysed the expression of the protein by western hybridization using Vl-NEP-1 polyclonal antiserum. 
Therefore, we grew wild type and Vl-NEP-1 mutants in the sugar rich complete PDB medium and in artificial synthetic SXM medium which simulates the basic nutritional condition of a xylem environment. Both the mycelium and supernatant of the cultures were used for western blotting.

\begin{tabular}{|c|c|c|c|c|c|c|c|}
\hline \multirow{2}{*}{\multicolumn{8}{|c|}{ kD }} \\
\hline & & & & & & & \\
\hline 30 & $=$ & & & & & & \\
\hline & & & & & & & \\
\hline & & & & & & & \\
\hline
\end{tabular}

Figure 30: Detection of Vl-NEP-1 protein in fungal mycelium and culture supernatant by western hybridization

$1=$ Marker

$\mathbf{2}=$ mycelium of wild type fungus grown in PDB medium

3 = culture supernatant of wild type fungus grown in PDB medium

$4=$ mycelium of wild type grown fungus in SXM medium

$\mathbf{5}=$ culture supernatant of wild type grown fungus in SXM medium

$\mathbf{6}=$ mycelium of Vl-NEP-1 mutant $\mathrm{m} 19$ grown in SXM medium

7 = culture supernatant of Vl-NEP-1 mutant $\mathrm{m} 19$ grown in SXM medium

We could only detect signals representing the expressed Vl-NEP-1 protein in extracts of $V$. longisporum grown in SXM medium, which suggests that the expression of V1-NEP-1 is induced by the presence of conditions imitating the xylem sap environment. Additionally, the culture supernatant also showed signals for V1-NEP-1, which indicated that this was a secretory protein, which, as shown in the literature, is a typical feature of different NLPs (15, 16). The band intensity displaying the protein expression of Vl-NEP-1 silencing mutant m19 grown in mycelium was slightly lower compared to wild type expression as a result of posttranscriptional silencing by RNAi.

As mentioned, the pathogenic life cycle of $V$. longisporum is characterized by the biotrophic growth of the fungus staying in the vascular system up to a late stage of B. napus infestation. After approximately $28 \mathrm{dpi}$, the fungus enters the saprophytic phase and starts spreading into the upper parts of the plant. A recent study showed that the amount of fungal DNA increases up to five times after $35 \mathrm{dpi}$ as compared to the amount after 28 dpi (45) indicating that the 
fungus does not leave the hypocotyl until this time. To find if Vl-NEP-1 can act as a signalling molecule during infection by $B$. napus, we harvested plant tissue from the root and the upper part of the stem after 28 dpi to see if we could detect signals for Vl-NEP-1 expression by western hybridization in the stem, although the fungus was absent in this part of the plant.

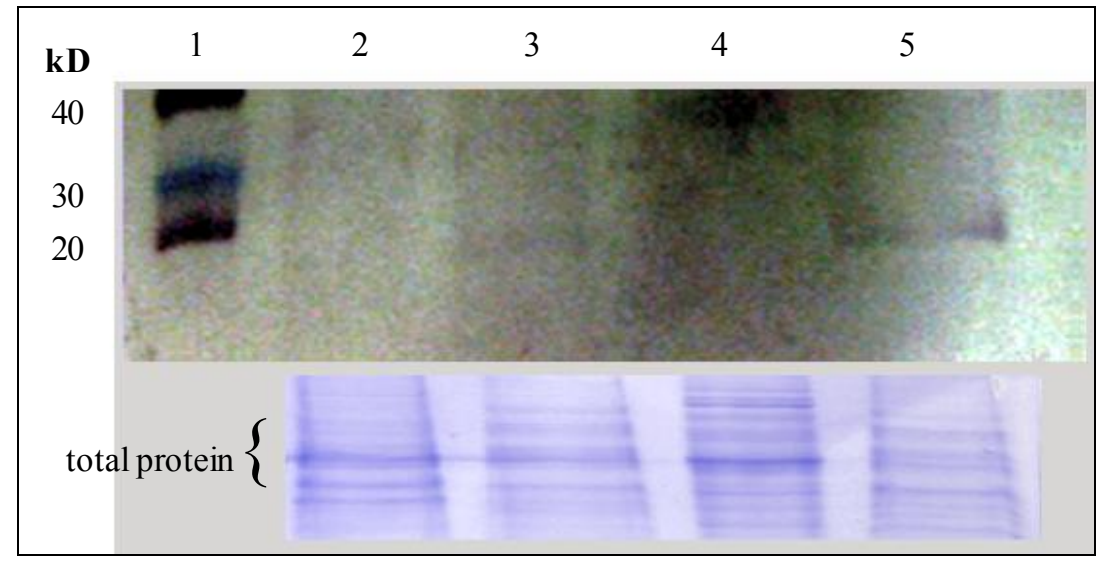

Figure 31: Detection of Vl-NEP-1 protein in infected plant tissue by western hybridization

$\mathbf{1}=$ Marker

2 = stem tissue of non-infected plants after $28 \mathrm{dpi}$

$3=$ stem tissue of infected plants after $28 \mathrm{dpi}$

4 = hypocotyl tissue of non-infected plants after $28 \mathrm{dpi}$

$\mathbf{5}$ = hypocotyl tissue of infected plants after $28 \mathrm{dpi}$

The blot showed a strong signal for Vl-NEP-1 expression in protein extracts of the hypocotyl tissue of infected plants, and furthermore a slighter signal in the lane using stem tissue of infected plants after 28 dpi. This may indicate that the protein is transported upwards in infected plants even though the fungus is still not present. This gives us a hint to an elicitorlike mode of action of Vl-NEP-1, but still the specific function of the protein remains unclear.

Recently we have started to use immunofluorescence microscopy with the aid of FITClabelled antibodies of V1-NEP-1 to investigate the distribution of the protein in terms of expression time and site of action, in order to clarify the putative effects of V1-NEP-1. Therefore, 20-30 $\mu \mathrm{m}$ thick samples from different plant parts were examined using a laser scanning fluorescence microscope. Preliminary results are highlighted by two digital images showing $V$. longisporum growing in the root after 28 dpi (see Figure 32 ) and a cross-section 
of the stem showing direct immunofluorescence due to antibody deposition mainly in the vascular system of B. napus (see Figure 33).

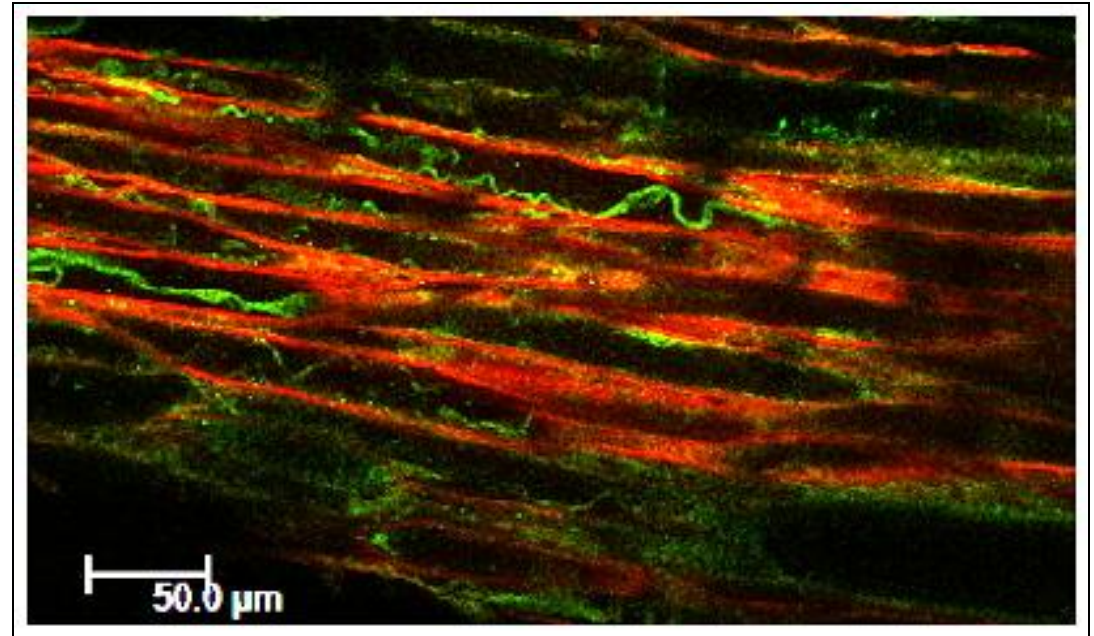

Figure 32: Digital image of a longitudinal section of a root sample after $28 \mathrm{dpi}$

During this experiment, we could only detect fungal hyphae in the root and rarely in hypocotyl samples of $V$. longisporum-infected plants, but we have never seen growing fungus in the stem even after 35 dpi. Nevertheless, a clear immunofluorescence could be observed after 28 dpi in both stem and leaf tissues in contrast to non-infected plant samples. The protein seems to accumulate in and around the central cylinder of the plants, which gives a further indication that V1-NEP-1 is transported upstream to the upper parts of the plant.

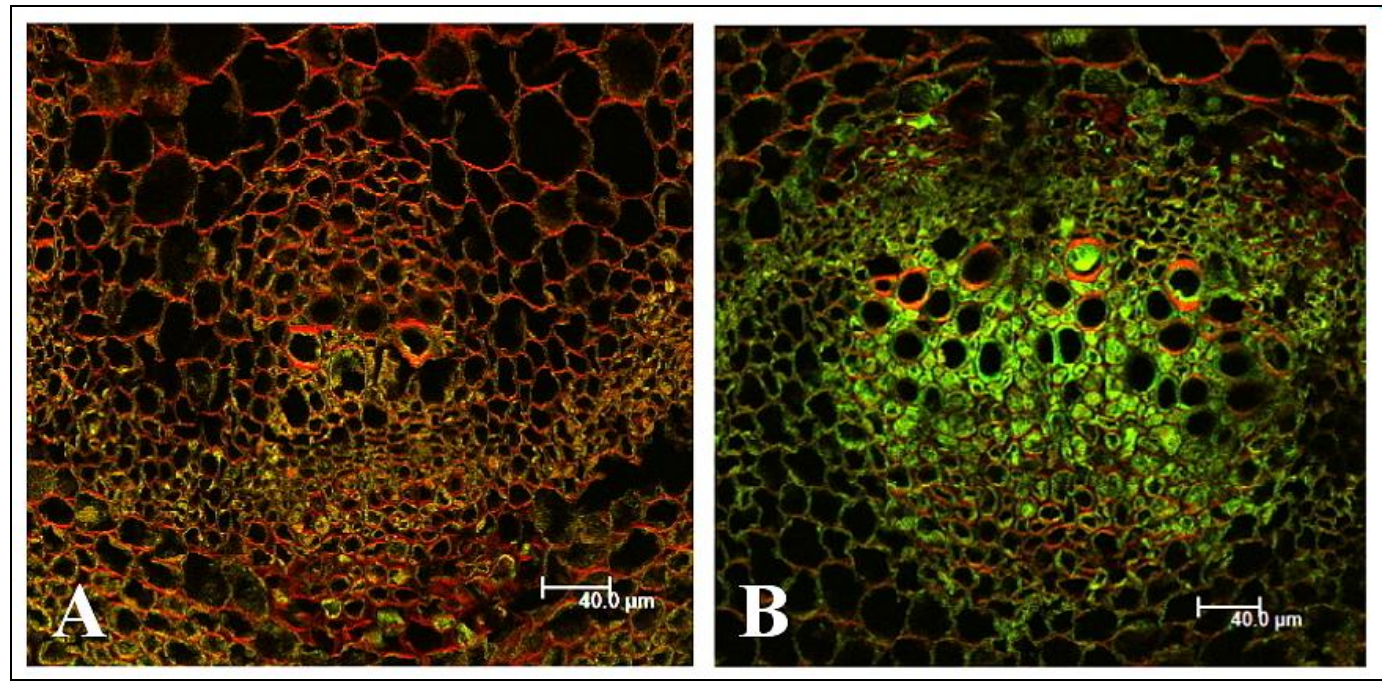

Figure 33: Digital image of a cross-section of a stem sample after $35 \mathrm{dpi}$

A $=$ control (uninfected plant) $\quad$ B $=$ infected plant 
The restricted localization of the V1-NEP-1 protein to the vascular system during the whole infection cycle of $V$. longisporum makes a function at this location likely. The hydrophillic property shown for NLPs (6) probably prevents the protein passing through the plasma membranes into the plant cells. Therefore it is most likely that NLPs act as signal molecules identified by receptors attached to the cell walls of plants. The identification of the putative receptor of the protein is closely connected with the identification of the function of V1-NEP1 of clarifying the impact of these protein in the plant-pathogen interaction of $V$. longisporum and B. napus.

\section{CONCLUSIONS}

In this chapter, we have reported on the identification of five NLPs of $V$. longisporum (see Figure 3 and Table 3) and the characterization of one of them named V1-NEP-1, which is the orthologous gene of Vd-NEP-A. This is found in the parental $V$. dahliae genome and has been proven in literature to have the ability to trigger plant responses such as wilting as a result of protein infiltration of natural host plant cotton. In 2002, Bailey demonstrated that a disruption or overexpression of an NLP gene from $F$. oxysporum had no impact on the ability of the fungus to exert an influence on the host plant Erythroxylum coca (4). However, that study was unable to detect any transcripts in the plant of these NLPs, even in the overexpressed mutants. In 2004, Pemberton et al. postulated that the nutritional limitations of the xylem sap result in the absence of any expression of NLPs in planta for pathogens mainly located in the xylem. Additionally, they mentioned that NLPs that are expressed in planta probably alert plants to the presence of pathogens and subsequently trigger plant defences that bring any infection to a sudden end (16). Nevertheless, due to the fact that $V$. longisporum is known to stay in the xylem up to a late stage of infection, living as a biotroph organism undetected by the plant, we could measure strong expression levels of three NLP genes (Vl-NEP-1, -2, -5) in planta by qRT-PCR. This finding makes acceptable a contribution in the pathogenic life cycle of $V$. longisporum while infecting B. napus as compared to non-expressed NLPs from other pathogens. Vl-NEP genes with higher homology to $V$. dahliae (Vl-NEP-1, -2, -5) were shown to be expressed; those to V. albo-atrum were not (compare Table 3 with Figure 5). Therefore, 
it must be assumed that $V$. dahliae genes in the $V$. longisporum genome express the virulence/pathogenicity of the fungus in B. napus.

Pathogenicity assays using 'rapid cycle rape' infected with generated Vl-NEP-1 mutants with a silencing efficiency of protein expression of over $90 \%$ show a significant reduction in symptom severity, indicated by reduced stunting and a lower disease score on plants infected with silencing mutants compared to wild type infection (Figure 10-12). The reproducibility of the effects on plants was proved by four independent experiments showing the same results as before. We are firmly convinced that the lower symptom severity was caused by a reduced presence of the fungus in the plants infected with the mutants as proven by the lower amount of fungal DNA we measured by qPCR (Figure 13). At this stage we believe that the Vl-NEP-1 silencing mutants may have partly lost their ability to enter the plant via the roots due to an up to date, unknown function of the Vl-NEP-1 protein. However, this assumption was rejected because of the results of CLSM studies on the infection of plants with both wild type and VlNEP-1 mutants, which showed no difference in the ability to enter the roots of the plants or in the speed of infection (Figure 14-15).

The recognition of pathogens by infected plants and the subsequent initiation of defence strategies and conversely the overcoming of these plant defences by the invader are of crucial importance in plant pathogen interactions and are significant features in the classification of the interaction between the pathogen and the host-plant into that of compatible or a incompatible interaction. Researchers have found over the past decades that plants have evolved manifold recognition strategies to counteract an imminent infection by expression of different classes of resistance genes (R-genes) such as NBS-LRR genes (80) or the cell surface pattern recognition receptors (PRR) (81). The gene products of R-genes can recognize certain AVR gene products expressed by the pathogen and therefore respond to the attack by triggering the hypersensitive response (HR) or the systemic acquired resistance (SAR) for example. All these responses involve the accumulation of chemical messengers, such as SA or JA. These phytohormones can therefore be used as distinctive indicators to prove a reaction by measuring them and comparing them to the accumulated phytohormones of non-infected plants. In contrast to JA, it was shown that SA plays an important role in the response of $B$. napus to the infection with $V$. longisporum. We could not detect any significant change in the production of JA due to $V$. longisporum wild type nor to Vl-NEP-1 silencing mutant infection 
of B. napus as compared to un-infected plants (69). These results did not match our finding for the expression analysis of the JA-marker gene PDF-1.2 showing an upregulation in wild type infected and a downregulation in Vl-NEP-1 silencing mutant infected plants, 14 dpi, in relation to the mock inoculated plants. Further measurements must be done to examine the impact of V1-NEP-1 on the plant defence driven by JA accumulation to prove the hypothesis that Vl-NEP-1 mutants are not detected as well as the wild type fungus. The lower levels of SAG measured for the mutants are explainable by the lower levels of fungal biomass measured for the mutants by qPCR as revealed by Ratziger in 2008 (70). In the near future we will also perform phytohormone- and marker-gene measurements using plant material harvested from plants we use for infiltration assays with the purified protein. This will provide a more detailed look at the impact of Vl-NEP-1 on the phytohormone balance of the plant infected with $V$. longisporum wild type and the silencing mutants, and will allow us to learn more about the role of Vl-NEP-1 in fungus during an infestation of B. napus.

We were able to prove the distinctive features mentioned for NLPs by using the purified protein for plant assays during this work. Necrotic lesion formation through NLPs was shown in literature not to be host-specific, to be artificially inducible by leaf infiltration of the protein, to act in a dose-dependent manner and to be restricted to dicots, as no effect was detectable in monocotyl plants $(32,56,62)$, moss, nor in any animal cell types (5). Here we have shown that the necrosis effect of Vl-NEP-1 is inducible on leaves of Brassica and Tobacco after infiltration of the protein, showing both a leaf age and a dose-dependent impact on the severity of necrosis symptom characteristics. In field trials and greenhouse experiments, B. napus does not show any necrosis during infection with $V$. longisporum as compared to infection of host plants by other plant pathogenic Verticillium spp.; therefore we postulate that the concentration of Vl-NEP-1 in the plant is apparently too low to induce necrosis in vivo and does not reach the phytotoxic threshold during natural infestation. Besides necrosis, the inhibition of root and cotyledon growth in Arabidopsis was reported (5, 23). However, we showed that V1-NEP-1 negatively affects the root growth of Arabidopsis seedlings but enhances the development of root hairs on all tested ecotypes when treated with the protein. In contrast to this, we were able to show that the growth of natural host plant $B$. napus is not affected at all by the treatment with the protein. As we showed by CLSM studies with V1-NEP-1 silencing mutants, the protein does not seem to be involved in the ability of the fungus to penetrate the root to get into the plant. There seems to be a crucial role for Vl- 
NEP-1 to infest the plant by giving the fungus the ability to spread in the plant but live undetected as a biotroph organism, as shown by pathogenicity assays using VL-NEP-1 silencing mutants and subsequent quantification of fungal DNA in the plant by qPCR. Pathogenicity assays using A. thaliana for inoculation showed no difference in symptom severity using Vl-NEP-1 silencing mutants compared to wild type infected plants, which suggests that Vl-NEP-1 does not play a crucial role during the infestation of Arabidopsis. This hypothesis seems to be supported by the fact that plants of $A$. thaliana react to morphological changes like inhibition of root length upon treatment with purified V1-NEP-1, whereas $B$. napus shows no changes, and therefore these plants probably differ in their defence reaction to infection. Furthermore, the reaction of Arabidopsis to $V$. longisporum does not lead to a drastic increase of SA compared to infection of B. napus, as proved by Ratzinger et al. in 2008 (70) and by our experiments, which leads to the assumption that the ways plants attempt to counteract fungal infestation vary.

Regarding our results from western hybridizations, showing the ability of Vl-NEP-1 to secrete out of the fungus (see Figure 30) and to be transported upwards in the plant (see Figure 31) which was strengthened by immunofluorescence microscopy analysis showing a clear immunofluorescence in stem tissue in the absence of any fungal hyphae, we concluded our observations during this work by showing that the protein probably had a function in the xylem vessels of allowing the fungus to grow and spread into the plant. By accepting the recent characterization of NLPs as showing phytotoxic activity (5), structural high similarity to cytolytic toxins (30) and plasma membrane permeabilization activity, we end up with the hypothesis that VINEP-1 is secreted in the xylem by the fungus and permeabilizes the surrounding cell-membranes of the xylem cylinder and causes leakage of nutrients from adjacent tissue into the xylem sap, thereby increasing the fitness of $V$. longisporum in the xylem.

\section{ACKNOWLEDGMENTS}

The author would like to thank the following people for their outstanding assistance with this chapter: 
Prof. Petr Karlovsky for giving me the opportunity to work on NLPs of $V$. longisporum, and his continuous assistance with scientific problems. Dr. Arne Weiberg for the excellent cooperation and the remarkable help with work on NLPs and with writing this chapter. Mona Quambusch for her assistance during B. napus pathogenicity assays, measuring phytohormone marker genes, and also for her work on CLSM studies. Haidi Yin and Ruth Pilot for working on the protein purification and subsequent related experiments. Dr. Richard Splivallo for measuring ethylene production of $V$. longisporum. Haiquan Xu for the construction of a $V$. longisporum genomic library and subsequent identification of Vl-NEP genes.

\section{REFERENCES}

1. Nürnberger T. (1999). Signal perception in plant pathogen defence. Cell. Mol. Life Sci. 55:167-182.

2. Luke H.H., Wheeler H.E. (1955). Toxin production by Helminthosporium victoriae. Phytopathol. 45:453-458.

3. Agrios G.N. (2005). Plant Pathology. Elsevier Academic Press, London.

4. Bailey B.A. (1995). Purification of a protein from cultures filtrates of Fusarium oxysporum that induces ethylene and necrosis in leaves of Erythroxylum coca. Phytopathol. 85:1250-1255.

5. Qutob D., Kemmerling B., Brunner F., Küfner I.,Engelhardt S.,Gust A.A., Luberacki B., et al. (2006). Phytotoxicity and Innate Immune Responses Induced by Nep1-Like Proteins. The Plant Cell 18:3721-3744.

6. Fellbrich G., Romanski A., Varet A., Blume B., Brunner F., Engelhardt S., Felix G., Kemmerling B., Krzymowska M., Nürnberger T. (2002). NPP1, a Phytophthora-associated trigger of plant defence in parsley and Arabidopsis. Plant J. 32:375-390.

7. Karapapa et al. (1997). Advances in Verticillium research and disease management. St. Paul, Minnesota, APS Press, 196-203.

8. Beckmann C.H. (1987). The nature of wilt disease of plants. St. Paul, MN, USA, APS Press. 
9. Pullman, G. S., De Vay, J. E. (1982). Epidemiology of Verticillium wilt of cotton: A relationship between inoculum density and disease progression. Phytopathology 72: 549-554.

10. Koike M., Fujita M., Nagoa H., Ohshima S. (1996): Random amplified polymorphic DNA analysis of Japanese isolates of Verticillium dahliae and V. albo atrum. Plant Disease 80: 1224-1227.

11. Xiao C. L., Subbaro K. V. (1998). Relationship between Verticillium dahliae inoculum density and wilt incidence, severity, and growth of cauliflower. Phytopathology 88: 1108-1115.

12. Debode, J., Claeys, D. \& Höfte, M. (2004). Control of Verticillium wilt of cauliflower with crop residues, lignin and microbial antagonists. IOBC WPRS Bull $27,41-45$.

13. Veronese P., Narasimhan M.L., Stevenson R.A., Zhu J.K., Weller S.C., Subbarao K.V., Bressan R.A. (2003). Identification of a locus controlling Verticillium disease symptom response in Arabidopsis thaliana. Plant J. 35:574-587.

14. Eynck C., Koopmann B., Grunewalft-Stocker G., Karlovsky P., von Tiedemann A. (2007). Differential interactions of Verticillium longisporum and $V$. dahliae with Brassica napus detected with molecular and histological techniques. Eur. J. Plant Pathol. 118:259-274.

15. Koch W., Wagner C., Seitz H.U. (1998). Elicitor-induced cell death and phytoalexin synthesis in Daucus carota L. Planta 206:523-532.

16. Pemberton C.L., Salmond G.P.C. (2004). The Nep1-like proteins - a growing family of microbial elicitors of plant necrosis. Mol. Plant Pathol. 5:353-359.

17. Ottmann C., Luberacki B., Küfner I., Koch W., Brunner F., Weyand M., Mattinen L., Pirhonen M., Anderluh G., Seitz H.U., Nürnberger T., Oecking C. (2009). A common toxin fold mediates microbial attack and plant defence. PNAS 106 (25):10359-10364.

18. Mattinen L., Tshuikina M., Mäe A., Pirhonen M. (2004). Identification and Characterization of Nip, Necrosis-Inducing Virulence Protein of Erwinia carotovora subsp. carotovora. MPMI 17 (12):1366-1375. 
19. Fellbrich G., Blume B., Brunner F., Hirt H., Kroj T., Ligterink W., Romanski A., Nürnberger T. (2000). Phytophthora parasitica Elicitor-Induced Reactions in Cells of Petroselinum crispum. Plant Cell Physiol. 41 (6):692-701.

20. Qutob D., Kemmerling B., Brunner F., Küfner I., Engelhardt S., Gust A.A., Luberacki B., Seitz H.U., Stahl D., Rauhut T., Glawischnig E., Schween G., Lacombe B., Watanabe N., Lam E., Schlichting R., Scheel D., Nau K., Dodt G., Hubert D., Gijzen M., Nürnberger T. (2002). Phytotoxicity and innate immune responses induced by Nep1-like proteins. Plant Cell 18:3721-3744.

21. Jennings J.C., Apel-Birkhold P.C., Bailey B.A., Anderson J.D. (2000). Induction of ethylene biosynthesis and necrosis in weed leaves by a Fusarium oxysporum protein. Weed Sci. 48:7-14.

22. Keates S.E., Kostman T.A., Anderson J.D., Bailey B.A. (2003). Altered gene expression in three plant species in response to treatment with Nep1, a fungal protein that causes necrosis. Plant Phsiol. 132:1610-1622.

23. Bae H., Kim M.S., Sicher R.C., Bae H.-J., Bailey B.A. (2006). Necrosis- and ethylene inducing peptide from Fusarium oxysporum induces a complex cascade of transcripts associated with signal transduction and cell death in Arabidopsis. Plant Physiol. 141:1056-1067.

24. Staats M., van Baarlem P., Schouten A., van Kan J.A.L., Bakker F.T. (2007). Positive selection in phytotoxic protein-encoding genes of Botrytis species. Fung. Genet. Biol. 44:52-63.

25. Garcia O., Macedo J.A., Tibúrcio R., Zaparoli G., Rincones J., Bittencourt L.M., Ceita G.O., Micheli F., Gesteira A., Mariano A.C., Schiavinato M.A., Medrano F.J., Meinhardt L.W., Pereira G.A., Cascardo J.C. (2007). Characterization of necrosis and ethylene-inducing proteins (NEP) in the basidiomycete Moniliophthora perniciosa, the causal agent of witches' broom in Theobroma cacao. Mycol. Res. 111 (4):443-455.

26. Schouten A., van Baarlen P., van Kan J.A.L. (2008). Phytotoxic Nep1-like proteins from the necrotrophic fungus Botrytis cinerea associate with membranes and the nucleus of plant cells New Phytologist 177:493-505. 
27. Cechin A.L., Sinigaglia M., Lemke N.,Echeverrigaray S., Cabrera O.G., Pereira G.A.G., Mombach J.C.M. (2008). Cupin: A candidate molecular structure for the Nep1- like protein family. BMC Plant Biol. 8:50.

28. Gijzen M., Nürnberger T. (2006). Nep1-like proteins from plant pathogens: Recruitment and diversification of the NPP1 domain across taxa. Phytochem. 67:1800- 1807.

29. Fradin E.F., Thomma B.P.H.J. (2006). Physiology and molecular aspects of Verticillium wilt diseases caused by $V$. dahliae and $V$. albo-atrum. Mol. Plant Pathol. 7:71-88

30. Küfner I, Ottmann C, Oecking C, Nürnberger T. (2009). Cytolytic toxins as triggers of plant immune response. Plant Signal Behav. 2009 Oct;4(10):977-9.

31. Wang J., Cai Y., Gou J., Mao Y., Xu Y., Jiang W., Chen X. (2004). Vd-NEP, an elicitor from Verticillium dahliae, induces cotton plant wilting. Appl. Environ. Microbiol. 70:4989-4995.

32. Veit S., Wörle J.M., Nürnberger T., Koch W., Seitz H.U. (2001). A novel protein elicitor (PaNie) from Pythium aphanidermatum induces multiple defence responses in carrot, Arabidopsis, and tobacco. Plant Physiol. 127:832-841.

33. Bailey B.A., Apel-Birkhold P.C, Luster D.G. (2002). Expression of NEP1 by Fusarium oxysporum f. sp. erythroxyli After Gene Replacement and Overexpression Using Polyethylene Glycol-Mediated Transformation. Phytopathol. 92 (8):833-841.

34. Zeise K., von Tiedemann A. (2001) Morphological and physiological differentiation among vegetative compatibility groups of Verticillium dahliae in relation to $V$. longisporum. Journal of Phytopathology 149: 469-475.

35. Williams PH. \& Hill C. B. (1986). Rapid-cycling populations of Brassica. Science $232,1385-1389$.

36. NASC ID: N1029, The European Arabidopsis Stock Centre, Loughborough, United Kingdom.

37. NASC ID: N1092, The European Arabidopsis Stock Centre, Loughborough, United Kingdom.

38. NASC ID: N1686, The European Arabidopsis Stock Centre, Loughborough, United Kingdom. 
39. Utermark J. (2008). Genetic transformation of filamentous fungi by Agrobacterium tumefaciens. Nature Protocols, Published online 20 March 2008.

40. Zeise, K. (1992). Gewächshaustest zur Resistenzprüfung von Winterraps (Brassica napus L. var. oleifera Metzger) gegen den Erreger der Rapswelke Verticillium dahliae Kleb. Nachrichtenblatt Deutscher Pflanzenschutzdienst 44:125-128.

41. Maniatis T., Fritsch EF., Sambrook J. (1982). Molecular Cloning: A Laboratory Manual. Trade paperback, Cold Spring Harbor Laboratory Press.

42. Xu H. (2011). Dissertation, Georg-August University of Goettingen.

43. Xiangqing Pan, Ruth Welti, Xuemin Wang (2010). Quantitative analysis of major plant hormones in crude plant extracts by high-performance liquid chromatographymass spectrometry. Nat Protoc. $2010 ; 5$ (6):986-92.

44. Zou WJ, Yoneyama K, Takeuchi Y, Iso S, Rugmekarat S, Chae SH, Sato D, Joel DM (2004) In vitro infection of host roots by differentiated calli of the parasitic plant Orobranche. Journal of Experimental Botany 55: 899-907.

45. Eynck C, Koopmann B., Grunewaldt-Stoecker G., Karlovsky P. and von Tiedemann A. (2007). Differential interactions of Verticillium longisporum and $V$. dahliae with Brassica napus detected with molecular and histological techniques. European Journal of Plant Pathology, 118(3):259-274.

46. Laemmli UK. (1970). Cleavage of structural proteins during the assembly of the head of bacteriophage T4. Nature 227 (5259): 680-685.

47. Blum H., Beier H., Gross HJ. (1987). Improved silver staining of plant-proteins, RNA and DNA in polyacrylamide gels. Electrophoresis 8, p. 93-99.

48. Bradford MM (1976) A rapid and sensitive method for the quantitation of microgram quantities of protein utilizing the principle of protein-dye binding. Annu Rev Biochem $72248-254$

49. Shi SR, Key ME, Kalra KL. (1991). Antigen retrieval in formalin-fixed, paraffinembedded tissues: an enhancement method for immunohistochemical staining based on microwave oven heating of tissue sections. J Histochem Cytochem.; 39(6):741-8.

50. The Broad Institute, homepage Verticillium group database (http://www.broad. mit.edu/annotation/genome/verticilliumdahliae/MultiHome.html).

51. National Center for Biotechnology Information, homepage (http://www.ncbi. nlm.nih.gov/). 
52. Emanuelsson O., Brunak S., von Heijne G., Nielsen H. (2007). Locating proteins in the cell using TargetP, SignalP, and related tools. Nature Protocols 2:953-971.

53. Larkin M.A., Blackshields G., Brown N.P., Chenna R., McGettigan P.A., McWilliam H., Valentin F., Wallace I.M., Wilm A., Lopez R., Thompson J.D., Gibson T.J., Higgins D.G. (2007). Clustal W and Clustal X version 2.0. Bioinformatics 23 (21):2947-2948.

54. Gijzen, M. and Nürnberger, T. (2006). Nep1-like proteins from plant pathogens: recruitment and diversification of the NPP1 domain across taxa. Phytochemistry 67(16): 1800-1807.

55. Rice P., Longden I., Bleasby A. (2000). EMBOSS: the European Molecular Biology Open Software Suite. Trends Genet.16 (6):276-277.

56. Motteram J., Küfner I., Deller S., Brunner F., Hammond-Kosack K.E., Nürnberger T., Rudd J.J. (2009). Molecular Characterization and Functional Analysis of MgNLP, the Sole NPP1 Domain-Containing Protein, from the Fungal Wheat Leaf Pathogen Mycosphaerella graminicola. MPMI 22 (7):790-799.

57. Saitou N., Nei M. (1987). The neighbor-joining method: A new method for reconstructing phylogenetic trees. Mol. Biol. Evol. 4:406-425.

58. Felsenstein J. (1985). Confidence limits on phylogenies: An approach using the bootstrap. Evolution 39:783-791.

59. Zuckerkandl E., Pauling L. (1965). Evolutionary divergence and convergence in proteins, pp. 97-166 in Evolving Genes and Proteins, edited by V. Bryson and H.J. Vogel. Academic Press, New York.

60. Tamura K., Dudley J., Nei M., Kumar S. (2007). MEGA4: Molecular Evolutionary Genetics Analysis (MEGA) software version 4.0. Mol. Biol. Evol. 24:1596-1599.

61. Neumann M.J., Dobinson K.F. (2003). Sequence tag analysis of gene expression during pathogenic growth and microsclerotia development in the vascular wilt pathogen Verticillium dahliae. Fung. Genet. Biol. 38:54-62.

62. Staats M., Van Baarlen P., Schouten A., Van Kan J.A.L. (2007). Functional analysis of NLP genes from Botrytis elliptica. Mol. Plant Pathol. 8 (2):209-214.

63. Tyler BM, Tripathy S, Zhang X, Dehal P, Jiang RH, Aerts A, Arredondo FD, Baxter L, Bensasson D, Beynon JL, Chapman J, Damasceno CMB, Dorrance AE, Dou D, Dickerman AW, Dubchak IL, Garbelotto M, Gijzen M, Gordon SC, 
Govers F, Grunwald NJ, Huang W, Ivors KL, Jones RW, Kamoun S, Krampis K, Lamour KH, Lee MK, McDonald WH, Medina M, Meijer HJG, Nordberg EK, Maclean DJ, Ospina- Giraldo MD, Morris PF, Phuntumart V, Putnam NH, Rash S, Rose JKC, Sakihama Y, Salamov AA, Savidor A, Scheuring CF, Smith BM, Sobral BWS, Terry A, Torto-Alalibo TA, Win J, Xu Z, Zhang H, Grigoriev IV, Rokhsar DS, Boore JL. (2006). Phytophthora genome sequences uncover evolutionary origins and mechanisms of pathogenesis. Science 313:1261-1266.

64. Barbara D.J., Clewes E. (2003). Plant pathogenic Verticillium species: how many of them are there? Mol. Plant Pathol. 4:297-305.

65. Fahleson J., Lagercrantz U., Hu Q., Steventon L.A., Dixelius C. (2003). Estimation of genetic variation among Verticillium isolates using AFLP analysis. Eur. J. Plant Pathol. 109:361-371.

66. Kadotani N., Nakayashiki H., Tosa Y., Mayama S. (2003). RNA Silencing in the Phytopathogenic Fungus Magnaporthe oryzae. MPMI 16 (9):769-776.

67. Nakayashiki H., Hanada S., Quoc N.B., Kadotani N., Tosa Y., Mayama S. (2005). RNA silencing as a tool for exploring gene function in ascomycete fungi. Fung. Genet. Biol. 42:275-283.

68. Pieterse CM, Van Loon LC. (2004). NPR1: the spider in the web of induced resistance signaling pathways. Curr Opin Plant Biol. 2004 Aug;7(4):456-64.

69. Glazebrook J. (2005). Contrasting mechanisms of defence against biotrophic and necrotrophic pathogens. Annu Rev Phytopathol. 2005;43:205-27.

70. Ratzinger A. (2008). Development and application of LC-MS-based differential metabolic profiling in plant systems. Dissertation, Georg-August Universität Göttingen.

71. Yalpani N, Balke NE, Schulz M (1992). Induction of UDP-glucose: salicylic acid glucosyltransferase in oat roots. Plant Physiol 100:1114-1119.

72. Buchanan B.B., Gruissem W., Jones R.L. (2002). Biochemistry and Molecular Biology of Plants. Am Soc Plant Phys (Rockville).

73. Wang K.C.L., Li H., Ecker J.R. (2002). Ethylene Biosynthesis and Signaling Networks. Plant Cell (Supplement) S131-S151. 
74. Thaler, J.S., Owen, B. and Higgins, V.J. (2004). The role of the jasmonate response in plant susceptibility to diverse pathogens with a range of lifestyles. Plant Physiol. $135,530-538$.

75. Tjamos, S.E., Flemetakis, E., Paplomatas, E.J. and Katinakis, P. (2005). Induction of resistance to Verticillium dahliae in Arabidopsis thaliana by biocontrol agent K165 and pathogenesis-related proteins gene expression. Mol. Plant-Microbe. Interact. $18,555-561$.

76. Johansson A, Staal J, Dixelius C (2006). Early responses in the ArabidopsisVerticillium longisporum pathosystem are dependent on NDR1, JA- and ETassociated signals via cytosolic NPR1 and RFO1. Mol Plant Microbe Interact 19:958969

77. Narang, R.A., Bruene, A., and Altmann, T. (2000). Analysis of phosphate acquisition efficiency in different Arabidopsis accessions. Plant Physiol 124, 17861799.

78. Meyer, R.C., Torjek, O., Becher, M., and Altmann, T. (2004). Heterosis of biomass production in Arabidopsis. Establishment during early development. Plant Physiol 134, 1813-1823.

79. Tappe H. (2008). Verticillium longisporum induced gene expression in Arabidopsis thaliana. Dissertation, Georg-August University of Goettingen.

80. McHale L, Tan X, Koehl P, Michelmore RW (2006). Plant NBS-LRR proteins: adaptable guards. Genome Biol 7 (4): 212.

81. Song W-Y Wang G-L, Zhu L-H Fauquet C, Ronald P (1995). A receptor kinaselike protein encoded by the rice disease resistance gene Xa21. Science 270: 1804 1806. 


\section{APPENDIX}

\begin{tabular}{|c|ll|}
\hline Primer name & \multicolumn{2}{|c|}{ Primer sequences } \\
\hline \multirow{2}{*}{ NEP-type A } & F & A TGCTTCCCTCCACAATC \\
& R & AAACGCGGCGCGCATGTTC \\
\hline \multirow{2}{*}{ NEP-type B } & F & TGCCACGAGATTTCTCTCCA \\
& R & CTGACATGCGGCGCACGTG \\
\hline \multirow{2}{*}{ NEP-type C } & F & CAATTCGTATCAAGATCCAACACAG \\
& R & CACCCGTCGGTCCATTGCT \\
\hline \multirow{2}{*}{ NEP-type D } & F & ATAGCATGCCAGCTGCACTC \\
& R & CGACTGCCAGAGCAGCTTGA \\
\hline \multirow{2}{*}{ NEP-type E } & F & GCAACAGCCTCATCAGCCTCA \\
& R & TCCGTATCTTGAGCACCGGA \\
\hline \multirow{2}{*}{ NEP-type F } & F & ATCTCACTAGCCTTGTCCTTC \\
& R & CTGGGTCTGGCTTCCATTGT \\
\hline \multirow{2}{*}{ NEP-type G } & F & ATCGGAAACATCTTCACTTGGC \\
& R & TGGGTCGTATTCGCAGTATC \\
\hline \multirow{2}{*}{ NEP-type H } & F & AGATGGCGACTCGGTTCTGGT \\
& R & TCATCTTCCGCATTAGCAAAGC \\
\hline
\end{tabular}

Table 6: $V$. dahliae NLP primers

\begin{tabular}{|c|ll|}
\hline Primer name & \multicolumn{2}{|c|}{ Primer sequences } \\
\hline Vl-NEP-1 & F & CCAGCCTCTGCTTCACATTGCCCACG \\
& R & GGCCTGGTTTGCGTTGTTCGAGTTGA \\
\hline \multirow{2}{*}{ Vl-NEP-2 } & F & ACGTAGTCGTCTTCGCACGCGGA \\
& R & CGGGCTCTTGTAGAACGAGCCTG \\
\hline \multirow{2}{*}{ Vl-NEP-3 } & F & GCGATTGTCTACCACAAGGACAGCA \\
& R & GCCTAGCCTTGCGAATGTTCTCAG \\
\hline \multirow{2}{*}{ Vl-NEP-4 } & F & TGCCGACGAGCGTAGCCATGCA \\
& R & TCCTCATTAGCCCATGCCATGTGA \\
\hline \multirow{2}{*}{ Vl-NEP-5 } & F & GTACGCTGCTTGGCTGGCACA \\
& R & GTTGTGAAGCCACGTGCCGTCA \\
\hline \multirow{2}{*}{ Vl-tubulin } & F & GTTCATCTTCAGACCGGTCAGT \\
& R & CGATCTCGTTTCGGAGTACCAGC \\
\hline \multirow{2}{*}{ Vl-rps17 } & F & GCATCTGCGATGAGATCGCCA \\
& R & TCGGAGTTCTGGGTAAAGTCGAGA \\
\hline
\end{tabular}

Table 7: V. longisporum qRT-PCR primers 


\begin{tabular}{|c|lc|}
\hline Primer name & \multicolumn{2}{|c|}{ Primer sequences } \\
\hline Vl-NEP-1-SB & F & TGACGACATTCTCCCAGTCG \\
& R & CGGTGAGGTCAAGTAAGACACGC \\
\hline
\end{tabular}

Table 8: Vl-NEP-1 specific primers for southern hybridization

\begin{tabular}{|c|ll|}
\hline Primer name & \multicolumn{1}{c|}{ Primer sequences } \\
\hline Bn-PR-1* & F & AGTCACTAACTGTTCTCGAC \\
& R & CGATTACACGTCCACATAATT \\
\hline Bn-PDF-1.2* & F & GAAGCACCAACAATGGTG \\
& R & GTGACACAGACTTATTGAACG \\
\hline Bn-aco-1 & F & CTCTCGAGACCGAAGTGGAAGA \\
& R & CTGTGTGAGCCCTAAGCCCTTTG \\
\hline Bn-acs-1 & F & ATCGATGACGTGTCAGTCAAGGAA \\
& R & CATCCGACAACATGGAAGCCAA \\
\hline Bn-act & F & AAGAGCAGTTCTTCGGTGGA \\
& R & GCGACCACCTTGATCTTCAT \\
\hline Bn-his & F & AAAGGTCGTTACGCGATCAG \\
& R & TTTGGCAGCTTTAGCAGCTT \\
\hline
\end{tabular}

*primer sequence published by Kamble et al. 2007.

Table 9: B. napus qRT-PCR primers

\begin{tabular}{|c|c|}
\hline Primer name & Primer sequence \\
\hline Vl-NEP-1-sense-SdaI-F & TAGTGACCTGCAGGTGACGACATTCTCCCAGTCG \\
\hline Vl-NEP-1-sense- $N d e I-R$ & GATATGCATATGCGGTGAGGTCAAGTAAGACACGC \\
\hline Vl-NEP-1-antisense- $A s c I-F$ & GAGCTCGGCGCGCCTGACGACATTCTCCCAGTCG \\
\hline Vl-NEP-1-antisense- $B g l$ III-R & GATATGAGATCTCGGTGAGGTCAAGTAAGACACGC \\
\hline intron- $N d e I-F$ & CTATACCATATGACTGCTCTACCCGTACGTTG \\
\hline intron- $B g l$ III-R & GATATGAGATCTCCTGGCACTCTTTGCTATTGTTGG \\
\hline
\end{tabular}

Table 10: Primer sequences to construct a HP-fragment of Vl-NEP-1

(bold: cloning sites; italic: gene-specific sequence)

\begin{tabular}{|c|c|}
\hline Primer name & Primer sequence \\
\hline OLG-70 & CAGCGAAACGCGATATGTAG \\
\hline OLG-71 & GGCTTGTAGGGGGTTTAGA \\
\hline
\end{tabular}

Table 11: Primer sequences to amplify a fragment of an ITS region from $V$. longisporum 
Chapter 3: Characterization of NEP-like proteins of Verticillium longisporum

\begin{tabular}{|c|cc|}
\hline Primer name & \multicolumn{2}{c|}{ Primer sequence } \\
\hline \multirow{2}{*}{ VL-NEP-1-cDNA-compl } & F & AGAGACATATGCAGCATCCCCCCAAGGTTA \\
& R & AGAGAGGATCCAGAAACGCGGCGCGCATGTTC \\
\hline
\end{tabular}

Table 12: Primer sequences to amplify complete cDNA of VI-NEP-1

Complete gDNA and cDNA sequences and alignments of VI-NEP genes

\section{Vl-NEP-1}

\section{gDNA sequence}

1 ATGCTTCCCTCCACAATCTTCTCGGTCTTTGCCCTCGTCGGCAGCGCCTT

51 GGCTCAGCATCCCCCCAAGGTTAACCACGACAGTATCAACCCCGTCCGCG

101 ATACTCTGGGGCCCAACGGCGACATGATCAGGAAGTTCCAGCCTCTGCTT

151 CACATTGCCCACGGTTGCCAGCCTTACTCCGCTGTCAACACCCGCGGTGA

201 GGTCAAGTAAGACACGCAGCACTCCCTTCAGCTTACACAAAGCTCCACGC

251 TAACACATATTCTGCAGCGCCGGTCTCCAAGACAGCGGTACCACCGCAGG

301 CGGCTGCAAGGAAACCAGCAAGGGCCAGACCTACGCCCGCTCCATGACCC

351 TGAACGGCCAGTTCGGCATCATGTACGCCTGGTACTGGCCCAAGGACCAG

401 CCCGCCGACGGCAACCTCGCCAGCGGCCACCGCCACGACTGGGAGAACGT

451 CGTCATCTGGTTCAACTCGAACAACGCAAACCAGGCCGGCATCCTGCGCG

501 GCGCCGCCTCGGGCCACGGCGACTACAAGAAGGTCAACAACCCCCAGCGC

551 AACAACAACAACCTCCACGTCGAGTACTTCACCAGCCTCGGCAAGAACCA

601 CGAGCTGCAGTTCAAGACGTCGCCCGGCCGCACCTACTGGATCTGGGACT

651 GGGACAGGATGGACAGCACCGTCCAGGGCGCCCTCAACCGCGCCGACTTT

701 GGCAGCGCCAACTGCCCCTTCAACAACAACAACTTTGAGAGGAACATGCG

751 CGCCGCGTTTTAA

\section{cDNA sequence}

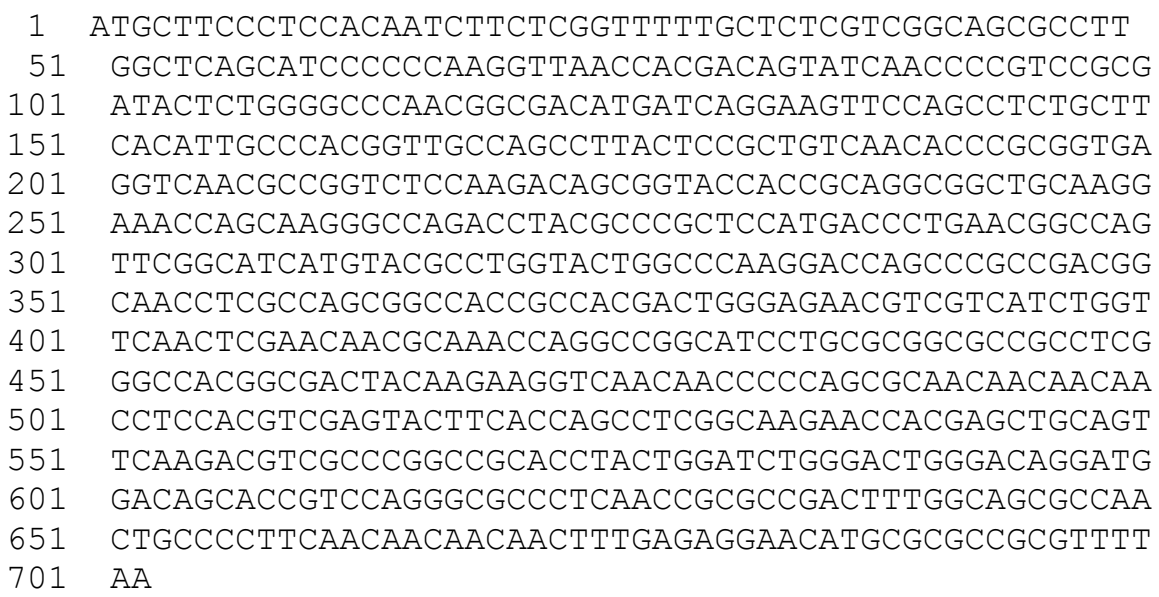

\section{Alignment}




\begin{tabular}{|c|c|c|c|}
\hline gDNA & 1 & ATGCTTCCCTCCACAATCTTCTCGGTCTTTGCTCTCGTCGGCAGCGCCTT & 50 \\
\hline CDNA & 1 & ATGCTTCCCTCCACAATCTTCTCGGTTCTTGCTCTCGTCGGCAGCGCCTT & 50 \\
\hline gDNA & 51 & GGCTCAGCATCCCCCCAAGGTTAACCACGACAGTATCAACCCCGTCCGCG & 100 \\
\hline CDNA & 51 & GGCTCAGCATCCCCCCAAGGTTAACCACGACAGTATCAACCCCGTCCGCG & 100 \\
\hline gDNA & 101 & ATACTCTGGGGCCCAACGGCGACATGATCAGGAAGTTCCAGCCTCTGCTT & 150 \\
\hline CDNA & 101 & ATACTCTGGGGCCCAACGGCGACATGATCAGGAAGTTCCAGCCTCTGCTT & 150 \\
\hline gDNA & 151 & CACATTGCCCACGGTTGCCAGCCTTACTCCGCTGTCAACACCCGCGGTGA & 200 \\
\hline CDNA & 151 & CACATTGCCCACGGTTGCCAGCCTTACTCCGCTGTCAACACCCGCGGTGA & 200 \\
\hline gDNA & 201 & GGTCAAGTAAGACACGCAGCACTCCCTTCAGCTTACACAAAGCTCCACGC & 250 \\
\hline CDNA & 201 & GGTCAA------------------------------- & 206 \\
\hline gDNA & 251 & TAACACATATTCTGCAGCGCCGGTCTCCAAGACAGCGGTACCACCGCAGG & 300 \\
\hline CDNA & 207 & ------------- CGCCGGTCTCCAAGACAGCGGTACCACCGCAGG & 239 \\
\hline gDNA & 301 & CGGCTGCAAGGAAACCAGCAAGGGCCAGACCTACGCCCGCTCCATGACCC & 350 \\
\hline CDNA & 240 & CGGCTGCAAGGAAACCAGCAAGGGCCAGACCTACGCCCGCTCCATGACCC & 289 \\
\hline gDNA & 351 & TGAACGGCCAGTTCGGCATCATGTACGCCTGGTACTGGCCCAAGGACCAG & 400 \\
\hline CDNA & 290 & TGAACGGCCAGTTCGGCATCATGTACGCCTGGTACTGGCCCAAGGACCAG & 339 \\
\hline gDNA & 401 & CCCGCCGACGGCAACCTCGCCAGCGGCCACCGCCACGACTGGGAGAACGT & 450 \\
\hline CDNA & 340 & CCCGCCGACGGCAACCTCGCCAGCGGCCACCGCCACGACTGGGAGAACGT & 389 \\
\hline gDNA & 451 & CGTCATCTGGTTCAACTCGAACAACGCAAACCAGGCCGGCATCCTGCGCG & 500 \\
\hline CDNA & 390 & CGTCATCTGGTTCAACTCGAACAACGCAAACCAGGCCGGCATCCTGCGCG & 439 \\
\hline gDNA & 501 & GCGCCGCCTCGGGCCACGGCGACTACAAGAAGGTCAACAACCCCCAGCGC & 550 \\
\hline CDNA & 440 & GCGCCGCCTCGGGCCACGGCGACTACAAGAAGGTCAACAACCCCCAGCGC & 489 \\
\hline gDNA & 551 & AACAACAACAACCTCCACGTCGAGTACTTCACCAGCCTCGGCAAGAACCA & 600 \\
\hline CDNA & 490 & АACAACAACAACCTCCACGTCGAGTACTTCACCAGCCTCGGCAAGAACCA & 539 \\
\hline gDNA & 601 & CGAGCTGCAGTTCAAGACGTCGCCCGGCCGCACCTACTGGATCTGGGACT & 650 \\
\hline CDNA & 540 & CGAGCTGCAGTTCAAGACGTCGCCCGGCCGCACCTACTGGATCTGGGACT & 589 \\
\hline gDNA & 651 & GGGACAGGATGGACAGCACCGTCCAGGGCGCCCTCAACCGCGCCGACTTT & 700 \\
\hline CDNA & 590 & GGGACAGGATGGACAGCACCGTCCAGGGCGCCCTCAACCGCGCCGACTTT & 639 \\
\hline CDNA & 701 & GGCAGCGCCAACTGCCCCTTCAACAACAACAACTTTGAGAGGAACATGCG & 750 \\
\hline gDNA & 640 & GGCAGCGCCAACTGCCCCTTCAACAACAACAACTTTGAGAGGAACATGCG & 689 \\
\hline gDNA & 751 & CGCCGCGTTTTAA & \\
\hline CDNA & 690 & CGCCGCGTTTTAA & \\
\hline
\end{tabular}

\section{Vl-NEP-2}

\section{gDNA sequence}

1 ATGCAGCATACTCTCTCTCTCAACCGCCCGCCCTGCTTGGCGCCCTGTCA

51 GCCGTCAATGCTTCTCCTGCGCGCCATTTTGAGGCGTGATATTATCACCG 


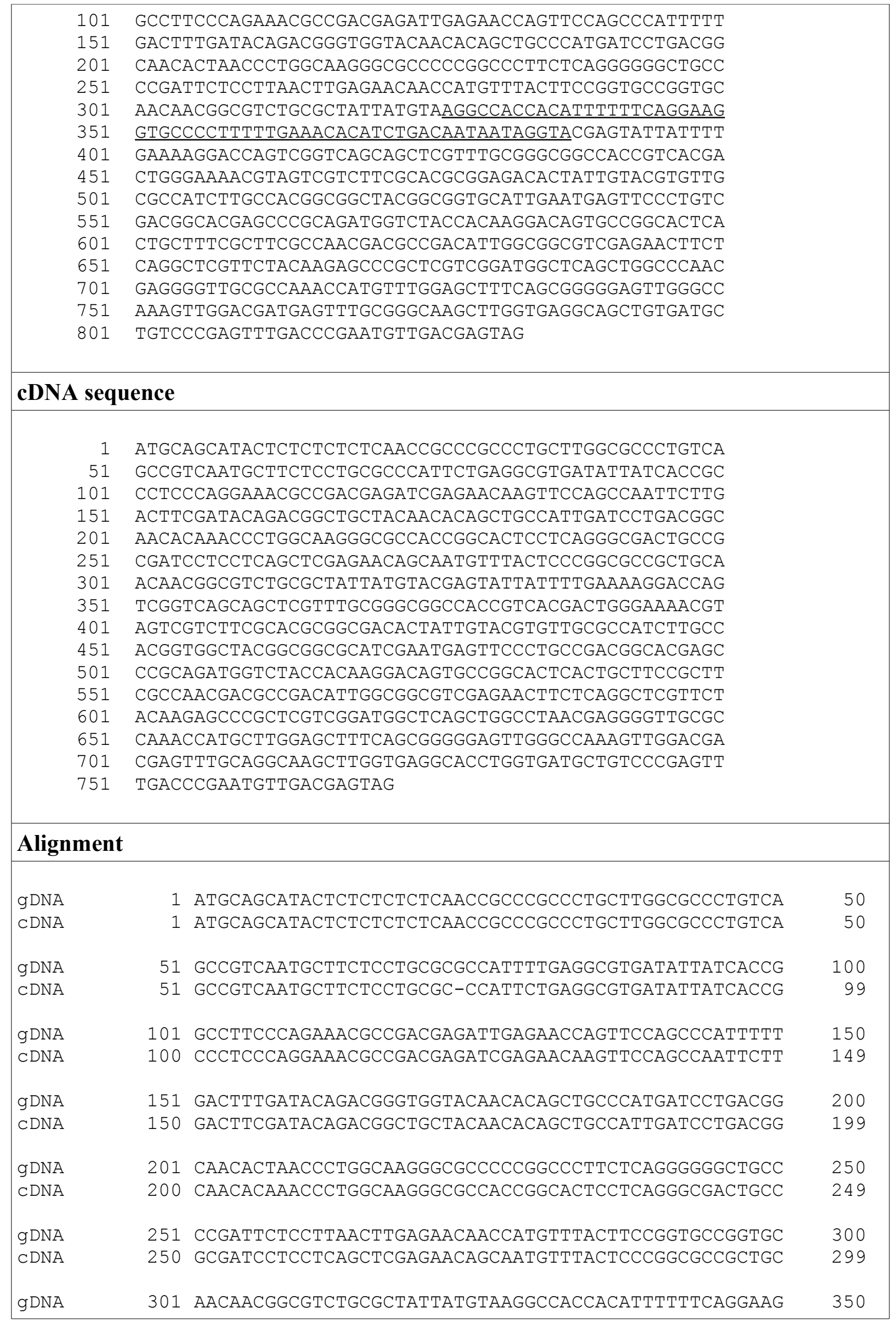


Chapter 3: Characterization of NEP-like proteins of Verticillium longisporum

\begin{tabular}{|c|c|c|c|}
\hline CDNA & 300 & AACAACGGCGTCTGCGCTATTATGTA--------------------- & 325 \\
\hline gDNA & 351 & GTGCCCCTTTTTGAAACACATCTGACAATAATAGGTACGAGTATTATTTT & 400 \\
\hline CDNA & 326 & ----------------------------------CGAGTATTATTTT & 338 \\
\hline gDNA & 401 & GAAAAGGACCAGTCGGTCAGCAGCTCGTTTGCGGGCGGCCACCGTCACGA & 450 \\
\hline CDNA & 339 & GAAAAGGACCAGTCGGTCAGCAGCTCGTTTGCGGGCGGCCACCGTCACGA & 388 \\
\hline gDNA & 451 & CTGGGAAAACGTAGTCGTCTTCGCACGCGGAGACACTATTGTACGTGTTG & 500 \\
\hline CDNA & 389 & CTGGGAAAACGTAGTCGTCTTCGCACGCGGCGACACTATTGTACGTGTTG & 438 \\
\hline gDNA & 501 & CGCCATCTTGCCACGGCGGCTACGGCGGTGCATTGAATGAGTTCCCTGTC & 550 \\
\hline CDNA & 439 & CGCCATCTTGCCACGGTGGCTACGGCGGCGCATCGAATGAGTTCCCTGCC & 488 \\
\hline gDNA & 551 & GACGGCACGAGCCCGCAGATGGTCTACCACAAGGACAGTGCCGGCACTCA & 600 \\
\hline CDNA & 489 & GACGGCACGAGCCCGCAGATGGTCTACCACAAGGACAGTGCCGGCACTCA & 538 \\
\hline gDNA & 601 & СTGCTTTCGCTTCGCCAACGACGCCGACATTGGCGGCGTCGAGAACTTCT & 650 \\
\hline CDNA & 539 & CTGCTTCCGCTTCGCCAACGACGCCGACATTGGCGGCGTCGAGAACTTCT & 588 \\
\hline gDNA & 651 & CAGGCTCGTTCTACAAGAGCCCGCTCGTCGGATGGCTCAGCTGGCCCAAC & 700 \\
\hline CDNA & 589 & CAGGCTCGTTCTACAAGAGCCCGCTCGTCGGATGGCTCAGCTGGCCTAAC & 638 \\
\hline gDNA & 701 & GAGGGGTTGCGCCAAACCATGTTTGGAGCTTTCAGCGGGGGAGTTGGGCC & 750 \\
\hline CDNA & 639 & GAGGGGTTGCGCCAAACCATGCTTGGAGCTTTCAGCGGGGGAGTTGGGCC & 688 \\
\hline gDNA & 751 & AAAGTTGGACGATGAGTTTGCGGGCAAGCTTGGTGAGGCAGCTGGTGATG & 799 \\
\hline CDNA & 689 & AAAGTTGGACGACGAGTTTGCAGGCAAGCTTGGTGAGGCACCTGGTGATG & 738 \\
\hline gDNA & 800 & CTGTCCCGAGTTTGACCCGAATGTTGACGAGTAG & \\
\hline CDNA & 739 & CTGTCCCGAGTTTGACCCGAATGTTGACGAGTAG & \\
\hline
\end{tabular}

\section{Vl-NEP-3}

\section{gDNA sequence}

1 ATGCTTTTCAGTGTCGGACTCCTCGCCCTTGCGGCTTTGCCTACGTCTTT

51 CGGAGCTGTCATTCAGGCGCGCCAGGACGACCCCGAGAACCCTCCCCGTG

101 AACCCCAGCCTCCTCCTCCCGGCCCCATCTTCGGACGGGCACCCGACCTC

151 GACAAGCGCTTCCAGCCTGCTCTTGACTTTGACACGGACAGCTGCTACAA

201 TGCACCAGCAATCGGCCCCAACGGCGACCTCGCCATTGGCATGTATCCCT

251 TCGAGTGGCCGCCTCAAGCGGGCTGCCGCAACGAAGAGATGCTGGACAGA

301 GGCAATGTCTACTCCCGCCAGCGCTGTAACAACGGCTATTGCGTCATCTT

351 TTACGCCTACTACTTCCAGAAGGATACGGCGACGCCCATTGACGGGCACC

401 GCCACGACTGGGAGCACATTGCCGTGTGGGTGCGCCAGAGCGACAGCTTC

451 GTCACGCACGTTGCCGTCAGCCAGCACAAGGGCTACGACATTCGTGAAAA

501 CTCCCAGATCACCTGGACTGCGGCGGAGAATGGAAAGCCGGCGATTGTCT

551 ACCACAAGGACAGCATTCTGACACACTGCTTCCGGTTCGGCAGTGGTGCC

601 GACGCCGGCGGTCCCGGGCCGGAGAACCACAGGAACCAGTGGATCACGGG

651 CCCGCTTCTGGGGTACTTCGGTTGGGACACTGTCGAGCAGAGGGACAGGA

701 TGCTGACGCACAACTGGGAGGCTGGCTCTATCGCCATCAAGAATGAGAAC

751 TTTGCTGAGAACATTCGCAAGGCTAGGCCTGCTGGGCTGGTCTCTGACGA

801 CAACTTTGACGACGAGGGCACGCACAACATCTGA 


\section{Vl-NEP-4}

gDNA sequence

1 ATGGTGCTGTCAGTGCCATCGACCGCCTCAGTCATGCGGCGCCAGAGCAA

51 CTCGAGTCGGATCCTCAGCGATAGTCAAGCGCTCGAACCCATCGTGGGCG

101 GCCACGACTTCGCCTACTATTTTGAAGTGAAGTTCCAGCCATTGGTGGAC

151 ATCGACACCGACAGCTGCTACAGCGTGCCCGCCATGACCATGGACGGAAC

201 CGCATCCGAGGGCCTTTCACCCTCCGACGATGTCGGTCCGTGCCGTCCCC

251 GCTCCGCCCTTGACCGGTCCAACGTGTATGTCAGGGGCCGCTGCAACCGC

301 GGATGGTGCGCATTCGTCTACGCCTATTACTTCCAGATGGACTGGGCCTG

351 GTCGTGGCCCGTGAGCAGCTACAACCACCGCCACGACTGGGAGCACGTCG

401 TCGTCTGGGCCAAGGAGGGCAAAGTCCGCGGCGTTTCCGTCTCGCAACAC

451 GGCGGCTACGAGAACCGCGTCGCGGAAGACCAGAGGCTTCGCTTCGACTA

501 CACACCAAAGGAGTTTCCGTATCCTGCGTGGGATCCCATGCCGACGAGCG

551 TAGCCATGCACCCCAAGGTCGTCTTTCACAAGGACGGTGCCCGCACGCAC

601 TGCTTCCGCTTCGCCAAGGACAGCGACGACTATGAGGGCCAGGAGAATGA

651 GAGAGGCGTTTGGATTCGTGGCGGTCTCATCAGTATGCTGCTCATGCCGA

701 GCGACTGGCAGGAGAAGTTCAGATCTCAGAATTGGGGGAGTGCTCACATG

751 GCATGGGCTAATGAGGAGGACTTTACCGGGCATCTCGTCAAGTCCATGCC

801 GCAGGAAGCCAGAGACGACGGGTTTGACTGTGCCTACGACGAGAATCCAG

851 CTCTCAAAGGCTTTCCTATGGACTGGAAGAAGTGGGGACTGA

\section{Vl-NEP-5}

\section{gDNA sequence}

1 ATGTATCACAAAATCCTTCTCGTCGGCGTGCTAGCCACCCTTACTGGGTT

51 GACTTCCGCCAATGACGCGATCCCAGGCAGTGCTTTCGAAAGTGAGCCAA

101 CCCAAGAACACAATTACAACACAGATCGCAGTCAACTAACGATCTATAGA

151 CAGCGGACAAGAAGCAGCCATCGCCGGTGCTCCCATGTATCACTTTGGTC

201 GCTCGTGGGACCGCAAGCCATGCTACCCAGAGGCCGGTCAGACTGACGGC

251 GTCAAGACGGACGGCGTTGACTCGGACCTGTGCTTCAGCAGTCAGAATGG

301 CGGTTGTGCCGATCCCGGACCCTGGAACGGCGTCAACTCTCCCGGAAACC

351 CGTTTCCGGTGTATTACACCGTTCGGCAGTGCAACGACAATGAGTGGCGC

401 GTTGCGTACAGCATCTACTATAAGAAGGATTCTGGCCATAAGAACGACTG

451 GGAGAACAGCATTGTCATCTGGAACGGAGACGGTGCTGGCGGCTGGAAGC

501 GGAGCGGTACGCTGCTTGGCTGGCACAGCGGTTGGGATTACATTGCTTGG

551 GGCGACATCCAGAACACTGTGAACAAGTAAGCAAAATCCAGGAGATGCAG

601 CTTTTCAAAGCGTCTTTGCTGACAAACGTAGCGACGGCGATCTTTTCGAC

651 CAGGGCGCCAAGGATCGAAACCATGCCAAGGCTTATCAGGGATTCTACTA

701 CCATGCCACGTTCTCGACTCGCAAGACGTCCCTCAACACCTGCGCCAACA

751 CTACGGACGAGTTCCGATCGAACGACTGGTACTTCCTCCCTGACGGCACG

801 TGGCTTCACAACGGAGATCTCATCCAAGGTAGGCTGGTAACGGAAAGAGT

851 AATACGTTGAGCATCAAACACTAACTCTGACTCCATCCAGATGGCTGGGA

901 TTAGGGCTCTGCCGACACAAACCCGTCTTCTCTGCCAAATGAGCGCGCTG

951 GATCTGCAACCGAGGCTGA

\section{cDNA sequence}

1 ATGTATCACAAAATCCTTCTCGTCGGCGTGCTAGCCACCCTTACTGGGTT

51 GACTTCCGCCAATGACGCGATCCCAGGCAGTGCTTTCGAAAACAGCGGAC 


$\begin{array}{ll}101 & \text { ATGAAGCAGCCATCGCCGGTGCTCCCATGTATCACTTTGGTCGCTCGTGG } \\ 151 & \text { GACCGCAAGCCATGCTACCCAGAGGCTGGTCAGACTGACGGCGTCAAGAC } \\ 201 & \text { GGACGGCGTTGACTCGGACCTTTGCTTCAGCAGTCAGAATGGCGGTTGTG } \\ 251 & \text { CCGATCCCGGACCCTGGAACGGGTCAACTCTCCCGGAAACCGTTTCCG } \\ 301 & \text { GTGTATTAACCGTTCGGCAGTGCAACGACAAGAGTGGCGCGTTGCGTA } \\ 351 & \text { CAGCATCTACTATAAGAAGGATTCTGGCCATAAGAACGACTGGGAGAACA } \\ 401 & \text { GCATTGTCATCTGGAACGGAGACGGTGCTGGCGGCTGGAAGCGGAGGGT } \\ 451 & \text { ACGCTGCTTGGCTGGCACAGCGGTTGGGATTACATTGCTTGGGGCGACAT } \\ 501 & \text { CCAGAACACTGTGAACAACGACGGCGATCTTTTCGACCAGGGCGCCAAGG } \\ 551 & \text { ATCGAAACCATGCCAAGGTTATCAGGGATTCTACTACCATGCCACGTTC } \\ 601 & \text { TCGACTCGCAAGACGTCCCTCAACACCTGCGCCAACACTAGGGACGAGTT } \\ 651 & \text { CCGATCGAACGACTGGTACTTCCTCCCTGACGGCACGTGGCTTCACAACG } \\ 701 & \text { GAGATCTCATCCAAGATGGCTGGGATTATGGCTCTGCCGACACGAACCCG } \\ 751 & \text { TCTTCTCTGCGAAATGAAGCACGCTGGATCTGCAACCGAGGCTGA }\end{array}$

\section{Alignment}

\begin{tabular}{|c|c|c|c|}
\hline gDNA & 1 & ATGTATCACAAAATCCTTCTCGTCGGCGTGCTAGCCACCCTTACTGGGTT & 50 \\
\hline $\mathrm{CDNA}$ & 1 & ATGTATCACAAAATCCTTCTCGTCGGCGTGCTAGCCACCCTTACTGGGTT & 50 \\
\hline gDNA & 51 & GACTTCCGCCAATGACGCGATCCCAGGCAGTGCTTTCGAAAGTGAGCCAA & 100 \\
\hline $\mathrm{CDNA}$ & 51 & GACTTCCGCCAATGACGCGATCCCAGGCAGTGCTTTCGAAA--------- & 91 \\
\hline gDNA & 101 & CCCAAGAACACAATTACAACACAGATCGCAGTCAACTAACGATCTATAGA & 150 \\
\hline $\mathrm{CDNA}$ & 92 & $-------------------------------------------------\mathrm{A}$ & 92 \\
\hline gDNA & 151 & CAGCGGACAAGAAGCAGCCATCGCCGGTGCTCCCATGTATCACTTTGGTC & 200 \\
\hline $\mathrm{CDNA}$ & 93 & CAGCGGACATGAAGCAGCCATCGCCGGTGCTCCCATGTATCACTTTGGTC & 142 \\
\hline gDNA & 201 & GCTCGTGGGACCGCAAGCCATGCTACCCAGAGGCCGGTCAGACTGACGGC & 250 \\
\hline $\mathrm{CDNA}$ & 143 & GCTCGTGGGACCGCAAGCCATGCTACCCAGAGGCTGGTCAGACTGACGGC & 192 \\
\hline gDNA & 251 & GTCAAGACGGACGGCGTTGACTCGGACCTGTGCTTCAGCAGTCAGAATGG & 300 \\
\hline CDNA & 193 & GTCAAGACGGACGGCGTTGACTCGGACCTTTGCTTCAGCAGTCAGAATGG & 242 \\
\hline gDNA & 301 & CGGTTGTGCCGATCCCGGACCCTGGAACGGCGTCAACTCTCCCGGAAACC & 350 \\
\hline $\mathrm{CDNA}$ & 243 & CGGTTGTGCCGATCCCGGACCCTGGAACGGCGTCAACTCTCCCGGAAACC & 292 \\
\hline gDNA & 351 & CGTTTCCGGTGTATTACACCGTTCGGCAGTGCAACGACAATGAGTGGCGC & 400 \\
\hline CDNA & 293 & CGTTTCCGGTGTATTACACCGTTCGGCAGTGCAACGACAATGAGTGGCGC & 342 \\
\hline gDNA & 401 & GTTGCGTACAGCATCTACTATAAGAAGGATTCTGGCCATAAGAACGACTG & 450 \\
\hline CDNA & 343 & GTTGCGTACAGCATCTACTATAAGAAGGATTCTGGCCATAAGAACGACTG & 392 \\
\hline gDNA & 451 & GGAGAACAGCATTGTCATCTGGAACGGAGACGGTGCTGGCGGCTGGAAGC & 500 \\
\hline CDNA & 393 & GGAGAACAGCATTGTCATCTGGAACGGAGACGGTGCTGGCGGCTGGAAGC & 442 \\
\hline gDNA & 501 & GGAGCGGTACGCTGCTTGGCTGGCACAGCGGTTGGGATTACATTGCTTGG & 550 \\
\hline CDNA & 443 & GGAGCGGTACGCTGCTTGGCTGGCACAGCGGTTGGGATTACATTGCTTGG & 492 \\
\hline gDNA & 551 & GGCGACATCCAGAACACTGTGAACAAGTAAGCAAAATCCAGGAGATGCAG & 600 \\
\hline CDNA & 493 & GGCGACATCCAGAACACTGTGAACAA----------------------- & 518 \\
\hline gDNA & 601 & СTTTTCAAAGCGTCTTTGCTGACAAACGTAGCGACGGCGATCTTTTCGAC & 650 \\
\hline CDNA & 519 & -------------------------- CGACGGCGATCTTTTCGAC & 537 \\
\hline gDNA & 651 & CAGGGCGCCAAGGATCGAAACCATGCCAAGGCTTATCAGGGATTCTACTA & 70 \\
\hline
\end{tabular}


Chapter 3: Characterization of NEP-like proteins of Verticillium longisporum

\begin{tabular}{|lclc|}
\hline cDNA & 538 & CAGGGCGCCAAGGATCGAAACATGCCAAGGTTTATCAGGGATTCTACTA & 587 \\
gDNA & 701 & CCATGCCACGTTCTCGACTCGCAAGACGTCCCTCAACACCTGCGCCAACA & 750 \\
CDNA & 588 & CCATGCCACGTTCTCGACTCGCAAGACGTCCCTCAACACCTGCGCCAACA & 637 \\
gDNA & 751 & CTACGGACGAGTTCCGATCGAACGACTGGTACTTCCTCCCTGACGGCACG & 800 \\
CDNA & 638 & CTAGGGACGAGTTCCGATCGAACGACTGGTACTTCCTCCCTGACGGCACG & 687 \\
gDNA & 801 & TGGCTTCACAACGGAGATCTCATCCAAGGTAGGCTGGTAACGGAAAGAGT & 850 \\
CDNA & 688 & TGGCTTCACAACGGAGATCTCATCCAAG------------------ & 715 \\
gDNA & 851 & AATACGTTGAGCATCAAACACTAACTCTGACTCCATCCAGATGGCTGGGA & 900 \\
CDNA & 716 & ------------------------------ATGGCTGGGA & 725 \\
gDNA & 901 & TTAGGGCTCTGCCGACACAAACCCGTCTTCTCTGCCAAATGA-GCGCGCT & 949 \\
CDNA & 726 & TTATGGCTCTGCCGACACGAACCCGTCTTCTCTGCGAAATGAAGCACGCT & 775 \\
gDNA & 950 & GGATCTGCAACCGAGGCTGA & 970 \\
CDNA & 776 & GGATCTGCAACCGAGGCTGA & 795 \\
\end{tabular}




\title{
Chapter 4: Detection and functional analysis of a polyketide synthase gene of Verticillium longisporum
}

\author{
Malte Beinhoff, Arne Weiberg, Haiquan Xu, Hanno Wolf, Wolfgang Hiegl and Petr \\ Karlovsky
}

Molecular Plant Pathology and Mycotoxin Research Unit, Department for Crop Sciences, Georg-August University of Goettingen, Grisebachstrasse 6, 37077 Goettingen, Germany.

\begin{abstract}
Polyketides from phytopathogenic fungi are known to often play a role during the hostpathogen interaction as toxins, or as pathogenicity or virulence factors. Here we report our results on a polyketide synthase (PKS) gene of Verticillium longisporum, named as V1-PKS-1, which we detected in the genome of the $V$. longisporum isolate VL43 using degenerated primers based on a fungal L-ketoacylsynthase (KS)-domain. The detected fragment shows high homology to other fungal PKS genes of the $w A$-type. Strongly enhanced transcript levels of Vl-PKS-1 in hypocotyl tissue of $V$. longisporum infected Brassica napus plants compared to the expression in grown mycelium implies the role of the gene in the interaction with the host plant, and this motivated us to construct knock down mutants to switch off the gene function in $V$. longisporum to elucidate the role of V1-PKS-1 in the pathogenic life cycle of the fungus.
\end{abstract}

\section{INTRODUCTION}

Fungal polyketides (PK) belong to a large group of well-characterized secondary metabolites with diverse biological functions (1) such as toxins (mycotoxin) like fumonisins, aflatoxins or zearalenones $(2,3,4)$, or as pigments such as melanin, which is known from literature to play an important role in appressoria-mediated infection processes of plant pathogens $(2,5)$. PKs 
have been deeply investigated in both prokaryotic and eukaryotic organisms, and it has been shown that despite the structural diversity of PKs these secondary metabolites are all derived from highly functionalized carbon chains assembled by a mechanism close to the fatty acid synthetic pathway (6). The biosynthesis of PKs is carried out by enzymes called polyketide synthases (PKSs). The large family of PKSs can be subdivided into three classes according to their functionality, and these are referred to as type I, type II and type III PKSs $(7,8)$. Type I PKSs are large multifunctional enzymes (9) that are encoded by a single gene, similar to the type I fatty acid synthases (FAS) of fungi and animals with up to $350 \mathrm{kDa}$ (10). These characteristic PKSs of fungi and vertebrates form reduced PKs such as erythromycin. The biosynthesis of the PKs is thereby derived by catalyzing the transfer of acetyl units from malonyl-coenzyme A (CoA) to the active site thiol of the $\beta$-ketoacyl synthase (KS) by an acetyl carrier protein (ACP) as a starting point for the elongation of the PK chain. These chains include several domains with defined function such as keto-reductase (KR) domains or dehydratase $(\mathrm{DH})$ domains, and this gives rise to the structural diversity of PKs and their manifold biological activities. Type II PKSs are characteristic of FAS II found in bacteria and plants, and form mostly aromatic PKs such as tetracycline by the use of only a single domain. Type III PKSs are only present in plants and show major differences compared to the other classes of PKSs. Type III PKSs are 80-85 $\mathrm{kDa}$ large enzymes which execute a direct condensation of malonyl-CoA and therefore lack the presence of an ACP domain which is a key enzyme in the fatty acid and PK biosynthesis.

The first fungal PKS gene was discovered in 1990 by Beck et al. in the filamentous fungus Penicillium patulum (11). The isolated type I PKS gene comprises five catalytic domains identified as KS, KR, DH, AT and ACP, and was characterized to synthesize the antibiotic 6methylsalicylic acid. Since then, many PKS genes that synthesize PKs with characteristics of mycotoxins or fungal pigments that are essential for the pathogenic life style of fungi have been detected in various plant pathogenic species $(3,12,13,14)$. PKs are primarily responsible for the colouring of fungal organs by pigments such as melanin, which have a great functional significance in appressoria or microsclerotia of fungui, giving these organs protection and stability against external influences such as micro-organism competitors or abiotic factors such as UV irradiation due to their toxic ability and their phenolic-like chemical structure. The essential function of melanins in the appressorial turgor generation and subsequent penetration of plant cell walls by fungal pathogens was first shown in 
Pyricularia oryzae $(2,5)$. In Colletotrichum lagenarium knock-down mutants of a type I PKS change to an albino phenotype with non-melanized appressoria showing a reduced ability to penetrate the cell wall of host plants (15). In fungi, the best researched melanin is produced by a pathway that forms 1,8-dihydroxynaphthalene (DHN), which is polymerized to so-called DHN melanin. This type of melanin is widely distributed among ascomycota fungi.

Here we report on the identification of a PKS from the ascomycota fungus $V$. longisporum named as V1-PKS-1. This has high homology to other fungal PKS genes of the $w A$-type, which are known to be involved in pigment and aflatoxin biosynthetic pathways. $V$. longisporum is a soil-borne plant pathogen that infects only Brassica and other cruciferous plants (16). The fungus has the characteristics of a hemibiotrophic pathogen, starting its pathogenic life cycle living as a biotroph organism undetected by the plant, and strictly restricted to the xylem vessels of host plants. Only at late stages of infection does $V$. longisporum switch its life style to that of a necrotrophic organism and release nutrients from dying plant tissue. During this stage of plant infestation, the fungus forms dark melanized resting structures that are released to the soil by dead plant tissue. Because of the protective and stabilizing features of melanins, these so-called microsclerotia can remain in the soil for many years and stay capable to germinate until the environmental conditions are suitable to start a new infection cycle. As known from study of other phytopathogenic fungi, $V$. longisporum does not show any melanized apressoria during infection of host plants; therefore the contribution of melanins in this infection process should not be assumed. During this report we give notes about a putative contribution of Vl-PKS-1 in the life cycle of $V$. longisporum.

\section{MATERIALS AND METHODS}

\section{Fungal and bacterial strains}

V. longisporum VL43 strain was provided by the Department of Crop Sciences, Section Plant Pathology and Crop Protection, (University of Goettingen, Goettingen, Germany) and was used for all experiments in this chapter. The isolate originates from oilseed rape plants 
collected in Northern Germany (17). Optimal growth temperature is between 20 and $23{ }^{\circ} \mathrm{C}$ and this was therefore used for all experiments using $V$. longisporum.

Gliocladium roseum (DSMZ 62726), Fusarium culmorum strain Fc3-8F (DSMZ 62223), F. verticilloides strain TR3 and F. proliferatum strain 3 was provided by Dr. Evelyn Möller (State Plant Breeding Institute, University of Hohenheim, Hohenheim, Germany (emeritus state)) and were used for a fungal interaction assay.

Trichoderma harzianum (DSMZ 63323) was provided by the Department of Crop Sciences, Section Plant Pathology and Crop Protection (University of Goettingen, Goettingen, Germany) and was also used for a fungal interaction assay.

Agrobacterium tumefaciens strain AGL1 was provided by Dr. Susanne Frick (Leibniz Institute of Plant Biochemistry, Martin-Luther University Halle-Wittenberg, Halle/Saale, Germany) and was used for the transformation of $V$. longisporum.

Electrocompetent Escherichia coli DH10 $\beta$ strain (New England Biolabs, Ipswich, United Kingdom) was used for cloning purposes.

\section{Preparation of spore suspensions}

Approximately $1 \times 10^{4}$ spores were spread on a PDA plate and incubated at $23{ }^{\circ} \mathrm{C}$ for 10 days in the dark. The plates were subsequently flooded with $15 \%$ glycerine suspension and the spores were released from the conidiophores by scratching the mycelium with a spatula. The suspension was filtered through a sterile gauze and the spore concentration was estimated using a Thoma hemacytometer with a depth of $0.1 \mathrm{~mm}$ (Roth $\mathrm{GmbH}$, Karlsruhe, Germany). Spore suspension was diluted to $1 \times 10^{7}$ spores per $\mathrm{ml}^{-1}$ with a $15 \%$ glycerine solution and immediately stored in a $-80^{\circ} \mathrm{C}$ freezer.

\section{Plant material}

The seed material of "rapid cycle rape" (Brassica napus var. napus, Genom ACaacc) (18) was provided by the Department of Crop Sciences, Section Plant Pathology and Crop Protection (University of Goettingen, Goettingen, Germany). 


\section{Plasmids}

For A. thumefaciens-mediated transformation (AMT) of $V$. longisporum, we used the binary vector pPK2 (19) including boarder sequences for the AMT and a hygromycin B resistance cassette containing the hygromycin phosphotransferase gene from E. coli (hph) for selection of positive transformants.

\section{Enzymes}

For the construction of a pPK2 vector containing a hairpin (HP)-cassette and a antisense (AS)-RNA cassette to knock down the function of V1-PKS-1 gene, we used restriction enzymes, "T4-DNA Ligase” and affiliated buffers purchased from Fermentas Inc. (Fermentas, St. Leon-Rot, Germany).

Enzymes and reagents for first strand cDNA synthesis, including "Oligo(dT)18 Primer", "RiboLock ${ }^{\mathrm{TM}}$ RNase Inhibitor" and "M-MuLV Reverse Transcriptase" were also purchased from Fermentas Inc..

"BiotaqTM DNA Polymerase" (Bioline, Luckenwalde, Germany) was used for general amplification of fragments by polymerase chain reaction (PCR).

The "ABsolute Blue QPCR Fluorescin Mix“ (Fisher Scientific GmbH, Schwerte, Germany) was used for quantitative reverse transcriptase real time PCR (qRT-PCR) to assess the silencing efficiency of $V$. longisporum mutants.

\section{Primer walking}

Starting from a known DNA sequence of the candidate gene Vl-PKS-1, which we obtained by sequencing of fragments we amplified using degenerated primers of conserved domains from other fungal PKSs for PCR, we searched for homologous sequences by comparing our sequence with a database of known sequences from other organisms to find homologies among these (23). Using an alignment of Vl-PKS-1 and highly homologous sequences, we designed deduced degenerated primer sequences to amplify new sequence-information of V1PKS-1 using gDNA of $V$. longisporum as a template for PCR. Amplification was performed using one primer as a starting point for DNA synthesis derived from specific sequence- 
information of Vl-PKS-1 and a degenerated primer derived from Vl-PKS-1 homologous sequences from other organisms, including several universal nucleotides. Amplification was performed starting from both the downstream and upstream end of the V1-PKS-1 fragment to obtain new sequence information from both directions of the gene. Primers we used for primer walking are listed in Table 5 in the appendix.

\section{Vl-PKS-1 gene silencing}

Construction of pPK2-HP vector, containing a Vl-PKS-1 specific HP- or AS RNA cassette, was performed as described in Chapter 2 (Construction of HP-fragments using conventional cloning steps, from page 48).

\section{Transformation of $V$. longisporum}

Agrobacterium tumefaciens-mediated transformation (AMT) of $V$. longisporum was performed as described in Chapter 2 (see page 31) using a protocol published by Utermark (20).

\section{Southern hybridization}

To analyse the number of V1-PKS-1 gene-copies present in the genome of wild type $V$. longisporum and to determine the number of copies in the transformed Vl-PKS-1 mutants compared to the wild type, southern hybridization was performed as described in Chapter 2 (see page 30$)$.

\section{Plant pathogenicity assay using Vl-PKS-1 silencing mutants}

To assess any changes in the ability of $V$. longisporum wild type compared to V1-PKS-1 silencing mutants to infest $B$. napus plants we performed a pathogenicity assay as described in Chapter 3 (see page 68). 


\section{Extraction of gDNA and total RNA}

Total RNA for qRT-PCR and gDNA for PCR and southern hybridization were extracted from fungal mycelium or plants as described in Chapter 2 (see page 30) using a modified protocol of Maniatis et al. (21).

\section{qRT-PCR}

Total RNA from fungal mycelium was used for gene expression analysis. QRT-PCR was performed as described in Chapter 2 (see page 32).

\section{Fungal interaction assay}

A variety of other soil-borne fungi ( $G$. roseum, $F$. culmorum, $F$. proliferatum, $F$. verticilloides, $T$. harzianum) were selected for co-inoculation along with $V$. longisporum wild type and V1-PKS-1 silencing mutants. Therefore, $5 \mu$ of a spore suspension with a defined concentration $\left(1 \times 10^{6}\right.$ spores $\left./ \mathrm{ml}^{-1}\right)$ of both $V$. longisporum wild type or Vl-PKS-1 mutants and the fungal interactor was dropped on opposite sites of a PDA plate and was then grown at 23 ${ }^{\circ} \mathrm{C}$ in the dark. Because of its slow growth rate as compared to some tested fungi, $V$. longisporum was in some cases pre-grown for 7 days before inoculating the other fungi. Every day we observed the plates to find any notable changes in the interaction of $V$. longisporum wild type or V1-PKS-1 silencing mutants on the growth of the fungal interactors.

\section{Statistical analysis}

For statistical analysis and creation of graphs we used the statistical analysis software STATISTICA (StatSoft GmbH, Hamburg, Germany). Data are presented as means \pm standard deviation. Differences of data sets obtained from experiments using V. longisporum wild type and silencing mutants were determined using one way analysis of variance (ANOVA) followed by a post hoc test using "Fisher's Least Significant Difference (LSD) test" to show which differences were significant. 


\section{RESULTS AND DISCUSSION}

Highly conserved domains that are present in members of the PK family can be used to target PKSs in diverse organisms without having knowledge of any specific gene-sequences of the organism. We used degenerate primers (see Table 4 in the Appenix) based on a fungal L-KSdomain (22) to amplify putative PKS genes by using gDNA of $V$. longisporum isolate VL43 as a template for PCR. The amplified gene fragments were sequenced (Eurofins MWG Operon, Ebersberg, Germany) and compared with a database of known sequences to find homologies (23). From the amplified fragments, we detected an alignment that showed high homology to other fungal L-KS domains. The sequence of the putative PKS gene of $V$. longisporum was extended using the "Primer walking" technique. The extended fragment with a length of $1986 \mathrm{bp}$ showed high homology to fungal PKS genes of the $w A$-type, especially those involved in the biosynthesis of 1,8-dihydroxynapthalene (DHN)-melanin. We designated the detected gene as Vl-PKS-1. The translated cDNA sequence of the gene has high sequence homology (76 \% identity, GenBank Accession No. D83643.1) to a PKS type I gene of Colletotrichum lagenarium, which is a fungal pathogen causing anthracnose on host plants. PKS-1 knock-down mutants of $C$. lagenarium morphologically changed to albinos (15). Therefore, the involvement of Vl-PKS-1 in the biosynthesis of melanin in the life cycle of $V$. longisporum is assumable. Among many sequence homologies to other PKSs from diverse fungi, we could also match a hit with a significantly high similarity (96\% identity, GenBank Accession No. XM_003008852.1) to the extended Vl-PKS-1 sequence to a conidial yellow pigment synthase from $V$. dahlia, which is reported to be a parental strain of amphihaploid $V$. longisporum $(24,25)$.

\footnotetext{
V. longisporum DPRFFNMSPREAYQTDPMQRMALTTAYEALEMSGYVPNRTASTRLDRIGTFYGQTSDDWR 60 V. dahliae DPRFFNMSPREAYQTDPMQRMALTTAYEALEMSGYVPNRTASTRLDRIGTFYGQTSDDWR 60 
V. longisporum
V. dahliae
C. lagenarium

V. longisporum

V. dahliae

C. lagenarium

V. longisporum

V. dahliae

C. lagenarium

V. longisporum

V. dahliae

C. lagenarium

V. longisporum

V. dahliae

C. lagenarium

V. longisporum

V. dahliae

C. lagenarium

V. longisporum

V. dahliae

C. lagenarium

V. Longisporum

V. dahliae

C. lagenarium
IADKDNVLAVILGTATNHSADAISITHPHGPTQSILSSAILDEAGVDPLDVDYVEMHGTG 240 IADKDNVLAVILGTATNHSADAISITHPHGPTQSILSSAILDEAGVDPLDVDYVEMHGTG 240 LADKDNVLAVILGTATNHSADAISITHPHGPTQSILSRAILDDAGVDPLDVDYVEMHGTG 240 : ***************************************** $* * * *$ : $* * * * * * * * * * * * * * * * *$

TQAGDGTEMVSVTDVFAPANRKRPANRPLYLGAVKSNIGHGEAASGVTALCKVLMMLQKN 300 TQAGDGTEMVSVTDVFAPANRKRPADRPLYLGAVKSNIGHGEAASGVTALCKVLMMLQKN 300 TQAGDGTEMVSVTNVFAPADRKRPADRPLYLGAVKSNIGHGEAASGVTALTKVLMMMRKN 300

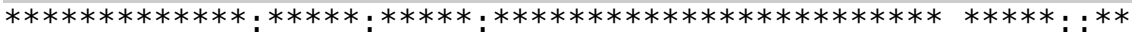

AIPPHVGIKKDINKTFPKDLAERNVNIAFHMTPLKRHDGKPRRIFINNFSAAGGNTGLLL 360 AIPPHVGIKKDINKTFPKDLAERNVNIAFHMTPLKRYDGKPRRIFINNFSAAGGNTGLLL 360 AIPPHVGIKKEINKTFPKDLSERNVNIAFHLTPFKRRDGKPRRIFVNNFSAAGGNTGLLL 360 ***********:*********; :*********; :**:** ********; :***************

EDGPSQTPTQADPRSAQVITITAKSKTAMIKNAEQLVTWMEKNPETPLADVAYTTTARRM 420

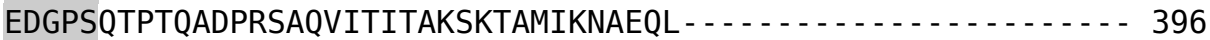
EDAPLIPAAEVDPRNVQVITVTGKSKAAMIRNAERLVGWMEQNPQTPLSHVAYTTTARRI 420 $* *$.* . : : : *** . .****:*,***:***:***:*

QHYWRLNVAASTLSEAMSAIKERLTQNFVPISTEQPKVAFIFTGQGSHYAGLGKDLYAHY 480

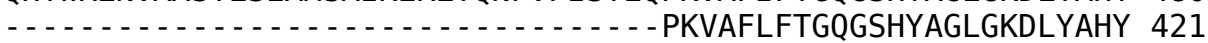
QHYWRMNVAASDLPEAQRLIKDRLKENFSPISTQQPKVAFMFTGQGSHYAGLGKDLYAHY 480 $* * * * *$ : $* * * * * * * * * * * * * * * * * * *$

AVFRDSINEFNHIAEVHGFPSFVPLIDGSEPDVSKLSPVVVQLGLCCFEMALARLWAAWG 540 AVFRDSIDEFNHIAEVHGFPSFVPLIDGSEPDVSNLSPVVVQLGLCCFEMALARLWSAWG 481 RVFRESIDEFNQLAQIHGFPSFLALIDGSEPDVAKLSPVIVQLGLCCFEMALARLWASWG 540

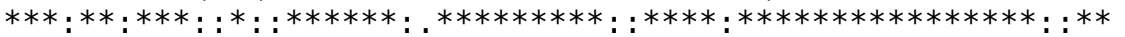

IRPAVVLGHSLGEYAALNAAGVLSASDTIYLVGSRAQLLVDRCTAGTHAMLAVQGPVGTV 600 IRPAVVLGHSLGEYAALNVAGVLSASDTIYLVGSRARLLVDRCTAGTHAMLAVQGPVGTV 541 IRPSAVMGHSLGEYAALNAAGVLSASDTIYLVGARAQLLVQKCTAGTHAMLAVTGPVDAV 600

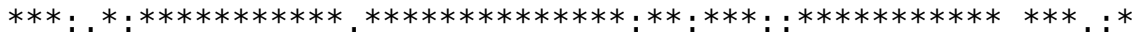

NEALGSEFASVNIACINGPRETVLSGETDHMMKIATQLGASGFKCTQLNVPYAFHS NEALGSESSSVNIACINGPRETVLSGEVDHMMRVATQLGASGFKCTQLKVPYAFHS MEALGSQAEAINVACINGPRETVLSGTAAKVSEISAQLGTSGFKCTQLKVPFAFHS 656

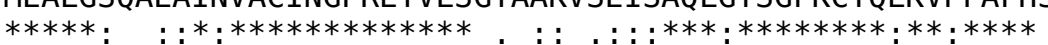

Figure 1: Alignment of translated cDNA sequence Vl-PKS-1 from $V$. longisporum with homologous protein sequences of $V$. dahliae and $C$. lagenarium

Multiple alignment of Vl-PKS-1 with PKS-1 form $C$. lagenarium and conidial yellow pigment synthase of $V$. dahliae constructed using the ClustalW2 algorithm. Greyed sequences indicate the conserved KS domain, Identical amino acids (aa) are indicated in the consensus line with asterisks, and conserved aa with dots.

As reported in the literature, pentaketide melanins are important virulence factors in fungal species that are pathogenic to plants or humans $(26,27,28)$. The detected PKS of $V$. dahliae named as conidial yellow pigment synthase is known from literature to condense acetate units to form a heptaketide napthopyrene YWA1, via a polyketomethylene intermediate step. YWA1 is a yellow pigment that is found in mature asexual spores (conidia) of Aspergillus nidulans. YWA1 knock-out mutants of A. nidulans produce albino conidia (29). In contrast to YWA1 of $A$. nidulans which is enzymatically converted to the pentaketide $1,3,6,8-$ 
tetrahydroxynaphthalene $(\mathrm{T} 4 \mathrm{HN})$ and produces its pigment without the use of the DHN pentaketide pathway (30), the enzyme produced by PKS-1, which was found in $C$. lagenarium, was identified to be a pentaketide synthase which synthesizes the pentaketide precursor TH4N directly for DHN melanin $(14,31)$. It is not known how A. nidulans uses a heptaketide synthase to initiate the biosynthesis of a pentaketide melanin but recent studies show that the heptaketide YWA1 is converted to the pentaketide 1,3,6,8 TH4N through a novel PK shortening mechanism (32).

Expression levels of V1-PKS-1 transcripts were measured by qRT-PCR in hypocotyl samples of $V$. longisporum infected B. napus plants and in in vitro samples of 10-day-old mycelium grown in artificial simulating xylem (SXM) medium in standing cultures with $12 \mathrm{~h}$ day/night change. Both were used to calculate a changefold factor describing the in planta vs. in vitro expression ratio.

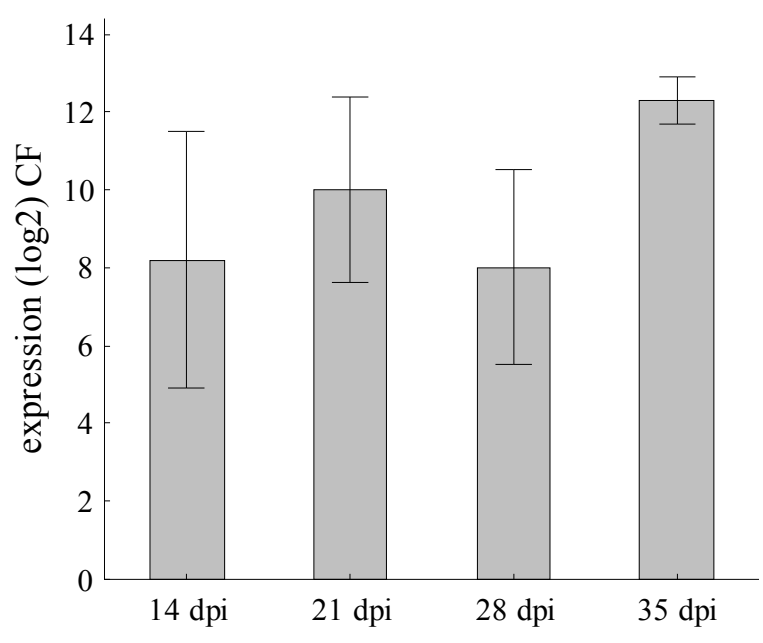

\section{Figure 2: Gene expression analysis of Vl-PKS-1}

Error bars indicate the standard error of three biological replicas.

Highly upregulated gene expression of V1-PKS-1 in planta makes a contribution to the pathogenic life cycle of $V$. longisporum assumable, and this motivated us to construct knockdown mutants for post-transcriptional inhibition of the candidate gene by intracellular expression of an HP-construct and also by expression of AS-RNA suitable to trigger RNAmediated gene silencing in $V$. longisporum. Transformation vectors V1-PKS-1-pPK2 carrying HP- or AS-cassettes were transformed into $V$. longisporum using Agrobacterium thumefaciens mediated transformation (AMT). Mutants were tested by PCR with primers for 
the hygromycin-cassette that was used for selection of positive transformants (data not shown) and also by southern hybridization. Four V1-PKS-1 (m2, 4, 9 and 10) mutants were generated by the intracellular expression of an HP cassette triggering RNAi in the fungus with a silencing efficiency up to $90 \%$. Transformants of $V$. longisporum that express an AS-RNA cassette for post-transcriptional silencing of Vl-PKS-1 show a moderate silencing efficiency of $70 \%$ at best (data not shown).

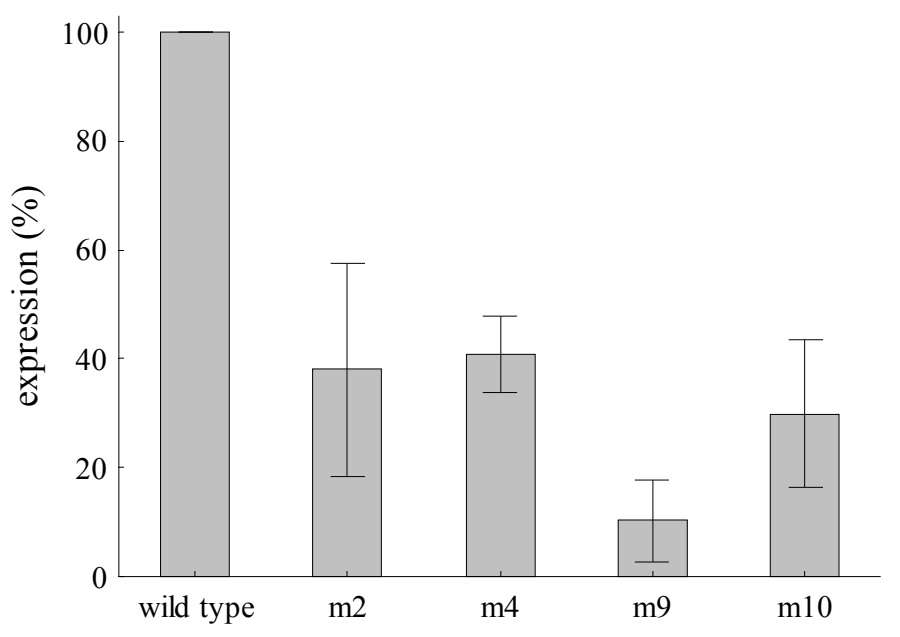

Figure 3: Gene silencing efficiency in Vl-PKS-1 transformants

Assessment of silencing efficiency triggered by the intracellular expression of an HP cassette in four mutants $(\mathrm{m} 2, \mathrm{~m} 4, \mathrm{~m} 9, \mathrm{~m} 10)$ was done in reference to wild type $V$. longisporum by qRT-PCR

Unexpectedly, the southern hybridization we performed using gDNA of $V$. longisporum and Vl-PKS-1 silencing mutants $\mathrm{m} 9$ and $\mathrm{m} 10$ for hybridization with a V1-PKS-1 specific 683 bp PCR-amplified probe, only showed a single native gene copy present in the genome of $V$. longisporum. Because the fungus is described as an interspecific hybrid of parental haploid $V$. dalhiae and $V$. albo-atrum strains $(16,17)$ and in both parental strains the homologous PKS to V1-PKS-1 named as conidial yellow pigment synthase could be detected by comparison with a Verticillium comparative genomics database (33), we expected that the V1-PKS-1 gene would be present twice in the genome of $V$. longisporum. For the Vl-PKS-1 mutants, additional signals could be detected on the blot accompanying the insertion of the HP-fragment into the genome of the fungus. 


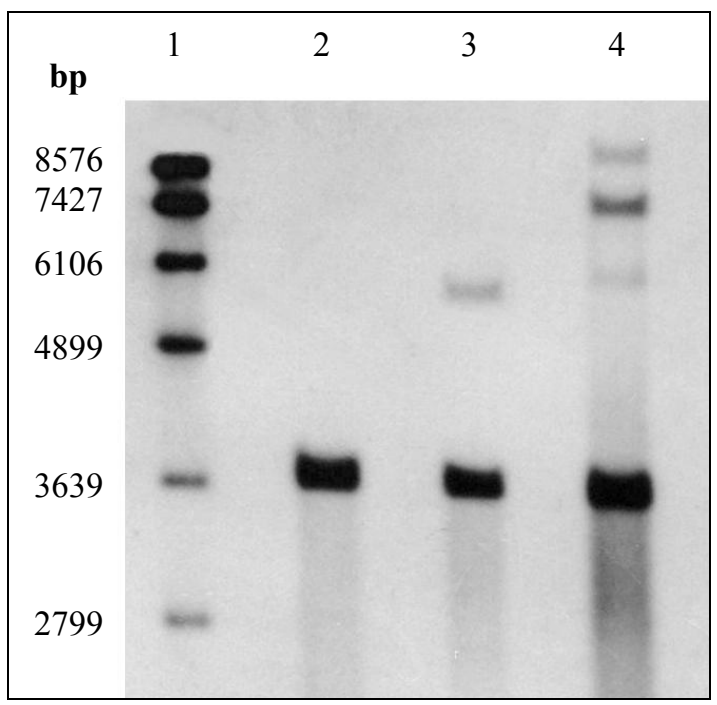

Figure 4: Southern-hybridization for candidate gene Vl-PKS-1

1 = DNA Molecular Weight Marker VII, DIG-labelled (Roche Diagnostics GmbH, Penzberg, Germany)

$2=$ gDNA from $V$. longisporum wild type cut with $N c o$ I

$\mathbf{3}=$ gDNA from Vl-PKS-1 silencing mutant $\mathrm{m} 9$ cut with $\mathrm{Nco}$

$4=$ gDNA from Vl-PKS-1 silencing mutant $\mathrm{m} 10$ cut with $\mathrm{NcoI}$

To evaluate any ectopic effects caused by the random integration of the silencing cassette into the fungal genome, we assessed the growth rate and germination efficiency of the mutants compared to the wild type of $V$. longisporum. For the evaluation of the spore germination rate of $V$. longisporum wild-type and the transformants, 50 spores were plated three-times and counted after 5 days of cultivation at $22{ }^{\circ} \mathrm{C}$ in the dark. No difference in the ability to germinate of the wild type fungus as compared to the silencing mutants could be detected. To assess the growth rate, single spores of wild-type and each transformant were plated threetimes and growth rates were measured every second day for 14 days. We observed an increased growth rate of the Vl-PKS-1 silencing mutants as compared to the wild type fungus. This growth rate became significant after $10 \mathrm{dpi}$. 

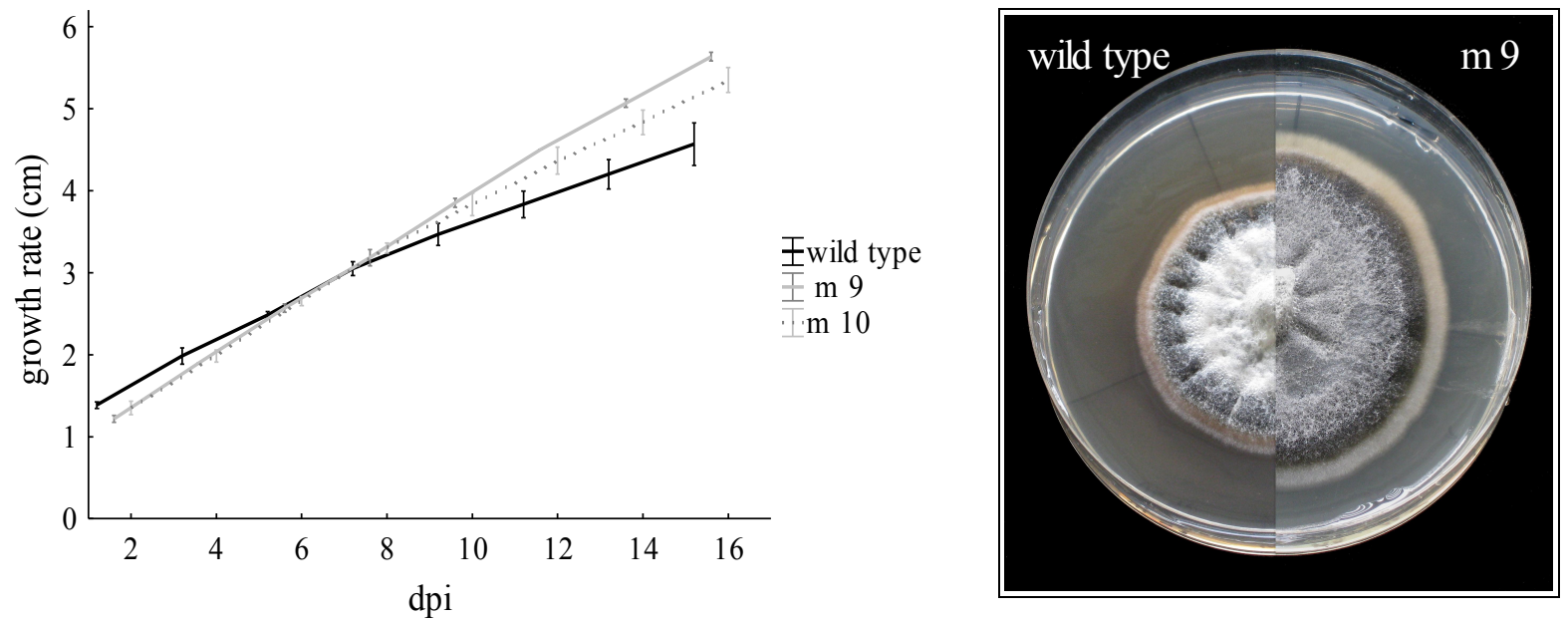

Figure 5: Growth rate of Vl-PKS-1 silencing mutants compared to $V$. longisporum wild types

left side $=$ radial growth was measured on four sides of the colonies, the graph shows the means of the calculated diameter with the standard deviation

right side $=$ single colonies of $V$. longisporum wild type and Vl-PKS-1 mutant m9 (20 dpi)

As reported in literature, PKS-1 knock-down-mutants of $C$. lagenarium and also YWA1 knock-out mutants of $A$. nidulans morphologically changed to albinos. We could demonstrate that V1-PKS-1 mutants show a delayed pigmentation of the mycelium when grown as a single colony on potato dextrose agar (PDA) medium. Pigmentation of $V$. longisporum wild type started at about 10 dpi when grown in the dark at $23{ }^{\circ} \mathrm{C}$. Vl-PKS-1 mutant pigmentation started at about 14 dpi. This effect was also observed for Vl-PKS-1 mutants that were generated using the AS-RNA technique for the post-transcriptional downregulation of the candidate gene (data not shown). Therefore, it is most likely that Vl-PKS-1 is involved in the biosynthesis of a pigment such as melanin.

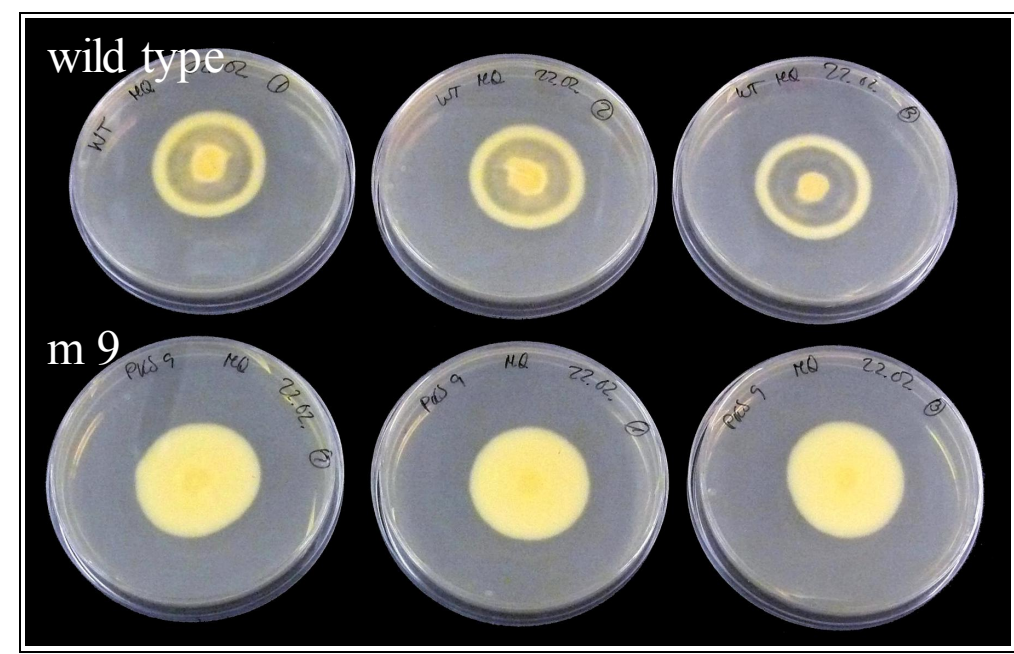

Figure 6: Phenotypic effect on the colonies of Vl-PKS-1 silencing mutant m9 grown on PDA plates compared to wild type fungus (12 dpi) 
We performed B. napus pathogenicity assays using "rapid cycle rape" to discover if Vl-PKS-1 is involved in the melanization process of microsclerotia of $V$. longisporum (a process which is initiated in planta at the end of the parasitic life cycle) or if it has any other impact on the pathogenic life style of the fungus while infecting B. napus. No significant changes could be observed by assessing using the disease score of Zeise et al. (34) or in the shoot length of $V$. longisporum wild type or V1-PKS-1 mutant-infected plants. Microsclerotia-formation, which started at about 50 dpi showed no differences in microsclerotia-pigmentation of V1-PKS-1 mutants compared to the wild types. In summary we can say that the reduced ability of $V$. longisporum-mutants to produce Vl-PKS-1 did not affect the pathogenicity to the natural host plant B. napus; therefore it is most likely that V1-PKS-1 is not a virulence or pathogenicity factor of the fungus in the interaction with B. napus.

Nevertheless, to understand the role of V1-PKS-1 in the $V$. longisporum life cycle, we tested whether V1-PKS-1 mutants have a different behaviour in their interaction with other soilborne fungi as compared to $V$. longisporum wild type. Putatively, V1-PKS-1 helps the fungus to compete with other fungi in the soil because of the potential toxic ability of the PK synthesized by V1-PKS-1. We tested five different soil-borne ascomycota fungi by coinoculating them along with $V$. longisporum wild type or V1-PKS-1 mutants. Then we plated both putative competitive fungi on opposite sides of a PDA plate and let them grow at $22{ }^{\circ} \mathrm{C}$ in the dark. We observed the fungal growth to detect if there were any changes in the interaction of the fungi. No changes in the interaction of $V$. longisporum wild type compared to V1-PKS-1 mutants could be observed while using $F$. verticilloides, $F$. proliferatum and $T$. harzianum for co-inoculation.

We observed notable changes in the interaction of $V$. longisporum wild type with G. roseum, which is known to be a natural competitor of different Verticillium species, as compared to the interaction while using Vl-PKS-1 mutants for co-inoculation with G. roseum. We were able to show a slight inhibition zone between $V$. longisporum wild type and $G$. roseum after 16 dpi which could not be observed between the V1-PKS-1 mutants and the competitor. At this time point, G. roseum was only able to overgrow the Vl-PKS-1 mutants but not the wild type. At later time points $G$. roseum also started to overgrow the surface of $V$. longisporum wild type but the mycelium of the competitor looked unhealthy and weak compared to that grown on the surface of V1-PKS-1 mutants. 

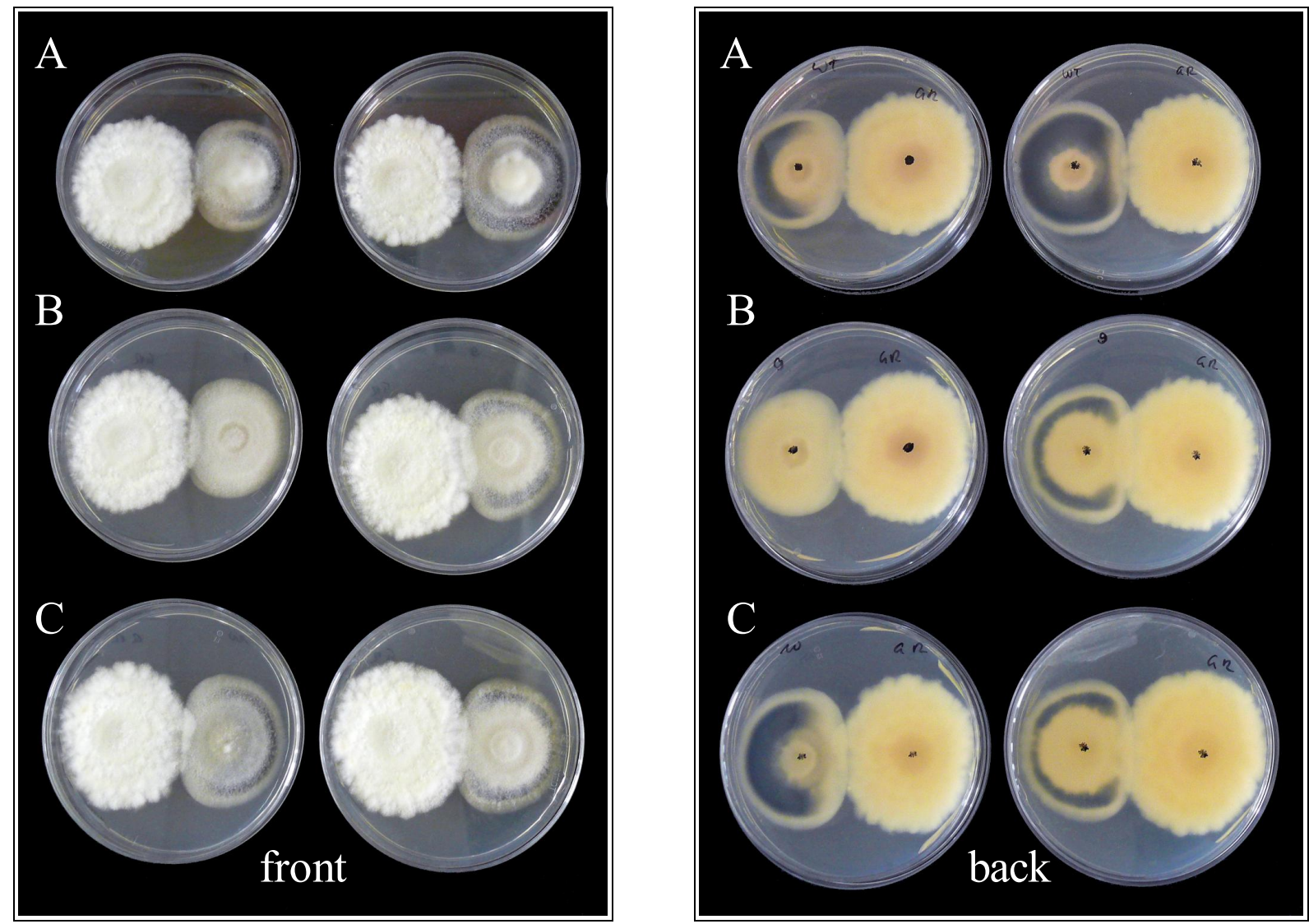

Figure 7: Fungal interaction assay using $V$. longisporum wild type and Vl-PKS-1 silencing mutants to display any changes in the growth against $G$. roseum

$\mathbf{A}=V$. longisporum wild type co-inoculated with $G$. roseum (both 16 dpi)

$\mathbf{B}=$ Vl-PKS-1 mutant m9 co-inoculated with G. roseum (both $16 \mathrm{dpi}$ )

$\mathbf{C}=$ Vl-PKS-1 mutant m10 co-inoculated with G. roseum (both $16 \mathrm{dpi}$ )

We noted another notable change in the growth of V1-PKS-1 mutants as compared to that of $V$. longisporum wild type while co-inoculating them along with $F$. culmorum. We observed the simultaneous inoculated fungi for 16 days without seeing any changes in the interaction of the fungi, but after 20 dpi we observed a significant change in the pigmentation of the grown mycelium of $F$. culmorum which was co-inoculated along with $V$. longisporum wild type. The mycelium of $G$. roseum which was co-inoculated along with Vl-PKS-1 mutants stayed naturally orange (Figure $8 \mathrm{~A}-\mathrm{C}$ ). Because of the comparable fast growth rate, F. culmorum was able to completely overgrow both $V$. longisporum wild type and Vl-PKS-1 mutants, but only showed a dark red pigmentation while growing along with the wild type fungus. In a repetition of the interaction assay, we inoculated $F$. culmorum only after 7 days of preincubation of $V$. longisporum on PDA plates to ensure that both fungi had the same size when 
they came into contact with each other. After a total of 14 dpi we observed that in the area where $V$. longisporum and $F$. culmorum touched each other, again, a dark red pigmentation of the mycelium of $G$. roseum appeared (Figure $8 \mathrm{D}$ ). When growing $F$. culmorum along with Vl-PKS-1 mutants, again, the mycelium stayed naturally orange as be observed when growing F. culmorum as a single colony on a PDA plate without any other fungi (Figure 8 E-F).
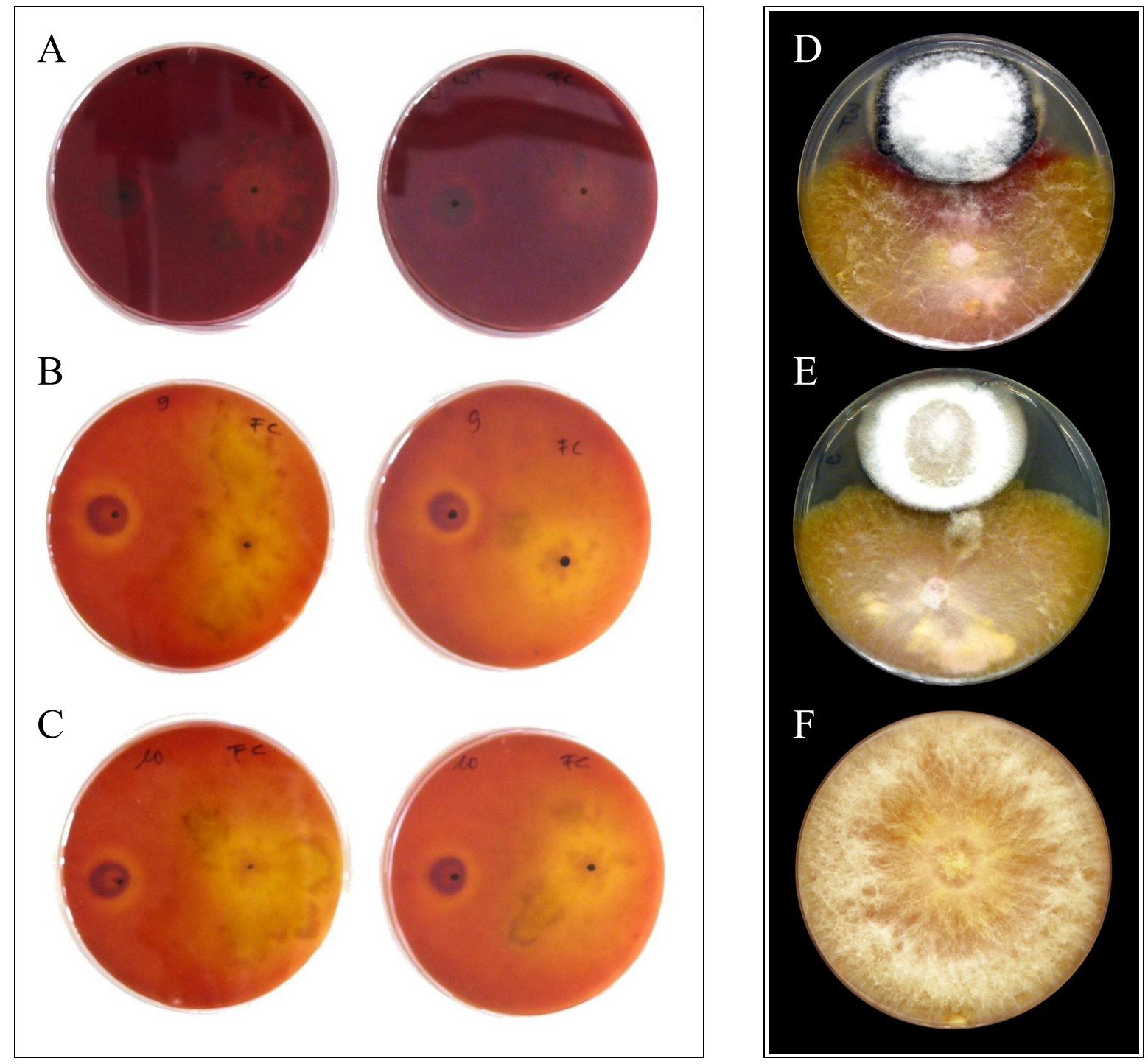

Figure 8: Fungal interaction assay using $V$. longisporum wild type and Vl-PKS-1 silencing mutants to display any changes in the growth against $F$. culmorum

$\mathbf{A}=V$. longisporum wild type co-inoculated with $F$. culmorum (both 20 dpi)

B $=$ Vl-PKS-1 mutant $\mathrm{m} 9$ co-inoculated with $F$. culmorum (both 20 dpi)

C $=$ Vl-PKS-1 mutant m10 co-inoculated with F. culmorum (both 20 dpi)

$\mathbf{D}=V$. longisporum wild type co-inoculated with $F$. culmorum $(F$. culmorum $7 \mathrm{dpi}, V$. longisporum $14 \mathrm{dpi})$

$\mathbf{E}=$ Vl-PKS-1 mutant $\mathrm{m} 9$ co-inoculated with F. culmorum (F. culmorum $7 \mathrm{dpi}$, V. longisporum $14 \mathrm{dpi}$ )

$\mathbf{F}=F$. culmorum grown without $V$. longisporum $(7 \mathrm{dpi})$ 
A similar effect was described by Schlegel et al. in 2001, showing that colonies of $F$. culmorum responded to an extract of Ulucladium by enhanced production of a darker orangered pigment as compared to the pigmentation which can be observed for the untreated fungus (35). The active compound of these extracts was identified as L-tenuazonic acid by using fractions of a column chromatography experiment from Ulucladium extract to test for their ability to induce the production of the orange-red pigment in the mycelium of $F$. culmorum. L-tenuazonic acid was first found in the fungus Alternaria tenuis and is described as a metabolite with antibiotic properties and that is believed to act as a mycotoxin. Schlegel postulated that L-tenuazonic acid strongly induces the production of a reddish PK such as fusarubin, which was reported to be expressed by F. culmorum (36). In our experiment the previously unknown PK, which is synthesized by V1-PKS-1, seemed to have a comparable ability to induce the production of a reddish pigment in F. culmorum.

When growing $V$. longisporum wild type at $22{ }^{\circ} \mathrm{C}$ in the dark, we observed that the PDA medium changed its typical yellow colour to a slight redder colouring after approximately 16 dpi. We could show that Vl-PKS-1 silencing mutants did not show any change in the colour of the media. The same effect could be observed when growing the fungi in liquid potato dextrose broth (PDB) medium.
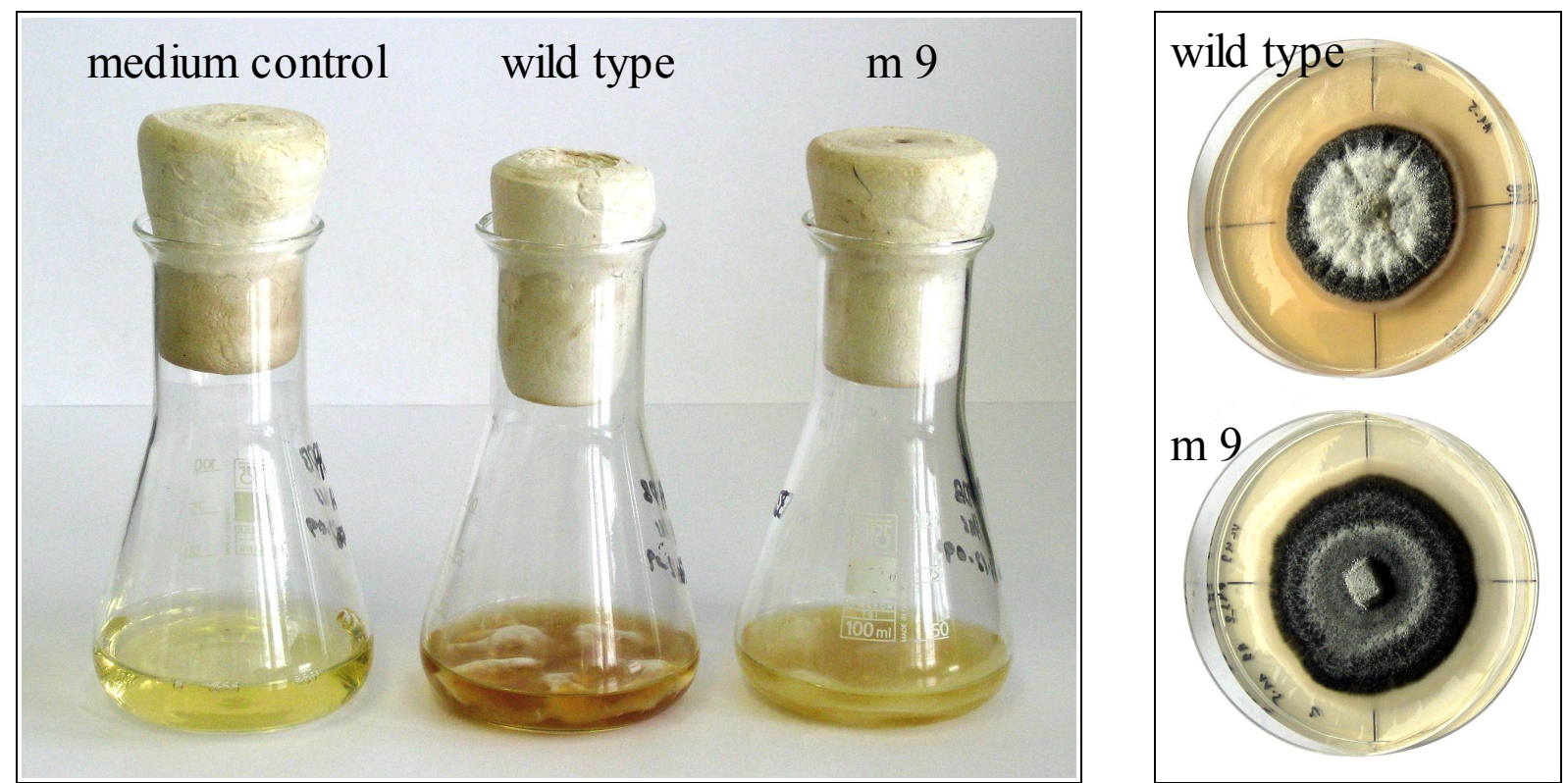

Figure 9: Colour change within the PDA medium caused by the growth of $V$. longisporum wild type left side $=V$. longisporum grown in liquid PDB medium (16 dpi) right side $=V$. longisporum grown on PDA plates (16 dpi) 
Starting at a $\mathrm{pH}$ value of approximately 4, PDA and also PDB medium change colour, without any grown fungus inside, to a redder colour as compared to a medium with a $\mathrm{pH}$ above 4 . The growth of $V$. longisporum typically decreases the $\mathrm{pH}$ value of culture media from the starting $\mathrm{pH}$ of 6 to a $\mathrm{pH}$ value of about 4.5-5, which is also present in the xylem sap of plants where the fungus mostly stays during its pathogenic life cycle and to which it is therefore adapted. We never measured any deviations in the $\mathrm{pH}$ value of the growth media of $V$. longisporum wild type as compared to the $\mathrm{pH}$ value measured in the growth media from Vl-PKS-1 mutants which could be linked to the previously mentioned absence of the reddish colour media of the Vl-PKS-1 mutant. To distinguish whether the reddish colouring we observed during coinoculation using $V$. longisporum wild type and $F$. culmorum is caused by the reddish colour we observed in growing cultures of $V$. longisporum, we have recently started to investigate the metabolic profiles of V1-PKS-1 mutants and wild type cultures grown in PDB medium to identify the V1-PKS-1 synthesized PK. Therefore, culture media will be extracted using ethyl acetate, and changes in the metabolic profiles will be investigated using HPLC-MS with an RP-C18 column with a gradient of $10 \%$ to $90 \%$ methanol. Further experiments using the isolated compound should clarify the role of this PK in the life cycle of $V$. longisporum.

\section{CONCLUSION}

Among the multitude of PKS domains, the KS domain is the most highly conserved one and is therefore a suitable target to screen for PKS genes in various organisms. We used degenerated primers LC1 and LC2 described by Bingle et al. for amplification of KS domain fragments using $V$. longisporum for PCR (22). We identified a gene showing high homology to other fungal PKS genes that are known to be involved in pigment and aflatoxin biosynthetic pathways referred to as PKSs of the $w A$-type. By the use of the "Primer walking" technique, we were able to extend the gene-sequence of the putative PKS of $V$. longisporum, which we named as V1-PKS-1, to 1986 bp. Sequence alignment using the known V1-PKS-1 sequence as a query to compare with a library of sequences from a comparative database, enlightened the conserved KS domain in the V1-PKS-1 sequence and thereby showed high sequence-homology to several PKS type I genes of diverse fungi. The highest homology we found was with a conidial yellow pigment synthase of both parental $V$. dahliae and $V$. albo- 
atrum strains, which is known to synthesize a heptaketide napthopyrene YWA1. YWA1 is a yellow pigment found in the conidia of different Aspergillus species. At the moment we are working on the elucidation of the complete genomic sequence of V1-PKS-1 to show all included conserved PKS domains to allow a more precise forecast of the function of the PKS that is encoded by the gene.

Despite the highly upregulated gene expression of V1-PKS-1 during all stages of the pathogenic life cycle of $V$. longisporum as shown by qRT-PCR analysis, we did not observe that silencing of the gene expression led to any alteration on the phenotype of the infected host plant B. napus. Nevertheless, we could show that Vl-PKS-1 silencing mutants exhibited major differences regarding the growth rate, the pigmentation of the mycelium and the interaction with other fungi as compared to the wild type of $V$. longisporum.

The delayed pigmentation of the mycelium of Vl-PKS-1 mutants as compared to the wild type fungus, when grown on PDA plates as a single colony, implies the involvement of the synthesized PK in the biosynthesis of a pigment like melanin. However, older cultures of VlPKS-1 mutants still show a strong pigmentation of the mycelium comparable to that we observed when growing $V$. longisporum wild type cultures. Up to now, we could not say with absolute certainty if the V1-PKS-1 mutants show a delayed, but finally existing pigmentation, because the gene-function of V1-PKS-1 was not fully switched off by RNAi in the mutants, or because of a homologous gene with a redundant function which is expressed by the fungus taking over the function of V1-PKS-1 and thereby synthesizing the related PK. Finally, it can be speculated that the first assumption is correct because of the knowledge gained about posttranscriptional downregulation of genes, triggered by the intracellular expression of an HP cassette by the release of a mechanism referred to as RNAi. It has often been reported that specific HP RNA of a candidate gene also executes downregulation of gene-function for redundant genes with high homology to the candidate gene (37).

In consideration of the enhanced growth rate of Vl-PKS-1 mutants and the ability of $G$. roseum to overgrow the mycelium of Vl-PKS-1 mutants as compared to that of $V$. longisporum wild type, we postulate that the synthesized PK by Vl-PKS-1 seems to act in a toxic manner, which leads to a low dimensional self-toxicity and thereby a slight suppression of fungal growth. Therefore, it can be explained that $V$. longisporum wild type showed a protective ability against competitive fungi like G. roseum due to assumed secretion of the PK 
into the surrounding growth medium. This assumption was supported by our observation of a reddish colouring of the medium of $V$. longisporum wild type when grown on PDA plates and even in liquid PDB medium. This colouring of the media is absent when growing the Vl-PKS1 mutants under the same conditions. Therefore, we postulate that the PK which is synthesized by Vl-PKS-1 is probably secreted into the medium. To investigate whether the dark-red colouring of the mycelium of F. culmorum that we observed during co-inoculation along with $V$. longisporum wild type is actually caused by the reddish colour we observed while growing $V$. longisporum wild type on PDA plates or liquid PDB medium without any other fungi, or is caused by an induction of an reddish PK such as fusarubin by the PK synthesized by V1-PKS-1, our focus is on the identification of the active compound that is synthesized by V1-PKS-1. Thereby we hope to prove the hypotheses we formulated based on the results of the experiments in this chapter.

\section{ACKNOWLEDGMENTS}

The author would like to thank the following people for their outstanding assistance during this chapter:

Prof. Petr Karlovsky for giving me the opportunity to work on V1-PKS-1 of V. longisporum and the continuous assistance regarding scientific problems. Dr. Hanno Wolf for the detection of V1-PKS-1 using degenerated primers for PCR. Wolfgang Hiegl for sequence extension of V1-PKS-1 gene using the "Primer walking" technique. Dr. Arne Weiberg for measuring V1-PKS-1 expression ratios in vitro and in planta and further, for the excellent cooperation and the remarkable help working on Vl-PKS-1. Mona Quambusch for her assistance during B. napus pathogenicity assays. Haiquan $\mathbf{X u}$ for the construction the ASRNA expression vector and the subsequent transformation of $V$. longisporum. 


\section{REFERENCES}

1. O'Hagan D. (1995). Biosynthesis of fatty acid and polyketide metabolites. Nat Prod Rep 12:1-32.

2. Kim Y.T., Lee Y.R., Jin J., Han K.H., Kim H., Kim J.C., Lee T., Yun S.H., Lee Y.W. (2005). Two different polyketide synthase genes are required for zearalenone in Gibberellazeae. Mol. Microbiol. 58:1102-1113.

3. Proctor R.H., Desjardins A.E., Plattner R.D., Hohn T.M. (1999). A polyketide synthase gene required for biosynthesis of fumonisin mycotoxins in Gibberella fujikuroi mating population A. Fung. Genet. Biol. 27:100-112.

4. Watanabe C.M., Wilson D., Linz J.E., Townsend C.A. (1996). Demonstration of the catalytic roles and evidence for the physical association of type I fatty acid synthases and a polyketide synthase in the biosynthesis of aflatoxin B1. Chem. Biol. $3: 463-469$.

5. Howard R.J., Ferrari M.A., Roach D.H., Money N.P. (1991). Penetration of hard substrates by a fungus employing enormous tugor pressures. PNAS 88:11281-11284.

6. O'Hagan D. (1991). Biosynthesis of polyketide metabolites. Nat. Prod. Rep., 9, 447479.

7. Hopwood DA. (1997). Genetic contributions to understanding polyketide synthases. Chem Rev 97:2465-2497.

8. Khosla C, Gokhale RS, Jacobsen JR, Cane DE (1999). Tolerance and specificity of polyketide synthases. Annu Rev Biochem 68:219-253.

9. Simpson T.J. (1995). Chemistry and Industry. Polyketide biosynthesis, 407-413.

10. Pieper, R., Luo, G. L., Cane, D. E. \& Khosla, C. (1995). Cell-free synthesis of polyketides by recombinant erythromycin polyketide synthases. Nature 378, 1995, 263-266.

11. Beck, J., Ripka, S., Siegner, A., Schiltz, E., and Schweizer, E. (1990) The Multifunctional 6- Methylsalicylic Acid Synthase Gene of Penicillium patulum - Its Gene Structure Relative to That of Other Polyketide Synthases. European Journal of Biochemistry 192: 487-498.

12. Brown DW, Yu J-H, Kelnar HS, Fernandes M, Nesbitt TC, Keller NP, Adams TH, Leonard TJ (1996). Twenty-five co-regulated transcripts define a 
sterigmatocystin gene cluster in Aspergillus nidulans. Proc Natl Acad Sci USA 93:1418-1422.

13. Chang PK, Cary JW, Yu J, Bhatnagar D, Cleveland TE (1995). The Aspergillus parasiticus polyketide synthase gene pksA, a homolog of Aspergillus nidulans $w A$, is required for aflatoxin B-1 biosynthesis. Mol Gen Genet 248:270-277.

14. Watanabe A, Fujii I, Sankawa U, Mayorga ME, Timberlake WE, Ebizuka Y (1999). Re-identification of Aspergillus wA gene to code for a polyketide synthase of naphthopyrone. Tetrahedron Lett 40:91-94.

15. Takano Y., Kubo Y., Shimizu K., Mise K., Okuno T., Furusawa I. (1995). Structural analysis of PKS1, a polyketide synthase gene involved in melanin biosynthesis in Colletotrichum lagenarium. Mol. Gen. Genet. 249:162-167.

16. Reinke, J.; Berthold, G. (1879). Die Zersetzung der Kartoffel durch Pilze: 63.

17. Zeise K., von Tiedemann A. (2001) Morphological and physiological differentiation among vegetative compatibility groups of Verticillium dahliae in relation to $V$. longisporum. Journal of Phytopathology 149: 469-475.

18. Williams PH. \& Hill C. B. (1986). Rapid-cycling populations of Brassica. Science $232,1385-1389$.

19. Debode, J., Claeys, D. \& Höfte, M. (2004). Control of Verticillium wilt of cauliflower with crop residues, lignin and microbial antagonists. IOBC WPRS Bull $27,41-45$.

20. Utermark J. (2008). Genetic transformation of filamentous fungi by Agrobacterium tumefaciens. Nature Protocols, Published online 20 March 2008.

21. Maniatis T., Fritsch EF., Sambrook J. (1982). Molecular Cloning: A Laboratory Manual. Trade paperback, Cold Spring Harbor Laboratory Press.

22. Bingle, L.E.H., Simpson, T.J. \& Lazarus, C.M. (1999). Ketosynthase Domain Probes Identify Two Subclasses of Fungal Polyketide Synthase Genes. Fungal Genetics and Biology 26: 209-223.

23. National Center for Biotechnology Information, homepage (http://www.ncbi. nlm.nih.gov/).

24. Barbara D.J., Clewes E. (2003). Plant pathogenic Verticillium species: how many of them are there? Mol. Plant Pathol. 4:297-305. 
25. Collins A., Okoli C.A.N., Morton A., Parry D., Edwards S.G., Barbara D.J. (2003). Isolates of Verticillium dahliae pathogenic to crucifers are of at least three distinct molecular types. Phytopathol. 93:364-376.

26. Dixon DM, Polak A, Szaniszlo PJ. (1987). Pathogenicity and virulence of wild-type and melanin-deficient Wangiella dermatitidis. J Med Vet Mycol.; 25(2):97-106.

27. Lundqvist, T.; Rice, J.; Hodge, C.N.; Basarab, G.; Pierce, J.; Lindqvist, Y. (1994). Crystal Structure of Scytalone Dehydratase: a Disease determinant of the Rice Pathogen Magnaporthe grisea. Structure 2, 937-944.

28. Perpetua NS, Kubo Y, Yasuda N, Takano Y, Furusawa I. (1996). Cloning and characterization of a melanin biosynthetic THR1 reductase gene essential for appressorial penetration of Colletotrichum lagenarium. Mol Plant Microbe Interact.; 9(5):323-9.

29. Mayorga ME, Timberlake WE. (1992). The developmentally regulated Aspergillus nidulans $w A$ gene encodes a polypeptide homologous to polyketide and fatty acid synthases. Mol Gen Genet. Nov;235(2-3):205-12.

30. Fujii I, Mori Y, Watanabe A, Kubo Y, Tsuji G, Ebizuka Y (2000). Enzymatic synthesis of 1,3,6,8-tetrahydroxynaphthalene solely from malonyl coenzyme A by a fungal iterative type tsI polyketide synthase PKS1. Biochemistry 39:8853-8858.

31. Fujii I, Mori Y, Watanabe A, Kubo Y, Tsuji G, Ebizuka Y. (1999). Heterologous expression and product identification of Colletotrichum lagenarium polyketide synthase encoded by the PKS1 gene involved in melanin biosynthesis. Biosci Biotechnol Biochem. 1999 Aug;63(8):1445-52.

32. Tsai HF, Fujii I, Watanabe A, Wheeler MH, Chang YC, Yasuoka Y, Ebizuka Y, Kwon-Chung KJ. (2001). Pentaketide melanin biosynthesis in Aspergillus fumigatus requires chain-length shortening of a heptaketide precursor. J Biol Chem.; 276(31): 29292-8.

33. The Broad Institute, homepage Verticillium group database (http://www.broad. mit.edu/annotation/genome/verticilliumdahliae/MultiHome.html).

34. Zeise, K. (1992). Gewächshaustest zur Resistenzprüfung von Winterraps (Brassica napus L. var. oleifera Metzger) gegen den Erreger der Rapswelke Verticillium dahliae Kleb. Nachrichtenblatt Deutscher Pflanzenschutzdienst 44:125-128. 
35. Schlegel B, Schmidtke M, Dörfelt H, Kleinwächter P, Gräfe U. (2001). (-)Terpestacin and L-tenuazonic acid, inducers of pigment and aerial mycelium formation by Fusarium culmorum JP 15. J Basic Microbiol.;41(3-4):179-83.

36. Laatsch, H. (1999). Antibase. Database of microbial metabolites. Chemical Concepts, Heidelberg.

37. C Napoli, C Lemieux, and R Jorgensen (1990). Introduction of a Chimeric Chalcone Synthase Gene into Petunia Results in Reversible Co-Suppression of Homologous Genes in trans. Plant Cell.; 2(4): 279-289.

\section{APPENDIX}

\begin{tabular}{|l|l|}
\hline \multicolumn{1}{|c|}{ primer name } & sequence $\left(\mathbf{5}{ }^{\prime} \rightarrow \mathbf{3}^{\prime}\right)$ \\
\hline sense- $S d a \mathrm{I}-\mathrm{F}$ & TAGTGACCTGCAGGACATCGAGAGGATCGACGCCAGC \\
\hline sense- $N d e \mathrm{I}-\mathrm{R}$ & GATATGCATATGACATGTCGCCGCGCGAGCCTAC \\
\hline antisense- $A s c \mathrm{I}-\mathrm{F}$ & GAGCTCGGCGCGCCACATCGAGAGGATCGACGCCAGC \\
\hline antisense- $B g l \mathrm{II}-\mathrm{R}$ & GATATGAGATCTACATGTCGCCGCGCGAGCCTAC \\
\hline spacer- $N d e \mathrm{I}-\mathrm{F}$ & CTATACCATATGACTGCTCTACCCGTACGTTG \\
\hline spacer-BglII-R & GATATGAGATCTCCTGGCACTCTTTGCTATTGTTGG \\
\hline
\end{tabular}

Table 1: Primer sequences for the amplification of fragments possess restriction sites suitable for the construction of an HP fragment using conventional cloning steps

\begin{tabular}{|c|c|}
\hline primer name & sequence $\left(\mathbf{5}^{\prime} \rightarrow \mathbf{3}^{\prime}\right)$ \\
\hline V1-PKS-1-SB-sense-F & ACATCGAGAGGATCGACGCCAGC \\
\hline Vl-PKS-1-SB-sense-R & ACATGTCGCCGCGCGAGCCTAC \\
\hline
\end{tabular}

Table 2: Primer sequences for the amplification of probes for southern hybridization

\begin{tabular}{|l|l|}
\hline \multicolumn{1}{|c|}{ primer name } & \multicolumn{1}{c|}{ sequence $\left(\mathbf{5}^{\prime} \rightarrow \mathbf{3}^{\prime}\right)$} \\
\hline Vl-PKS-1-RT-sense-F & AGCGTCCTGCAAACAGACC \\
\hline Vl-PKS-1-RT-sense-R & TGTCAGTGGGAAAGCGATG \\
\hline tubulin-F & GTTCATCTTCAGACCGGTCAGT \\
\hline tubulin-R & CCAGACTGGCCGAAAACGAAGT \\
\hline rps17-F & GCATCTGCGATGAGATCGCCA \\
\hline rps17-R & TCGGAGTTCTGGGTAAAGTCGAGA \\
\hline
\end{tabular}

Table 3: Primer sequences to measure silencing efficiency of silencing mutants by qRT-PCR 
Chapter 4: Detection and functional analysis of a polyketide synthase gene of Verticillium longisporum

\begin{tabular}{|l|l|}
\hline \multicolumn{1}{|c|}{ primer name } & \multicolumn{1}{c|}{ sequence $\left(\mathbf{5}^{\prime} \rightarrow \mathbf{3}^{\prime}\right.$ ) } \\
\hline LC1 & GTGTTGTGTTGCGGCCGCGAYCCNMGNTTYTTYAAYATG \\
\hline LC2 & GTNCCNGTNCCRTGCATYTC \\
\hline
\end{tabular}

Table 4: Degenarated primers according to Bingle et al.

\begin{tabular}{|l|l|}
\hline \multicolumn{1}{|c|}{ primer name } & \multicolumn{1}{c|}{ sequence $\left(\mathbf{5}^{\prime} \rightarrow \mathbf{3}^{\prime}\right)$} \\
\hline Vl-PKS-1 W1-F & CTACCAACCATTCTGCCGACGCC \\
\hline Vl-PKS-1 W1-R & CCYTGNCCNGTRAANATRAANGC \\
\hline Vl-PKS-1 W2-F & ATCCCGAAACCCCGCTTGCTG \\
\hline Vl-PKS-1 W2-R & ACYTGNGCNGARTGRAANGC \\
\hline Vl-PKS-1 W3-F & GTNTAYGGNTCNTAYCAYGC \\
\hline Vl-PKS-1 W3-R & TCATCGGAGGTCTGACCGTAA \\
\hline
\end{tabular}

Table 5: Primers used for "primer walking" to extend the Vl-PKS-1 sequence

\section{VI-PKS-1}

\section{gDNA sequence (incomplete)}

1 GATCCGAGGTTTTTTAACATGTCGCCGCGCGAAGCCTACCAGACCGACCC

51 CATGCAACGCATGGCCCTGACCACGGCTTATGAAGCCTTGGAAATGTCTG

101 GGTATGTCCCGAATAGGACAGCCTCTACCAGGCTTGACCGGATTGGTACA

151 TTTTACGGTCAGACCTCCGATGATTGGCGAGAGATCAATGCCGCACAGGA

201 AGTCGACACATACTTCATCACCGGGGGAGTACGCGCCTTTGGCCCTGGCA

251 GAATCAACTACCACTTCGGTTTCAGTGGACCTAGTCTGAACATCGATACA

301 GCCTGTTCTTCCAGTGCCGCAGCTCTGCAAATCGCATGCACCTCGCTCTG

351 GGCCAAGGACTGTGACACGGCAGTCGTTGGCGGCTTGTCTTGCATGACCA

401 ACCCCGATATTTTCTCAGGACTCAGCCGTGGCCAGTTCTTGTCCAAGACT

451 GGTCCCTGTGCTACGTTTGACAATGGAGCTGATGGTTACTGCCGAGCTGA

501 TGGCTGCGCCTCCGTCATTGTGAAGCGTCTGGATGATGCCATTGCCGACA

551 AGGACAATGTCCTGGCGGTCATCCTGGGCACGGCTACCAACCATTCTGCC

601 GACGCCATATCGATTACCCATCCTCATGGACCTACGCAGTCGATCCTATC

651 ATCAGCCATTCTCGATGAGGCTGGCGTCGATCCTCTCGATGTTGACTACG

701 TCGAGATGCATGGGACAGGCACTCAGGCCGGTGATGGCACGGAAATGGTC

751 TCTGTCACAGACGTATTCGCACCTGCCAACCGCAAGCGTCCTGCAAACAG

801 ACCTCTGTATCTCGGCGCTGTGAAATCTAACATCGGCCACGGTGAGGCTG

851 CTTCAGGCGTGACAGCTCTCTGCAAGGTTCTCATGATGTTGCAAAAAAAC

901 GCCATCCCTCCTCACGTCGGCATAAAAAAGGATATCAACAAGACCTTTCC

951 TAAGGATCTTGCGGAGCGAAACGTCAACATCGCTTTCCACATGACACCTC

1001 TCAAAAGGCATGATGGGAAACCCAGGAGAATCTTCATCAACAACTTCAGC

1051 GCCGCCGGTGGTAATACCGGTCTCCTCCTTGAGGATGGTCCCAGCCAGAC

1101 GCCCACACAGGCGGACCCTCGCAGTGCTCAAGTCATTACTATCACGGCCA

1151 AGTCCAAGACGGCCATGATTAAGAATGCTGAACAATTGGTGACGTGGATG

1201 GAGAAGAATCCCGAAACCCCGCTTGCTGATGTTGCTTACACCACAACGGC

1251 CCGTCGCATGCAACACTACTGGCGCCTGAATGTCGCCGCCTCCACCTTGT

1301 CTGAAGCCATGTCAGCCATCAAGGAGAGGCTCACTCAAAACTTTGTGCCC

1351 ATCTCGACTGAGCAGCCAAAGGTGGCCTTCATCTTCACAGGCCAAGGCTC

1401 TCACTATGCTGGTCTTGGCAAGGACCTCTACGCCCACTACGCTGTCTTCA

1451 GAGACAGCATCAATGAGTTCAATCATATCGCCGAAGTCCATGGCTTCCCG

1501 TCTTTTGTGCCATTGATTGATGGCAGCGAACCTGACGTCTCCAAGCTATC

1551 ACCCGTGGTTGTGCAGCTTGGCCTCTGCTGCTTCGAGATGGCTCTAGCCA

1601 GACTGTGGGCTGCATGGGGTATCAGGCCCGCTGTGGTTCTGGGGCACTCT 


$\begin{array}{ll}1651 & \text { CTCGGAGAATATGCTGCTCTGAACGCCGCCGGCGTACTGTCCGCAAGCGA } \\ 1701 & \text { CACCATCTATCTCGTCGGCAGTCGCGCTCAGCTTCTCGTCGACAGGTGCA } \\ 1751 & \text { CTGCTGGTACCCATGCCATGCTTGCTGTGCAGGGCCCGGTTGGGACTGTC } \\ 1801 & \text { AACGAGGCTCTCGGATCCGAATTCGCCTCAGTCAACATCGCCTGCATCAA } \\ 1851 & \text { CGGGCCTCGTGAGACCGTTCTCAGTGGTGAAACTGACCACATGATGAAGA } \\ 1901 & \text { TTGCCACGCAATTGGGCGCGTCTGGATTCAAGTGCACCCAGCTGAATGTT } \\ 1951 & \text { CCCTATGCCTTCCACTCC }\end{array}$

Table 6: gDNA sequence of Vl-PKS-1 obtained by „Primer walking“ 


\section{Chapter 5: Final discussion}

This thesis was realized during participation in the DFG research unit FOR 546, whose task was to identify and elucidate signals which shape the interaction between the plant-pathogenic fungus $V$. longisporum and its host plants (1). The genus Verticillium includes many plant pathogenic species that cause serious economic losses through the infection of host plants, and it belong to one of the most widespread groups of plant pathogens in the world (2). The species with the highest impact on yield loss on important agricultural crops, including e.g. cotton, strawberry, tomato and potato $(3,4)$, are $V$. dahliae and $V$. albo-atrum, which are present in temperate and subtropical regions (5) and cause diverse symptoms that vary among host plants. $V$. longisporum is described as an amphihaploid interspecific hybrid of parental $V$. dahliae and $V$. albo-atrum strains $(6,7)$, and therefore shares many characteristics with these strains. Like $V$. dahliae and $V$. albo-atrum, $V$. longisporum is a soil-borne vascular pathogen with a hemibiotrophic lifestyle, but notwithstanding, the host range is strictly limited to the family of Brassicaceae (8). The fungus also did not show any wilting symptoms after infection of hosts in the field nor in the greenhouse $(9,10,11,12)$, which is described to be a typical symptom on host plants with Verticillium infection. The basis of the infection of $V$. longisporum on plants is mostly unknown and, therefore, studying the host-pathogen interaction using molecular-genetic and chemical-analytical methods provides the opportunity for a better understanding of the disease caused by the fungus, and thereby helps in finding new strategies for the prevention or the control of infection. Comparative studies were done by other members of the DFG research unit FOR 546, using liquid chromatography mass spectrometry (HPLC-MS)-derived metabolic profiles and cDNA-amplified fragment-length polymorphism (AFLP)-derived transcriptome profiles of xylem sap from uninfected plants. These were compared to $V$. longisporum-infected plants and the result revealed 19 metabolites and 8 transcript-derived fragments (TDFs) to be accumulated or expressed differently upon $V$. longisporum infection $(13,14)$. Metabolites, including salicylic acid (SA) and its glucoside (SAG), and TDFs, including a water-soluble carbohydrate binding protein and a zinc finger transcription factor, are putatively involved in the host-pathogen interaction upon infection. Selected TDFs with an upregulated expression during plant-infestation were tested for having a role in the pathogenic-life cycle of the fungus by switching of the candidate gene function (15). Because of its amphihaploid genome, which comprises two almost complete sets of haploid genomes derived from parental strains in one single nucleus, it is most likely that $V$. 
longisporum often carries more than one gene-copy of specific candidate genes, and therefore the production of knock-out mutants using homologous recombination to switch off specific gene functions is hampered.

\section{Gene silencing in $V$. longisporum}

HP expression of candidate genes has been reported in the literature to be the most potent trigger for post-transcriptional downregulation in ascomycota fungi (16), and it was recently shown, by another member of the DFG research unit, that RNA interference (RNAi) could be released by intracellular expression of hairpin (HP)-constructs in $V$. longisporum (17). Our attempts to use the overlap-extension (OE)-PCR technique for the construction of HPfragments without the use of any conventional cloning steps was impaired by the strong tendency of the HP-fragments to anneal after each denaturation step of PCR, forming HP structures by pairing of homologous sequences of sense and antisense ssDNA fragments (see Chapter 2). The use of asymmetric OE-PCR led to only one correctly assembled HP fragment out of more than one hundred attempts, and was therefore not worth the effort needed to correctly assemble sense and antisense fragments with the spacer. By using a method based on conventional cloning steps, we succeeded in HP fragment construction. We assembled flanking sense and antisense arms ranging from 180 to $696 \mathrm{bp}$ length and an intervening 125 bp spacer of a native intron from the $V$. longisporum hydrophobin gene $V l H 1$. We created several $V$. longisporum mutants by Agrobacterium thumefaciens mediated transformation (AMT) (18) by integrating HP expression-cassettes of different candidate genes suitable for triggering RNAi in the fungus. The generated mutants showed silencing efficiency of candidate genes of $98 \%$ at best as compared to $V$. longisporum wild type gene expression. Additionally we were able to show that intracellular expression of an antisense RNA (ASRNA), which was designed complementary to the specific mRNA of the candidate gene, was a potent trigger for triggering postranscriptional downregulation of gene-function in $V$. longisporum. AS- RNA expression results in a moderate silencing-efficiency of candidate genes of up to $70 \%$ compared to wild type gene expression (15).

Both, HP RNA and AS-RNA, were used during the research of this thesis for functional characterization of pathogenicity-related genes of the ascomycota fungus $V$. longisporum. Many candidate genes were efficiently silenced in the "Molecular phytopathology and 
mycotoxin research" laboratory, including the upregulated TDFs displayed by cDNA-AFLP (14), and also genes which were reported in literature to be potential virulence or pathogenicity factors of ascomycetes during infection of host plants. During the research reported in this thesis we gave preference to the results for two genes that showed notable changes due to silencing of specific gene-functions.

\section{The impact of Vl-NEP-1 on the pathogenicity to B. napus}

Previous studies regarding pathogenicity factors expressed by Verticillium species during the host-pathogen interaction showed that mostly polysaccharolytic activ peptides, such as pectinases, which have a degradative feature on plant cell walls, are linked to a successful infestation of the plant by the pathogen. Neverthless, pectinase-deficient mutants of $V$. longisporum show interfered symptom development in the plant but finally no change in the degree of colonization compared to wild type infected plants. Accordingly, pectinases have been classified as virulence factors and not as pathogenicity factors (19, 20). During our research, we demonstrated that downregulation of a gene with a high homology to the necrosis and ethylene inducing peptide (NEP)- family, which we therefore designated as VlNEP-1, was connected to symptom severity caused by $V$. longisporum on the natural host plant B. napus, and thereby indicated a reduced ability of the fungus to spread into the plant. In summary, we detected five NEP genes, designated as Vl-NEP-1 to 5, in the genome of $V$. longisporum from which we could measure strong expression levels of three NEP genes (V1NEP-1, -2, -5) in planta by qRT-PCR. This makes a contribution of these genes to the pathogenic life cycle of $V$. longisporum while infecting $B$. napus acceptable.

Our results for Vl-NEP-1 suggest that the related gene product is secreted in the xylem by the fungus and permeabilizes the surrounding cell membranes of the xylem cylinder, causing leakage of monomers from adjacent tissue into the xylem sap. These monomers are putatively used as nutrients by the fungus and thereby increase the fitness of $V$. longisporum in the xylem. Distinctive features of NEP-like proteins (NLPs) could be proved while using the purified V1-NEP-1 protein to test for plant reactions after treatment. Consistent with previous reports which showed that necrotic lesion formation is artificially inducible by leaf infiltration of the protein (21), we were able to induce lesions on leaves of Brassica and Tobacco. Thereby, lesion formation was proved to be both leaf age and dose dependent after infiltration 
of the protein. Necrosis on host plants was never observed as a sympton after natural infection of host-plants with $V$. longisporum, or on artificially infected plants in the laboratory. Therefore, we believe that the concentration of Vl-NEP-1 in the plant is apparently too low to induce necrosis and does not reach the phytotoxic threshold that is required to induce necrosis in the plant. Recently conducted pathogenicity-assays on B. napus using spore solutions with $1 \times 10^{7}$ to $1 \times 10^{9}$ spores $/ \mathrm{ml}^{-1}$ for root-dip inoculation revealed that infected plants show serious symptoms, including necrotic lesion formation.

Besides necrosis, the inhibition of root growth in Arabidopsis was reported as a result of treatment of NLPs $(22,23)$. We also showed that V1-NEP-1 treatment results in reduced root length while adding the protein to the growth medium of Arabidopsis seedlings from different ecotypes. In contrast, we showed that $B$. napus plants were not affected at all by the treatment with the purified protein. This could be an indication that Vl-NEP-1 silencing mutants showed reduced symptom development on B. napus plants; however A. thaliana did not show any change as a result of inoculation with Vl-NEP-1 mutants as compared to $V$. longisporum wild type infection. This finding suggests that V1-NEP-1 seems to have a crucial role in the infection-process of the natural host plant B. napus but not in A. thaliana. Further tests must be performed to show if the expression of Vl-NEP-1 in A. thaliana-infected plants is not as strong as in B. napus- infected plants or if an assumed receptor of the protein is not present in the xylem-cylinders of $A$. thaliana plants. We are firmly convinced that the identification of a Vl-NEP-1 related receptor in B. napus is linked with functional understanding of the protein.

\section{The role of Vl-PKS-1 in the life cycle of $V$. longisporum}

Another candidate gene shows notable effects as a result of post-transcriptional downregulation of gene function using RNAi, and has high homology to fungal type I polyketide synthase (PKS) genes of the $w A$ type, and we therefore named this gene Vl-PKS-1. PKS catalyze the series of small carboxylic acids into polyketides (PK) which belong to a large group of fungal secondary metabolites that are described as compounds not primarily needed for essential processes concerning the survival and the reproduction of the fungus (24). PKS includes several highly conserved domains, each of which has a defined function. Type I PKS consists of starting modules referred to as acyltransferase (AT) and an acyl carrier protein (ACP) which executes the synthesizing of the growing PK chain. A keto synthase 
(KS) initiates the elongation of the PK chain. Several elongation modules, such as ketoreductase $(\mathrm{KR})$ domains or dehydratase $(\mathrm{DH})$ domains, which give rise to the structural diversity of PKs and their manifold biological activities, are stepwise added to the chain. The thio esterase (TE) domain acts as a termination module hydrolyzing the completed polyketide from the ACP.

We used degenerate primers based on fungal KS-domains (25) to amplify putative PKS genes from the gDNA of $V$. longisporum by PCR. We were able to detect a gene, which we named Vl-PKS-1, that has a highly upregulated gene expression in planta as compared to in vitro, and this makes a contribution in the pathogenic life cycle of $V$. longisporum assumable. V1PKS-1 show high homology to a conidial yellow pigment synthase gene from $V$. dahliae, which is reported to be a parental strain of amphihaploid $V$. longisporum $(26,27)$. The conidial yellow pigment synthase is known to be involved in a process that forms the heptaketide napthopyrene YWA1, which is a yellow pigment first found in mature asexual spores (conidia) of Aspergillus nidulans (28). Gene silencing mutants of V1-PKS-1 show major differences in their growth characteristics as compared to those of $V$. longisporum wild type. As compared to the wild type of $V$. longisporum, a significant increased growth rate of Vl-PKS-1 mutants and their partial loss of competitive capacity, which we demonstrated by an fungal-interaction assay using $G$. roseum for co-inoculation with $V$. longisporum, both plated on PDA agar, suggests that the metabolite synthsized by V1-PKS-1 has a toxic ability, as mentioned in literature for different PKs known from other fungi $(29,30,31)$. Additionally we could show that, when growing $V$. longisporum wild type both in liquid potato dextrose broth (PDB) and on solid potato dextrose agar (PDA), the medium changed its colour from typical yellow to a redder colour, which we could not observe when growing the V1-PKS-1 mutants in the same way. A similar effect was shown during the fungal-interaction assay while growing $V$. longisporum along with Fusarium culmorum. Thereby, $V$. longisporum wild type seems to induce a reddish colouring of the mycelium of F. culmorum, which we never observed when using the Vl-PKS-1 mutants for co-inoculation with F. culmorum. It was not clear whether the colour change was indeed caused by the induction-ability of the metabolite synthesized by V1-PKS-1 or was due to the secretion of a reddish compound by the fungus we observed in the PDB medium. Therefore, we recently started to identify the metabolite synthesized by V1-PKS-1 using HPLC-MS to get a closer look at its function. 
As compared to type I PKS knock out mutants from Colletotrichum lagenarium and $A$. nidulans, which shows an albino phenotype, we were able to observe a delayed pigmentation on V1-PKS-1 mutants. The albino phenotype, which was apparent on V1-PKS-1 mutants after $12 \mathrm{dpi}$ as compared to the strong pigmentation of $V$. longisporum wild type fungus at the same time, was most likely revoked due to the gene function of Vl-PKS-1 not being fully switched off by RNAi. In 2005, Kehr et al. postulated that defence-related proteins with capacities to degrade fungal cell walls (32) are present in the xylem sap. When growing $V$. longisporum in simulated xylem medium (SXM), which simulates the basic nutritional condition of a xylem environment (33), the fungus showed a much stronger and earlier pigmentation as compared to the growth in other media. This could be an indication for that $V$. longisporum melanization is a response to these defence-related proteins in the xylem sap (17). It was also mentioned in literature that strong melanized fungi are less susceptible to host-plant defence mechanisms (34), but we could not show any reduction in the symptom severity on B. napus plants infected with V1-PKS-1 mutants as compared to $V$. longisporum wild type-infected plants.

\section{Outlook}

For the results presented in this thesis on two candidate genes, we were able to demonstrate, firstly, a reduction in symptom severity on the natural host plant B. napus (V1-NEP-1), and secondly, a phenotypic change in the growth-characteristics of $V$. longisporum (V1-PKS-1). These were both a result of downregulation of specific gene functions. Further experiments to identify the putative receptor molecule of Vl-NEP-1 present in B. napus should elucidate the role of the protein in the pathogenicity and thereby enlighten the function of the protein while infecting B. napus. We recently began the construction of HP constructs suitable for triggering RNAi for the other Vl-NEP genes that were shown to be upregulated upon infection. The purpose is to prove that they also have a role in the pathogenic life cycle of $V$. longisporum while infecting the natural host plant $B$. napus. The identification of the Vl-PKS1 -synthesized PK is connected to understanding the protein-function in the life cycle of $V$. longisporum, and should help us to elucidate the role of this metabolite and its impact on the $V$. longisporum life cycle. It is intended that both V1-NEP-1 and Vl-PKS-1 will be subject to further study in the "Molecular phytopathology and mycotoxin research" laboratory headed by Prof. Petr Karlovsky. 


\section{REFERENCES}

1. Research Unit DFG 546 homepage (http://www.ubpb.gwdg.de/ forschergruppe/ index.html).

2. Pegg, G.F., Brady, B.L. (2002). Verticillium Wilts. Wallingford, UK: CAB Publishing

3. Gordon, T.R., Kirkpatrick, S.C., Hansen, J., Shaw, D.V. (2006). Response of strawberry genotypes to inoculation with isolates of Verticillium dahliae differing in host origin. Plant Pathology 55, 766-769.

4. Heale, J.B. (2000). Diversification and speciation in Verticillium - An overview. In: Advances in Verticillium research and disease management. Tjamos, E.C., Rowe, R.C., Heale, J.B., Fravel, D.R. (eds.), St. Paul, Minnesota, APS Press, 175-177.

5. Schwantes, H.O. (1996). Biologie der Pilze. Verlag Eugen Ulmer, Stuttgart 6.

6. Barbara D.J., Clewes E. (2003). Plant pathogenic Verticillium species: how many of them are there? Mol. Plant Pathol. 4:297-305.

7. Fahleson J., Lagercrantz U., Hu Q., Steventon L.A., Dixelius C. (2003). Estimation of genetic variation among Verticillium isolates using AFLP analysis. Eur. J. Plant Pathol. 109:361-371.

8. Fire A, Xu S, Montgomery MK, Kostas SA, Driver SE, Mello CC. (1989). Potent and specific genetic interference by double-stranded RNA in Caenorhabditis elegans. Nature. 1998 Feb 19;391(6669): 806-11.

9. Pullman, G. S., De Vay, J. E. (1982). Epidemiology of Verticillium wilt of cotton: A relationship between inoculum density and disease progression. Phytopathology 72: $549-554$.

10. Koike M., Fujita M., Nagoa H., Ohshima S. (1996): Random amplified polymorphic DNA analysis of Japanese isolates of Verticillium dahliae and V. albo-atrum. Plant Disease 80: 1224-1227.

11. Xiao C. L., Subbaro K. V. (1998). Relationship between Verticillium dahliae inoculum density and wilt incidence, severity, and growth of cauliflower. Phytopathology 88: 1108-1115. 
12. Debode, J., Claeys, D. \& Höfte, M. (2004). Control of Verticillium wilt of cauliflower with crop residues, lignin and microbial antagonists. IOBC WPRS Bull $27,41-45$.

13. Ratzinger A. (2008). Development and application of LC-MS-based differential metabolic profiling in plant systems. Dissertation, Georg-August Universität Göttingen.

14. Weiberg, A. (2008). Identifizierung von Xylemsaft-induzierten Genen im vaskulären Pathogen Verticillium longisporum mittels einer verbesserten cDNA-AFLP Methode für transkriptomweite Expressionsstudien. Dissertation, Georg-August Universität Göttingen.

15. Xu H. (2011). Dissertation, Georg-August Universität Göttingen.

16. Kadotani N., Nakayashiki H., Tosa Y., Mayama S. (2003). RNA silencing in the phytopathogenic fungus Magnaporthe oryzae. Mol Plant Microbe Interact. 2003 Sep;16(9):769-76.

17. Singh S. (2008). Study of genes of the phytopathogenic fungus Verticillium longisporum involved in the colonization of xylem vessels of its host Brassica napus. Dissertation, Universität Göttingen.

18. Utermark J. (2008). Genetic transformation of filamentous fungi by Agrobacterium tumefaciens. Nature Protocols, Published online.

19. Durrands P.K., Cooper R.M. (1988). Selection and characterization of pectinase deficient mutants of the vascular pathogen Verticillium dahliae. Physiol. Mol. Plant Pathol. 32:343-362.

20. Durrands P.K., Cooper R.M. (1988). The role of pectinases in vascular wilt disease as determined by defined mutants of Verticillium albo-atrum. Physiol. Mol. Plant Pathol. 32:363-371.

21. Veit S., Wörle J.M., Nürnberger T., Koch W., Seitz H.U. (2001). A novel protein elicitor (PaNie) from Pythium aphanidermatum induces multiple defence responses in carrot, Arabidopsis, and tobacco. Plant Physiol. 127:832-841.

22. Qutob D., Kemmerling B., Brunner F., Küfner I.,Engelhardt S.,Gust A.A., Luberacki B. (2006). Phytotoxicity and Innate Immune Responses Induced by Nep1like Proteins. The Plant Cell 18:3721-3744. 
23. Bae H., Kim M.S., Sicher R.C., Bae H.-J., Bailey B.A. (2006). Necrosis- and ethylene inducing peptide from Fusarium oxysporum induces a complex cascade of transcripts associated with signal transduction and cell death in Arabidopsis. Plant Physiol. 141:1056-1067.

24. Karlovsky P. (2008). Secondary metabolites in soil ecology. Springer Verlag, Berlin.

25. Bingle, L.E.H., Simpson, T.J. \& Lazarus, C.M. (1999). Ketosynthase Domain Probes Identify Two Subclasses of Fungal Polyketide Synthase Genes. Fungal Genetics and Biology 26: 209-223.

26. Barbara D.J., Clewes E. (2003). Plant pathogenic Verticillium species: how many of them are there? Mol. Plant Pathol. 4:297-305.

27. Collins A., Okoli C.A.N., Morton A., Parry D., Edwards S.G., Barbara D.J. (2003). Isolates of Verticillium dahliae pathogenic to crucifers are of at least three distinct molecular types. Phytopathol. 93:364-376.

28. Mayorga ME, Timberlake WE. (1992). The developmentally regulated Aspergillus nidulans $w A$ gene encodes a polypeptide homologous to polyketide and fatty acid synthases. Mol Gen Genet. Nov;235(2-3): 205-12.

29. Kim Y.T., Lee Y.R., Jin J., Han K.H., Kim H., Kim J.C., Lee T., Yun S.H., Lee Y.W. (2005). Two different polyketide synthase genes are required for zearalenone in Gibberellazeae. Mol. Microbiol. 58: 1102-1113.

30. Proctor R.H., Desjardins A.E., Plattner R.D., Hohn T.M. (1999). A polyketide synthase gene required for biosynthesis of fumonisin mycotoxins in Gibberella fujikuroi mating population A. Fung. Genet. Biol. 27:100-112.

31. Watanabe C.M., Wilson D., Linz J.E., Townsend C.A. (1996). Demonstration of the catalytic roles and evidence for the physical association of type I fatty acid synthases and a polyketide synthase in the biosynthesis of aflatoxin B1. Chem. Biol. 3:463-469.

32. Mauch F, Staehelin LA (1989). Functional implications of the subcellular localization of ethylene-induced chitinase and beta 1,3-glucanase in bean leaves. The Plant Cell 1:447-457.

33. Neumann M.J., Dobinson K.F. (2003). Sequence tag analysis of gene expression during pathogenic growth and microsclerotia development in the vascular wilt pathogen Verticillium dahliae. Fung. Genet. Biol. 38:54-62. 
34. Taborda, C.P., da Silva, M.B., Nosanchuk, J.D., and Travassos, L.R. (2008). Melanin as a virulence factor of Paracoccidioides brasiliensis and other dimorphic pathogenic fungi: a minireview. Mycopathologia 165: 331-339. 


\section{Danksagung}

$\mathrm{Zu}$ allererst möchte ich mich ganz herzlich bei Prof. Petr Karlovsky für die Bereitstellung des Themas der vorliegenden Dissertationsschrift sowie für die allumfassende Hilfe in wissenschaftlichen Fragestellungen bedanken. Die mir von ihm gewährten Freiheiten während der Erstellung meiner Arbeit und sein stets freundschaftlicher Umgang mit mir werden mir in guter Erinnerung bleiben.

Bei Prof. Andrea Polle bedanke ich mich für die bereitwillige Übernahme des Korreferats meiner Dissertation. Ebenso gilt mein Dank Prof. Heiko Becker, der als dritter Gutachter fungiert hat.

Ein großer Dank gilt den Mitarbeitern der Abteilung „Molecular Phytopathology and Mycotoxin Research“ der Universität Göttingen, die durch das Schaffen einer freundschaftlichen Atmosphäre und durch den stetigen Austausch von wissenschaftlichen Themen maßgeblich an dem gelingen der Experimente meiner Dissertation Anteil hatten. Ein besonderer Dank gilt dabei Dr. Arne Weiberg, Dr. Jan Utermark und Björn die mir zu Beginn meiner Promotion, aufgrund ihrer Laborerfahrung, den Einstieg in die experimentelle Arbeit sehr erleichtert haben. Hervorheben möchte ich ebenso Heike Rollwage, die mir bei der Durchführung der Experimente sehr geholfen hat. Ebenso danke ich Mona Quambusch für ihre hervorragende Mitarbeit an verschiedenen Experimenten meiner Arbeit. Bei Haidi Yin (Peking University, Beijing, China) und Ruth Pilot bedanke ich mich für die Arbeit bezüglich der Proteinaufreinigung von V1-NEP-1 und den darauf aufbauenden Experimenten.

Darüber hinaus bedanke ich mich bei allen Mitarbeitern des Departments für Nutzpflanzenwissenschaften der Universität Göttingen für die gute Arbeitsatmosphäre. Ein besonderer Dank gilt dabei Tobias Wulf, der mir bei der statistischen Auswertung meiner Daten geholfen hat.

Bei der Deutschen Forschungsgemeinschaft (DFG) möchte ich mich für die finanzielle Unterstützung meiner Promotion bedanken.

Ebenso möchte mich bei allen Mitgliedern der DFG Forschergruppe FOR 543 ("Signalling between the soil-borne fungus Verticillium longisporum and its host plants") für die Einsichten in die experimentelle Arbeit der interdisziplinären Arbeitsgruppen bedanken. Die 
gehaltenen wissenschaftlichen Vorträge und die anschließenden Diskussionen in der Forscherguppe haben mir dabei geholfen, die Gesamtheit des Pathosystems V. longisporum besser $\mathrm{zu}$ verstehen und angewandte Methoden aus den verschiedenen Bereichen der Forschung kennenzulernen.

Mein größter Dank gilt jedoch meiner Mutter, meinem Bruder und meinem Vater, die mir mit ihrer finanziellen und besonders psychologischen Unterstützung ermöglicht haben, meine Promotion durchzuführen. Einen großen Anteil am Gelingen meiner Promotion haben auch meine hoffentlich zukünftigen Schwiegereltern. Mein abschließender Dank gilt meiner Freundin, die mir in den vergangenen Jahren immer zur Seite gestanden hat.

\section{Herzlichen Dank}




\title{
Curriculum vitae
}

\section{Persönliche Daten}

Name:

Geburtsdatum:

Geburtsort:

Familienstand:

Staatsangehörigkeit:

\author{
Malte Matthias Beinhoff \\ 7. März 1981 \\ Hannover \\ ledig \\ deutsch
}

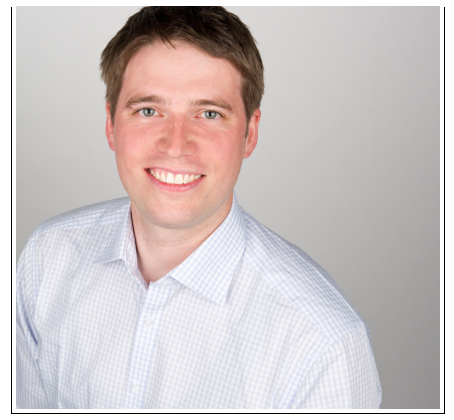

\section{BerufspraXis}

seit $02 / 2007$

wissenschaftlicher Mitarbeiter

Abteilung „Molecular Phytopathology and Mycotoxin

Research" (Link)

Georg-August-Universität Göttingen

DFG-Forschergruppe:

Mitglied in der Research Unit FOR 546

Thematik: „Signalling between the soil-borne plant pathogen

Verticillium longisporum and its host plants“ (Link)

Tagungen/Kongresse:

"From Foliar to Root-Interacting Pathogens and Symbionts"

Göttingen (Februar 2011) (Link)

10th International Verticillium Symposium

Korfu, Griechenland (Mai 2009) (Link)

VAAM-Tagung „Molekularbiologie der Pilze“

Hamburg (September 2008)

\section{STudium}

$07 / 2011$

Abschluss als promovierter Agrarwissenschaftler

(Note: magna cum laude)

$12 / 2007-07 / 2011$

Promotionsstudiengang für Agrarwissenschaften Georg-August-Universität Göttingen

Thematik: „Molecular and functional characterization of potential pathogenicity related genes from Verticillium longisporum"

(Betreuer: Prof. Dr. Petr Karlovsky, Prof. Dr. Andrea Polle) 
$12 / 2007$

$12 / 2006-12 / 2007$

$10 / 2001-12 / 2007$

\section{ZiviLdienst/SchulbiLdung}

$08 / 2000-06 / 2001$

$06 / 2000$
Abschluss als Diplom-Biologe

(Note: befriedigend)

Diplomarbeit

Thematik: „Identifikation und Charakterisierung von pathogenitätsrelevanten Genen des Rapspathogens Verticillium longisporum"

(Betreuer: Prof. Dr. Christiane Gatz, Prof. Dr. Petr Karlovsky)

Studium der Biologie

Georg-August-Universität Göttingen

Hauptfach: Botanik

Nebenfächer: Genetik, Mikrobiologie

Zivildienst in der Alten- und Behindertenpflege

Diakoniestation Sarstedt

Allgemeine Hochschulreife

Robert-Bosch-Gesamtschule Hildesheim 


\section{Eidesstattliche Erklärung}

Hiermit erkläre ich eidestattlich, dass diese Dissertation selbständig und ohne unerlaubte Hilfe angefertigt wurde.

Göttingen, im Juni 2011 